VNiVERSiDAD DE SALAMANCA

DEPARTAMENT@ DE ANATOMÍA E HiSTOLOGíA HVMANAS

LABOR ATOR IO DE NEVR GENDOCR INOLOGíA

INSTITVTO DE NEVR OCIENCIAS DE CASTILLA Y LEÓN (INCYL)

iNSTiTVTO DE INNVESTiGACiÓN Bi̊MMÉDiCA DE SALAMANCA (iBSAL)

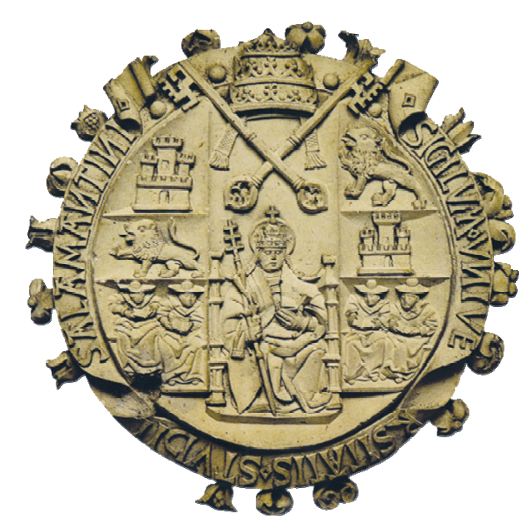

Análisis de imagen in vivo, a partir de Resonancia Magnética, de los Procesos Neurodegenerativos que acontecen en ratones knock out para la proteína sustrato del receptor insulínico IRS-2.

Manuel Carretero González

Salamanca, 2012 
José CARRETERO GONZÁLEZ, Catedrático de Embriología y Anatomía Humana, de la Facultad de Medicina de la Universidad de Salamanca, en su calidad de Director del trabajo de Tesis Doctoral,

\section{HACE CONSTAR:}

Que el trabajo titulado:

Análisis de imagen in vivo, a partir de Resonancia Magnética, de los Procesos Neurodegenerativos que acontecen en ratones ko para la proteína sustrato del receptor insulínico IRS-2.

Ha sido realizado bajo mi dirección por el Ldo. D. Manuel Carretero González, en el laboratorio de Neuroendocrinología del Instituto de Neurociencias de Castilla y León, ubicado en el Departamento de Anatomía e Histología Humanas de la Facultad de Medicina de la Universidad de Salamanca.

Que, a mi entender, el trabajo reúne los requisitos suficientes de experimentalidad, originalidad e interés científico y aplicativo como para ser presentado y defendido como trabajo de Tesis Doctoral.

Y, para que así conste, firmo la presente en Salamanca a 15 de Octubre de 2012.

José Carretero González 


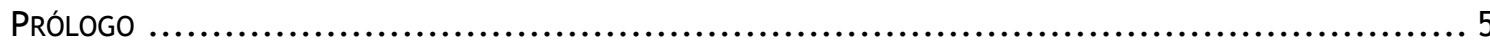

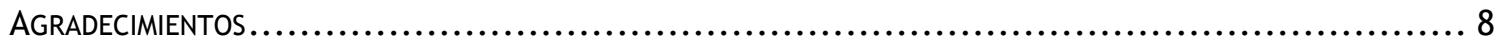

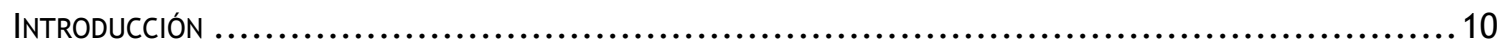

Resonancia Magnética .............................................................. 11

Fundamentos físicos................................................................... 11

Comportamiento magnético de los núcleos atómicos........................................ 12

Orientación del momento. .............................................................. 14

Energía de interacción. .................................................................... 14

Movimiento de precesión. ............................................................. 15

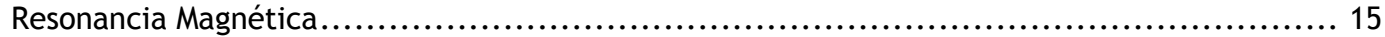

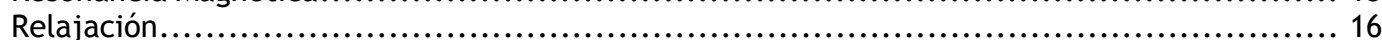

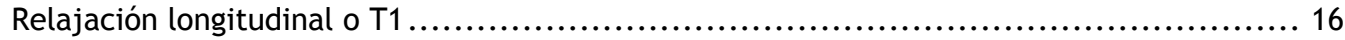

Relajación transversal o T2 .......................................................... 16

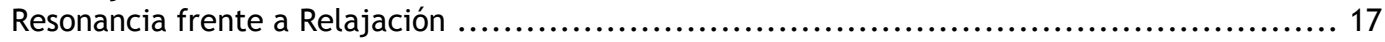

Recursos técnicos en Resonancia Magnética ............................................... 17

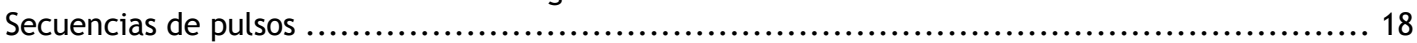

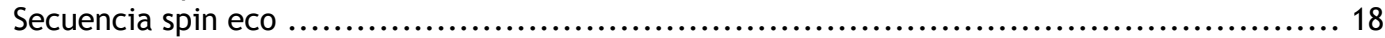

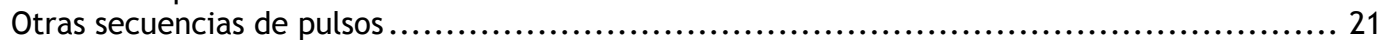

Gradientes en Resonancia Magnética ...................................................... 22

Gradiente de selección de corte. ....................................................... 23

Gradiente codificador de frecuencia y gradiente de codificación de fase. ........................ 24

Tratamiento informático de las señales ....................................................... 24

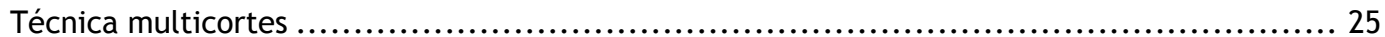

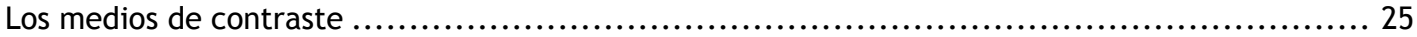

Técnicas de adquisición de datos............................................................. 26

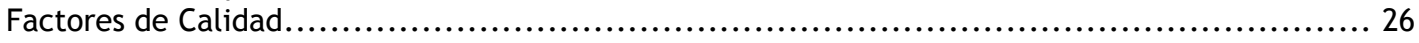

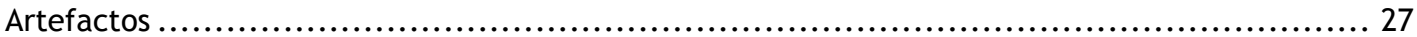

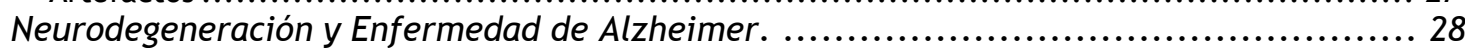

La proteína Tau y la Enfermedad de Alzheimer.......................................... 32

La Resonancia Magnética en el diagnóstico de la Enfermedad de Alzheimer. ................ 33

Genotipo de ApoE en pacientes con la Enfermedad de Alzheimer ......................... 40

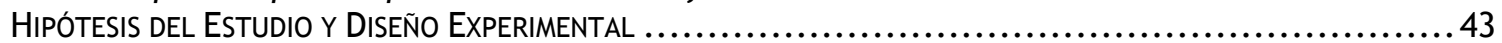

Antecedentes del estudio ............................................................... 44

Hipótesis del Trabajo. Objetivo general del estudio..................................... 45

Objetivos específicos del trabajo y su Diseño experimental. ............................... 45

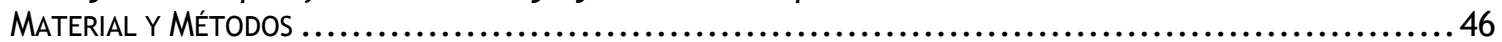

Animales empleados para el estudio.................................................. 47

Genotipaje....................................................................... 47

Extracción, aislamiento y purificación del DNA. ............................................ 47

Amplificación del DNA purificado, PCR. ...................................................... 48

Resonancia Magnética Nuclear. ..................................................... 49

Sacrificio de los animales y Extracción de las muestras. ................................ 52

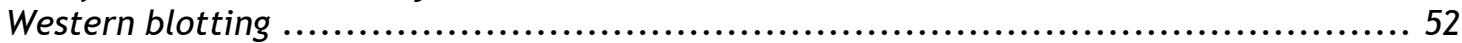

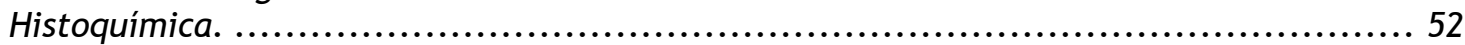

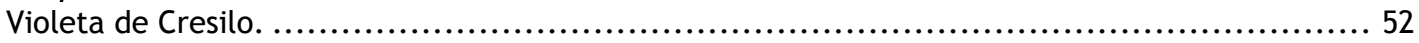

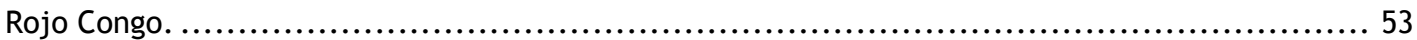

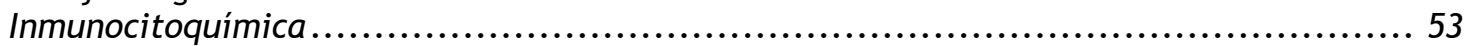

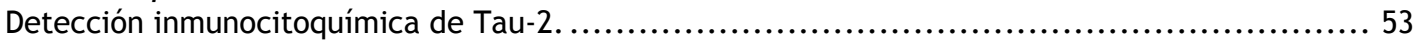

Detección inmunocitoquímica de $\beta$ amiloide. ................................................ 54

Detección inmunocitoquímica de GFAP. ....................................................... 55

Controles de las reacciones inmunocitoquímicas. .......................................... 55

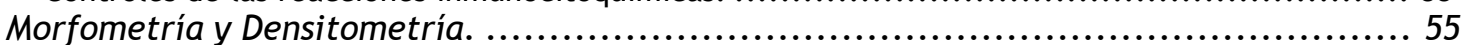

Densitometría óptica integrada de las bandas de western blotting........................... 56

Análisis morfométrico de los cortes histológicos........................................... 57

Análisis morfométrico de las imágenes obtenidas por Resonancia Magnética.......................... 57

Análisis Estadístico de los resultados .............................................. 61

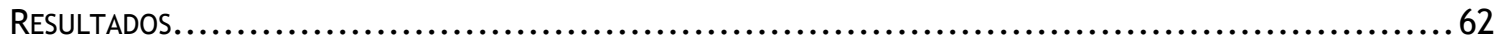

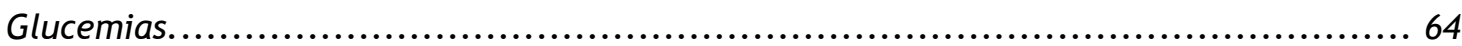

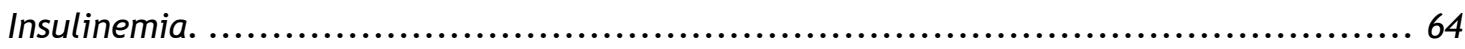

Western Blotting y análisis densitométrico......................................... 65

Análisis post-mortem de la variación de la fosfatasa desfosforiladora PP2A de gato. ............ 65 
Análisis post-mortem de la variación de la fosfatasa desfosforiladora PP2A (PR65).

Análisis post-mortem de la variación de la fosfatasa desfosforiladora PP2B de gato.

Análisis post-mortem de la variación de la proteína básica de la mielina MBP. .................... 71

Análisis post-mortem de la presencia de las isoformas 1 y 2 de Tau. ............................. 73

Análisis post-mortem de la existencia de Tau-fosforilada. Presencia de AT180. .................. 75

Análisis post-mortem de la existencia de Tau-fosforilada. Presencia de AT8..................... 77

Análisis post-mortem de la presencia de Tau fosforilada mediante inmunocitoquímica. ... 79

Animales Wilde Type. .................................................................... 79

Animales Knock Out. ......................................................................... 79

Análisis post-mortem de la presencia de depósitos de amiloide y amiloidosis vascular.

Tinción de Rojo Congo. ............................................................. 81

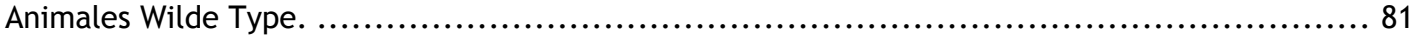

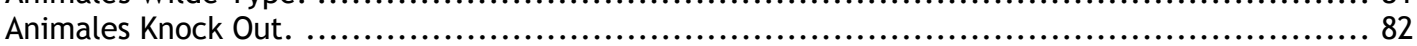

Análisis post-mortem de la presencia de $\beta$-amiloide................................... 84

Animales Wilde Type. ........................................................................ 84

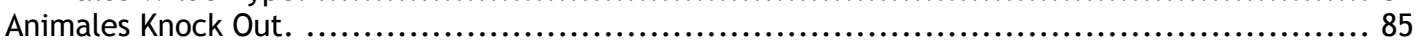

Análisis post-mortem de la dilatación ventricular. Estudio histológico. ................... 89

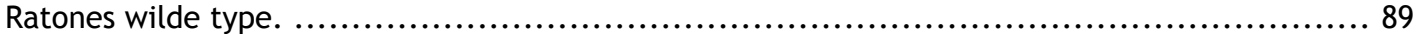

Ratones knock out. ........................................................................ 89

Análisis postmortem de la reacción glial en los ratones Knock Out hidrocefálicos. ......... 92

Estudio morfométrico histológico del Hipocampo. ....................................... 94

Estudio morfométrico histológico de la Corteza Entorrinal................................ 96

Estudio in vivo con Resonancia Magnética. ........................................... 97

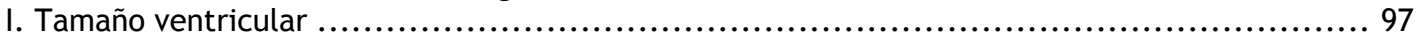

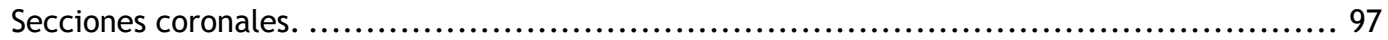

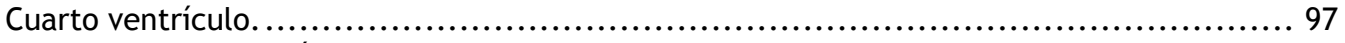

Acueducto mesencefálico ............................................................ 99

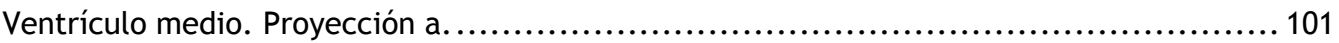

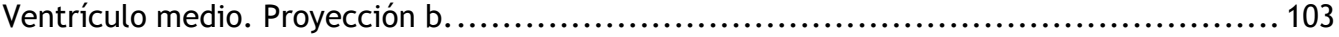

Ventrículo medio. Proyección c. ....................................................... 105

Ventrículo lateral. Proyección a. ..................................................... 107

Ventrículo lateral. Proyección b. ........................................................ 109

Ventrículo lateral. Proyección c. ..................................................... 111

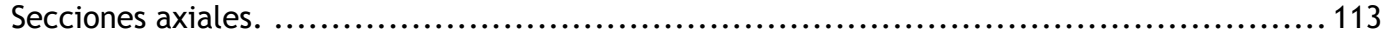

Ventrículo medio. ..................................................................... 113

Ventrículo lateral....................................................................... 115

Cisterna magna. .......................................................................... 117

II. Áreas y perímetros encefálicos. ........................................................ 119

III. Espesor de la Corteza Cerebral en cortes axiales......................................... 120

Hendidura interhemisférica.......................................................... 120

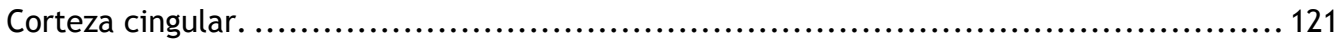

Corteza motora. ..................................................................... 121

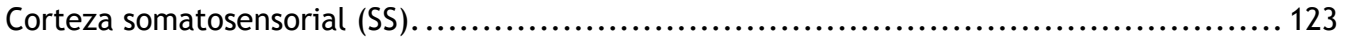

Corteza insular....................................................................... 123

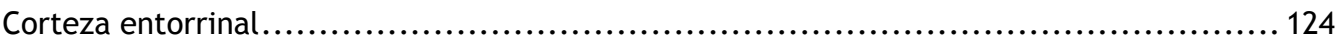

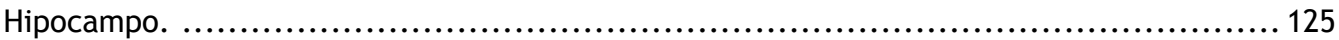

IV. Diámetros de los Ganglios Basales en cortes axiales. .......................................... 127

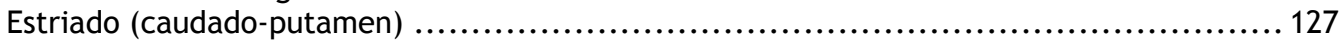

DISCUSIÓN................................................................................... 128

Comentarios relacionados con la metodología empleada ................................... 129

Inmunocitoquímica ........................................................................... 129

Morfometría y cuantificación celular ...................................................... 130

Empleo de ratones genéticamente modificados para el estudio de la Enfermedad de Alzheimer. . 132

Resonancia Magnética y Diagnóstico de la Enfermedad de Alzheimer y otras enfermedades neurodegenetivas ..................................................................... 133

Comentarios relacionados con los resultados obtenidos..................................... 138

Fosforilación de Tau. ...................................................................... 139

Amiloidosis y depósitos de $\beta$-amiloide ..................................................... 148

Proteína básica de la mielina. ........................................................... 150

Atrofia Cortical y de los Ganglios de la Base en la Neurodegeneración. .......................... 151

Gliosis reactiva asociadas a Neurodegeneración. Hallazgos Histológicos. Dilatación Ventricular... 153

Diabetes tipo II, IRS2 y Neurodegeneración............................................... 157

CONCLUSIONES ............................................................................ 171

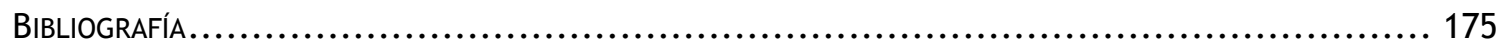


Prólogo 
El desarrollo social, científico y tecnológico ha mejorado la calidad de vida de la humanidad, aumentado la esperanza de vida que se sitúa, por ejemplo en España, alrededor de los 80 años de edad. Este hecho trae consigo que aumente el número de personas que padecen enfermedades asociadas a procesos neurodegenerativos que ocurren de forma más frecuente en personas de edad avanzada, como la enfermedad de Alzheimer.

Sin duda alguna, es misión del ser humano afrontar los nuevos retos que aparecen como consecuencia de su nueva situación social, buscando las soluciones más apropiadas. Detectar el problema, encontrar el origen, identificar las variables, desarrollar un remedio y evaluar los resultados son los pasos claves para solucionar cualquier situación conflictiva que se dé tanto en la Medicina como en cualquier otra ciencia.

La evolución humana tiene mucho que ver con este interminable proceso. Ante un problema, una solución; pero, rápidamente, surge otra situación que lleva inexorablemente a otro problema. Si repasamos la Historia, descubrimos que los científicos abarcaban varias áreas de estudio simultáneamente, de manera que muchos de ellos investigaban tanto en Matemáticas, como en Física, Medicina, o Filosofía. Es muy probable que el escaso número de investigadores, junto con la complejidad de los problemas que obligaba a utilizar técnicas y hallazgos de diferentes saberes, fueran las razones de la concentración multidisciplinar en una misma persona.

En la actualidad, la labor de los científicos está muy especializada en parcelas del saber muy concretas. Sin embargo, sigue siendo necesaria la colaboración entre ellos para poder estudiar con éxito los nuevos desafíos que van surgiendo día a día. Un claro ejemplo se recoge en este trabajo de investigación. El problema es una enfermedad del ser humano, por tanto es materia de la Medicina. Pero la herramienta que se utiliza para hacer el estudio es la imagen por resonancia magnética que se obtiene por la interacción de campos magnéticos y ondas de radiofrecuencia con la materia, procedimiento desarrollado por la Física y la Química.

El gran número de investigadores dedicados a un mismo aspecto del conocimiento $\mathrm{y}$, sobre todo, la habilidad para interrelacionar los diferentes hallazgos y técnicas de cada uno es lo que está proporcionando los mejores resultados en la investigación científica. Esta es la línea que hemos seguido en este trabajo convencidos de que el estudio morfométrico realizado sobre el ratón con procesos neurodegenerativos puede contribuir a mejorar el conocimiento de la enfermedad de Alzheimer, tanto en el diagnóstico temprano, como en el tratamiento y la curación de la misma. 
Además de la aportación al acervo científico y a la mejora de la salud de la humanidad, la realización de este trabajo ha supuesto para mí un avance importante en mi formación universitaria. Desde la búsqueda y selección bibliográfica hasta la composición escrita del trabajo; desde el aprendizaje de las técnicas básicas de investigación con imágenes hasta la discusión de los resultados; todo ha supuesto una acumulación de experiencias positivas que me ponen en disposición de desarrollar mi labor investigadora junto con la de profesor universitario.

Confío en que toda la investigación realizada y recogida en esta Tesis Doctoral con la que pretendo optar al título de Doctor por la Universidad de Salamanca, pueda ser aprovechada para mejorar las condiciones de vida de las personas en general, y de los pacientes con la enfermedad de Alzheimer en particular. 
Agradecimientos 
El trabajo de Tesis Doctoral que se presenta ha sido realizado en el Dpto. de Anatomía e Histología Humanas de la Facultad de Medicina, en el laboratorio de Neuroendocrinología del Instituto de Neurociencias de Castilla y León, financiado con cargo al proyecto CICYT I+D+I, BMC2002-00872.

Desde aquí quiero mostrar mi agradecimiento a todas aquellas personas que, de una manera u otra, han participado en la realización de este trabajo de investigación.

En primer lugar quisiera agradecer al Dr. D. José Carretero González, Director de este trabajo de Tesis Doctoral, el haberme enseñado como manejarme en él, compartiendo conmigo sus conocimientos, y resolviendo mis dudas con paciencia.

A la Dra. Débora Jane Burks, investigadora principal del proyecto que ha financiado el estudio, por su ayuda metodológica, sus apreciaciones científicas y por haber aportado los ratones knock out que han sido utilizados en el estudio.

A Dña. Marisa Fontanillo, por llevarme de la mano en mis primeros encuentros con las técnicas de laboratorio.

Y, por último, a toda mi familia que me ha acompañado y alentado a lo largo del tiempo empleado en la elaboración de este trabajo que culmina con la presentación del mismo. 
Introducción 


\section{Resonancia Magnética}

(Modificado de Cabrero FJ, 2004)

Uno de los avances tecnológicos más importantes alcanzados en el campo de la radiología digital ha sido la obtención de imágenes basadas en la resonancia magnética.

A diferencia de las técnicas que utilizan rayos $X$ para obtener imágenes, la resonancia magnética emplea los campos magnéticos y la radiación no ionizante de radiofrecuencia del espectro electromagnético.

El principio físico de la Resonancia Magnética se conoce desde 1946, año en el que Bloch y Purcell demostraron que ciertos núcleos sometidos a la acción de un campo magnético intenso son capaces de absorber energía de ondas de radiofrecuencia y de emitir, a su vez, señales de radiofrecuencia que pueden ser captadas por una antena.

Este fenómeno se ha aplicado a diferentes campos de la técnica y la ciencia. En el de la química permitió determinar la existencia de elementos químicos presentes, aún en cantidades mínimas, en una muestra, técnica conocida como espectroscopia de resonancia magnética.

Las primeras experiencias biomédicas con Resonancia Magnética se llevaron a cabo en 1955. Más tarde, en 1972 se propuso un método para la obtención de imágenes empleando la Resonancia Magnética, lo que mostró la posibilidad de utilizarla en el diagnóstico médico. Cuatro años después se obtuvo la primera imagen de un animal vivo mediante Resonancia Magnética. Desde entonces, el desarrollo en el campo de la radiología ha sido extraordinario.

\section{Fundamentos físicos}

La Resonancia Magnética se basa en la interacción de los campos magnéticos y las ondas de radiofrecuencia con la materia. Sus fundamentos físicos son los siguientes:

1. El momento magnético de los núcleos de hidrógeno del organismo ha de estar orientado en la dirección de un campo magnético constante, homogéneo y de gran intensidad entre 0,5 y 3 Teslas.

2.- Un pulso de ondas electromagnéticas de una frecuencia precisa, igual a la frecuencia de resonancia de los núcleos de hidrógeno, hace que el momento magnético de estos átomos se oriente en otro sentido. De esta forma, los núcleos de hidrógeno absorben energía del haz de radiofrecuencia y empiezan a girar acompasados, lo que recibe el nombre de Resonancia.

Para que haya resonancia es condición imprescindible la coincidencia entre las frecuencias de dos sistemas. En los movimientos oscilantes reales se disipa energía mecánica debido a las fuerzas de fricción o rozamiento que producen amortiguamiento. Para evitarlo, es necesario introducir energía en el sistema, convirtiéndolo en un oscilador forzado. 
Cuando se actúa sobre un oscilador comunicándole energía con la misma frecuencia con la que oscila, es decir, cuando la frecuencia impulsora coincide con la frecuencia natural del sistema, éste oscilará con una gran amplitud, mucho mayor que la propia amplitud de la fuerza impulsora.

El fenómeno recibe el nombre de resonancia. La frecuencia natural del sistema se denomina frecuencia de resonancia. La frecuencia natural de un oscilador se corresponde con la frecuencia que tendría si no estuviesen presentes ni el amortiguamiento ni el sistema impulsor.

3.- Cuando cesa el pulso de radiofrecuencia se produce una liberación de energía, también en forma de onda de radiofrecuencia, como resultado de la vuelta del momento magnético de los núcleos a su orientación inicial, fenómeno conocido como relajación.

La energía liberada o señal de relajación es portadora de gran cantidad de información y puede ser detectada con una antena para su posterior análisis.

4.- Las señales que proceden de cada volumen elemental de la zona explorada son sometidas a un tratamiento informático cuya finalidad es proporcionar una imagen de dicha zona.

La utilización de este proceso en el diagnóstico médico supone colocar al paciente dentro de un imán, emitir una onda de radiofrecuencia que posteriormente es interrumpida para captar la señal emitida por el paciente y que es utilizada para reconstruir digitalmente la imagen.

\section{Comportamiento magnético de los núcleos atómicos}

La base de los estudios de imagen por radiofrecuencia es el comportamiento de los núcleos de los átomos de hidrógeno bajo la influencia de campos magnéticos.

Estos núcleos poseen un único protón, que debido a su carga eléctrica y movimiento de giro, produce un campo magnético muy reducido en la dirección de su eje de rotación. Por ello, puede ser considerado como un pequeño imán con polo norte y sur, formando un dipolo magnético.

La relación entre el magnetismo y los fenómenos eléctricos se conoce gracias a los experimentos realizados por Oersted en 1819, que le permitieron afirmar que toda carga eléctrica en movimiento crea a su alrededor un campo magnético cuya presencia detectamos al colocar otra carga $q$, que se mueva cerca de la primera.

Sobre ella se ejercerá una fuerza $\vec{F}=q(\vec{v} \wedge \vec{B})$, cuya dirección es perpendicular al plano determinado por los vectores $\vec{v}$, velocidad de la carga en un punto determinado, y $\vec{B}$, campo magnético en dicho punto.

De dicha expresión se deduce que la fuerza magnética será cero cuando la carga esté en reposo $(v=0)$ o cuando $\vec{v}$ y $\vec{B}$ tengan la misma dirección (el ángulo $\varphi$ entre ambos sea de 0 ó $\pi$ radianes) porque, cualquiera que sea el signo de la carga, el módulo de la fuerza es $F=q v B \operatorname{sen} \varphi$. 
Ocurre, por tanto, que el movimiento de giro que realiza el protón le confiere desde el punto de vista mecánico un momento cinético $\vec{s}$ (o spin nuclear) y desde el punto de vista eléctrico un momento magnético $\vec{\mu}$.

Ambos están relacionados, siendo el momento magnético proporcional al momento cinético de rotación: $\vec{\mu}=\gamma \vec{S}$ donde $\gamma$, constante giromagnética característica del núcleo, se expresa en velocidad angular por tesla $\left(\right.$ radian $\left.\cdot s^{-1} \cdot T^{-1}\right)$. En la práctica, se utiliza la cantidad $\gamma / 2 \pi$ expresada en hertzios por tesla $\left(\mathrm{Hz} \cdot \mathrm{T}^{-1}\right)$.

El valor de esta constante giromagnética para los protones es de $42,58 \mathrm{MHz}^{-1}$, de manera que la frecuencia de resonancia a $1.5 \mathrm{~T}$ sería de $63.86 \mathrm{MHz}$.

En realidad, en Resonancia Magnética se consideran dos tipos de momentos magnéticos: los momentos individuales $\vec{\mu}$ de cada protón y los momentos magnéticos $\vec{M}$ de cada pequeño volumen (vóxel) de la zona estudiada, que resultan de la suma de todos los momentos individuales $\vec{\mu}$ de sus protones, $\vec{M}=\sum \vec{\mu}$.

El elemento base de las técnicas de diagnóstico por imagen de Resonancia Magnética es el hidrógeno porque es el más abundante en el organismo. Constituye entre el 60 y el $90 \%$ de la estructura de los tejidos y es, técnicamente, el núcleo más fácil de tratar con campos magnéticos.

No obstante, los principios y conceptos se podrían aplicar a cualquier núcleo que posea un momento magnético "no nulo". Es decir, núcleos con un número impar de nucleones ya sean protones o neutrones.

Una carga eléctrica (electrón o protón) que posee un spin crea un momento magnético alineado con el eje del spin. Los neutrones también poseen un momento magnético (aunque sean eléctricamente neutros) porque están constituidos por subpartículas positivas y negativas en rotación, los quarks (cargas eléctricas fraccionarias en incrementos de 1/3 o 2/3 de la carga del electrón) y, aunque la suma de las cargas positivas y negativas sea nula, la aparición del momento magnético deriva de diferencias orbitales.

Por consiguiente, sólo los núcleos con número impar de nucleones poseen un momento magnético neto, es decir, núcleos cuyo número de protones es impar siendo el número de neutrones par, o núcleos en los que el número de protones es par y el de neutrones impar.

El núcleo de hidrógeno $\left({ }^{1} H\right)$ tiene un magnetismo sensiblemente superior que la de otros núcleos como ${ }^{19} \mathrm{~F},{ }^{31} \mathrm{P},{ }^{23} \mathrm{Na},{ }^{13} \mathrm{C}$, al ser mayor su constante giromagnética. Sin embargo, desde el punto de vista médico, éstos tienen gran interés y algunos como el ${ }^{31} \mathrm{P}$ o el ${ }^{23} \mathrm{Na}$ pueden ser también estudiados en Resonancia Magnética en técnicas de espectroscopia in vivo.

Al considerar los momentos magnéticos individuales de los protones existentes en un volumen elemental de materia, se observa que sin influencia de campos magnéticos externos se orientan de forma aleatoria. 
Los protones giran al azar y sus momentos magnéticos se neutralizan. Sin embargo, al someter una zona orgánica a la acción de un campo magnético intenso $\vec{B}_{0}$, los momentos magnéticos de los protones se orientan en la dirección de dicho campo, unos en el mismo sentido (paralelo) y otros en sentido contrario (antiparalelo), siendo el momento magnético resultante en dirección a $\vec{B}_{0}$ muy débil.

Estos tipos de alineación están a diferentes niveles de energía, y como el estado preferido es aquel que necesita menos energía, hay más protones paralelos al campo magnético externo. Aunque la diferencia es muy pequeña, es suficiente para producir la señal de Resonancia Magnética.

En realidad, la interacción se traduce en tres fenómenos: una orientación del momento, una energía de interacción y un movimiento de precesión.

\section{Orientación del momento.}

Los momentos magnéticos $\vec{\mu}$ de los protones forman con la dirección del campo $\vec{B}_{0}$ dos ángulos de distinto valor en función del sentido paralelo o antiparalelo de la orientación, encontrándose cada uno de ellos en una posición cualquiera sobre uno de los dos conos que se forman.

La orientación de los momentos magnéticos de los protones de un volumen elemental de materia en presencia del campo $\vec{B}_{0}$ da lugar a la aparición de una resultante global $\vec{M}_{z}$ paralela a $\vec{B}_{0}$.

Esto se explica porque fuerzas magnéticas en direcciones opuestas se cancelan unas a otras y, como hay más protones orientados en sentido paralelo, el resultado final es la aparición de un nuevo vector de magnetización, resultante de la suma de todos ellos, orientado según el campo $\vec{B}_{0}$.

En conclusión, la magnetización que aparece cuando el paciente es colocado en el imán de una unidad de Resonancia Magnética se encuentra en la dirección y sentido del campo magnético externo (magnetización longitudinal, $\vec{M}_{z}$ ).

La utilización de un sistema de coordenadas $x$, y (perpendiculares a $\vec{B}_{0}$ ) y z (paralelo a $\vec{B}_{0}$ ) permite representar fácilmente la descripción del movimiento del protón en un campo magnético.

Energía de interacción.

A cada una de las orientaciones, paralela o antiparalela al campo $\vec{B}_{0}$, le corresponde un nivel de energía definido.

La diferencia entre los dos niveles es muy pequeña y es proporcional a la intensidad del campo magnético: $\Delta E=\hbar \hbar B_{0}$, donde $\hbar$ representa la constante de Planck dividida por $2 \pi$.

Suministrando una cantidad de energía $\Delta E$, aportada por las ondas electromagnéticas, los pulsos de radiofrecuencia, es posible inducir transiciones de un nivel a otro y, por tanto, modificar la orientación de $\vec{M}_{z}$. 
Movimiento de precesión.

La presencia del campo externo provoca, junto a la orientación del momento, un movimiento de rotación de los protones alrededor de $\vec{B}_{0}$ que recibe el nombre de movimiento de precesión.

La precesión se efectúa a una velocidad angular igual al producto del campo magnético por la constante giromagnética: $\vec{\omega}_{0}=\gamma \vec{B}_{0}$. La frecuencia de rotación correspondiente recibe el nombre de frecuencia de Larmor o frecuencia de precesión $v_{0}$.

Esta frecuencia, que indica el número de vueltas que da el protón por unidad de tiempo, es específica de cada especie de núcleo y depende de la intensidad del campo magnético externo.

Cuanto más intenso sea el campo magnético $\vec{B}_{0}$, mayor será la frecuencia de precesión. Se relacionan por la ecuación, $v_{0}=\omega_{0} / 2 \pi=\gamma B_{0} / 2 \pi$.

La frecuencia de Larmor del hidrógeno es de $42,58 \mathrm{MHz}$ en un campo magnético de 1T. Hay que señalar que existen variaciones locales en la frecuencia de Larmor debidas a no homogeneidades del campo magnético, a interacciones entre protones vecinos (interacciones spin-spin) y a la diferente composición química del hidrógeno cuando está ligado al agua o a la grasa (desplazamiento químico).

\section{Resonancia Magnética}

Una vez colocado el paciente en el equipo de Resonancia Magnética se aplica a la zona de estudio un pulso de radiofrecuencia igual a la frecuencia de Larmor correspondiente que es captado de forma selectiva por los protones.

Se produce, por tanto, una transferencia de energía por resonancia a los protones lo que ocasiona que experimenten el movimiento de precesión.

Mientras dura el pulso suceden dos cosas:

1.- Algunos protones se sitúan en un nivel superior de energía (sus momentos magnéticos son orientados "hacia abajo"). En consecuencia, la magnetización longitudinal disminuye porque un número igual de protones orientados "hacia arriba" es neutralizado.

2.- Los protones precesan sincrónicamente acompasados (puesta en fase), es decir, se orientan en la misma dirección al mismo tiempo. Sus vectores magnéticos se suman dando como resultado un vector orientado en dirección transversal $\vec{M}_{x y}$ (magnetización transversal).

Dependiendo del pulso de radiofrecuencia aplicado, la magnetización longitudinal puede llegar incluso a desaparecer (pulso de $90^{\circ}$ ).

Así, un pulso de $90^{\circ}$ inclina el vector de magnetización neta a la orientación transversal. Un pulso de $180^{\circ}$ provoca la reaparición de un vector longitudinal en la dirección opuesta (invierte el vector de magnetización $\vec{M}_{z}$ ) y la rotación del vector transversal en la dirección opuesta respecto al campo principal. 
En resumen, el pulso de radiofrecuencia o excitación hace que disminuya la magnetización longitudinal y se establezca una nueva magnetización transversal.

\section{Relajación}

El proceso de relajación se inicia al desconectar el pulso de radiofrecuencia.

En la relajación, los protones excitados recuperan tras un período de tiempo su estado de equilibrio, lo que se traduce en un desfase rápido $\left(\vec{M}_{x y}\right.$ disminuye rápidamente hasta anularse) y en la vuelta de los protones al nivel de menor energía (de antiparalelos a paralelos, con una recuperación progresiva de $\vec{M}_{z}$ ).

Cuando cesa el pulso de radiofrecuencia, se pierde la fase porque el campo magnético externo no es totalmente uniforme ni homogéneo y, por tanto, existen diferentes frecuencias de precesión de los protones.

Se puede hablar, por tanto, de dos tipos de relajación. La relajación transversal debida a la desaparición de la magnetización transversal y la relajación longitudinal producida por la vuelta de la magnetización longitudinal a su tamaño original.

Al representar gráficamente las magnetizaciones longitudinal y transversal en función del tiempo, después de interrumpir el pulso de radiofrecuencia, se obtienen la curva T1 que representa la recuperación exponencial de la magnetización longitudinal y la curva T2 para el descenso exponencial de la magnetización transversal respectivamente. Las relajaciones T1 y T2 son características de un determinado tejido.

\section{Relajación longitudinal o T1}

T1 es el tiempo que tarda la magnetización longitudinal en recuperar el 63\% de su estado de equilibrio.

El T1 varía con la estructura molecular, es más largo en los líquidos que en lo sólidos y es más corto en los tejidos grasos. Su valor varía en los tejidos biológicos desde 500 a 1000 ms. Esta variación hace posible su diferenciación histológica en la imagen.

\section{Relajación transversal o T2}

T2 es el tiempo que tarda la magnetización transversal inducida en descender en un 63\% de su fuerza máxima (o, lo que es igual, persiste el $37 \%$ de $\vec{M}_{x y}$ ).

Los valores de $\mathrm{T} 2$ varían en los distintos tejidos biológicos de forma similar a los de $\mathrm{T} 1$, aunque son mucho más cortos, de $50 \mathrm{a} 100 \mathrm{~ms}$ ), de manera que el descenso de la magnetización transversal es mucho más rápido que la recuperación de la magnetización longitudinal.

El T2 varía con la estructura molecular, así como con el estado sólido o líquido de la materia. El T2 es más largo en los líquidos que en los sólidos o en los tejidos formados por grandes moléculas. 
Existen pequeños campos magnéticos locales que interaccionan con $\vec{B}_{0}$ (no homogeneidades de origen "molecular") y que, en función del entorno molecular en el que se encuentren los protones, pueden mantenerse o ser anulados.

Así, en los líquidos se anulan, lo que se traduce en un alargamiento del T2. Sin embargo, en los sólidos o en las grandes moléculas se mantienen y acortan el T2 (desfase de los protones).

\section{Resonancia frente a Relajación}

Para representar los fenómenos de resonancia y relajación podemos utilizar flechas dibujadas sobre un sistema de coordenadas cartesianas. Con un tipo de flecha representamos a los vectores de magnetización longitudinal (eje z) y transversal (plano $\mathrm{x}-\mathrm{y}$.

Con otro, dibujamos un vector suma que representa el momento magnético total de un tejido corporal, es decir, un vector de magnetización neta, resultante de los vectores longitudinal y transversal, que durante el proceso de "excitación" (resonancia) se inclina progresivamente hacia la orientación transversal mientras gira a la frecuencia de Larmor.

El vector suma vuelve durante la relajación a la dirección longitudinal realizando un movimiento en espiral hasta igualarse con la magnetización longitudinal. Al colocar una antena, se obtiene la señal de Resonancia Magnética.

La señal es de mayor magnitud inmediatamente después de interrumpir el pulso de radiofrecuencia. Luego disminuye, desapareciendo con el tiempo. Recibe el nombre de caída libre de la inducción o free induction decay (FID), esto es, una pérdida de la señal debida al desfase rápido de los protones producido por las pequeñas diferencias que existen en la frecuencia de precesión de los mismos (inhomogeneidad de origen "molecular").

A estas inhomogeneidades hay que añadir las propias del campo magnético externo $\vec{B}_{0}$ que hacen disminuir la FID de forma aún más rápida.

La relajación T2 corresponde a las inhomogeneidades de origen "molecular" que implican desfase de los protones (spins). A la suma de éstas con las inhomogeneidades propias y constantes del campo $\vec{B}_{0}$ la denominados como T2* El T2* no es el verdadero $\mathrm{T} 2$.

En definitiva, el vector de magnetización $\vec{M}$ describe durante la relajación una espiral ascendente, una superficie en forma de pabellón de trompeta que es el resultado de los fenómenos de relajación longitudinal y transversal que ocurren simultáneamente.

Sin embargo, durante la excitación, el vector de magnetización describe una espiral formando una superficie en forma de esfera debido a la reducción progresiva de su componente longitudinal y a la aparición de un componente transversal.

\section{Recursos técnicos en Resonancia Magnética}

Para desarrollar la Resonancia Magnética es necesario contar con un campo magnético intenso, muy homogéneo y extremadamente estable en el tiempo. 
Por otra parte, es preciso intensificar la débil señal emitida por el volumen elemental de tejido utilizando secuencias de pulsos de radiofrecuencia.

Además, como el objetivo de la exploración es generar la imagen de un corte del interior del organismo, hay que identificar la información proveniente de cada uno de los vóxeles que lo componen, aplicando gradientes de campo magnético.

Por último, una vez captada adecuadamente la señal emitida mediante antenas, un sistema computarizado realiza el tratamiento informático que permite obtener la imagen.

\section{Secuencias de pulsos}

La señal de radiofrecuencia emitida en el proceso de relajación por los protones que forman cada volumen elemental de tejido es muy débil. Para intensificarla se emplean pulsos de radiofrecuencia consecutivos separados por pausas formando una secuencia que se repite varias veces.

La utilización de parámetros de medición adecuados permite el estudio de los tiempos de relajación de los tejidos.

Se diferencia entre el tiempo de eco que es el que pasa desde que se envía el pulso hasta que se recibe la señal y el tiempo de repetición correspondiente al intervalo existente entre pulsos sucesivos de radiofrecuencia.

En Resonancia Magnética se aplican diferentes pulsos e intervalos de tiempo entre pulsos con lo que se obtienen distintas secuencias: spin eco, saturación recuperación, saturación parcial, inversión recuperación, secuencias rápidas, etc.

\section{Secuencia spin eco}

Ya hemos comentado que la señal de caída libre de la inducción (FID) está relacionada con inhomogeneidades debidas a pequeñas diferencias en la frecuencia de precesión de los protones que forman parte del volumen corporal estudiado (T2) y a inhomogeneidades propias del campo externo $\vec{B}_{0}$ que aceleran el desfase de los protones (spins). Ambos efectos considerados conjuntamente (T2*) hacen que la señal de FID disminuya con mayor rapidez.

La secuencia spin-eco elimina las inhomogeneidades constantes del campo $\vec{B}_{0}$ (propias del equipo) y permite disponer del verdadero T2 y no del T2*.

El fenómeno del spin-eco comienza con un pulso de $90^{\circ}$ que desvía el vector de magnetización al plano transversal $\left(\vec{M}_{x y}\right)$. Si consideramos exclusivamente dos protones (spins), éstos se desfasan rápidamente al cesar la onda de radiofrecuencia debido a las interacciones entre ellos y a las inhomogeneidades del campo $\vec{B}_{0}$.

En consecuencia, se produce una disminución de la magnetización transversal y una pérdida de la señal. En ese instante, un pulso de $180^{\circ}$ enviado después de un cierto tiempo (tiempo de eco/2) invierte los desfases sin modificar el sentido de la rotación. 
Este pulso hace que el protón con una frecuencia de precesión más rápida, que se había alejado más rápidamente del vector inicial en el plano transversal, "alcance" el protón más lento y juntos vuelvan a la situación original (casi en fase) generando una señal de eco de spin en el tiempo de eco.

Decimos casi en fase porque persiste un desfase como consecuencia de la interacción spin-spin y, por tanto, el "nuevo" vector $\vec{M}_{x y}$ es ligeramente más pequeño. Después, aunque los protones pierden otra vez la coherencia de fase, es posible enviar nuevos pulsos de $180^{\circ}$ para obtener más de una señal.

La gráfica que representaría la intensidad de la señal en función del tiempo muestra una curva que conecta las intensidades de los spin eco (curva T2).

Es, la envoltura que une los picos de los distintos ecos, producidos por los sucesivos pulsos de $180^{\circ}$ que invierten los desfases de los protones y hacen que éstos vuelvan a estar "casi en fase", generando señales de spin eco en sucesivos tiempos de eco.

La intensidad de la señal decae muy rápidamente si no se utiliza el pulso de $180^{\circ}$. Sin este pulso es imposible decir si la disfunción en la intensidad de la señal es debida a las propiedades inherentes del tejido o a las influencias externas (inhomogeneidades constantes del campo magnético externo). Estas últimas son neutralizadas por el pulso de $180^{\circ}$.

La secuencia spin eco, una de las más utilizadas en Resonancia Magnética, en su versión estándar se desarrolla de la siguiente manera: Pulso de $90^{\circ}$, espera de valor igual a la mitad del tiempo de eco, pulso de $180^{\circ}$ que produce el eco, espera igual a la anterior, registro de la señal y repetición de la secuencia al cabo de un tiempo de repetición.

Esta secuencia se repite varias veces hasta conseguir la información correspondiente a la imagen.

En realidad, se usan tres tipos de secuencias spin eco: eco sencillo estándar, multieco estándar y fast spin eco.

La secuencia de eco sencillo se utiliza para producir imágenes potenciadas en $\mathrm{T} 1\left(90^{\circ} / 180^{\circ}\right)$.

Las secuencias de multieco se basan en la aplicación de pulsos de radiofrecuencia de $180^{\circ}$ adicionales (un eco por cada pulso de $180^{\circ}$ ) $\left(90^{\circ} / 180^{\circ} / 180^{\circ} / \ldots\right)$; se utilizan para obtener imágenes potenciadas en densidad protónica (tiempo de eco corto) e imágenes potenciadas en T2 (tiempo de eco largo).

La secuencia fast spin eco es una secuencia rápida (parecida a la anterior) en la que se aplican múltiples pulsos de $180^{\circ}$ para producir múltiples ecos.

El operador puede modificar el tiempo de repetición y el tiempo de eco. Los valores límites que se consideran para la diferenciación de estos tiempos son: tiempo de repetición corto $(<500 \mathrm{~ms})$, tiempo de repetición largo (>1500 ms), tiempo de repetición corto $(<30 \mathrm{~ms})$ y tiempo de repetición largo $(>80 \mathrm{~ms})$. 
Aunque la mayoría de las imágenes contienen información T1 y T2, utilizar unos tiempos u otros, potenciará más la presencia de una de las dos informaciones, permitiendo visualizar mejor la morfología del órgano o el proceso clínico que se estudia.

En una representación gráfica de las curvas T1 de dos tejidos con diferentes tiempos de relajación longitudinal se puede ver que al esperar un tiempo de repetición largo después de un primer pulso de $90^{\circ}$, los tejidos han recuperado casi por completo la magnetización longitudinal.

Sin embargo, al enviar el segundo pulso después de un tiempo de repetición más corto, la diferencia en $\vec{M}_{z}$ es grande (el tejido que tiene un T1 más corto, tejido $A$, ha recuperado más parte de su magnetización longitudinal que el otro, tejido B).

Cuando un segundo pulso incline la magnetización longitudinal $90^{\circ}$, el vector de magnetización transversal del tejido A será mayor que el del $\mathrm{B} y$, por tanto, producirá una señal más intensa en la antena.

En definitiva, habrá mejor contraste entre los tejidos, lo que permitirá su diferenciación (imagen potenciada en T1). En la gráfica se observará un intervalo de tiempo donde el contraste entre los tejidos es más pronunciado.

En las imágenes de cortes cerebrales potenciadas en T1 (tiempo de repetición corto y tiempo de eco corto) el líquido cefalorraquídeo aparece negro y la sustancia gris más oscura que la sustancia blanca. Estas imágenes en T1 son muy anatómicas, lo que facilita el estudio morfológico de la zona.

Por otra parte, se pueden representar las curvas T2 de dos tejidos, A y B, con diferentes tiempos de relajación transversales. Ambas curvas comienzan inmediatamente después de interrumpir el pulso de $90^{\circ}$. Después de enviar el pulso de $180^{\circ}$ y de esperar un tiempo se recibe una señal (spin eco).

Cuanto más corto sea el tiempo de eco, más fuerte será la señal obtenida de un tejido, pero la diferencia en la intensidad de la señal entre el tejido $A$ y el $B$ será muy pequeña. En este caso, los tejidos serán difíciles de distinguir al no existir contraste entre ellos.

Sin embargo, las diferencias en las curvas T2 son más pronunciadas con un tiempo de eco largo y, por tanto, el contraste entre los tejidos es mejor (imagen potenciada en T2).

En cualquier caso, si el tiempo de eco es demasiado largo, la intensidad total de la señal se hace cada vez más pequeña, disminuye la relación señal/ruido y da lugar a la aparición de

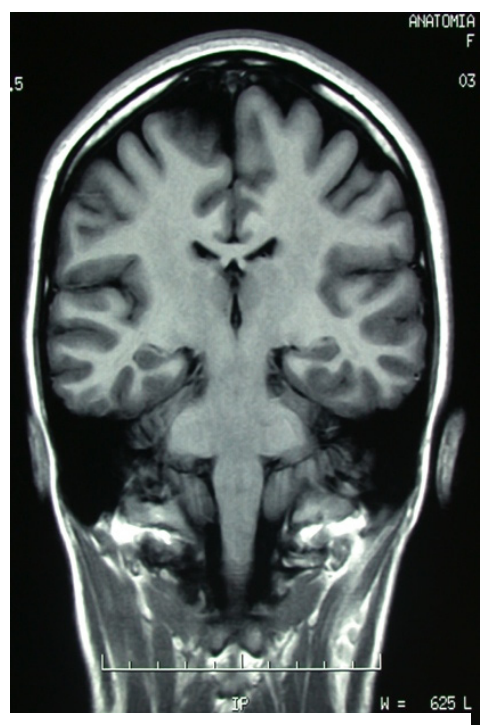

Figura 11. Corte frontal del encéfalo humano obtenido por resonancia magnética. una imagen con grano. 
En las imágenes potenciadas en T2 (tiempo de repetición largo y tiempo de eco largo) los cortes axial, sagital y coronal del cerebro muestran los líquidos, por ejemplo el cefalorraquídeo, blancos. Las imágenes potenciadas en T2 son más fisiopatológicas y más diagnósticas.

Los tejidos que emiten señales intensas de Resonancia Magnética aparecen en blanco (hiperintensidad), mientras que los que emiten una señal baja o nula se muestran de color gris oscuro o negro (hipointensidad). Entre estos extremos hay un rango de intensidades de señal o tonalidades de gris que reflejan las diferencias entre los tejidos en la imagen.

Las imágenes de Resonancia Magnética potenciadas en densidad protónica (tiempo de repetición largo y tiempo de eco corto) están influidas por la diferencia en la densidad protónica de los tejidos (a más protones, más señal). Los líquidos se observan, de nuevo, más oscuros.

En la imagen de Resonancia Magnética potenciado en densidad protónica de un corte axial del cerebro, el líquido céfalo-raquídeo aparece oscuro aunque la intensidad de señal es mayor que en una imagen potenciada en T1. La sustancia gris del cerebro aparece menos oscura que la sustancia blanca (la intensidad de señal es mayor porque la sustancia gris tiene mayor contenido de agua, esto es, más protones).

\section{Otras secuencias de pulsos}

La elección por el radiólogo de otras secuencias (saturación recuperación, saturación parcial, inversión recuperación, secuencias rápidas, etc.) permite modificar la señal resultante.

Aunque las secuencias de pulso saturación recuperación y saturación parcial son básicamente iguales porque sólo utilizan pulsos de $90^{\circ}$, se diferencian en que utilizan diferentes tiempos de repetición.

En la secuencia de saturación recuperación $\left(90^{\circ} /\right.$ señal $)$, con un tiempo de repetición largo, los protones tienen tiempo de relajarse antes del siguiente pulso y, por tanto, la señal es influida por la densidad protónica, es decir, la señal a su máxima intensidad es directamente proporcional al número de protones en precesión.

En la saturación parcial $\left(90^{\circ} / \mathrm{señal}\right)$, con tiempo de repetición corto, los vectores de magnetización longitudinal de los vóxeles no se han recuperado por completo (los protones no se han relajado).

Las señales emitidas una vez cesa el siguiente pulso que les devuelve al plano transversal, presentarán diferentes intensidades porque los vóxeles que recuperaron una mayor magnetización longitudinal (T1 más corto) emitirán con amplitudes más altas.

Por tanto, este tipo de secuencia dará lugar a una imagen que mostrará diferencias en T1 entre vóxeles (imagen potenciada de T1).

La secuencia de pulso inversión recuperación $\left(180^{\circ} / 90^{\circ} /\right.$ señal) consta de una serie de pulsos de $180^{\circ}$ seguidos cada uno de ellos por un pulso de $90^{\circ}$ que se aplica después de un tiempo de inversión (T1). 
El pulso de $180^{\circ}$ (inversión) invierte la magnetización $\vec{M}_{z}$. La magnetización longitudinal crece entonces desde $-\vec{M}_{z}$ a $+\vec{M}_{z}$ pasando por cero. El pulso de $90^{\circ}$ desvía el vector de magnetización al plano transversal. La imagen obtenida está fuertemente potenciada en T1.

El desarrollo de secuencias rápidas que acortan el tiempo de exploración ha supuesto un nuevo avance en la tecnología de imagen médica por Resonancia Magnética.

Por una parte, permiten examinar un mayor número de pacientes. Por otra, la calidad de la imagen se ve favorecida ya que el menor tiempo de exploración disminuye los artefactos provocados por el movimiento del paciente.

Estas secuencias emplean ángulos iniciales de excitación menores de $90^{\circ}$, no usan pulsos de $180^{\circ}$ y generan la señal de eco mediante una inversión de gradiente (secuencias rápidas de eco de gradiente).

$\mathrm{El}$ eco de gradiente consiste en aplicar durante un tiempo muy pequeño (ms) un gradiente de desfase (negativo) que hace que los protones (spins) procesen desfasados. Inmediatamente después se aplica un gradiente de refase (positivo) que compensa exactamente los desfases provocados por el primer gradiente. Cuando los desfases se anulan, se recoge la señal (eco de gradiente).

La utilización de un eco de gradiente asociado a ángulos de excitación reducidos (por ejemplo, a $10-35^{\circ}$ ) permite disminuir el tiempo de repetición muy por debajo del T1 sin pérdida de la señal.

Son estrategias de exploración como FLASH (fast low-angle shot) o GRASS (gradient-recalled acquisition in the steady state), secuencias SEP (steady state of free precession), etc.

En los últimos años se han desarrollado técnicas ultrarrápidas de Resonancia Magnética que presentan tiempos de adquisición muy cortos, con duraciones por corte desde 1-4 s hasta 50-100 ms.

También existen técnicas cuya aplicación permite la supresión de la grasa en aquellos casos en que la señal del tejido adiposo genere problemas que afecten a la calidad de la imagen y otras que reducen el impacto producido en la imagen por artefactos derivados del movimiento durante la exploración.

\section{Gradientes en Resonancia Magnética}

El campo magnético de la unidad de resonancia magnética es muy homogéneo. Por eso, al colocar al paciente dentro del imán todos los protones del cuerpo tendrán la misma frecuencia de Lamor y serán excitados por el mismo pulso de radio frecuencia.

Como el objetivo de la exploración es generar la imagen de un corte específico del interior del organismo, deben excitarse los protones de ese corte y obtenerse una información espacial en el mismo.

Para ello deben captarse las señales procedentes de cada elemento de volumen, o vóxel que lo componen, lo que permite determinar la localización espacial de 
la señal. La obtención de esta información espacial hace necesario conocer las coordenadas z, x e y de cada vóxel.

Esta información se consigue utilizando gradientes de campo magnético, que al igual que en cualquier otra variable física, conllevan una variación lineal del campo magnético en la dirección que se aplican.

Se producen por tres sistemas de bobinas de gradientes: uno en la dirección del campo principal y dos perpendiculares a este eje. La selección de la adecuada conmutación de los gradientes permite definir toda clase de planos de imagen (axiales, coronales, sagitales y oblicuos) sin mover al paciente.

Todos los datos obtenidos en la realización del corte conforman una matriz dispuesta en filas y columnas. Cada valor se traduce por un determinado tono de la escala de grises, proporcional a la señal emitida por el vóxel correspondiente.

De esta manera se genera la imagen de resonancia magnética en la que cada píxel (elemento de superficie de la imagen) representa la información obtenida del vóxel (elemento de volumen del corte).

Gradiente de selección de corte.

El gradiente de selección de corte, conocido como Gz, se sobrepone al campo magnético principal $\vec{B}_{0}$, para seleccionar un corte específico que estará definido por una determinada coordenada $\mathrm{z}$.

En ausencia de este gradiente, todos los protones que forman parte del volumen del paciente situado en el interior del imán estarán en condiciones de resonar si la frecuencia de la onda de radiofrecuencia es igual a la frecuencia de precesión de los mismos.

El establecimiento del gradiente de selección de corte a lo largo del paciente, al variar la intensidad del campo magnético de los pies a la cabeza, hace que una radiofrecuencia concreta sólo resuene con los protones localizados en un estrecho corte transversal porque la frecuencia de precesión de éstos cambia al variar la intensidad del campo.

El cambio de la frecuencia del pulso de radiofrecuencia desplazará el corte transversal a otra posición a lo largo del gradiente, donde se empareja a la frecuencia de Lamor de los protones, ya que según la ecuación de Lamor la frecuencia del movimiento de precesión es directamente proporcional a la intensidad del campo magnético $\vec{B}_{0}$.

El gradiente de selección de corte determina la posición del corte y su grosor. Con las técnicas actuales se obtienen cortes de menos de $1 \mathrm{~mm}$ a $10 \mathrm{~mm}$, en función de la anchura de banda del pulso de radio frecuencia.

Éstos se componen de una frecuencia central y un estrecho margen de frecuencias o ancho de banda (típicamente de $1 \mathrm{a} 2 \mathrm{kHz}$ ). Cuanto más estrecha sea la anchura de banda, más fino será el corte excitado. Además, a igual banda de frecuencia, el grosor del corte depende de la intensidad del gradiente. 
La orientación del gradiente de pies a cabeza permite realizar cortes axiales (para obtener cortes sagitales o coronales se orienta de derecha a izquierda y de delante atrás, respectivamente).

Gradiente codificador de frecuencia y gradiente de codificación de fase.

Las coordenadas $x$ e y necesarias para completar la definición del vóxel se pueden obtener aplicando dos gradientes adicionales: el gradiente codificador de frecuencia, conocido como Gx, que codifica las columnas de la matriz, y el gradiente de codificación de fase, conocido como Gy, que codifica las filas de la matriz.

En ausencia de gradiente, la precesión de los protones es la misma, por lo que giran a la misma velocidad angular $\omega_{0}$. Al aplicar el gradiente de codificación de frecuencia, la frecuencia de precesión de los protones de una columna es la misma pero, al girar éstos en las restantes columnas a velocidades crecientes cambia en cada una de ellas. Es decir, la frecuencia de precesión de los protones aumenta en cada una de las columnas. De esta forma, se consigue codificar las columnas de la matriz e individualizarlas dentro del plano de corte.

Antes del gradiente, los protones de una misma columna giran a igual velocidad $\omega_{0}$ y se mantienen en fase. El gradiente de codificación de fase hace que los protones de cada columna, mantenidos en fase, aumenten sus velocidades angulares, de acuerdo con la intensidad del campo magnético al que están expuestos, por lo que acelerarán sus precesiones de diferente forma de unos a otros.

Al interrumpir el gradiente, todos los protones de la columna experimentan otra vez el mismo campo magnético y vuelven a girar a la misma velocidad $\omega_{0}$ pero, al haber perdido la fase, van a poder diferenciarse.

El gradiente de codificación de fase permite seleccionar las distintas filas dentro del plano de corte.

La aplicación de estos gradientes en resonancia magnética comienza con el gradiente de codificación de fase para codificar las filas de la matriz de la imagen. Posteriormente se aplica el gradiente de codificación de frecuencia para codificar las columnas. El método permite obtener información de una sola fila de la matriz. El resto de filas se consiguen aplicando los dos gradientes para cada una de ellas.

El conjunto de señales procedentes de los vóxeles que componen el corte explorado es captado mediante una bobina o antena.

\section{Tratamiento informático de las señales}

El conjunto de señales emitidas por los vóxeles y recibidas por la antena es sometido a un análisis de Fourier, que a través de la transformada de Fourier permite extraer las diferentes frecuencias que componen las señales.

Las amplitudes de señal alta se visualizan hacia el blanco y las amplitudes bajas hacia el negro dentro de una escala de grises.

La resonancia magnética proporciona imágenes primarias en cualquier plano del espacio (axiales, coronales, sagitales y oblicuas) mediante la selección de la de- 
bida conmutación de los gradientes y permite la realización de reconstrucciones tridimensionales de las estructuras exploradas.

En estudios vasculares muestra los vasos sanguíneos y ofrece imágenes 3D sin necesidad de emplear un medio de contraste.

\section{Técnica multicortes}

Anteriormente hemos visto las características de una de las secuencias más empleadas en resonancia magnética, la secuencia spin eco, y la utilización de los tres gradientes que permiten localizar la señal procedente de cada vóxel: pulso de $90^{\circ}$ y aplicación del gradiente de selección de corte $\mathrm{Gz}$; pulso $180^{\circ}$ y gradiente de codificación de fase Gy; y gradiente codificador de frecuencia Gx.

Este ciclo proporciona la información de una fila de la matriz de imagen. Las restantes filas se obtienen una a una repitiendo la secuencia.

El tiempo de adquisición necesario para obtener la imagen depende de varios parámetros cuyas variaciones consiguen reducir dicho tiempo:

El tiempo de repetición. Tiempo que separa dos pulsos de $90^{\circ}$ y que coincide con el paso de una fila a otra, ya que cada una de éstas empieza con un pulso de $90^{\circ}$.

El número de filas o hileras de la matriz. El número de columnas de la matriz no influye en la duración de la secuencia.

El número de excitaciones. Número de veces que se repite la secuencia por cada línea con objeto de mejorar la calidad de la imagen (relación señal/ruido).

El desarrollo de técnicas que permiten obtener varios cortes, en el mismo período de tiempo, ha reducido la duración de las exploraciones de resonancia magnética.

La técnica multicortes se basa en el aprovechamiento del largo tiempo que transcurre entre la medida de la señal (tiempo de eco entre 20 y $120 \mathrm{mseg}$ ) después de un primer pulso de $90^{\circ} \mathrm{y}$ el nuevo pulso de $90^{\circ}$ (tiempo de repetición entre 400 y 2500) que marca el inicio para la obtención de las señales correspondientes a la siguiente fila de la matriz.

Este tiempo "muerto" se gestiona para conseguir los siguientes cortes: durante el primer tiempo de repetición se obtienen las señales procedentes de la primera fila de cada corte; durante el segundo tiempo de repetición, las señales que corresponden a las segundas filas de los planos de corte sucesivos; y durante el último tiempo de repetición (256 ó 128) las señales procedentes de la última fila.

Al final del proceso, en función de si se potencia en T1 o en T2, se habrán obtenido 10 ó 13 cortes paralelos. No se reduce el tiempo de adquisición pero se logran durante el mismo un mayor número de planos de corte.

\section{Los medios de contraste}

En resonancia magnética se emplean sustancias paramagnéticas como el gadolinio (gadopentetato de dimeglumina), una tierra rara que en estado libre es tóxi- 
ca, por lo que se utiliza en forma de complejo gadolinio-ácido dietilentriaminopenta-acético (gadolinio-DTPA), administrado por vía intravenosa.

El efecto del medio de contraste es un cambio en la intensidad de la señal, debido a un acortamiento del tiempo de relajación de los protones, que mejora el contraste de tejidos (después de administrar un medio de contraste, la técnica de imagen preferida es la potenciada en T1).

La utilización de medios de contraste aumenta la detección de lesiones y la precisión diagnóstica. Es ideal para detectar lesiones neoplásicas ya que el gadolinio entra en el tejido tumoral y acorta el T1. Como el sistema de alrededor no se ve influido, el contraste entre ambas estructuras mejora enormemente en imágenes potenciadas en $\mathrm{T} 1$.

También hay medios de contraste orales cuya utilidad en resonancia magnética se circunscribe fundamentalmente a la patología intestinal. Son contraste orales positivos (alta intensidad de señal) y negativos (baja intensidad de señal). Los contrastes negativos (bromuro de perfluoroctilo [PFOB]) son útiles para reducir los artefactos que produce el peristaltismo.

\section{Técnicas de adquisición de datos}

En resonancia magnética se utilizan tres técnicas de adquisición de datos: multicorte 2D, corte secuencial 2D y volumen tridimensional 3D.

La imagen multicorte 2D es la más utilizada. El hardware de los equipos actuales permite realizar la excitación y detección de varios cortes dentro de un mismo período de tiempo de repetición.

En la técnica de corte secuencial 2D toda la información de un corte se consigue antes de empezar a obtener información de cualquier otro corte.

En la adquisición de volumen en 3D se estimulan volúmenes de tejido de 30 a $150 \mathrm{~mm}$ (en imágenes 2D se estimulan volúmenes de 3 a $10 \mathrm{~mm}$ ) que se subdividen en cortes individuales.

\section{Factores de Calidad}

La calidad de la imagen obtenida es un aspecto fundamental en el diagnóstico por resonancia magnética y depende de factores relacionados con el hardware del equipo, factores propios de la técnica utilizada (programación de la secuencia) o la presencia de artefactos.

En cualquier caso, existen criterios objetivos de calidad que permiten su valoración: relación señal/ruido, resolución espacial y contraste. Los dos primeros están directamente relacionados con el tiempo de adquisición de la imagen.

El contraste, o variación de la intensidad de la señal entre dos estructuras adyacentes, depende de parámetros propios de los tejidos o seleccionados por el operador como tiempos de relajación, tiempo de repetición, tiempo de eco, etc.

La consecución de una calidad de imagen óptima implica la búsqueda de la mejor "combinación" posible: buena relación señal/ruido, resolución espacial óptima y duración de la exploración aceptable. 


\section{Artefactos}

La presencia de artefactos afecta negativamente a la calidad de la imagen ya que pueden modificar la morfología real de una estructura anatómica o simular un proceso patológico y, por tanto, provocar la aparición de errores de interpretación.

Básicamente, se trata de artefactos relacionados con el sistema de resonancia magnética (aliasing, desplazamiento químico y defectos del sistema) y de artefactos relacionados con el paciente (metálicos y de movimiento).

El aliasing aparece cuando el objeto explorado es mayor que el campo de visión. Se traduce en un desdoblamiento o repliegue de las estructuras externas al campo al lado contralateral de la imagen. Por ejemplo, una determinada estructura de la región frontal en una imagen de resonancia magnética de cabeza puede reconocerse con facilidad en la región occipital o simular un proceso patológico.

Los artefactos de desplazamiento químicos tienen su origen en la diferente frecuencia de resonancia de los protones del agua y de la grasa, apareciendo en regiones anatómicas en las que existen interfases entre tejidos grasos y blandos (acuosos).

Los artefactos metálicos se originan por la presencia de material ferromagnético que porta el paciente y tienen como consecuencia la aparición de una zona de ausencia de señal con refuerzo en la periferia y una deformación en la imagen.

Los artefactos de movimiento del paciente son los más frecuentes. Actúan sobre la calidad de la imagen degradándola y se producen tanto por movimientos voluntarios como involuntarios. 


\section{Neurodegeneración y Enfermedad de Alzheimer.}

Se habla de enfermedad neurodegenerativa cuando el paciente sufre un proceso crónico y progresivo caracterizado por pérdidas selectivas de neuronas en los sistemas motor, sensorial y cognitivo. Entre ellas, destacan la enfermedad de Alzheimer, la de Parkinson, la de Creutzfeldt-Jakob, la degeneración multisistémica y la esclerosis múltiple.

Las enfermedades neurodegenerativas son muy heterogéneas y su clasificación es muy complicada debido a que se solapan entre sí desde el punto de vista clínico y anatomopatológico, presentando gran variedad de síntomas, muchos idénticos, en sus estados iniciales.

Hace 25 años, poco se conocía de las causas de las enfermedades neurodegenerativas. Hoy se sabe que en todas ellas hay algún tipo de proceso anormal que afecta a las proteínas neuronales. Según Prusiner pueden ser:

a) Plegamiento anormal de proteínas.

b) Alteraciones en las modificaciones post-translacionales de proteínas nuevamente sintetizadas.

c) Anormalidades en el proceso proteolítico.

d) Anomalías en los genes que intervienen en el acoplamiento ("splicing").

e) Expresión impropia.

f) Reducción del aclaramiento, eliminación, de las proteínas degradadas.

Cuando las proteínas específicas de cada circuito celular son procesadas de forma inadecuada, los mecanismos celulares para su eliminación son ineficaces, acumulándose en el tejido nervioso, dentro y fuera de las neuronas, produciendo el mal funcionamiento de las mismas, su muerte (generalmente asociada a estrés oxidativo) y las consiguientes manifestaciones de la enfermedad.

La enfermedad de Alzheimer es una enfermedad neurodegenerativa que produce deterioro intelectual progresivo y una amplia variedad de alteraciones neuropsiquiátricas y conductuales.

Las personas afectadas pierden memoria, se vuelven incapaces para realizar las tareas cotidianas, ven alterado su lenguaje, su capacidad laboral y su vida social.

En el año 2006 afectó a más de 26 millones de personas en todo el mundo, según un estudio de la Universidad Johns Hopkins en Baltimore. España se erige actualmente como el segundo país europeo, detrás de Suecia, con el mayor número de afectados por esta enfermedad, que ronda los 700.000. La media española de personas que sufren esta patología supone el 1,5\% y supera claramente la media europea, que está en el 1,28\%. Si la lucha contra esta enfermedad, tanto desde la vertiente asistencial como la sanitaria e investigadora, no ofrece perspectivas más serias, en el año 2.020 el número de enfermos de Alzheimer en nuestro país se duplicará y superará los 1,5 millones de personas. 
El diagnóstico de la enfermedad de Alzheimer se ha establecido mediante dos tipos de criterios. Por un lado, los Criterios Diagnóstico DSM-IV-TR (Diagnostic and Statistical Manual of Mental Disorders, Fourth Edition, texto revisado en el año 2000) aportados por la American Psychiatric Association; y, por otro, los Criterios Diagnóstico NINDCS-ADRDA (National Institute of Neurological and Communicative Disorders and the Alzheimer's Disease and Related Disorders Association).

Ambos, presentan como primer criterio la presencia de deterioro de la memoria y otros déficits cognitivos. Para determinar los diferentes perfiles cognitivos de los pacientes se puede recurrir a pruebas neuropsicológicas como el examen Folstein Mini Mental State, la Signoret Memory Battery, el Boston Naming Test, el Verbal Fluency (FAS), el Wechsler Adult Intelligence Scale, y el Trail Making Test.

Así, por ejemplo, los pacientes con demencia del lóbulo frontal obtienen resultados significativamente mejores en test de memoria, cálculo, visión espacial, habilidades y pruebas visuo-verbales; mientras que los enfermos con Alzheimer son mejores en la ejecución de tareas (Allegri y col., 1998).

A pesar de los resultados, puede ser muy difícil distinguir entre la enfermedad de Alzheimer y otras demencias a través de los cuadros clínicos consistentes en destacados daños cognitivos, por ejemplo, la amnesia. De ahí que se añadan nuevos criterios para un mejor diagnóstico.

Actualmente se utiliza el DSM en su cuarta edición, revisada en el año 2000, que establece los siguientes criterios:

Desarrollo de déficits cognitivos múltiples manifestados por deterioro de la memoria (tanto para aprender información nueva como recordar información aprendida) y uno o más de los siguientes déficits: afasia (trastorno del lenguaje), apraxia (deterioro de la capacidad para llevar a cabo actividades motoras), agnosia (fallo en el reconocimiento o identificación de objetos) y alteraciones en funciones ejecutivas (planificación, organización, secuenciación y abstracción).

Los déficits cognitivos provocan un deterioro significativo de la actividad laboral y/o social y suponen una disminución con respecto al nivel funcional previo del paciente.

El curso es caracterizado por un comienzo gradual y declinación continua.

Los déficits cognitivos no son debidos a:

Otras enfermedades del sistema nervioso central que provocan déficits de memoria y cognitivos, como enfermedad vascular cerebral, enfermedad de Parkinson, enfermedad de Huntington, hematoma subdural, hidrocefalia a presión normal o tumor cerebral.

Enfermedades sistémicas que producen demencia, como hipotiroidismo, deficiencia de vitamina B12 o de ácido fólico, déficit de niacina, hipercalcemia, neurosífilis o infección por el virus de la inmunodeficiencia humana $(\mathrm{VlH})$.

Estados inducidos por sustancias.

Los déficits no aparecen de manera exclusiva en el transcurso de un delirium. 
La alteración no se explica mejor por la presencia de un trastorno depresivo mayor o esquizofrenia.

Los avances científicos en el estudio de la enfermedad han determinado biomarcadores fiables y característicos para la enfermedad de Alzheimer que pueden ser obtenidos a través de imagen por resonancia magnética, neuroimagen molecular por PET y análisis del líquido cefalorraquídeo. Esto sugiere que se debe incorporar a los criterios diagnósticos la presencia de valores anormales en, al menos, alguno de estos biomarcadores (Lin y col., 2012). Cobra mayor importancia si se tiene en cuenta que muchos de los medicamentos que se están desarrollando se encaminan directamente a cambiar la patogénesis, en particular la producción y eliminación de beta amiloide y el estado de hiperfosforilación de Tau (Dubois y col., 2007).

Los Criterios Diagnóstico NINDCS-ADRDA para Enfermedad de Alzheimer incorporan esta idea, y además, habla de enfermedad de Alzheimer probable o enfermedad de Alzheimer definitiva debido a que en el diagnóstico pueden existir dudas razonables.

Se piensa en una enfermedad de Alzheimer probable cuando se cumplen uno o más de los criterios diagnósticos de cada uno de los siguientes grupos:

Presencia de deterioro de la memoria episódica significativa y temprana que incluye las siguientes características:

Cambio gradual y progresivo en la función de la memoria reportada por pacientes o informantes durante más de 6 meses.

Evidencia objetiva de memoria episódica alterada significativamente en pruebas: estas generalmente consisten en recordar el déficit que no mejoran significativamente o no se normalizan con pruebas de reconocimiento y después de que la codificación efectiva de la información ha sido previamente controlada.

La alteración de la memoria episódica puede ser aislada o asociada con otros cambios cognitivos al comienzo de la enfermedad de Alzheimer o en la progresión de la enfermedad de Alzheimer.

Presencia de atrofia del lóbulo temporal medial.

Pérdida de volumen del hipocampo, corteza entorrinal, amígdala evidenciada en la RNM con valoración cualitativa utilizando escoring visual (referenciado como el normal para la población y edad) o volumetría cuantitativa de regiones de interés (referenciado como el normal para la población y edad)

Biomarcadores anormales en líquido cefalorraquídeo.

Concentraciones baja de amiloide B1-42, concentraciones aumentadas de Tau total, o concentraciones aumentadas de fosfo-Tau, o combinaciones de los tres.

Otros marcadores validados que pueden ser descubiertos en el futuro.

Patrón específico en neuroimágenes funcionales con PET. 
Reducido metabolismo de la glucosa en regiones parieto- temporal bilateral.

Otros ligandos validados, incluyendo aquellos que son predecibles y que podrían surgir como el complejo Pittsburg B o FDDNP.

Mutación autosómica dominante de EA en familiares inmediatos.

Cuando se dan los siguientes criterios, puede rechazarse la existencia de una enfermedad de Alzheimer:

Comienzo súbito.

Recurrencia temprana de los siguientes síntomas: trastornos en la marcha, convulsiones, cambios de conducta.

Signos de foco neurológico incluyendo hemiparesia, trastornos sensitivos, déficit del campo visual.

Signos extrapiramidales tempranos.

Otras condiciones médicas suficientemente severas como para producir alteraciones en la memoria y síntomas relacionados, como Demencia no Alzheimer, Depresión mayor, Enfermedad cerebrovascular, Anormalidades tóxicas y metabólicas, que puedan requerir estudios específicos y Anormalidades en la señal Resonancia Magnética FLAIR o T2 en el lóbulo temporal medial que pueden ser consecuencia de enfermedades infecciosas o vasculares.

La enfermedad de Alzheimer es considerada definitiva si los siguientes criterios de diagnóstico están presentes:

Evidencias clínica e histopatológica (biopsia cerebral o autopsia) de la enfermedad, son requeridas por los criterios NIA-Reagan para el diagnóstico post-mortem de enfermedad de Alzheimer; ambos criterios deberían estar presentes.

Ambas evidencias clínica y genética (mutación en el cromosoma 1, 14, ó 21) de enfermedad de Alzheimer; ambos criterios deberían estar presentes. 


\section{La proteína Tau y la enfermedad de Alzheimer.}

Tau es una proteína, principalmente axonal que normalmente actúa como una proteína asociada a microtúbulos, es por tanto una MAP, que presumiblemente estabiliza los microtúbulos y así favorece el transporte citoplásmico.

Tau es también el principal componente de los pares de filamentos helicoidales que caracterizan a la enfermedad de Alzheimer.

Las diferencias entre la Tau normal y la de la enfermedad de Alzheimer radican en múltiples procesos como: la agregación, la fosforilación, degradación proteolítica, la pérdida o disminución de unión a los microtúbulos, la glicosilación y la ubiquitinación (Kosik y col., 1994).

Hay por tanto una gran complejidad en la degeneración de Tau durante la enfermedad de Alzheimer por lo que se hace interesante conocer algunas de las características estructurales de esta proteína.

La molécula de Tau es una molécula alargada, midiendo en torno a $35 \mathrm{~nm}$ (Wille y col., 1992), aunque, a diferencia de la mayoría de las proteínas solubles, Tau no tiene una forma bien definida semejando a un polímero.

Tau estabiliza los microtúbulos neuronales y promueve el crecimiento y extensión de las neuritas (Drubin y Kirschner, 1986; Knops y col., 1991). La unión a los microtúbulos se realiza a través de la mitad $\mathrm{C}$-terminal de la molécula, mientras que la porción $\mathrm{N}$-terminal probablemente actúe como espaciador entre los microtúbulos, como punto de anclaje para otras proteínas o participe en alguna otra función específica del tejido. Dos partes de la molécula de Tau, los dominios $P$ y $R$, se unen a un único protofilameto, mientras que los dominios repeats, situados entre los dominios $\mathrm{P}$ y $\mathrm{R}$, se ensamblan a un protofilamento adyacente, por lo que la unión cruzada de protofilamentos precisa de la acción combinada de los dominios $\mathrm{P}$ y $\mathrm{R}$ y de los dominios repeat: Tau se anclaría en un protofilamento, por los dominios P y R, y, a través de los dominios repeat, al unirse a otro protofilamento adyacente, sería el actor del ensamblaje de los microtúbulos (Mandelkow y col., 1996).

En diferentes lugares de la molécula, Tau está normalmente fosforilada; sin embargo, en la enfermedad de Alzheimer, Tau está fosforilada 3 veces más que en condiciones normales (Ksiezak-Reding y col., 1992; Watanabe y col., 1993; Drechsel y col., 1992; Köpke y col., 1993), lo que parece relacionarse con la escasa capacidad estabilizadora de Tau en la enfermedad de Alzheimer (Yoshida e Ihara, 1993).

La fosforilación en la serina 262 se da sólo en la enfermedad de Alzheimer (Hasegawa y col., 1992; Gross y col., 1994) y esto parece ser más importante en el proceso de unión de Tau a los protofilamentos y en la estabilización de los microtúbulos, que el que Tau esté muy fosforilada, pues se pueden alcanzar fosforilaciones hasta 12 veces superiores a la fosforilación nativa de Tau sin que se pierda su capacidad estabilizadora de los microtúbulos (Mandelkow y col., 1996). 


\section{La Resonancia Magnética en el diagnóstico de la Enfermedad de Alzheimer.}

La obtención de imágenes basadas en la técnica de resonancia magnética ha supuesto uno de los avances tecnológicos más importantes logrados en el campo de la radiología digital. Su utilización se ha generalizado en la Medicina para el diagnóstico y tratamiento de las enfermedades relacionadas, sobre todo, con las partes blandas del cuerpo humano, como el sistema nervioso central, el sistema músculo esquelético, el tórax, el abdomen o los estudios del flujo vascular.

Aunque las exploraciones de resonancia magnética someten a los pacientes a un campo magnético intenso, a gradientes rápidamente cambiantes y a un campo de alta frecuencia, no se han demostrado alteraciones biológicas perjudiciales.

A diferencia de las técnicas que utilizan rayos $X$ para obtener imágenes, la resonancia magnética emplea campos magnéticos y radiación no ionizante de radiofrecuencia del espectro electromagnético.

Las técnicas con imagen tales como la tomografía computerizada de rayos- $\mathrm{X}$ y la resonancia magnética son ampliamente usadas en la evaluación clínica de pacientes con desórdenes de demencia. La tomografía computerizada fue introducida para prácticas clínicas en los primeros años de la década de los 70 . La aparición de la imagen de resonancia magnética vino después con el primer equipo usado para propósitos clínicos en la primera mitad de la década de los 80 .

Las dos modalidades difieren en que la tomografía computerizada tiene una resolución de contraste inferior comparada con la imagen por resonancia magnética y es también más rápida y a menudo más conveniente para los pacientes. Por otro lado, la resonancia magnética da una imagen superior del tejido cerebral sin el uso de agentes de contraste.

Coinciden en que ambas no se alteran con artefactos por el hueso. Esto es de especial importancia en el estudio de enfermedades de demencia (especialmente en el Alzheimer) donde los cambios estructurales se presentan en el cerebro, en el interior de la envoltura ósea del cráneo.

La obtención de imágenes del lóbulo temporal a través de tomografía computarizada axial revela que los pacientes con la enfermedad de Alzheimer presentan un espesor medio mínimo del lóbulo temporal medial significativamente menor que pacientes con demencia vascular u otras enfermedades psiquiátricas. La técnica aplicada a pacientes con la enfermedad de Alzheimer, tanto declarados como más suaves, arrojan unos índices de sensibilidad de 0.75 y 0.61 ; una especificidad de 0.9 y 0.91 ; y de 0.81 para la precisión en el diagnóstico (Denihan y col., 2000)

A pesar de los buenos resultados indicados anteriormente, según Wahlund LO, 1996, la posibilidad de imágenes en planos arbitrarios hace a la MRI más adecuada para el estudio de las estructuras cerebrales más relevantes en el diagnóstico de la enfermedad de Alzheimer.

El análisis de estas imágenes aportan patrones cerebrales característicos para el deterioro progresivo y gradual de las habilidades cognitivas y de comportamiento detectadas clínicamente en los pacientes. 
Por esta razón, una cantidad importante de los hallazgos anatómicos y funcionales de la neuroimagen están relacionados con la enfermedad de Alzheimer, siendo la asociación entre la enfermedad y la atrofia del hipocampo una de las más altamente identificadas.

A pesar de que en los años 90 no existían pruebas de sangre o de laboratorio fidedignas que diagnosticaran clínicamente la enfermedad de Alzheimer, los estudios de la configuración del cerebro usando imágenes de resonancia magnética ya mostraban la atrofia diferencial, sobre todo del lóbulo temporal, que está presente en la mayoría de casos (Thomson, 1990).

La severidad de la demencia indicada por las puntaciones del Mini Examen del Estado Mental, la Escala Global de Deterioro y la Escala Breve de Evaluación Cognitiva se correlacionaba significativamente con los volúmenes del complejo amigdalo-hipocampal bilateral, pero no con el volumen total cerebral o con el ratio del ventrículo cerebral.

De ahí la importancia de las subestructuras meso-temporales en la etiología y progresión de la demencia del tipo Alzheimer. El volumen del complejo amigdalo-hipocampal puede ser monitorizado mediante imagen de resonancia magnética y usado para seguir la progresión de la enfermedad (Pantel y col., 1996).

Las medidas volumétricas basadas en imágenes de resonancia magnética de las estructuras del lóbulo temporal medio pueden discriminar entre sujetos con un envejecimiento normal y pacientes con la enfermedad de Alzheimer en estado moderado o severo. Sin embargo, las medidas normalizadas del volumen del hipocampo basadas en resonancia magnética, ajustadas con la edad y género, son un marcador sensitivo de la degeneración neuroanatómica desde las etapas tempranas del desarrollo de la enfermedad (Jack y col., 1997).

Comparando las medidas de los lóbulos temporales de pacientes con enfermedad de Alzheimer de grado suave a moderado con las de sujetos sanos de edad semejante y las de jóvenes sanos, se obtiene que los cambios significativos de volumen ocurren en el lóbulo temporal para los sujetos de edad y enfermos de Alzheimer, con mayor porcentaje de reducción en la amígdala en enfermos de Alzheimer.

La atrofia neocortical temporal y la atrofia límbica temporal parecen estar asociadas con diferentes patrones de actuación y comportamiento en pacientes de Alzheimer.

Los enfermos de Alzheimer mostraban mayores reducciones en la amígdala (33\%, $\mathrm{p}=0.0001)$ e hipocampo $(20 \%, \mathrm{p}=0.006)$ pero no en el lóbulo temporal $(7 \%$, $\mathrm{p}=0.15)$.

Los sujetos sanos de mayor edad presentaban menores reducciones de volumen en la amígdala $(17 \%, \mathrm{p}=0.02)$ y el hipocampo $(15 \%, \mathrm{p}=0.0001)$, pero mayor en el lóbulo temporal $(22 \%, \mathrm{p}=0.0001)$.

Además, en los pacientes con enfermedad de Alzheimer, el volumen del lóbulo temporal izquierdo se correlaciona fuertemente con la puntuación del mini examen del estado mental (ajustada $\mathrm{r} 2=0.46, \mathrm{p}=0.0006$ ) mientras que el volumen de la amígdala derecha se relacionaba inversamente con la puntuación no cognitiva 
obtenida según la escala de valoración de la enfermedad de Alzheimer (ajustada $r 2=0.46, p=0.0006$ ) (Smith y col., 1999).

Para poder utilizar los estudios volumétricos sobre imágenes por resonancia magnética como método que ayuda al diagnóstico clínico de la enfermedad de Alzheimer es necesario valorar la exactitud de esta técnica para distinguir entre pacientes con Alzheimer, individuos con suaves daños cognitivos y personas con envejecimiento normal.

Se han obtenido medidas de las regiones del amigdalino, el hipocampo y el giro parahipocampal significativamente diferentes $(p<0.005)$ en los enfermos de Alzheimer respecto a los otros dos grupos.

Las medidas volumétricas de estas tres regiones en el hemisferio cerebral izquierdo fueron significativamente diferentes entre los individuos con daños cognitivos suaves y los individuos normales de control.

El análisis con una función discriminante clasificó correctamente el $88.14 \%$ de los pacientes con Alzheimer y los individuos control, el $81.67 \%$ de los pacientes con Alzheimer y los sujetos con daños cognitivos suaves y el $80.49 \%$ de éstos últimos y los individuos de control (Bottino y col., 2002).

Por tanto, las medidas de las regiones del lóbulo temporal medial son útiles para identificar los pacientes de los grupos indicados y separarlos de los individuos con un envejecimiento normal

Aunque en la práctica clínica la volumetría del hipocampo puede ser más posible, porque el método es más fácil de usar y tiene menos variabilidad, si se combina con las medidas volumétricas de la corteza entorrinal, la función discriminante que se obtiene permite distinguir a los pacientes de Alzheimer de los sujetos control con una fiabilidad del $90 \%$, utilizando un análisis multivariante de la varianza (Juottonen y col., 1999)

La estimación del volumen del cuerpo amigdalino y del área basolateral temporal parece ser el factor más importante para el diagnóstico de la demencia de tipo Alzheimer, según se desprende de un estudio de Morys y col., 2002.

En él, se compararon los volúmenes del giro superior temporal, el área basolateral temporal, el giro del hipocampo, la cabeza del hipocampo, el cuerpo amigdalino y el cuerno inferior del ventrículo lateral medidos sobre imágenes coronales de resonancia magnética perpendiculares al eje longitudinal del hipocampo y normalizados por el volumen intracraneal.

Los volúmenes de todas las estructuras analizadas fueron menores en los sujetos enfermos, siendo mayores las diferencias para el cuerpo amigdalino y el área basolateral temporal.

El análisis discriminatorio, incluyendo el volumen de ambas estructuras, permitió clasificar correctamente al $100 \%$ de los pacientes de Alzheimer y al $93 \%$ de los controles.

Además de atrofia en el hipocampo, los enfermos con Alzheimer temprano presentan atrofia en la corteza parietal y la ínsula, no así, en la corteza estriada. Tampoco aparecen diferencias significativas entre las partes izquierda y derecha 
de las regiones estudiadas. La atrofia en la corteza insular puede contribuir a los déficits cognitivos típicos en los comienzos de la enfermedad (Foundas y col., 1997).

Se ha correlacionado la enfermedad de Alzheimer con medidas del cuerpo calloso y la comisura blanca anterior, comparándolas con descensos en el volumen de los giros temporales superior medio e inferior en el lóbulo temporal.

Estos estudios han demostrado que los enfermos de Alzheimer presentan, en comparación con sujetos normales, un cuerpo calloso de tamaño reducido, que se acompaña de afectación en el giro temporal medio, el itsmo y la rodilla; sin afectación de la comisura blanca anterior y el giro temporal superior (Black y col., 2000).

Aparte de los análisis volumétricos, la inspección visual de la atrofia del lóbulo temporal medial sobre imágenes realizadas con resonancia magnética tiene un importante valor diagnóstico para distinguir pacientes con enfermedad de Alzheimer.

Combinando las puntuaciones del mini examen del estado mental con los ratios visuales de la atrofia del lóbulo temporal medial se obtuvo, en la identificación de los grupos, una sensibilidad del 95\% para enfermos de Alzheimer, 85\% para otras demencias y $96 \%$ para los sujetos sin demencia.

La volumetría por sí sola no ha dado valor a la puntuación del mini examen del estado mental. La medición visual de la atrofia del lóbulo temporal medial es un método clínicamente útil y es más rápida y más acertada que la volumetría (Wahlund y col., 2000).

Junto a las medidas volumétricas, las medidas lineales de la atrofia hipocampal pueden ser útiles en la rutina para el diagnóstico de la enfermedad de Alzheimer, incluso en las primeras etapas de desarrollo.

Un exhaustivo estudio midió la región frontal (índice bifrontal, ancho de la fisura interhemisférica), el lóbulo temporal (distancia interuncal, espesura mínima del lóbulo medial temporal) y la atrofia hipocampal (altura o longitud hipocampal, anchura del surco hipocampal, anchura del cuerno temporal) sobre imágenes por resonancia magnética.

Aunque la medida de mayor sensibilidad fue la anchura del cuerno temporal, la composición de las medidas de varias regiones dio buenos resultados en la distinción de los grupos estudiados.

La combinación de la anchura del cuerno temporal, la anchura del surco del hipocampo, la longitud del hipocampo y la distancia interuncal discriminó a los pacientes con suave Alzheimer con un $86 \%$ de sensibilidad.

La validación en pacientes moderados confirmó la utilidad del modelo con un $81 \%$ de sensibilidad.

Considerando únicamente las medidas de la atrofia del hipocampo en pacientes con suave Alzheimer la sensibilidad es sólo del $83 \%$, mientras que la validación cruzada en pacientes moderados arroja $87 \%$ de sensibilidad (Frisoni y col., 1996). 
La medida del área del lóbulo temporal y del hipocampo en pacientes con la enfermedad de Alzheimer arroja diferencias según los diferentes grados de demencia.

La media del área de ambos hipocampos en pacientes en estados 3-5 de la escala Reisberg fue $378.6+/-86.1 \mathrm{~mm}^{2}$ y en estados $6-7$ fue de $364.7+/-62.2 \mathrm{~mm}^{2}$.

La media del área de ambos lóbulos temporales en pacientes con estado 3-5 fue de $2177.03+/-411.4 \mathrm{~mm}^{2}$ y en estados 6-7, fue de $1945.0+/-303.3 \mathrm{~mm}^{2}$ (Rodríguez y col., 1995).

Pero no se puede deducir una relación clara entre la reducción en tamaño del lóbulo temporal y del hipocampo en pacientes con enfermedad de Alzheimer y el grado de demencia.

Solamente se aprecia que la proporción de cambio para la anchura del cuerpo calloso y para los daños cognitivos es mayor en los casos severos, mientras que en las áreas del lóbulo temporal permanece constante a lo largo de la enfermedad.

Los grados de progresión de la atrofia son diferentes en las distintas regiones cerebrales a lo largo de los distintos estados de la enfermedad.

Así, la combinación de las medidas del área del lóbulo temporal y los ratios de atrofia temporo-parietal se pueden utilizar para la diagnosis y seguimiento de la enfermedad de Alzheimer (Bracco y col., 1999).

La evaluación del tamaño total y regional del cuerpo calloso con respecto a los volúmenes de los lóbulos frontal, temporal y parietal indica que la parte del pico del cuerpo calloso está significativamente correlacionado con los volúmenes del lóbulo frontal, la parte del cuerpo con los volúmenes del lóbulo temporal y el tamaño de la parte caudal con los volúmenes del lóbulo parietal en el grupo de pacientes con Alzheimer estudiado.

Además, la atrofia del cuerpo calloso en la enfermedad de Alzheimer refleja la severidad y el patrón del daño neuronal de la corteza.

La severidad de la demencia está significativamente correlacionada con el tamaño de las secciones medias del cuerpo calloso (pico y cuerpo).

Las correlaciones obtenidas entre la atrofia del cuerpo calloso y la severidad de la demencia indican que la desconexión ínter hemisférica "córtico-cortical" puede contribuir al síndrome de la demencia (Pantel y col., 1999).

La imagen de resonancia magnética, aparte de distinguir a los pacientes con enfermedad de Alzheimer de los sujetos sanos, puede ser una importante ayuda para diferenciarlos de otros sujetos con enfermedades similares, que también presenten desórdenes asociados con daños cognitivos.

En este sentido, la elaboración de modelos completos de la atrofia cerebral permite diferenciar a los pacientes con demencia fronto-temporal de los afectados por Alzheimer.

Las medidas obtenidas a partir de imágenes por resonancia magnética indican que los pacientes con demencia fronto-temporal tienen atrofia suave en el hipocampo, severa en el lóbulo frontal y muy severa en el temporal. 
Por su parte, los enfermos con Alzheimer presentan atrofia moderada en el hipocampo y el lóbulo temporal y muy suave en el lóbulo frontal.

Sin embargo, los valores de la asimetría de la atrofia, sobre todo en los lóbulos temporales (mayor en la parte izquierda en pacientes con demencia frontotemporal que con Alzheimer), son los que permiten distinguir los pacientes con una u otra enfermedad con un $90 \%$ de sensibilidad y un $93 \%$ de especificidad (Boccardi y col., 2003).

Las alteraciones estructurales de la línea media cerebral reflejan modelos diferenciales de degeneración para ambas enfermedades, produciendo índices morfométricos que pueden facilitar el estudio de las razones del comportamiento cerebral y el diagnóstico diferencial de la demencia.

El tamaño de la región del cuerpo calloso era mucho menor en los sujetos con demencia frontotemporal, mientras que las áreas del espacio del líquido cefalorraquídeo pericalloso eran significativamente mayores, particularmente en regiones anteriores.

Las relaciones entre el cuerpo calloso y el espacio pericalloso totales y anteriores eran marcadamente más bajos en los pacientes con demencia frontotemporal.

Entre los grupos, las relaciones entre los tamaños totales del cuerpo calloso y del espacio pericalloso se correlacionaron significativamente con el área cerebral medio-sagital y con la puntuación del mini examen del estado mental (Kaufer y col., 1997).

Las medidas del volumen de las estructuras del lóbulo temporal, hipocampo, parahipocampo y giro dentado, a partir de imágenes obtenidas con resonancia magnética, también permiten establecer diferentes modelos de la atrofia del lóbulo temporal según que los pacientes presenten demencia con cuerpos de Lewy o enfermedad de Alzheimer u otras demencias (Varma y col., 2002b).

Los volúmenes del hipocampo y parahipocampo son significativamente mayores en sujetos con demencia con cuerpos de Lewy que en enfermos de Alzheimer.

Existen diferencias de volumen en toda la extensión del hipocampo entre ambos tipos de pacientes y todos los pacientes con demencia tienen una asimetría hipocampal si se comparan con individuos sanos.

Ambos tipos de pacientes presentan correlación entre la atrofia del lóbulo temporal y los deterioros de memoria.

Los modelos obtenidos presentan las diferencias más notables en las estructuras del lóbulo temporal medial y no en las del lateral. Estas diferencias podrían explicar la relativa conservación de la función memorística en enfermos con demencia con cuerpo de Lewy frente a los de Alzheimer (Barber y col., 2001).

La atrofia del lóbulo temporal medial en imágenes obtenidas con resonancia magnética cerebral puede ayudar a diferenciar entre la enfermedad de Alzheimer y las demencias vasculares.

Se vio un incremento desigual en la señal periventricular u objetos brillantes no identificados en 2 de los 11 enfermos con Alzheimer, 10 de los 20 con Alzheimer y demencia vascular y 26 de los 32 pacientes con demencia vascular. 
Series más largas, correlacionadas con autopsias, pueden verificar que la atrofia del lóbulo temporal medial es un indicador específico razonable para la enfermedad de Alzheimer y los objetos brillantes no identificados son un marcador sensitivo, pero no específico, para las demencias vasculares (Barclay y col., 1992).

La atrofia temporal medial es un posible marcador de neuroimagen en la enfermedad de Alzheimer. La complejidad de las técnicas volumétricas impide su aplicación en la práctica clínica. Por ello se ha aplicado la escala de estimación de la atrofia temporal medial de Scheltens (Scheltens y col., 2000).

La escala de Scheltens para valorar la atrofia temporal medial determina cinco grados de 0 a 4, de acuerdo con el ensanchamiento de la cisura coroidea, la disminución de la altura del hipocampo y la dilatación del asta temporal ventricular.

Los estudios de Martin y col (2010) parecen demostrar que la estimación semicuantitativa de la atrofia temporal medial empleando resonancia magnética mediante la escala de Scheltens puede apoyar el diagnóstico clínico positivo de la enfermedad de Alzheimer en la práctica clínica.

El empleo de otros parámetros como las medidas lineales del cuerno temporal y el volumen del hipocampo dan resultados muy semejantes a los obtenidos sólo con el empleo de la escala de Scheltens (Bresciani y col., 2005).

Los cambios atróficos del hipocampo en pacientes con la enfermedad de Alzheimer están asociados con la reducción de la actividad funcional en las regiones temporales límbicas y asociativas (neocorteza temporal, región temporal medial izquierda y corteza cingular posterior izquierda) durante los procesos de memoria episódica.

También aparece un incremento de la actividad en las áreas frontales (lóbulos frontales, giro frontal inferior izquierdo y derecho y la ínsula), posiblemente por mecanismos de compensación.

Lo sugiere el estudio estadístico realizado sobre datos obtenidos con imagen por resonancia magnética de las estructuras cerebrales.

Primero, identificando los grupos de voxels con reducción significativa de la concentración de sustancia gris en la región del hipocampo.

Segundo, buscando la correlación de esta atrofia con las medidas del flujo cerebral sanguíneo en las diferentes regiones.

Éstas, se obtuvieron con tomografía computerizada de emisión simple de fotones (SPECT), durante la realización de tareas de memoria de reconocimiento verbal por varios sujetos controles y otros con enfermedad de Alzheimer (Garrido y col., 2002).

La diferencia en los índices medios de flujo sanguíneo cerebral del lóbulo temporal medial a cerebeloso entre pacientes con Alzheimer y sujetos de control fue de $12 \%$, en un estudio realizado por Julin y colaboradores en 1997. Según estos autores, la mejor distinción entre enfermos y controles sanos se obtuvo combinando las medidas de la atrofia por imagen de resonancia magnética y las medi- 
das de flujo sanguíneo con tomografía computerizada por emisión de fotones individuales.

La comparación directa de los cambios estructurales y funcionales es posible con esta técnica de resonancia magnética-guiada por la tomografía computerizada por emisión de fotones individuales, pudiendo mejorar el diagnóstico temprano de la enfermedad de Alzheimer y su diferenciación con otras enfermedades neurodegenerativas.

Los estudios realizados con esta técnica sobre grupos de pacientes con la enfermedad de Alzheimer, la demencia frontotemporal y la demencia vascular ofrecen datos significativos.

Aparece atrofia asimétrica sólo en pacientes con demencia frontotemporal. Éstos también fueron los más atróficos mientras que la atrofia severa fue raramente observada en la demencia vascular.

La atrofia severa frontal (unilateral o bilateral) y/o la atrofia asimétrica en imágenes de resonancia magnética tiene un valor diagnóstico (sensibilidad 0.71 , especificidad 0.93 , LR 10.24) para la demencia frontotemporal dentro de un grupo de pacientes con y sin demencia frontotemporal. Éstos sí presentaban alguna de las otras dos demencias.

La atrofia parietal suave o severa con gran reducción del flujo sanguíneo en la región parietal del cerebro en tomografía computerizada por emisión de fotones individuales permite el diagnóstico de la enfermedad de Alzheimer (sensibilidad 0.71, especificidad 0.76, LR 3.02) dentro de un grupo de pacientes con y sin ella. Éstos sí presentaban alguna de las otras dos demencias. (Varma y col., 2002a).

Por otro lado, los enfermos con Alzheimer muestran mayor reducción de la perfusión en la corteza témporo-parietal izquierda que los enfermos con depresión, tanto de comienzo tardío como temprano. No se relacionan los valores del flujo sanguíneo con la anchura del lóbulo temporal, pero sí entre la reducción del mismo y los cambios en la sustancia blanca periventricular observados en imágenes por resonancia magnética (Ebmeier y col., 1997).

\section{Genotipo de ApoE en pacientes con la enfermedad de Alz- heimer}

Como hemos visto en el apartado anterior, los estudios volumétricos realizados sobre imágenes por resonancia magnética sobre pacientes con enfermedad de Alzheimer han encontrado consistentemente una extensiva pérdida de volumen en estructuras del lóbulo temporal medial, incluyendo la amígdala y el hipocampo, que aparecen ya en las primeras fases de la enfermedad.

Así pues esta enfermedad se puede diferenciar de otras enfermedades neuropsiquiátricas por la extensión y distribución de cambios estructurales que pueden facilitar el diagnóstico diferencial en vivo (Schonknecht y col., 2001).

Por otro lado, los estudios patológicos y bioquímicos proporcionan dos marcadores importantes para la enfermedad. Éstos son la deposición de $\beta$-amiloide en el líquido cefalorraquídeo y la presencia del alelo epsilon 4 del gen de la apolipo- 
proteína E que aumenta el riesgo de desarrollar la enfermedad de Alzheimer y disminuye la edad media de establecimiento de la misma.

Parece necesario estudiar la relación entre estos dos marcadores y los cambios cerebrales que se pueden valorar con fidelidad mediante imágenes de resonancia magnética.

Los resultados obtenidos en estudios clínicos indican que los cambios en niveles cerebrales de $\beta$-amiloide 4 contribuyen a la atrofia del lóbulo temporal en la enfermedad de Alzheimer y soportan la posibilidad de que $\beta$-amiloide 4 sea crucial para la etiología de la enfermedad. (Schroder y col., 1997).

Fueron comparadas las concentraciones totales de $\beta$-amiloide 4 en el líquido cefalorraquídeo y las de sus variantes más abundantes $\beta$-amiloide 41 -40 y $\beta$ amiloide 4 1-42 con los valores de cambios cerebrales medidos mediante imágenes por resonancia magnética.

Significativamente, $(P<0.05)$, los niveles reducidos de $\beta$-amiloide $41-40$ y $\beta$ amiloide 4 1-42 se encontraron en pacientes con enfermedad de Alzheimer (17 mujeres, 6 hombres, criterios AD/NINCDS-ADRDA) en comparación con los pacientes con mayor depresión (siete mujeres, 2 hombres, DSM-IIIR).

Dentro del grupo con Alzheimer los niveles de $\beta$-amiloide 4 y $\beta$-amiloide 4 1-42 estaban significativamente correlacionados con el volumen de los lóbulos temporales ( $r=0.46$ y $r 0.48$, respectivamente) pero no con ninguna otra de las medidas volumétricas.

Aunque la asimetría de las estructuras cerebrales es común en todas las especies y está presente incluso desde la gestación, algunas enfermedades relativas al desarrollo, patológicas o demencias, como la enfermedad de Alzheimer, están asociadas con alteraciones en las asimetrías anatómicas normales.

Diferentes estudios evalúan los efectos del genotipo de ApoE sobre la asimetría del hipocampo en pacientes con la enfermedad de Alzheimer y en sujetos sin déficit cognitivo.

Los datos obtenidos indican cierta dependencia del volumen asimétrico del hipocampo con el alelo epsilon4 de la ApoE, que siendo un importante factor de riesgo para la enfermedad, también puede participar en determinar algunos cambios morfológicos cerebrales.

El tratamiento informático de las diferencias volumétricas entre los lados derecho e izquierdo del hipocampo, obtenidas con imagen de resonancia magnética, en 28 pacientes con Alzheimer portadores de 0,1 y 2 copias del alelo (14 -/-, 9 epsilon4/-, y 5 epsilon4/4) y 30 controles sin déficit cognitivo, nos revela información al respecto.

En los controles, el hipocampo derecho era más largo que el izquierdo, mientras que en pacientes con la enfermedad de Alzheimer la asimetría se reduce progresivamente con el incremento de la dosis genética del alelo epsilon4, y se invierte en el grupo de pacientes de Alzheimer con epsilon4/4.

La media de las diferencias entre los volúmenes derecho e izquierdo fueron: 1.2, $0.7,0.2$ y -1.0 en sujetos control y en pacientes -/-, epsilon4/-, y epsilon4/4 respectivamente (Geroldi y col., 2000). 
Sin embargo, en otro estudio realizado sobre un grupo de pacientes formado por 85 sujetos con Alzheimer, 59 con desórdenes cognitivos o neuropsiquiátricos y 30 con daños cognitivos moderados, ninguna asimetría significativa del volumen hipocampal y de otras estructuras del lóbulo temporal se pudo asociar con la presencia del alelo epsilon4.

La asimetría se obtuvo restando el volumen del lado izquierdo del derecho y dividiendo por el volumen total intracraneal. También se examinó si la asimetría influía en el comportamiento neuropsicológico, pero se observaron mínimos efectos. Donde hubo significatividad, un mejor comportamiento neuropsicológico fue asociado con el mayor volumen parenquimal de las estructuras del lóbulo temporal (Bigler y col., 2002).

Aunque está claro que el alelo epsilon4 del gen de la apolipoproteína E y la atrofia del hipocampo están asociados con la enfermedad de Alzheimer, parece que es de forma independiente ya que los volúmenes del hipocampo no varían significativamente en base al genotipo de la ApoE (Jack y col., 1998b).

Sí se ha encontrado un compromiso del alelo epsilon4 de la ApoE en la progresión de la atrofia del hipocampo en un estudio realizado a 55 pacientes con probable enfermedad de Alzheimer en el que se determinó la tasa anual de atrofia del hipocampo utilizando imágenes por resonancia magnética a intervalos de 1 año.

Los autores del estudio sugieren que este resultado tiene implicaciones para realizar propuestas terapéuticas para la enfermedad de Alzheimer y deberían tenerse en cuenta en estudios longitudinales incluyendo pruebas clínicas con fármacos (Mori y col., 2002).

La tasa media anual de atrofia del hipocampo fue significativamente diferente entre los grupos de pacientes con alelo epsilon4 de la ApoE $(9.76+/-4.27 \%)$ y sin el alelo $(6.99+/-4.24 \%)$.

Además, la dosis del alelo obtuvo correlación significativa con la tasa de la atrofia del hipocampo ( $\mathrm{rs}=0.277$, coeficiente de correlación Spearman), sugiriendo un efecto de la dosis del gen.

También se ha analizado la relación entre el genotipo de la ApoE, la atrofia del lóbulo temporal medial y las hiperintensidades de la sustancia blanca (periventricular y profunda) en grupos de pacientes con Alzheimer, demencia con cuerpos de Lewy y con demencia vascular.

Los métodos utilizados para obtener los datos fueron el de reacción en cadena para la determinación de la ApoE y la tasación visual en imágenes de resonancia magnética con escalas estándares para la atrofia y las intensidades.

En todos los sujetos con demencia no se encontró asociación significativa entre el estado del alelo epsilon4 de la ApoE y la atrofia del lóbulo temporal medial y las hiperintensidades de la sustancia blanca.

Por tanto, el alelo epsilon4 de la ApoE, aunque puede modificar el riesgo de adquirir la demencia, no influye en los procesos patológicos posteriores ya que no determina la atrofia del lóbulo temporal medial o las lesiones de la sustancia blanca en ninguna de las tres enfermedades. (Barber y col., 1999). 
Hipótesis del Estudio y Diseño Experimental 
El envejecimiento es el mayor factor de riesgo para las enfermedades neurodegenerativas en general, y de forma más específica para la enfermedad de Alzheimer. La mejora de la calidad de vida ha llevado a un envejecimiento cada vez mayor de la población en los países desarrollados o con economías emergentes.

Con la creciente esperanza de vida, la incidencia de la enfermedad de Alzheimer $y$, por lo tanto, su impacto en la situación socioeconómica, es cada vez mayor.

La enfermedad de Alzheimer afecta actualmente a unos 4,5 millones de estadounidenses y se calcula que supera el medio millón de españoles, lo que supone un gasto para la economía del país, en los Estados Unidos es superior a los 100 millones de dólares por año.

El número de pacientes con Alzheimer se proyecta que aumente a cifras entre 11-16 millones en el año 2050, lo que supondría un coste superior a 380 millones por año (Hebert y col., 2003; Mueller y col., 2005).

Estas cifras se multiplican por 20 cuando se trata de la diabetes, especialmente de la diabetes tipo II por resistencia periférica a la insulina.

Como veremos a continuación, existen sospechas de que ambos procesos pueden guardar relación, de ahí lo interesante del estudio de la hipótesis que se planteó al inicio de este trabajo de Tesis Doctoral.

\section{Antecedentes del estudio.}

Múltiples estudios indican que los pacientes con diabetes tienen un mayor riesgo de desarrollar la enfermedad de Alzheimer en comparación con sujetos sin diabetes de la misma edad y sexo (Brands y col., 2005; Strachan y col., 1997; Ott y col., 1999; Cox y col., 2005).

Las proteínas de sustrato de receptor insulínico (IRS) integran señales, desde los receptores de insulina y del factor insulínico de crecimiento IGF-1, con otros procesos para controlar el crecimiento, la función y la supervivencia celular, ya que la insulina y el IGF-1 ejercen sus efectos fisiológicos a través de la fosforilación y activación de las IRS.

El amplio papel regulador de IRS-1 e IRS-2 sobre el crecimiento y la supervivencia celular pone de manifiesto una vía reguladora común para el desarrollo, el crecimiento corporal, la fertilidad, la proliferación neuronal y el envejecimiento (White, 2002).

En este sentido, se ha demostrado que la actuación de una de las IRS, la IRS-2, es de gran importancia dentro del tejido nervioso porque:

La proteína IRS-2 promueve la maduración y supervivencia de los fotorreceptores retinianos inmediatamente después del parto (Yi y col., 2005).

La deleción del gen de IRS-2 en ratones reduce dramáticamente el tamaño cerebral debido a una proliferación celular anormal durante el desarrollo embrionario (Schubert y col., 2003). 
La ausencia de IRS-2 en adultos produce una patología adicional en el cerebro de estos animales: la hiperfosforilación y el acúmulo de la proteína Tau asociada a los microtúbulos (Schubert y col., 2003).

Los ratones knock out para IRS-2 desarrollan una resistencia a la insulina y, a posteriori, una diabetes tipo 2 (Withers y col., 1998), aunque las lesiones y alteraciones en el crecimiento cerebral aparecen previas a la aparición de la hiperglucemia.

Por ello, la desregulación de la cascada de señales mediada por IRS-2 podría ser un puente molecular entre la diabetes y las enfermedades neurodegenerativas.

Se ha demostrado que el envejecimiento, época de la vida en la que es frecuente la aparición de lesiones cerebrales neurodegenerativas, se acompaña en muchas ocasiones de una resistencia periférica a la insulina por un descenso del $75 \%$ en la fosforilación de la IRS-2 y del 79\% en la PI3-quinasa (Carvalho y col., 1996).

Puesto que los ratones knock out IRS-2 e IRS-2-RIP-Tg presentan modificaciones neurodegenerativas que podrían semejar la enfermedad de Alzheimer se hace sumamente interesante desarrollar un sistema experimental que permita estudiar in vivo los hechos que van aconteciendo en los procesos neurodegenerativos en estos animales, para así comprender mejor la fisio- y anatomo-patología de la neurodegeneración, a la vez que sirva para poder ensayar experimentos terapéuticos.

\section{Hipótesis del Trabajo. Objetivo general del estudio.}

Comprobar mediante inmunocitoquímica, resonancia magnética y análisis morfométricos y densitométricos si la deleción de IRS-2 produce alteraciones neurodegenerativas semejantes a las que acontecen en la enfermedad de Alzheimer y, si así fuera, estudiar si es posible estandarizar un método de valoración in vivo del proceso neurodegenerativo.

\section{Objetivos específicos del trabajo y su Diseño experimental.}

El trabajo realizado está englobado dentro de una línea de investigación del Departamento y del Instituto de Neurociencias de Castilla y León cuyo objetivo principal es analizar el papel de las hormonas en la neurodegeneración y la neuroprotección.

En particular, se plantean como objetivos específicos para este trabajo:

1.- Obtener animales ko para IRS-2.

2.- Estudiar el cerebro de estos animales mediante Resonancia Magnética.

3.-Relacionar los cambios observados en la resonancia con los hallazgos anatomopatológicos postmortem de los animales y analizar los signos de neurodegeneración que aparezcan.

4.- Valorar si es posible emplear la resonancia magnética mediante patrones de medida morfométricos y densitométricos, como un sistema de seguimiento para el estudio y evolución de procesos neurodegenerativos y el ensayo de tratamientos in vivo. 
Material y Métodos 


\section{Animales empleados para el estudio.}

Para alcanzar los objetivos propuestos y llevar a cabo el diseño experimental, hemos estudiado 19 ratones machos de los que 9 eran ratones wilde type y 10 eran ratones knock out para IRS2, todos ellos de 18 meses de edad. Dado que los progenitores knock out son estériles, los animales se obtuvieron a partir de progenitores heterozigotos.

\section{Genotipaje}

La determinación de la deleción-sustitución de IRS2 se realizó mediante PCR. Para ello, cuando los ratones tenían 1 mes de edad, se tomó el fragmento distal de la cola para aislar el DNA.

\section{Extracción, aislamiento y purificación del DNA.}

La extracción, aislamiento y purificación del DNA se realizó empleanto el kit de Roche $(R)$ siguiendo las instrucciones del fabricante.

En un tubo de microcentrífuga de $1.5 \mathrm{~mL}$ y libre de nucleasas se añadieron: 2 a 5 $\mathrm{mm}$ de la cola del ratón, $200 \mu \mathrm{l}$ del tampón de lisis de tejidos y $40 \mu \mathrm{l}$ de proteinasa $\mathrm{K}$ reconstituida. Se mezcló e incubó durante 3 horas a $55^{\circ} \mathrm{C}$. Transcurrido ese tiempo, con una jeringa de $1 \mathrm{~mL}$, se aspiró la muestra dentro de la jeringa y luego se expulsó, en repetidas ocasiones hasta obtener el lisado. Se añadieron $200 \mu \mathrm{l}$ de tampón de unión y $100 \mu \mathrm{l}$ de isopropanolol; para después centrifugar 5 minutos a $13000 x g$.

Tras insertar un tubo de alto filtrado en un tubo de recogida, se pipeteó el líquido de la muestra en el reservorio superior del tubo de filtrado. Todo el tubo ensamblado se sentrifugó 1 minuto a $8000 x g$. Después de centrifugar, se retiró el tubo de filtrado del tubo de recogida y se desecharon el líquido filtrado y el tubo de recogida.

Se colocó de nuevo el tubo de filtrado en un nuevo tubo de recogida y se añadieron $500 \mu \mathrm{l}$ del tampón inhibidor de removida al reservorio superior del tubo de filtrado, para centrifugar 1 minuto a $8000 x g$. Después de centrifugar y retirar el tubo de filtrado del tubo de recogida y desechar el tubo de recogida y el líquido filtrado, se colocó de nuevo el tubo de filtrado en un nuevo tubo de recogida y se añadieron $500 \mu l$ de tampón de lavado al reservorio superior del tubo de filtrado. Posteriormente se centrifugó 1 minuto a $8000 x g$. Esta operación se realizó dos veces. Se centrifugó durante 10 segundos a velocidad máxima y se desechó el tubo de recogida.

Tras insertar el tubo de filtrado en un tubo de microcentrífuga de $1.5 \mathrm{~mL}$ limpio y estéril, se añadieron $200 \mu$ del tampón de elución precalentado en el reservorio superior del tubo de filtrado y se centrifugó durante 1 minuto a $8000 x g$. Centrífuga empleada: centrífuga para eppendorf Hermle Z233 M-2.

Después de esta sucesión de pasos, el tubo de microcentrífuga contenía ya el DNA eluido que se utilizó inmediatamente o bien, fue almacenado entre $2-8^{\circ} \mathrm{C} o$ 
bien entre $-15^{\circ}$ y $-25^{\circ}$ para análisis posteriores (dependiendo del tiempo a transcurrir hasta la realización del análisis).

\section{Amplificación del DNA purificado, PCR.}

Una vez aislado el DNA se procedió a realizar la amplificación del fragmento de DNA para detectar la deleción-sustitución del gen de IRS2 por el recombinante, empleando el kit PCR Master mix de Promega ${ }^{\circledR}$, con un volumen de $5 \mu$ de DNA aislado y empleando como primers:

Superior-Recombinante: ctt ggc tac cat gtt gtt att gtc

Inferior-Silvestre: agc tct gga ggt tta ctt tcc tag

La reacción de amplificación se realizó mediante 30 ciclos $\left(94^{\circ} \mathrm{C}-65^{\circ} \mathrm{C}-72^{\circ} \mathrm{C}\right)$ en un termocicladorPTC-100 Peltier Thermal Cycler $®$.

Una vez amplificado, se realizó una electroforesis en gel de agarosa a $150 \mathrm{mV}$, utilizando una muestra de $20 \mu \mathrm{l}$ de cada producto amplificado en tampón de carga, con bromuro de etidio. Las bandas obtenidas se fotografiaron bajo luz ultravioleta. La figura MM1 muestra los resultados obtenidos tras la electroforesis.

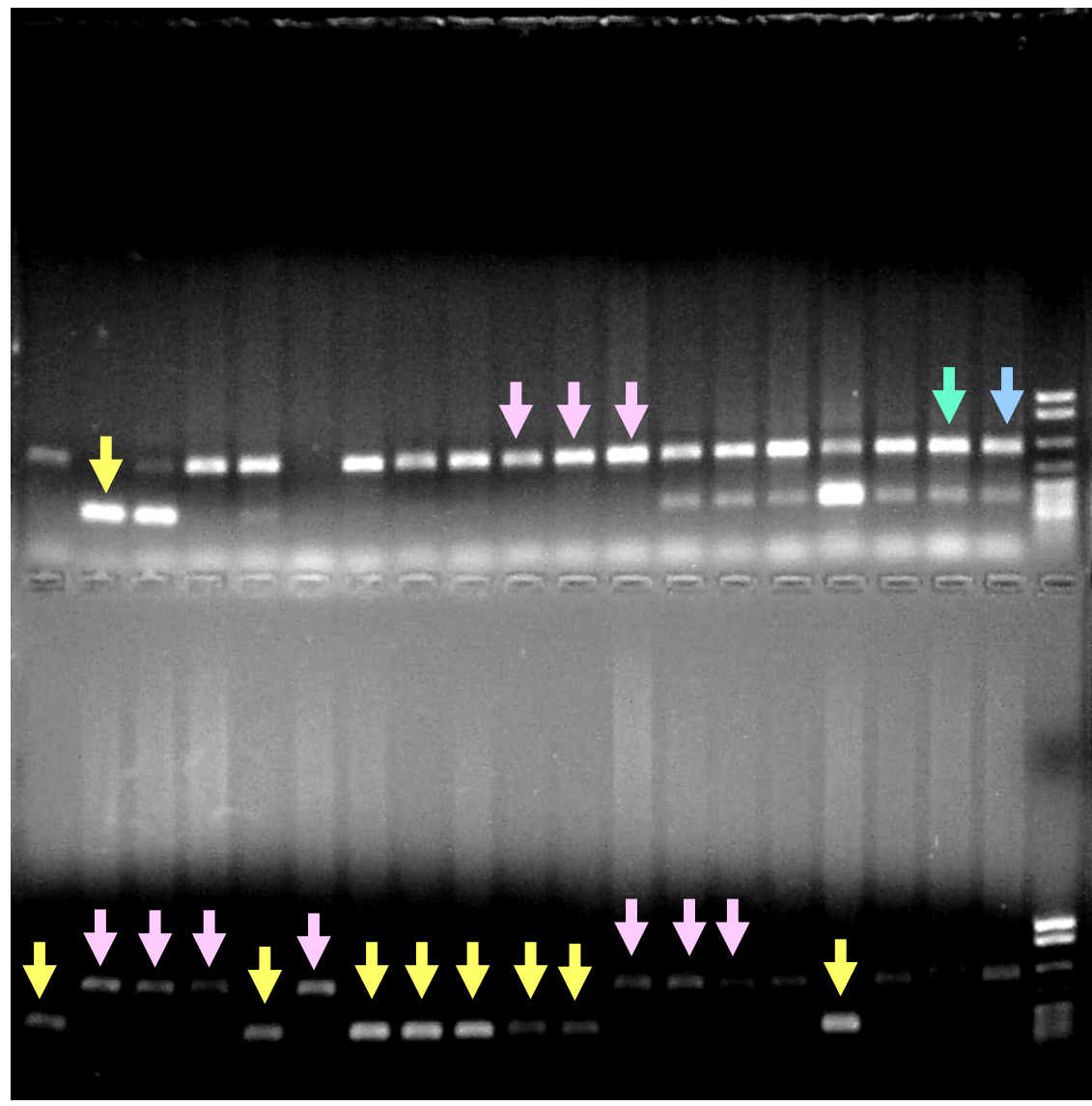

Figura MM1 Electroforesis del DNA amplificado por PCR para el gen de IRS2.

En la imagen se aprecian las bandas de electroforesis obtenidas tras el producto de amplifiación con PCR del gen silvestre y el recombinante para IRS2, de los animales empleados en el estudio. La flecha verde corresponde con la amplificación del DNA de la hembra progenitora y la flecha azul del macho progenitor. Las flechas amarillas marcan el DNA amplificado por PCR para los ratones wilde type empleados en el estudio y las flechas rosas el de los ratones knock out. 


\section{Resonancia Magnética Nuclear.}

Los animales seleccionados tras el genotipaje fueron sometidos a Resonancia Magnética Nuclear, en T2, para visualizar bien los compartimentos de líquido cefalorraquídeo del sistema ventricular.

Bajo anestesia general con isoflurano se les practicó la RMN en el Insituto de Investigaciones Biomédicas de Madrid.

Las imágenes MM2, MM3 y MM4 muestran algunas de las series obtenidas.
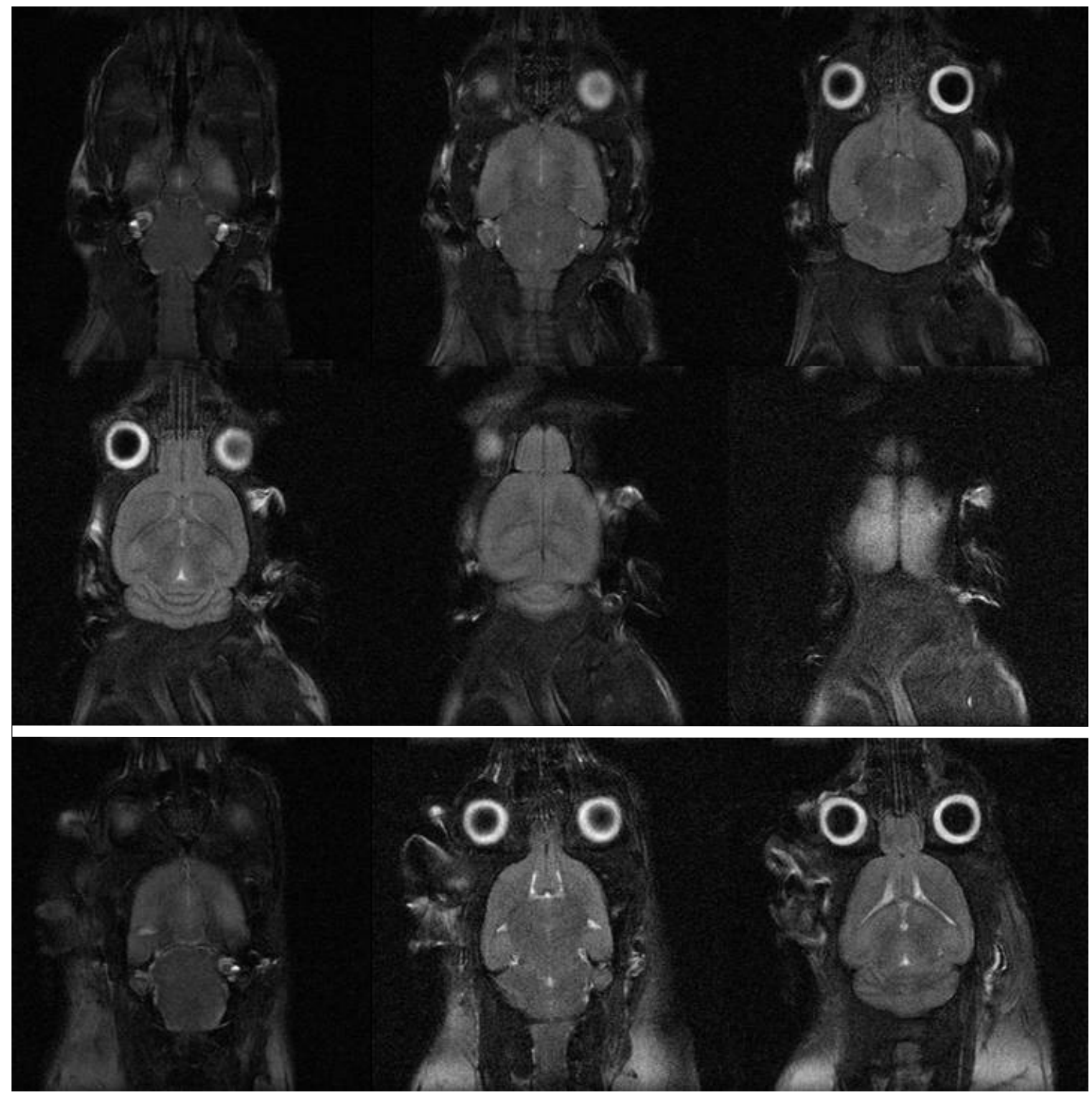

Figura MM2. Imágenes de Resonanacia Magnética, cortes axiales u horizontales.

En la imagen se presentan, de forma abeviada, dos series de Resonancia Magnética obtenidas en los ratones. Las seis imágenes superiores se corresponden con un animal wilde type, las tres inferiores pertenecen a un ratón knock out. 


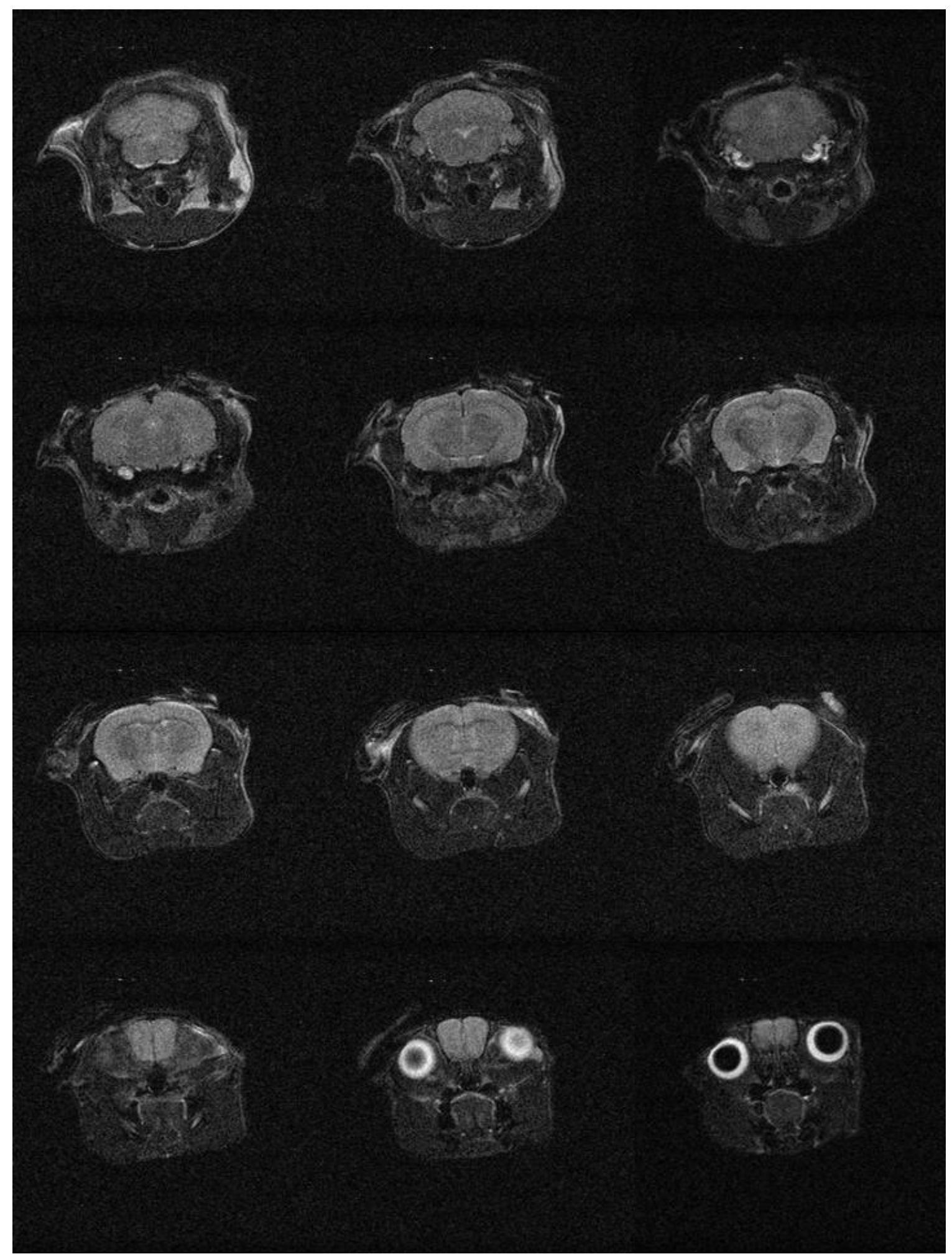

Figura MM3. Imágenes de Resonancia Magnética, cortes frontales.

En la imagen se presenta una serie de cortes frontales de Resonancia Magnética obtenida en uno de los ratones wilde type. 


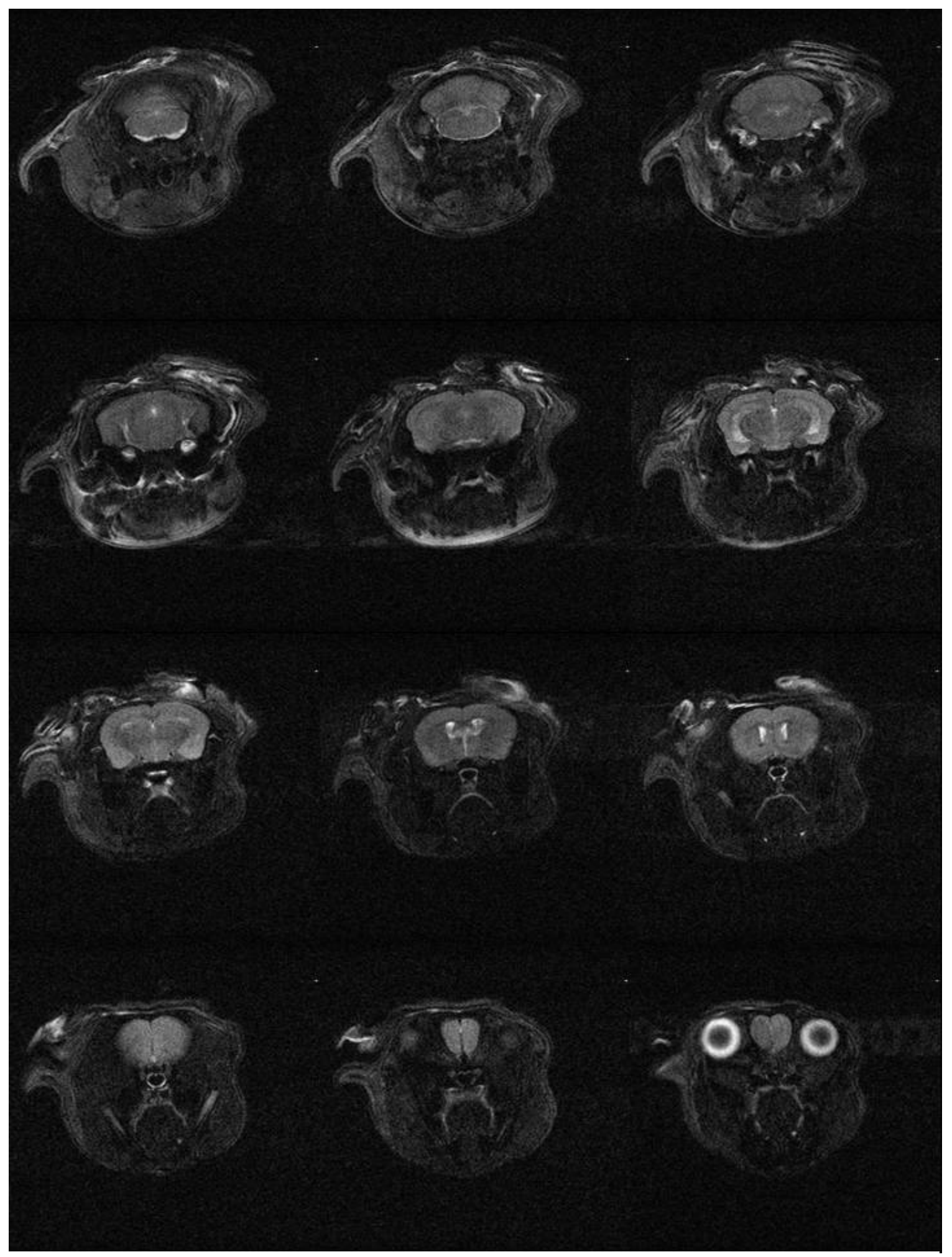

Figura MM4. Imágenes de Resonancia Magnética, cortes frontales.

En la imagen se presenta una serie de Resonancia Magnética obtenida en uno de los ratones knock out. 


\section{Sacrificio de los animales y Extracción de las muestras.}

Antes del sacrificio, se procedió a realizar tomas de sangre en condiciones de ayuno y postprandiales para la determinación de las glucemias y de la insulinemia.

Una vez realizado el estudio de resonancia magnética, al día siguiente de las tomas de sangre, los animales fueron sacrificados para comparar los resultados obtenidos por resonancia con un análisis postmortem, bioquímico e histológico.

Los animales fueron decapitados y, después de la apertura meticulosa de la calota encefálica, se procedió a extraer mediante disección cuidadosa el encéfalo. Las muestras para westernblotting se congelaron inmediatamente en nitrógeno líquido. Las muestras para el estudio histológico se fijaron por inmersión en paraformaldehído al $4 \%$ en tampón fosfato $(0,1 \mathrm{M}, \mathrm{pH}: 7.4)$ durante 8 horas.

Una vez fijadas, se lavaron en el mismo tampón durante 4 horas y se procedió a su deshidratación en etanoles crecientes en concentración (70, 80, 96 y 100\%). Ya deshidratadas se procedió a su aclaramiento en benceno para su posterior inclusión en parafinas. La deshidratación, el aclaramiento y la inclusión se realizó en un procesador histológico Leica ${ }^{\circledR}$.

De los bloques obtenidos se obtuvieron secciones de $5 \mu \mathrm{m}$ de grosor empleando un microtomo Microm HM35.

\section{Western blotting}

1.- Recoger las muestras en hielo.

1b. - Pesar la muestra.

2.- Homogeneizar en PBS con $1 \%$ de cholate y $0.18 \%$ de SDS.

3.- Estimar la concentración de proteínas

3b. - BCA Proetin Assay Reagent (Pierce Chemical Co. Rockfort, IL) empleando BSA (albúmina sérica bovina) como estándar.

4. - Hacer electroforesis ( $50 \mu$ g de proteína por línea) en gel de poliacrilamida-SDS (Amresco, Solon, $\mathrm{OH}$ ) en tampón $50 \mathrm{mM}$ Tris, $383 \mathrm{mM}$ glicina, $10 \%$ SDS y $0.4 \mathrm{mM}$ EDTA.

5.- Hacer electroblot de las proteínas del gel a una membrana de nitrocelulosa.

6. - Hacer immunoblot con el anti-aromatasa (1:100) a temperatura ambiente.

7.- Análisis de imagen.

\section{Histoquímica.}

\section{Violeta de Cresilo.}

La tinción mediante violeta de cresilo se realizó de forma estándar según el proceder simplificado. 
Para ello, tras desparafinizar con xilol los cortes histológicos, se procedió a su rehidratación en etanoles de concentración decreciente y lavado en agua destilada y desionizada.

Los cortes fueron sumergidos durante 30 minutos en una solución acuosa de Violeta de Cresilo al $1 \%$ en agua destilada.

Transcurrido ese tiempo, se deshidrataron en etanol creciente, se aclararon en xilol y se montaron con DePeX, para su estudio al microscopio óptico.

\section{Rojo Congo.}

Tras desparafinizar y lavar en agua destilada y desionizada, las preparaciones se sumergieron en alcohol alcalino (a $50 \mathrm{ml}$ de etanol al $80 \%$ saturado con cloruro de sodio se le añadieron $0.5 \mathrm{ml}$ de hidróxido de potasio al 1\%) durante 20 minutos; posteriormente, se sumergieron en una solución alcalina de Rojo Congo $(\mathrm{a} 50 \mathrm{ml}$ de etanol al $80 \%$ saturado con cloruro de sodio y después saturado con rojo congo, se le añadieron $0.5 \mathrm{ml}$ de hidróxido de potasio al 1\%) durante 20 minutos.

Tras la tinción, las muestras se deshidrataron rápidamente en 3 baños de etanol $100 \%$ (diferenciando la tinción), las muestras se aclararon en xilol y se montaron con DePeX.

\section{Inmunocitoquímica}

La inmunocitoquímica se ha empleado para detectar Tau-2 (detecta Tau hiperfosforilada), $\beta$ amiloide y GFAP (proteína fibrilar glial ácida)

\section{Detección inmunocitoquímica de Tau-2.}

Las muestras se incubaron en estufa a $58^{\circ} \mathrm{C}$ durante 1 hora, tras lo que se prodeció a la desparafinización y rehidratación, con lavado en agua destilada y desionizada durante 5 minutos.

Se bloqueó la peroxidasa endógena sumergiendo las muestras en un baño de Metanol-Agua oxigenada al $3 \%(200 \mathrm{ml} / 30 \mathrm{ml})$, durante 10 minutos.

Transcurrido ese tiempo, las muestras se prepararon para la detección de Tau, para lo que se calentaron en un volumen apropiado de tampón citrato $10 \mathrm{mM} \mathrm{pH}$ 6.0 hasta $98^{\circ} \mathrm{C}$, durante 20 minutos a $98^{\circ}$ en baño termostático.

Posteriormente se lavaron, primero en agua destilada, a temperatura ambiente, durante 20 minutos. Luego en TBS (Trizma base $0.01 \mathrm{M}$, pH 7.4, con $0.09 \%$ de $\mathrm{NaCl}$ ), durante 20 minutos, $\mathrm{y}$, por último, en TBS durante 5 minutos.

Para inhibir reacciones inespecíficas, se incubaron con suero no inmune obtenido en cabra (diluido 1:30 en TBS), durante 20 minutos.

A continuación, se procedió con la reacción inmunocitoquímica, para lo que las muestras se incubaron con suero monoclonal anti-Tau2 (novocastra(R), diluido 1:100 en TBS), a $4^{\circ} \mathrm{C}$ toda la noche. Seguido de dos lavados en TBS de 5 minutos.

El suero monoclonal se detectó incubando con suero biotinado de cabra anti Ig $\mathrm{G}$ de ratón (Caltag $(\mathrm{R})$, diluido 1:150 en TBS) durante 45 minutos a temperatura ambiente; seguido de dos lavados en TBS de 5 minutos. 
Por último, se procedió a incubar con estrepto-avidina-peroxidasa (Caltag (R), diluido 1:150 en TBS) durante 45 minutos a temperatura ambiente; seguido de dos lavados en TBS de 5 minutos.

El revelado de la reacción se hizo con 3-3'diaminobencidina (Sigma al 25\% en TB: Trizma base $0.01 \mathrm{M}, \mathrm{pH} 7.4$ ) a la que se añadió un $0.03 \%$ de agua oxigenada inmediatamente antes de su empleo.

Tras lavado en agua destilada, las preparaciones fueron contrastadas con Hemaoxilina de Mayer y tras su lavado en agua, se deshidrataron y aclararon en etanol-xilol y se montaron con DePeX.

Detección inmunocitoquímica de $\beta$ amiloide.

Las muestras se incubaron en estufa a $58^{\circ} \mathrm{C}$ durante 1 hora, tras lo que se prodeció a la desparafinización y rehidratación, con lavado en agua destilada y desionizada durante 5 minutos.

Se bloqueó la peroxidasa endógena sumergiendo las muestras en un baño de Metanol-Agua oxigenada al $3 \%(200 \mathrm{ml} / 30 \mathrm{ml})$, durante 10 minutos.

Transcurrido ese tiempo, las muestras se prepararon para la detección de $\beta$ amiloide, para lo que se sumergieron en un baño de ácido fórmico al $98 \%$ durante 3 minutos, se lavaron en agua destilada y desionizada (1x30 segundos y 1x5 minutos).

De ahí se pasaron a un baño en TBS durante 5 minutos.

Para inhibir reacciones inespecíficas, se incubaron con suero no inmune obtenido en cabra (diluido 1:30 en TBS), durante 20 minutos.

A continuación, se procedió con la reacción inmunocitoquímica, para lo que las muestras se incubaron con suero monoclonal anti- $\beta$ amiloide (NCL- $\beta$-amyloid, visionsystems (R), diluido $1: 75$ en TBS) a $4^{\circ} \mathrm{C}$ durante 48 horas. Seguido de dos lavados en TBS de 10 minutos.

El suero monoclonal se detectó incubando con suero biotinado de cabra anti lg $\mathrm{G}$ de ratón (Caltag (R), diluido 1:150 en TBS) durante 45 minutos a temperatura ambiente; seguido de dos lavados en TBS de 5 minutos.

Por último, se procedió a incubar con estrepto-avidina-peroxidasa (Caltag (R), diluido 1:150 en TBS) durante 45 minutos a temperatura ambiente; seguido de dos lavados en TBS de 5 minutos.

El revelado de la reacción se hizo con 3-3'diaminobencidina (Sigma al 25\% en TB: Trizma base $0.01 \mathrm{M}, \mathrm{pH} 7.4$ ) a la que se añadió un $0.03 \%$ de agua oxigenada inmediatamente antes de su empleo.

Tras lavado en agua destilada, las preparaciones fueron contrastadas con Hemaoxilina de Mayer y tras su lavado en agua, se deshidrataron y aclararon en etanol-xilol y se montaron con DePeX. 


\section{Detección inmunocitoquímica de GFAP.}

Las muestras se incubaron en estufa a $58^{\circ} \mathrm{C}$ durante 1 hora, tras lo que se prodeció a la desparafinización y rehidratación, con lavado en agua destilada y desionizada durante 5 minutos.

Se bloqueó la peroxidasa endógena sumergiendo las muestras en un baño de Metanol-Agua oxigenada al $3 \%(200 \mathrm{ml} / 30 \mathrm{ml})$, durante 10 minutos.

Transcurrido ese tiempo, las muestras se prepararon para la detección de GFAP, para lo que se sumergieron en un baño de ácido fórmico al 98\% durante 3 minutos, se lavaron en agua destilada y desionizada ( $1 \times 30$ segundos y $1 \times 5$ minutos).

De ahí se pasaron a un baño en TBS durante 5 minutos.

Para inhibir reacciones inespecíficas, se incubaron con suero no inmune obtenido en cabra (diluido 1:30 en TBS), durante 20 minutos.

A continuación, se procedió con la reacción inmunocitoquímica, para lo que las muestras se incubaron con suero policlonal obtenido en conejo anti-GFAP (Dako (R), diluido 1:500 en TBS) a $4^{\circ} \mathrm{C}$ durante 24 horas. Seguido de dos lavados en TBS de 10 minutos.

El suero policlonal se detectó incubando con suero de cerdo anti lg $\mathrm{G}$ de conejo (Dako (R), diluido 1:100 en TBS) durante 45 minutos a temperatura ambiente; seguido de dos lavados en TBS de 5 minutos.

Por último, se procedió a incubar con el complejo soluble peroxidasaantiperoxidasa (Dako (R), diluido 1:100 en TBS) durante 45 minutos a temperatura ambiente; seguido de dos lavados en TBS de 5 minutos.

El revelado de la reacción se hizo con 3-3'diaminobencidina (Sigma al 25\% en TB: Trizma base $0.01 \mathrm{M}, \mathrm{pH} 7.4$ ) a la que se añadió un $0.03 \%$ de agua oxigenada inmediatamente antes de su empleo.

Tras lavado en agua destilada, las preparaciones fueron contrastadas con Hemaoxilina de Mayer y tras su lavado en agua, se deshidrataron y aclararon en etanol-xilol y se montaron con DePeX.

\section{Controles de las reacciones inmunocitoquímicas.}

En todas las reacciones se sustituyó el suero primario específico por suero no inmune de ratón o conejo, diluido en TBS a la misma concentración que se diluyó el suero inmune.

En todos los casos, no se obtuvo positividad al finalizar el proceso.

\section{Morfometría y Densitometría.}

Todos los estudios morfométricos y densitométricos realizados en este estudio se hicieron empleando el software libre de NIH Image J.

Para ello se trabajó sobre imágenes digitales a máxima resolución que se homogeneizaron en brillo-contraste con el software adobe photosop CS5 (R), con umbrales de entrada-salida idénticos. Las micrografías obtenidas por microscopía óptica se obtuvieron con un microscopio Zeiss-Axiophot (R) con iluminación 
estándar unificada por un estabilizador de corriente en habitación oscura, siendo capturadas con una cámara digital Olympus DP70 $®$ y el software de captura de imagen Olympus DP Controller 1.1..1.65®. Todo el estudio se realizó con un ordenador dotado de un procesador PentiumV doble cuore (R) y 16Mb de RAM, tarjeta gráfica Nvidia de $5 \mathrm{Mb}$ y monitor Sony Bravia de alta resolución.

Las mediciones fueron realizadas a doble ciego, por el doctorando y el director de la Tesis Doctoral, con un error intraensayo de $0.176 \%$.

Los valores obtenidos se expresan en micras.

Densitometría óptica integrada de las bandas de western blotting.

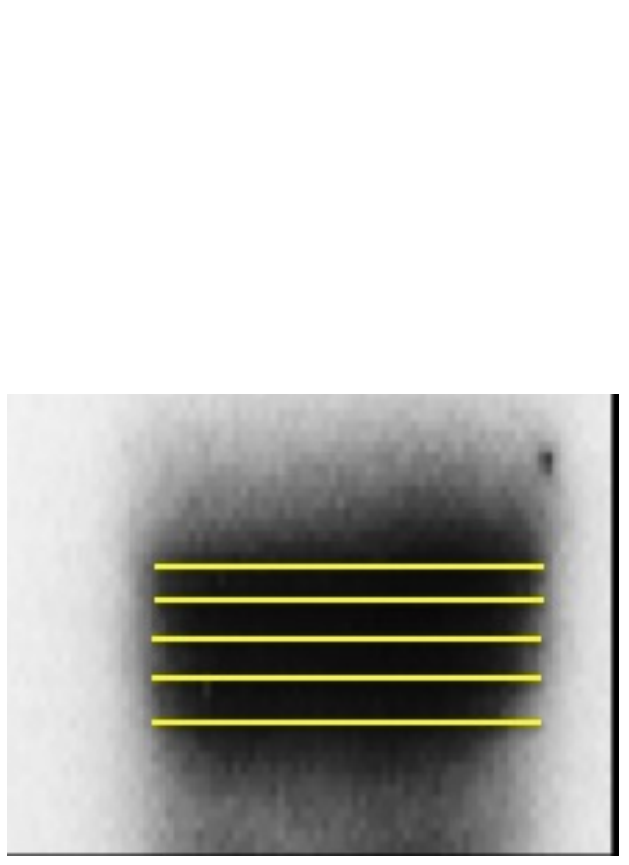

Figura MM5. Banda de western blotting y perfiles densitométricos.

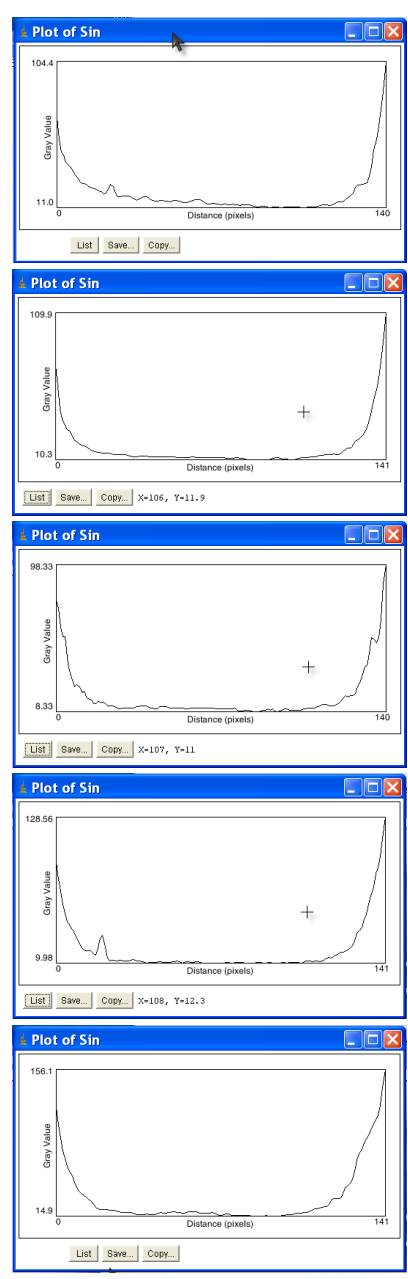

Empleando la apliación Image J del software libre de NIH (Instituto nacional de la salud de los Estados Unidos) se procedió a contornear las bandas obtenidas en western blotting, lo que permitió calcular el área ocupada por la banda y el nivel gris medio homogeneizado de toda la banda.

Con la misma aplicación informática se procedió a trazar aleatoriamente hasta 5 líneas por banda, que recorrían de izquierda a derecha y a diferente altura toda la banda. Tras ello, se obtuvo el perfil densitométrico en niveles de gris de cada una de las líneas trazadas y se calculó la

media de los valores obtenidos en cada distancia para trazar el correspondiente perfil densitométrico definitivo, que se corresponde con la media aritmética de 5 perfiles diferentes por banda.

Los valores obtenidos se expresan en niveles de gris ( 0 a 256). 
Análisis morfométrico de los cortes histológicos.

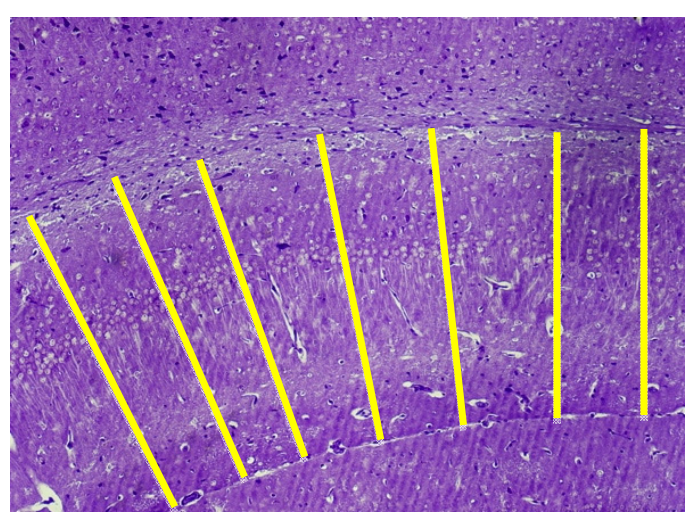

Figura MM6. Corte histológico de la corteza cerebral y marcas que indican cómo se realizó la morfometría
Para el análisis morfométrico de los cortes histológicos se eligieron 4 secciones transversales de cada animal, bien conservadas en su estructura y separadas al menos por $35 \mu \mathrm{m}$. En cada sección se trazaron perfiles de la región a medir separados unos de los otros por, al menos, $10 \mu \mathrm{m}$ y siguiendo la disposición radial de las neuronas y sus prolongaciones, tal y como se muestra en la Figura MM6. De esta manera se calculó la longitud de, al menos, 50 perfiles de cada animal y de cada región a estudiar, de los cuales se extrajo el valor medio por procederes estadísticos. Los valores obtenidos se expresan en micras.

\section{Análisis morfométrico de las imágenes obtenidas por Resonancia Magnética.}

El análisis morfométrico de las imágenes de resonancia se realizó sobre tres proyecciones coronales en las que la situación y la morfología de los ventrículos medio y laterales son claramente diferentes, además se realizó sobre cortesfrontales correspondientes con el mesencéfalo y la intersección bulboprotuberancial. Las imágenes analizadas se corresponden con las proyecciones estereotáxicas del atlas del cerebro de ratón de Franklin y Paxinos, (1997), que se ajustan a las coordenadas que se recogen en la siguiente tabla:

\begin{tabular}{|c|c|c|c|}
\hline Corte RM & C. interaural & C. Bregma & Figura \\
\hline Cerebral a & $2.34 \mathrm{~mm}$ & $-1.46 \mathrm{~mm}$ & MM7 \\
\hline Cerebral b & $2.86 \mathrm{~mm}$ & $-0.94 \mathrm{~mm}$ & MM8 \\
\hline Cerebral c & $3.4 \mathrm{~mm}$ & $-0.46 \mathrm{~mm}$ & MM9 \\
\hline Mesencéfalo & $-0.56 \mathrm{~mm}$ & $-4.36 \mathrm{~mm}$ & MM10 \\
\hline $\begin{array}{c}\text { Bulbo- } \\
\text { Protuberancia }\end{array}$ & $-2.32 \mathrm{~mm}$ & $-6.12 \mathrm{~mm}$ & MM11 \\
\hline
\end{tabular}

Además, se realizó el mismo estudio en una sección horizontal que afectaba a los ventrículos laterales, el ventrículo medio y la cisterna magna (Figura MM12). 
En cada imagen, empleando la aplicación Image $\mathrm{J}$ de $\mathrm{NIH}$, se procedió a perfilar el contorno ventricular para efectuar el cálculo del área y el perímetro ventricular de los ventrículos laterales, el ventrículo medio, el acueducto mesencefálico y el cuarto ventrículo. Además, se calcularon diferentes diámetros de la luz de cada ventrículo, tal y como se recoge en las figuras MM7 a MM12.

Por último, se calcularon los diámetros dorso-ventral y medio-lateral del hipocampo en su totalidad (figura MM7) y del estriado, caudado-putamen (figura MM9).

Los valores morfométricos obtenidos a partir de las imágenes de resonancia magnética se expresan en milímetros.

Las mediciones fueron realizadas a doble ciego, por el doctorando y el director de la Tesis Doctoral, con un error intraensayo de $0.23 \%$.

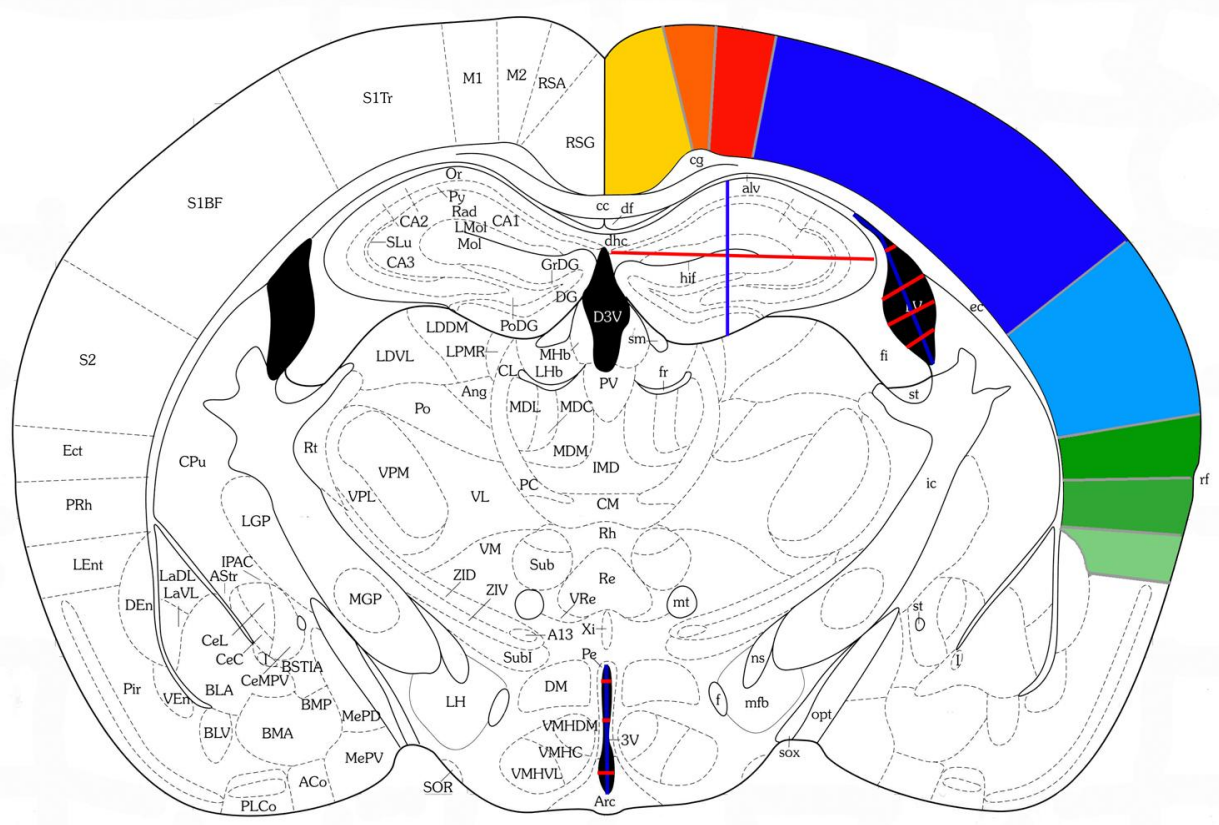

Figura MM7. Esquema modificado de Franklin y Paxinos, correspondiente al corte cerebral a.

Las diferentes zonas corticales estudiadas se representan en diferentes colores: amarillo, corteza cingular; naranja, corteza motora secundaria; rojo, corteza motora primaria; azul marino, corteza somatosensorial primaria,; azul claro, corteza somatosensorial secundaria; verde oscuro, corteza ectorrinal; verde intermedio, corteza insular; verde claro, corteza entorrinal. En el hipocampo, se representan los diámetros estudiados: dorso-ventral, azul; medio-lateral, rojo). 


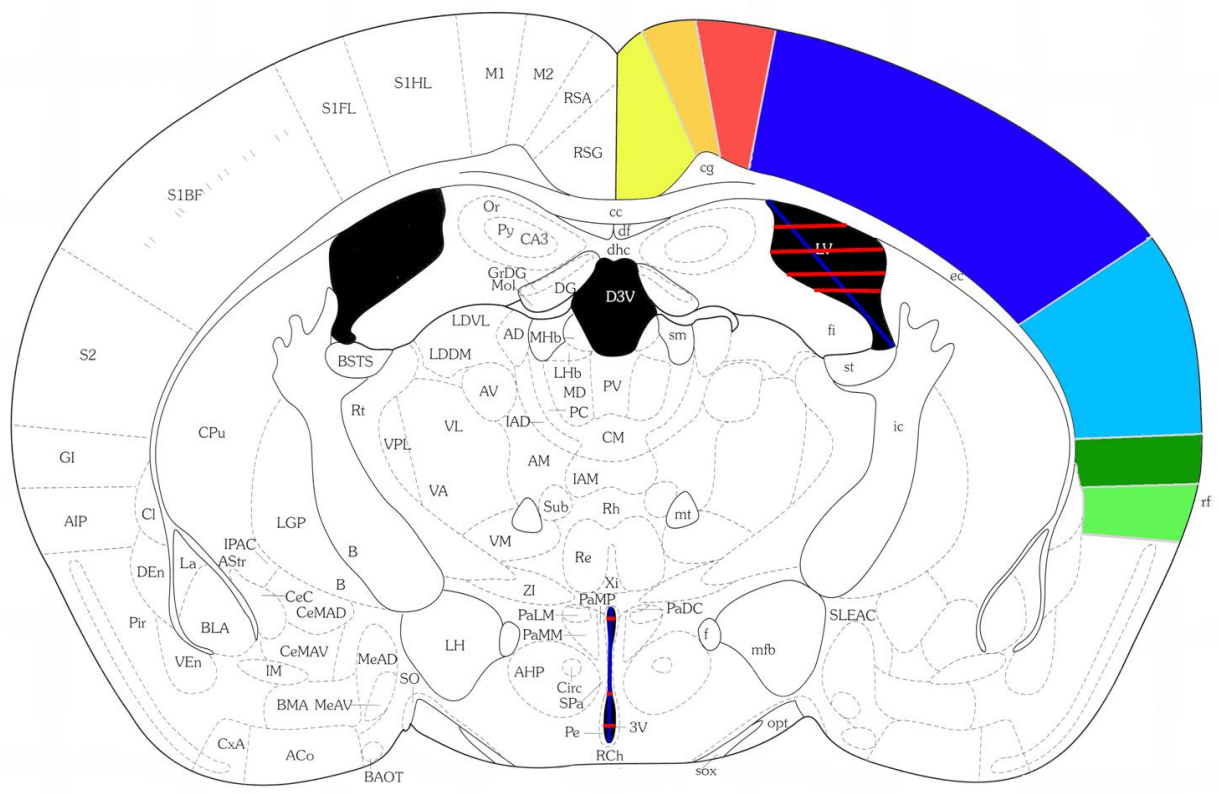

Figura MM8. Esquema modificado de Franklin y Paxinos, correspondiente al corte cerebral b.

Las diferentes zonas corticales estudiadas se representan en diferentes colores: amarillo, corteza cingular; naranja, corteza motora secundaria; rojo, corteza motora primaria; azul marino, corteza somatosensorial primaria,; azul claro, corteza somatosensorial secundaria; verde oscuro, corteza ectorrinal; verde intermedio, corteza insular; verde claro, corteza entorrinal.

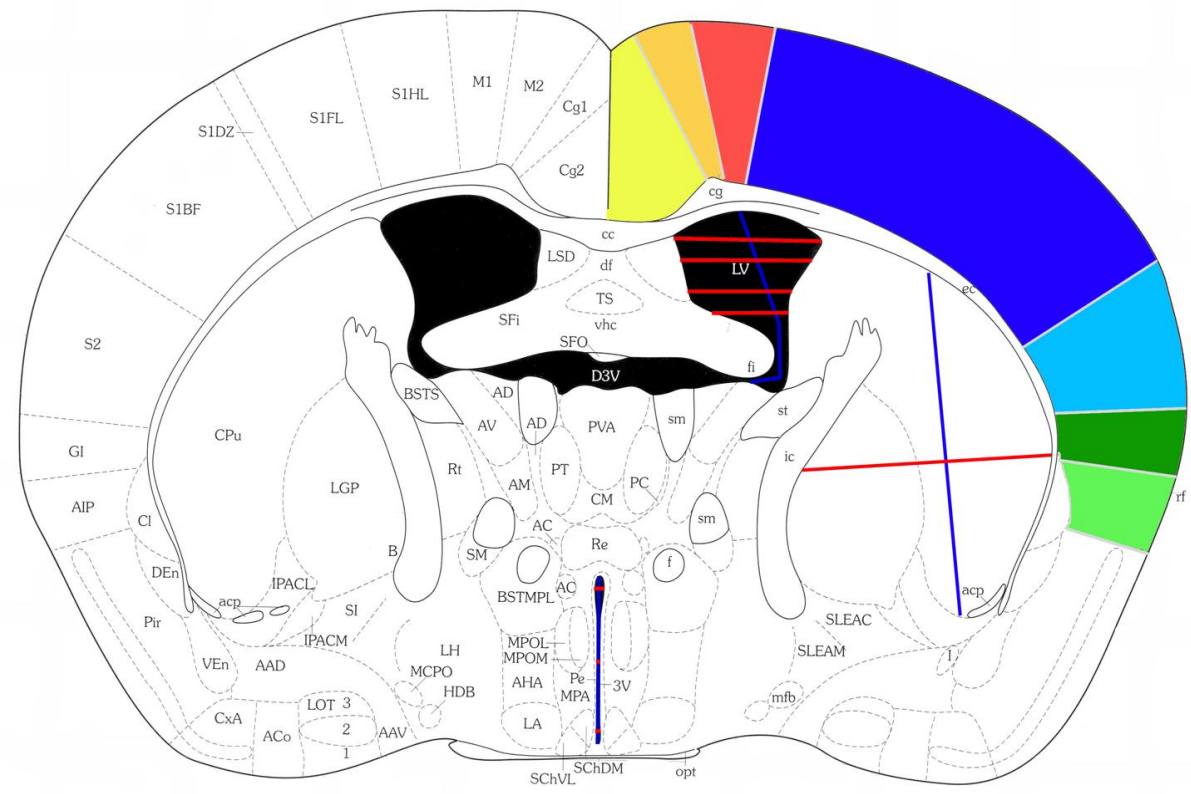

Figura MM9. Esquema modificado de Franklin y Paxinos, correspondiente al corte cerebral c.

Las diferentes zonas corticales estudiadas se representan en diferentes colores: amarillo, corteza cingular; naranja, corteza motora secundaria; rojo, corteza motora primaria; azul marino, corteza somatosensorial primaria,; azul claro, corteza somatosensorial secundaria; verde oscuro, corteza ectorrinal; verde intermedio, corteza insular; verde claro, corteza entorrinal. En el estriado, se representan los diámetros estudiados: dorso-ventral, azul; medio-lateral, rojo). 


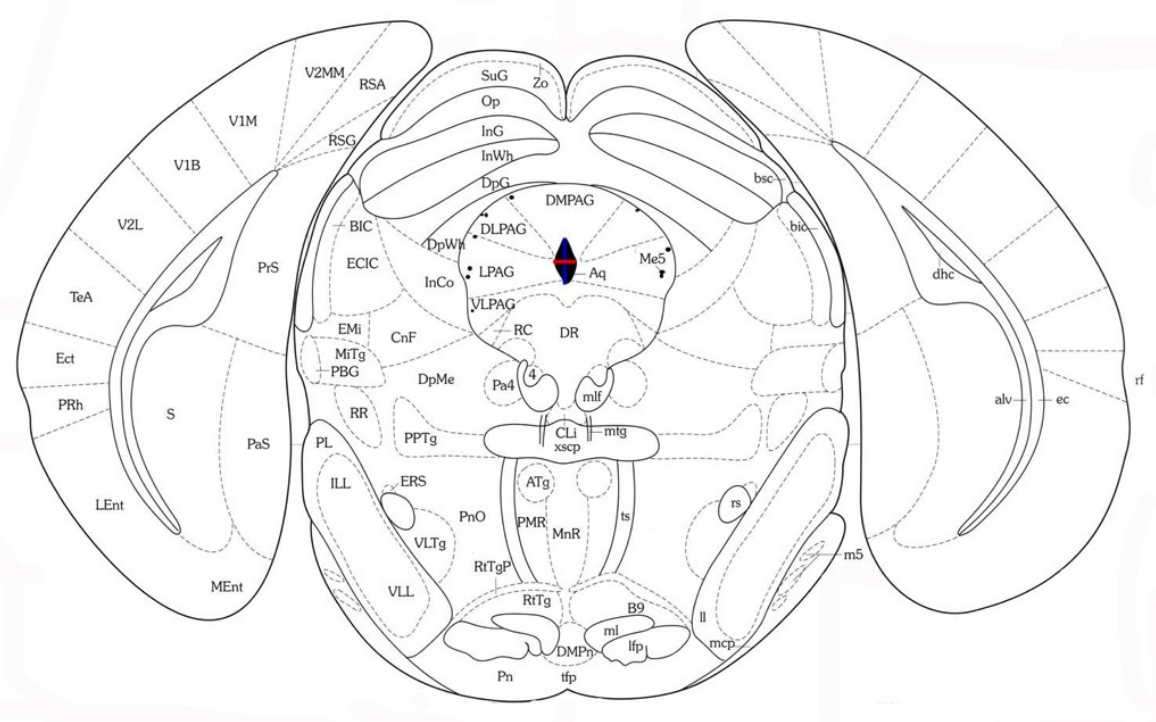

Figura MM10. Esquema modificado de Franklin y Paxinos, correspondiente al corte del mesencéfalo.

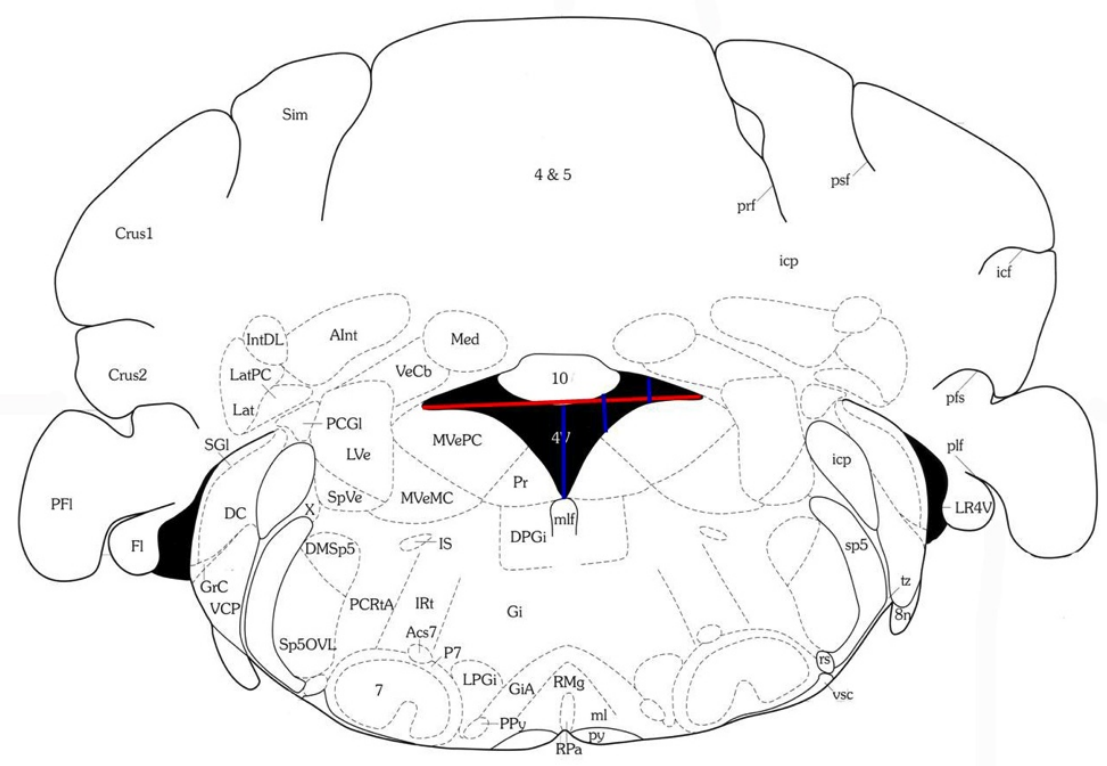

Figura MM11. Esquema modificado de Franklin y Paxinos, correspondiente al corte bulbo-protuberancial. 


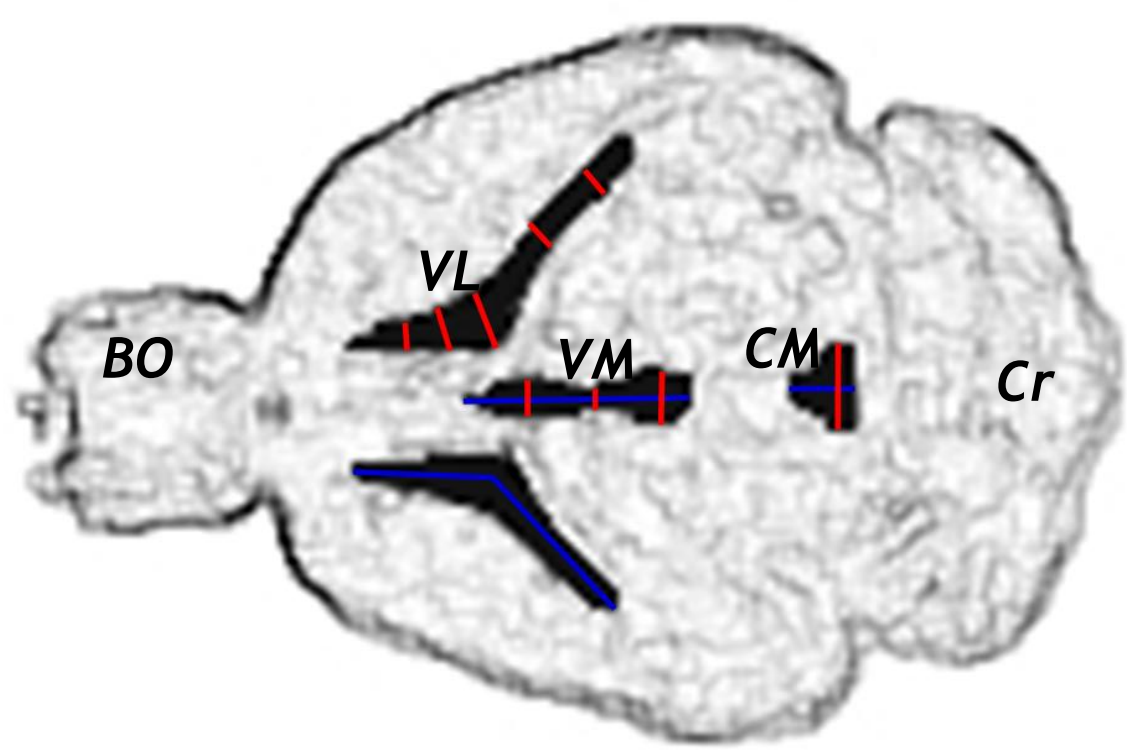

Figura MM12. Esquema resultado de perfilar con Adobe Photosop CS5 la imagen correspondiente a una sección horizontal que pasa por el ventrículo lateral, el ventrículo medio y la cisterna magna..

BO: bulbo olfativo, VL: ventrículo lateral, T: tálamo, CM: cisterna magna, VM: ventrículo medio, Cr: cerebelo.

\section{Análisis Estadístico de los resultados.}

Empleando la aplicación SPSS, de los valores obtenidos se hallaron medidas de centralización y dispersión. Las diferencias observadas entre los ratones wilde type y los ratones knock out se contrastaron aplicando el análisis de la t de Student, aceptando como significativos valores menores de $\mathrm{p}<0.05$. 
Resultados 
Para un análisis más rápido y simple de los resultados obtenidos en el estudio, los hemos subdividido en diferentes apartados, de forma que su comprensión resulte más sencilla.

En primer lugar, describiremos los resultados tras analizar la glucemia y la insulinemia de los animales; para luego pasar a detallar los resultados obtenidos mediante western blotting de una serie de proteínas relacionadas con la neurodegeneración, en particular la Tau-fosforilada, los enzimas desfosforiladores y las proteínas resultantes de la fosforilación de Tau. Además, se describen los resultados obtenidos al analizar la presencia de la proteína básica de mielina.

En segundo lugar, desarrollamos los resultados obtenidos mediante el análisis inmunocitoquímico de las variaciones observadas en la localización de la proteína Tau.

A continuación se describen los hallazgos obtenidos al estudiar los focos neurodegenerativos mediante rojo congo, seguido de la localización inmunocitoquímica del péptido $\beta$-amiloide.

Un cuarto apartado lo constituye el estudio postmortem sobre cortes histológicos de la dilatación ventricular, haciendo especial hincapié en los animales que presentaron hidrocefalia.

El estudio post-mortem se completa con la descripción de los hallazgos obtenidos al analizar la gliosis reactiva observada en los ratones knock out para IRS-2, mediante el estudio inmunocitoquímico con GFAP.

En el siguiente apartado, se presentan los resultados obtenidos en los animales analizados, inmediatamente antes de su sacrificio, al estudiar los cerebros mediante resonancia magnética nuclear. Desplegando en primer lugar las variaciones morfométricas relativas a las áreas, perímetros y diámetros ventriculares desde el cuarto ventrículo hasta el ventrículo lateral en cortes frontales y horizontales.

Por último, se presenta un análisis morfométrico de algunas regiones específicas del cerebro de estos animales, con especial énfasis en la corteza cerebral, el hipocampo y los ganglios basales. 


\section{Glucemias.}

Como se ha comentado en el capítulo de material y métodos, hemos determinado las glucemias: basal y postprandial en los ratones de este estudio.

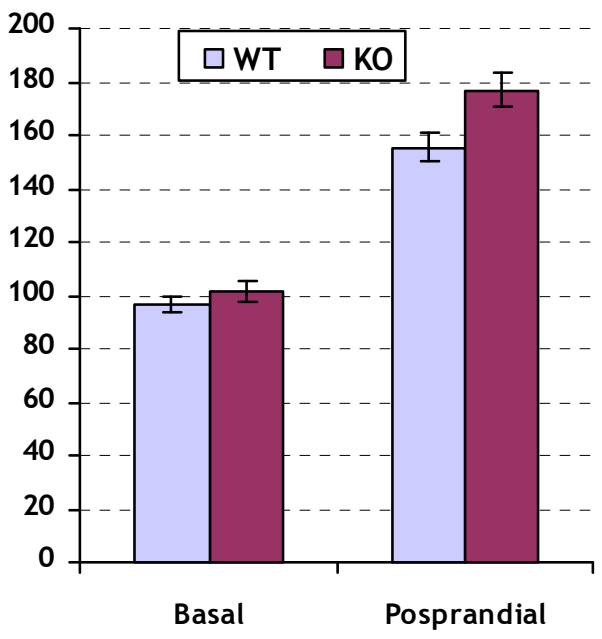

Figura R1 Glucemias.

Como muestra la gráfica de la figura R1, aunque los niveles de glucosa en sangre fueron ligeramente superiores en los ratones knock out para IRS-2 que en los ratones wilde type, sobre todo postprandialmente, los niveles de glucosa no superaron en ningún caso valores que pudieran ser estimados fuera de los límites normales, por lo que todos los animales empleados en el estudio se consideraron como normoglucémicos.

Gráfica que muestra los niveles medios de glucosa en sangre en condiciones basales y postprandiales, obtenidos en los ratones wilde type (WT) y knock out para IRS-2 (KO).

\section{Insulinemia.}

Tras la determinación por RIA de la insulina en el suero de los animales estudiados, hemos podido comprobar que los ratones knock out para IRS-2 no tenían déficit de insulina, sino que presentaban unos niveles séricos de insulina superiores a los observados en los ratones wilde type, aunque las diferencias no eran estadísticamente significativas, (figura R2).

Figura R2 Insulinemias.

Gráfica que muestra los niveles medios de insulina en suero, expresados en unidades internacionales por mililitro, obtenidos en los ratones wilde type (WT) y knock out para IRS-2 (KO).

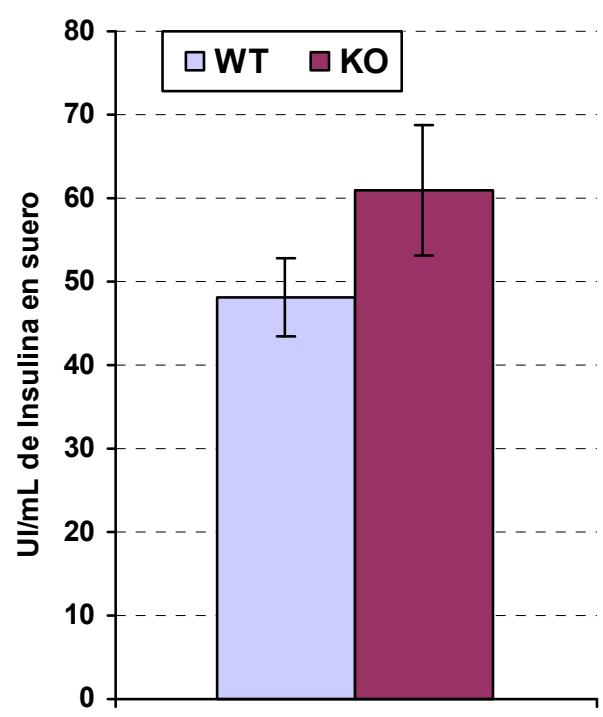




\section{Western Blotting y análisis densitométrico.}

Análisis post-mortem de la variación de la fosfatasa desfosforiladora PP2A de gato.

La fosfatasa desfosforiladora PP2A de gato disminuyó en los animales Knock out para IRS-2 con respecto a los animales wilde type.

Mediante western blotting se comprobó la presencia de una banda casi inapreciable de esta proteína en los lisados de cerebro de los knock out (figura R3).

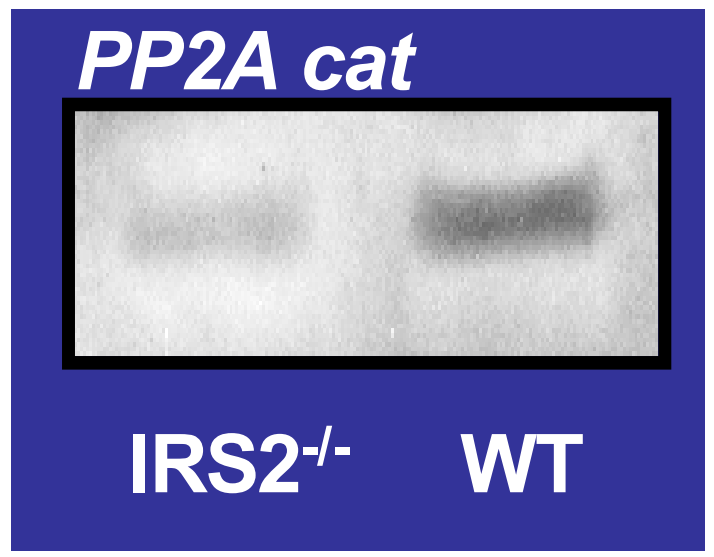

Figura R3 Western blotting de lisados de cérebro para PP2A de gato.

Aspecto que presentaban las bandas de western blotting para PP2A de gato en los lisados de cerebro de ratones knock out para IRS-2 (IRS2-/-) y los de los wilde type (WT).

Una vez calculados los valores medios de los niveles de gris y el área ocupada por las bandas de western de ambos grupos de animales, se apreció una diferencia significativa ( $<<0.05$, para el área y $p<0.001$ para los niveles de gris) entre ambos grupos de animales, lo que demostraba cuantitativamente que los cerebros de los ratones knock out para IRS-2 tenían disminuida la fosfatasa desfosforiladora PP2A (figura R4).

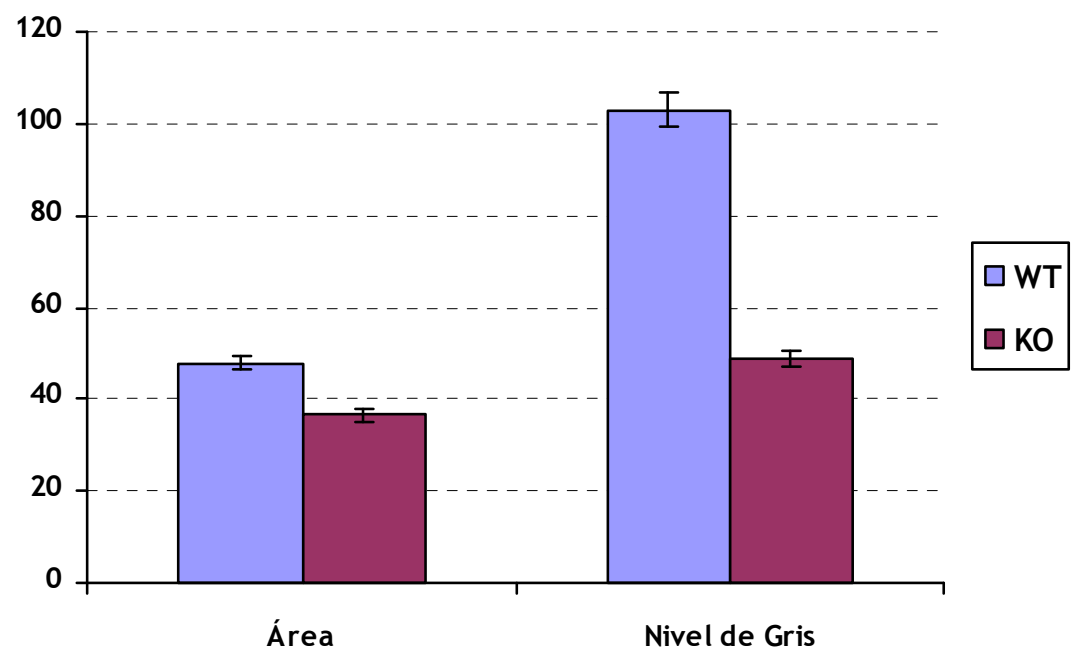

Figura R4 Área ocupada por las bandas de Western blotting y niveles medios de gris para PP2A de gato.

El área ocupada por la banda de los animales knock out para IRS-2 (KO) fue significativamente menor $(p<0.05)$ que la ocupada en los animales Wilde type (WT). Los niveles medios de gris fueron mucho menores $(p<0.001)$ en los animales knock out que en los wilde type. 
Al analizar densitométricamente las bandas del western, se observaron perfiles marcadamente diferentes entre los knock out y los wilde type, de manera que a lo largo de todo el perfil de la banda se apreciaron niveles de gris menores en los knock out. En ambos casos, los perfiles mostraban dientes de sierra que pusieron de manifiesto que el contenido en enzima de la banda no era homogéneo a lo largo de su recorrido (figura R5).

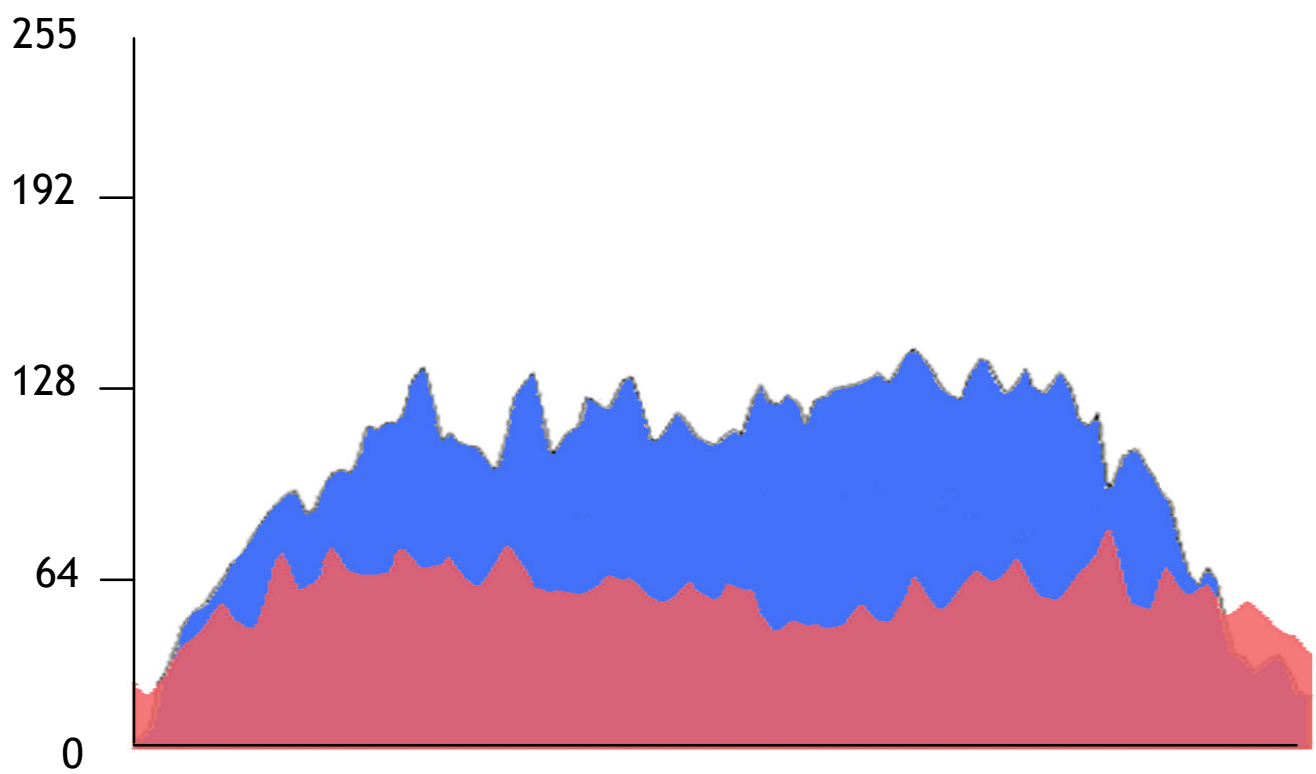

Figura R5 Perfil densitométrico para PP2A de gato.

El perfil densitométrico de las bandas de western blotting para PP2A de gato demuestra claramente que los niveles de gris en la banda correspondiente a los ratones KO para IRS-2 (color rojo) fueron mucho menores que los observados en los animales WT (color azul). A lo largo del perfil se aprecia en ambos casos los dientes de sierra que sugieren que la cantidad de proteína a lo ancho de la banda no era homogénea (blanco=0, negro= 255). 
Análisis post-mortem de la variación de la fosfatasa desfosforiladora PP2A (PR65).

La fosfatasa desfosforiladora PP2A (PR65) disminuyó en los animales Knock out para IRS-2 con respecto a los animales wilde type.

Mediante western blotting se comprobó la presencia de una banda irregular y poco marcada de este enzima en los lisados de cerebro de los knock out (figura R6).

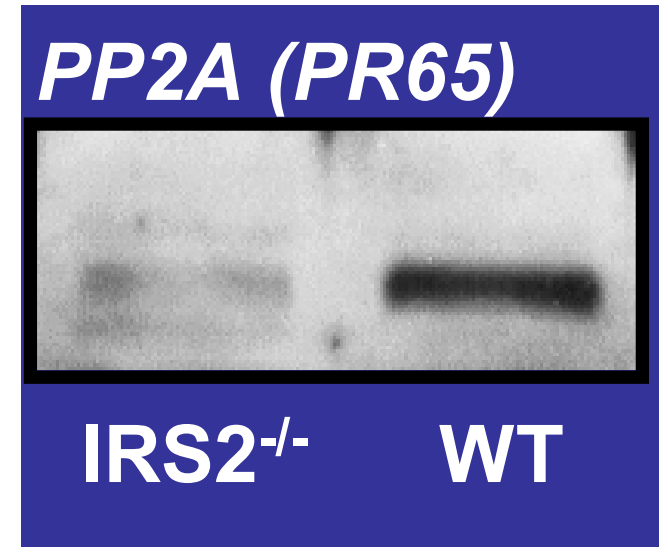

Figura R6 Western blotting de lisados de cérebro para PP2A (PR65).

Aspecto que presentaban las bandas de western blotting para PP2A (PR65) en los lisados de cerebro de ratones knock out para IRS-2 (IRS2-/-) y los de los wilde type (WT).

Una vez calculados los valores medios de los niveles de gris y el área ocupada por las bandas de western de ambos grupos de animales, se apreció una diferencia significativa ( $<<0.05$, para el área y $p<0.001$ para los niveles de gris) entre ambos grupos de animales, lo que demostraba cuantitativamente que los cerebros de los ratones knock out para IRS-2 tenían disminuida la fosfatasa desfosforiladora PP2A (PR65) (figura R7)

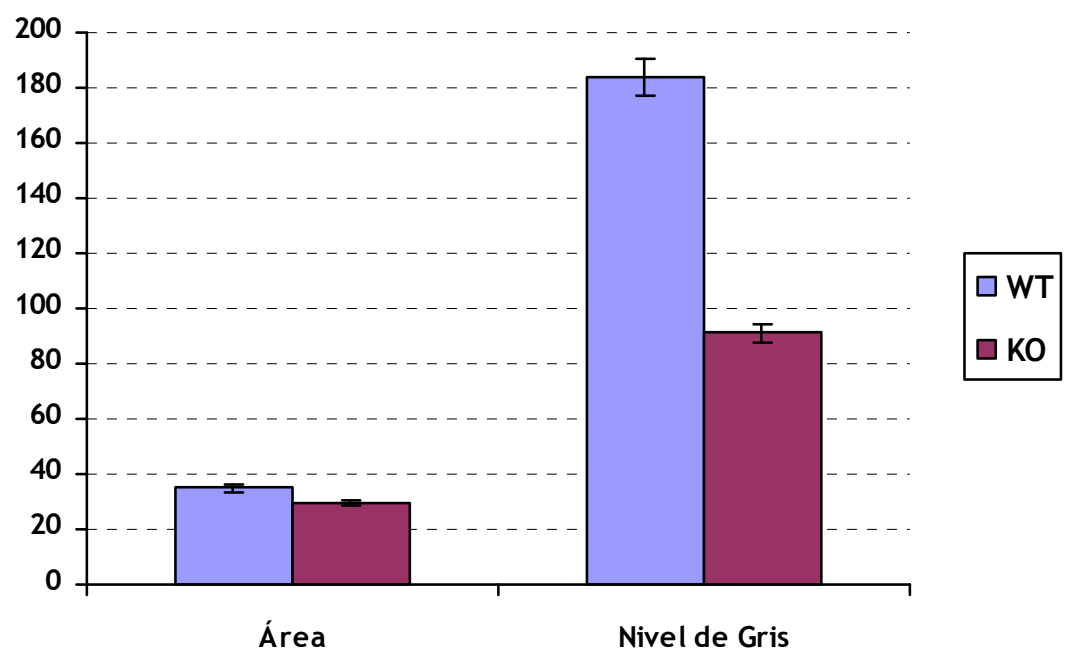

Figura R7 Área ocupada por las bandas de Western blotting y niveles medios de gris para PP2A (PR65).

El área ocupada por la banda de los animales knock out para IRS-2 (KO) fue significativamente menor $(p<0.05)$ que la ocupada en los animales wilde type (WT). Los niveles medios de gris fueron mucho menores $(p<0.001)$ en los animales knock out que en los wilde type. 
Al analizar densitométricamente las bandas del western se observaron perfiles marcadamente diferentes entre los knock out y los wilde type, de manera que a lo largo de todo el perfil de la banda se apreciaron niveles de gris menores en los knock out. En ambos casos, los perfiles mostraban dientes de sierra que pusieron de manifiesto que el contenido en enzima de la banda no era homogéneo a lo largo de su recorrido (figura R8).

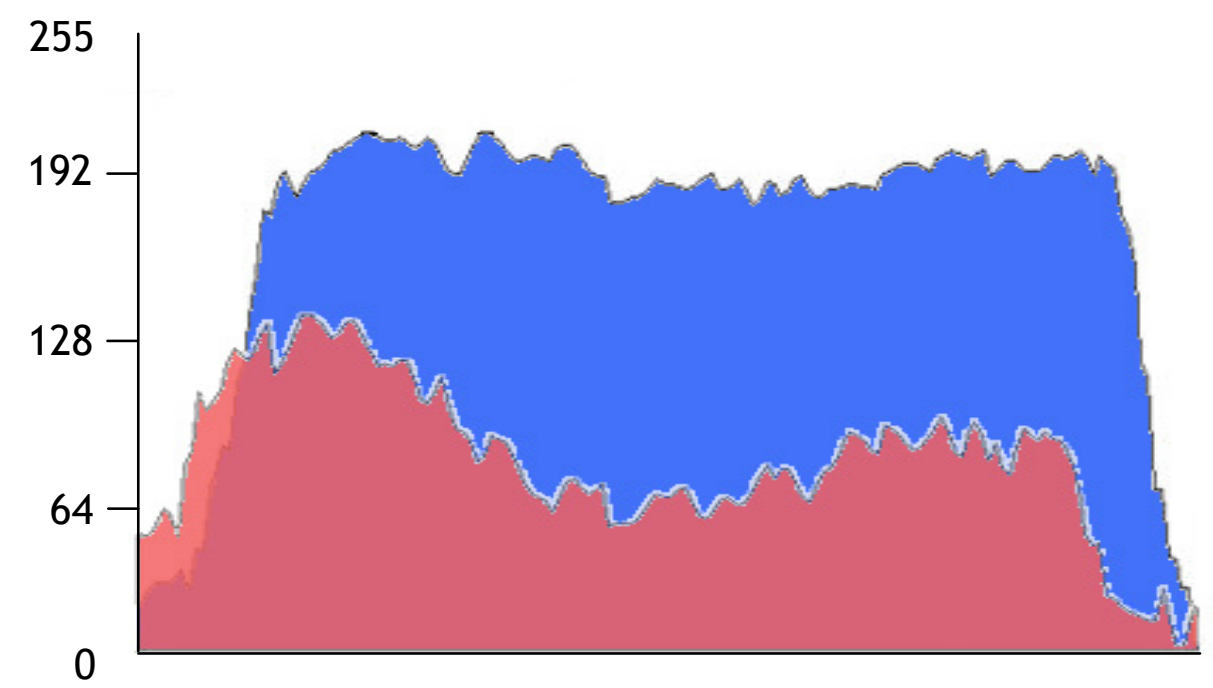

Figura R8 Perfil densitométrico para PP2A (PR65).

El perfil densitométrico de las bandas de western blotting para PP2A (PR65) demuestra claramente que los niveles de gris en la banda correspondiente a los ratones KO para IRS-2 (color rojo) fueron mucho menores que los observados en los animales WT (color azul) (blanco=0, negro= 255). 
Análisis post-mortem de la variación de la fosfatasa desfosforiladora PP2B de gato.

La fosfatasa desfosforiladora PP2B de gato disminuyó en los animales Knock out para IRS- 2 con respecto a los animales wilde type.

Mediante western blotting se comprobó la presencia de una banda fina y poco marcada de este enzima en los lisados de cerebro de los knock out (figura R9).

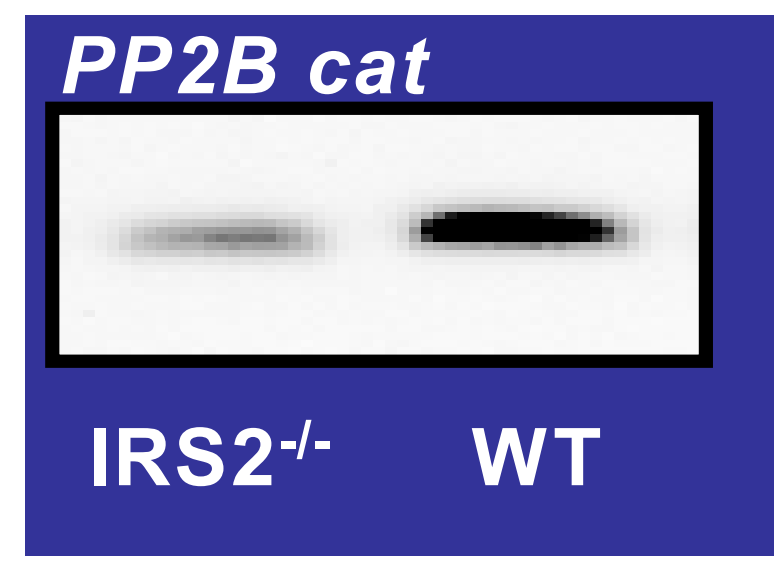

Figura R9 Western blotting de lisados de cérebro para PP2B de gato.

Aspecto que presentaban las bandas de western blotting para PP2B de gato en los lisados de cerebro de ratones knock out para IRS-2 (IRS2-/-) y los de los wilde type (WT).

Una vez calculados los valores medios de los niveles de gris y el área ocupada por las bandas de western de ambos grupos de animales, no se apreció una diferencia significativa para el área ocupada por las bandas, pero sí en los niveles de gris $(p<0.001)$ entre ambos grupos de animales, lo que demostraba cuantitativamente que los cerebros de los ratones knock out para IRS-2 tenían disminuida la fosfatasa desfosforiladora PP2B (figura R10)

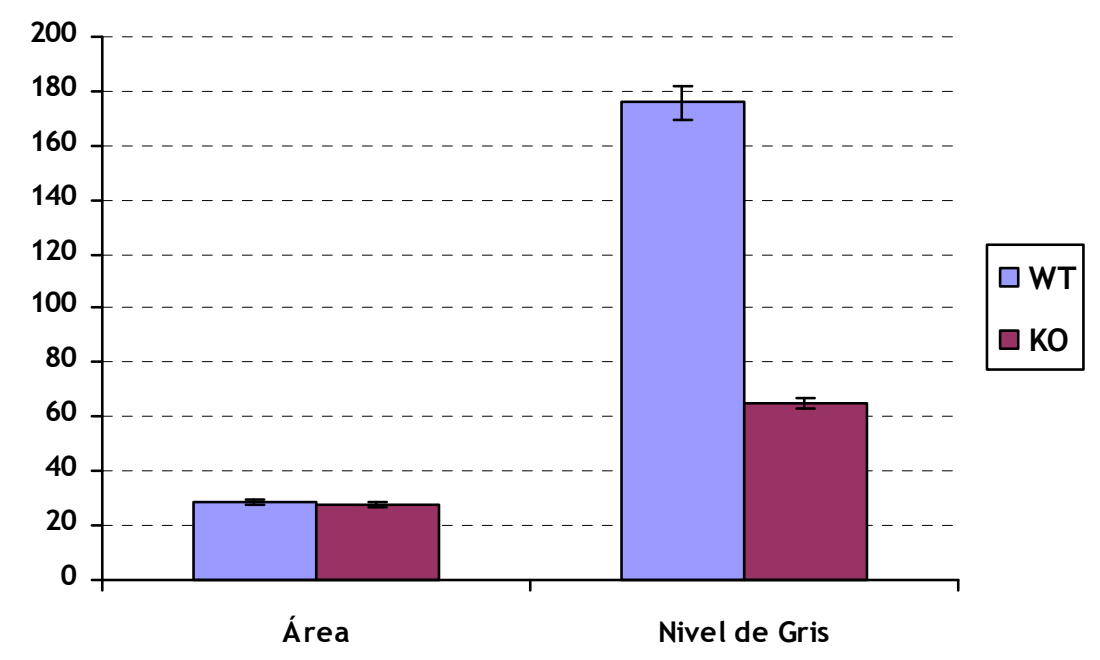

Figura R10 Área ocupada por las bandas de Western blotting y niveles medios de gris para PP2B de gato.

El área ocupada por la banda de los animales knock out para IRS-2 (KO) fue semejante a la ocupada en los animales wilde type (WT). Los niveles medios de gris fueron mucho menores $(p<0.001)$ en los animales knock out que en los wilde type. 
Al analizar densitométricamente las bandas del western se observaron perfiles marcadamente diferentes entre los knock out y los wilde type, de manera que a lo largo de todo el perfil de la banda se apreciaron niveles de gris menores en los knock out. Mientras que los animales wilde type presentaron un perfil elevado y plano, los knock out mostraron un perfil con un pico central y dientes de sierra que ponían de manifiesto una disposición irregular de las cantidades de proteína dentro de la banda (figura R11).

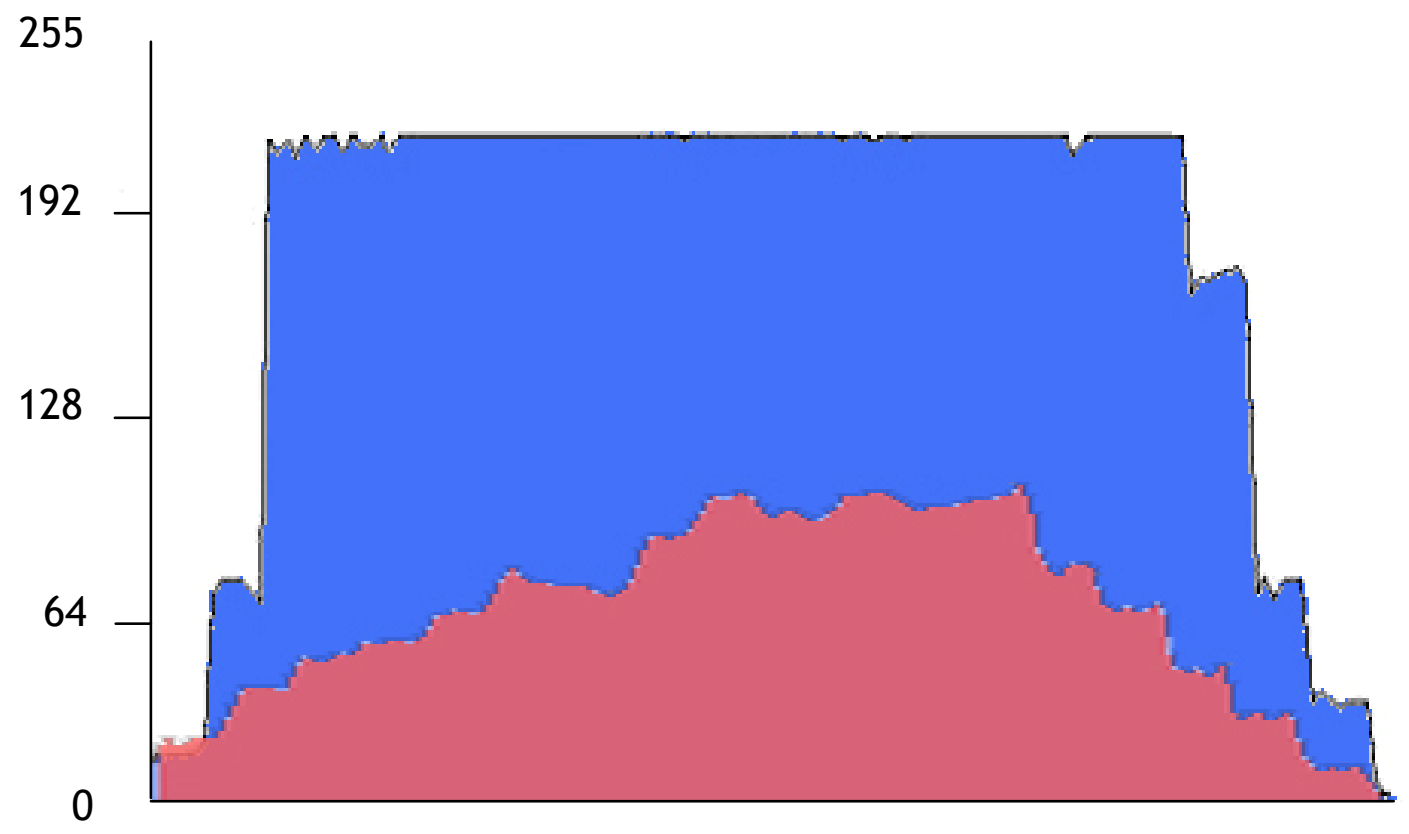

Figura R11 Perfil densitométrico para PP2B de gato.

El perfil densitométrico de las bandas de western blotting para PP2B de gato demuestra claramente que los niveles de gris en la banda correspondiente a los ratones KO para IRS-2 (color rojo) fueron mucho menores que los observados en los animales WT (color azul) (blanco $=0$, negro $=255$ ). 
Análisis post-mortem de la variación de la proteína básica de la mielina MBP.

La proteína básica de la mielina disminuyó en los animales Knock out para IRS-2 con respecto a los animales wilde type.

Mediante western blotting se comprobó la presencia de una banda desigual y poco marcada de esta proteína en los lisados de cerebro de los knock out (figura R12).

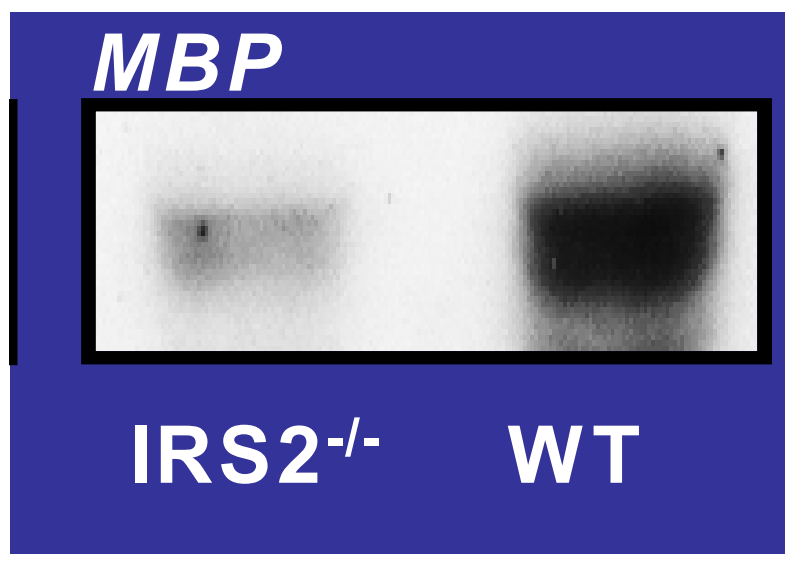

Figura R12 Western blotting de lisados de cérebro para MBP.

Aspecto que presentaban las bandas de western blotting para MBP en los lisados de cerebro de ratones knock out para IRS-2 (IRS2-/-) y los de los wilde type (WT).

Una vez calculados los valores medios de los niveles de gris y el área ocupada por las bandas de western de ambos grupos de animales, se apreció una diferencia significativa ( $<<0.05$, para el área y $p<0.001$ para los niveles de gris) entre ambos grupos de animales, lo que demostraba cuantitativamente que los cerebros de los ratones knock out para IRS-2 tenían disminuida la proteína básica de la mielina (figura R13)

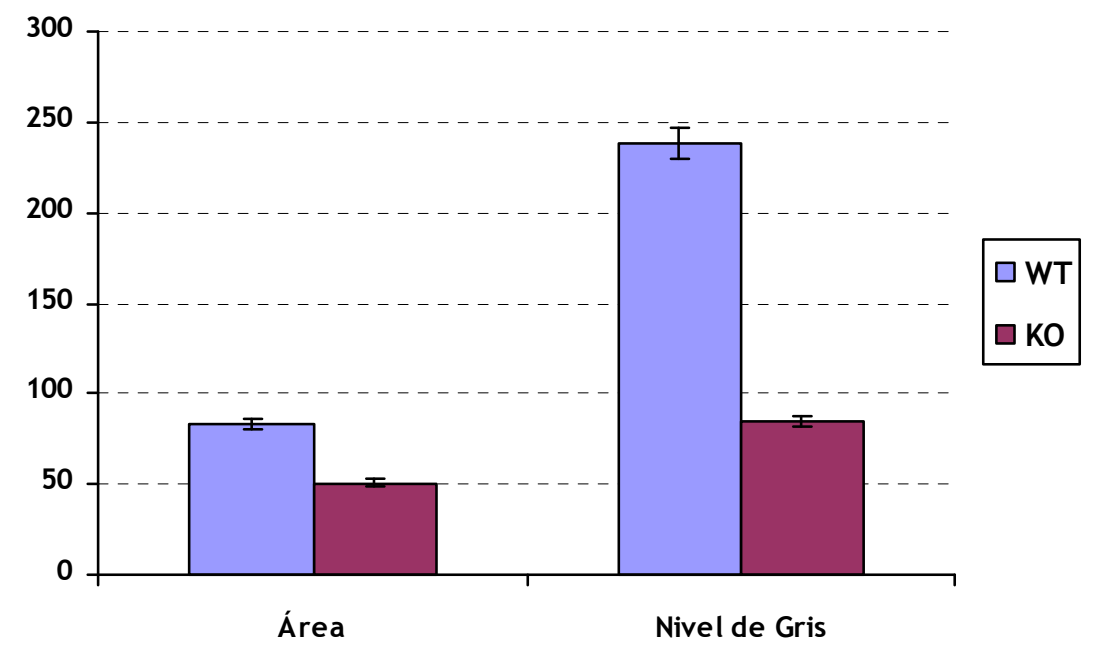

Figura R13 Área ocupada por las bandas de Western blotting y niveles medios de gris para MBP.

El área ocupada por la banda de los animales knock out para IRS-2 (KO) fue significativamente menor $(p<0.05)$ que la ocupada en los animales wilde type (WT). Los niveles medios de gris fueron mucho menores $(p<0.001)$ en los animales knock out que en los wilde type. 
Al analizar densitométricamente las bandas del western se observaron perfiles marcadamente diferentes entre los knock out y los wilde type, de manera que a lo largo de todo el perfil de la banda se apreciaron niveles de gris menores en los knock out. En ambos casos, los perfiles mostraban dientes de sierra, más acentuados en el caso de los animales knock out para IRS-2, que pusieron de manifiesto que el contenido en enzima de la banda no era homogéneo a lo largo de su recorrido (figura R14).

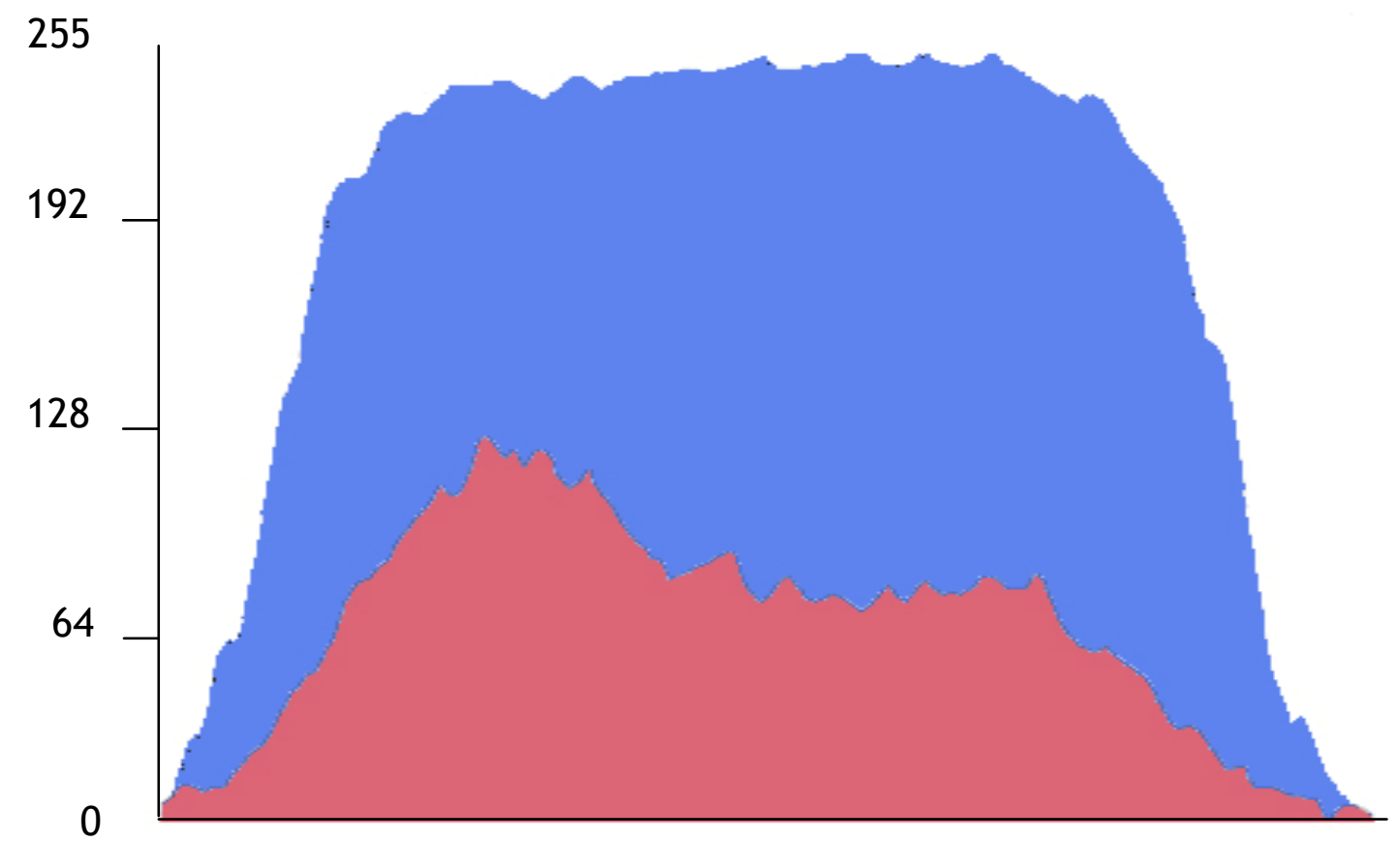

Figura R14 Perfil densitométrico para MBP.

El perfil densitométrico de las bandas de western blotting para MBP demuestra claramente que los niveles de gris en la banda correspondiente a los ratones KO para IRS-2 (color rojo) fueron mucho menores que los observados en los animales WT (color azul) (blan$\mathrm{CO}=0$, negro $=255$ ). 


\section{Análisis post-mortem de la presencia de las isoformas 1 y 2 de Tau.}

Las isoformas 1 y 2 de Tau disminuyeron en los animales Knock out para IRS-2 con respecto a los animales wilde type.

Mediante western blotting se comprobó la presencia de una banda de aspecto semejante, aunque menos intensa, de esta proteína en los lisados de cerebro de los knock out (figura R15).

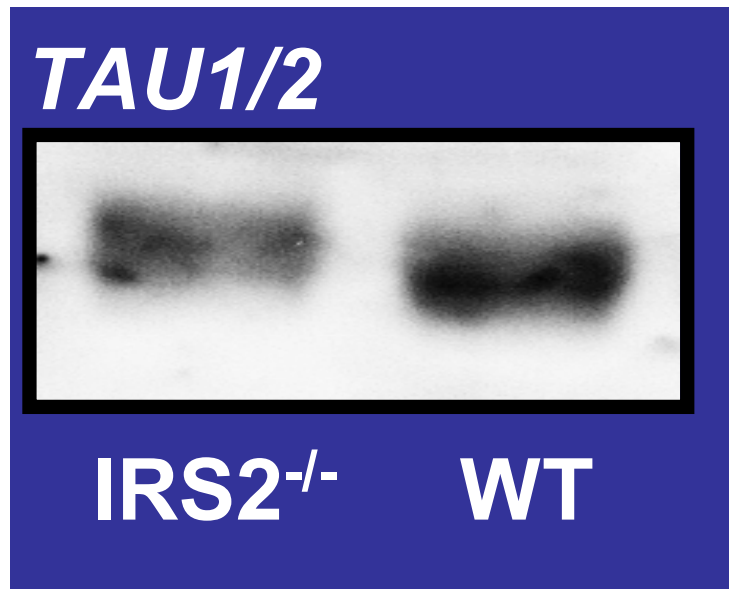

Figura R15 Western blotting de lisados de cérebro para Tau $1 / 2$.

Aspecto que presentaban las bandas de western blotting para Tau $1 / 2$ en los lisados de cerebro de ratones knock out para IRS-2 (IRS2-/-) y los de los wilde type (WT).

Una vez calculados los valores medios de los niveles de gris y el área ocupada por las bandas de western de ambos grupos de animales, no se apreció una diferencia significativa para el área ocupada por las bandas, pero sí para los niveles de gris $(p<0.05)$ entre ambos grupos de animales, lo que demostraba cuantitativamente que los cerebros de los ratones knock out para IRS-2 tenían disminuida la Tau $1 / 2$ (figura R16)

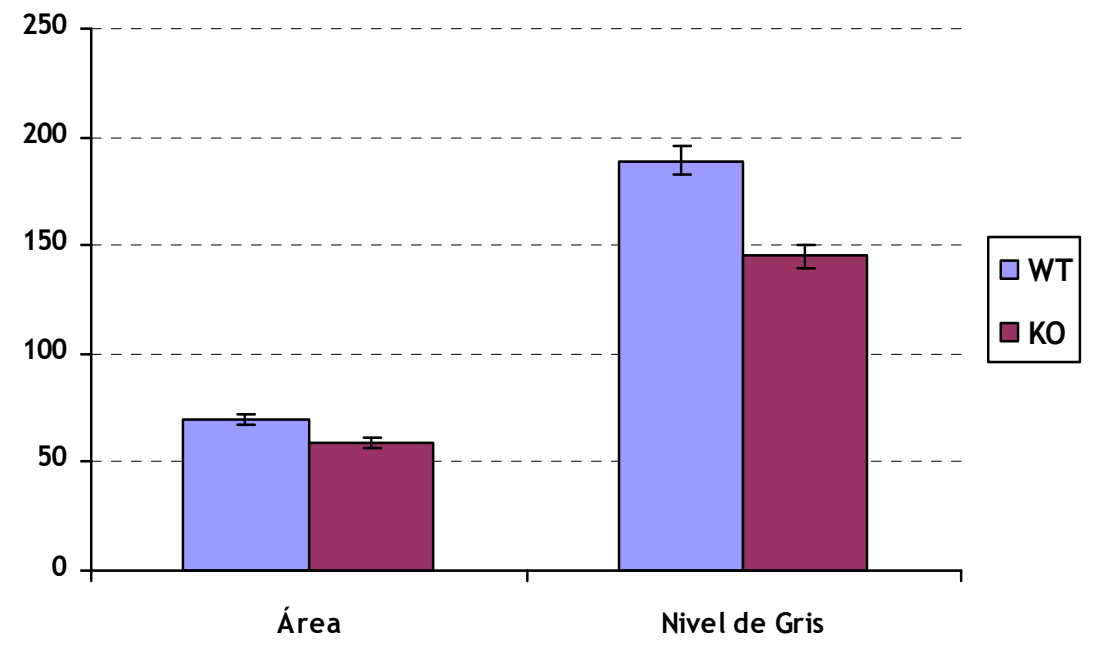

Figura R16 Área ocupada por las bandas de Western blotting y niveles medios de gris para Tau $1 / 2$.

El área ocupada por la banda de los animales knock out para IRS-2 (KO) fue semejante a la ocupada en los animales wilde type (WT). Los niveles medios de gris fueron menores $(p<0.05)$ en los animales knock out que en los wilde type. 
Al analizar densitométricamente las bandas del western se observaron perfiles de aspecto y trazado semejante entre los knock out y los wilde type, aunque a lo largo de todo el perfil de la banda se apreciaron niveles de gris menores en los knock out. En ambos casos, los perfiles mostraban dientes de sierra, más acentuados en los animales knock out que pusieron de manifiesto que el contenido de Tau 1/2 en la banda no era homogéneo a lo largo de su recorrido (figura R17).

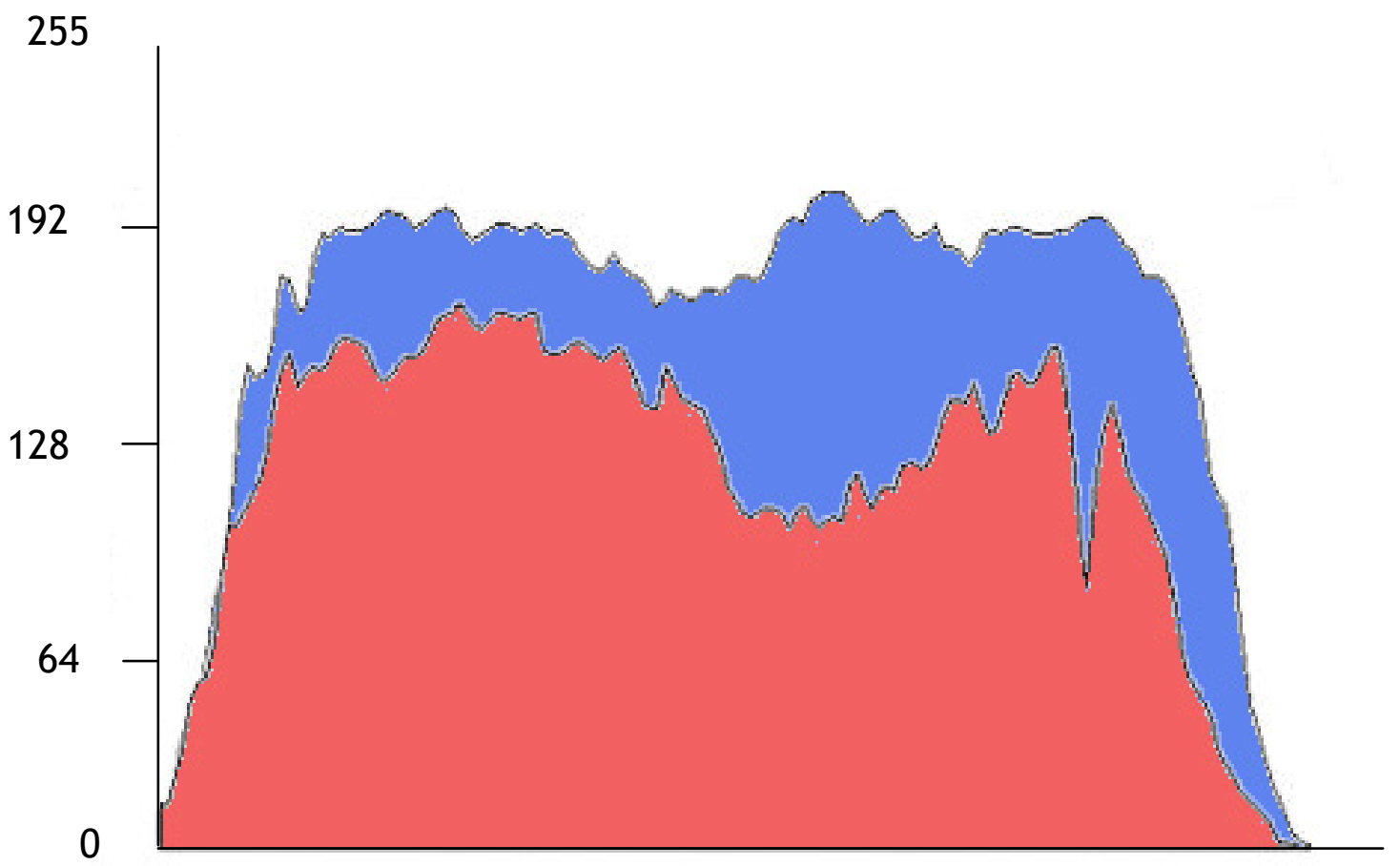

Figura R17 Perfil densitométrico para Tau 1/2.

El perfil densitométrico de las bandas de western blotting para Tau $1 / 2$ demuestra que los niveles de gris en la banda correspondiente a los ratones KO para IRS-2 (color rojo) fueron menores que los observados en los animales WT (color azul) (blanco=0, negro $=255$ ). 


\section{Análisis post-mortem de la existencia de Tau-fosforilada. Presencia}

de AT180.

La proteína AT180 resultado de la fosforilación de Tau no varió significativamente en los animales Knock out para IRS-2 con respecto a los animales wilde type.

Mediante western blotting se comprobó la presencia de bandas muy parecidas de AT180 en los lisados de cerebro de ambos grupos de animales (figura R18).

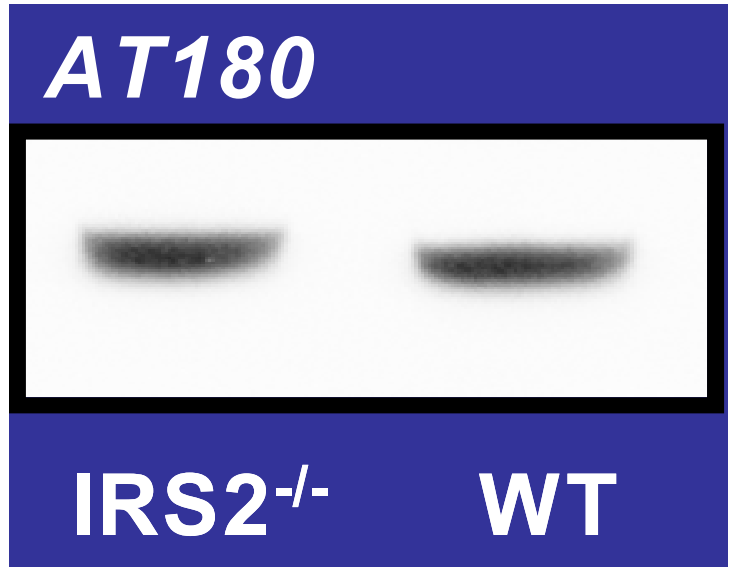

Figura R18 Western blotting de lisados de cérebro para AT180.

Aspecto que presentaban las bandas de western blotting para AT180 en los lisados de cerebro de ratones knock out para IRS-2 (IRS2-/-) y los de los wilde type (WT).

Una vez calculados los valores medios de los niveles de gris y el área ocupada por las bandas de western de ambos grupos de animales, se apreció un ligero aumento no significativo en el área ocupada por la banda de AT180 en los animales knock out con respecto a los wilde type. Al analizar el nivel de gris medio, por contra, el valor fue ligeramente menor en los knock out. Sin embargo, las diferencias no fueron significativas. Considerados ambos parámetros conjuntamente se puede decir que el western blotting para AT180 no puso de manifiesto diferencias considerables entre los dos grupos de animales estudiados (figura R19).

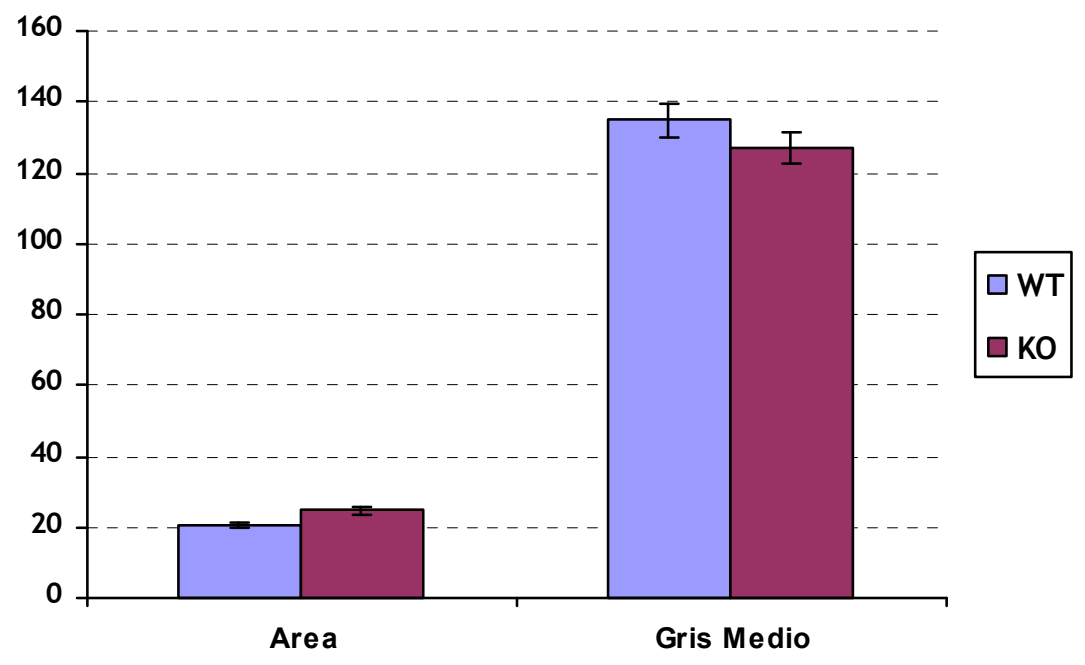

Figura R19 Área ocupada por las bandas de Western blotting y niveles medios de gris para AT180.

El área ocupada por la banda de los animales knock out para IRS-2 (KO) y los niveles medios de gris fueron semejantes y sin variación significativa entre los animales knock out y los wilde type. 
Al analizar densitométricamente las bandas del western se observaron perfiles prácticamente idénticos en su recorrido, morfología y niveles de gris a lo largo de toda la banda. Aunque ambos perfiles mostraron trayecto irregular, los dientes de sierra estaban muy atenuados, lo que indicaba una distribución homogénea de AT180 dentro de la banda (figura R20).

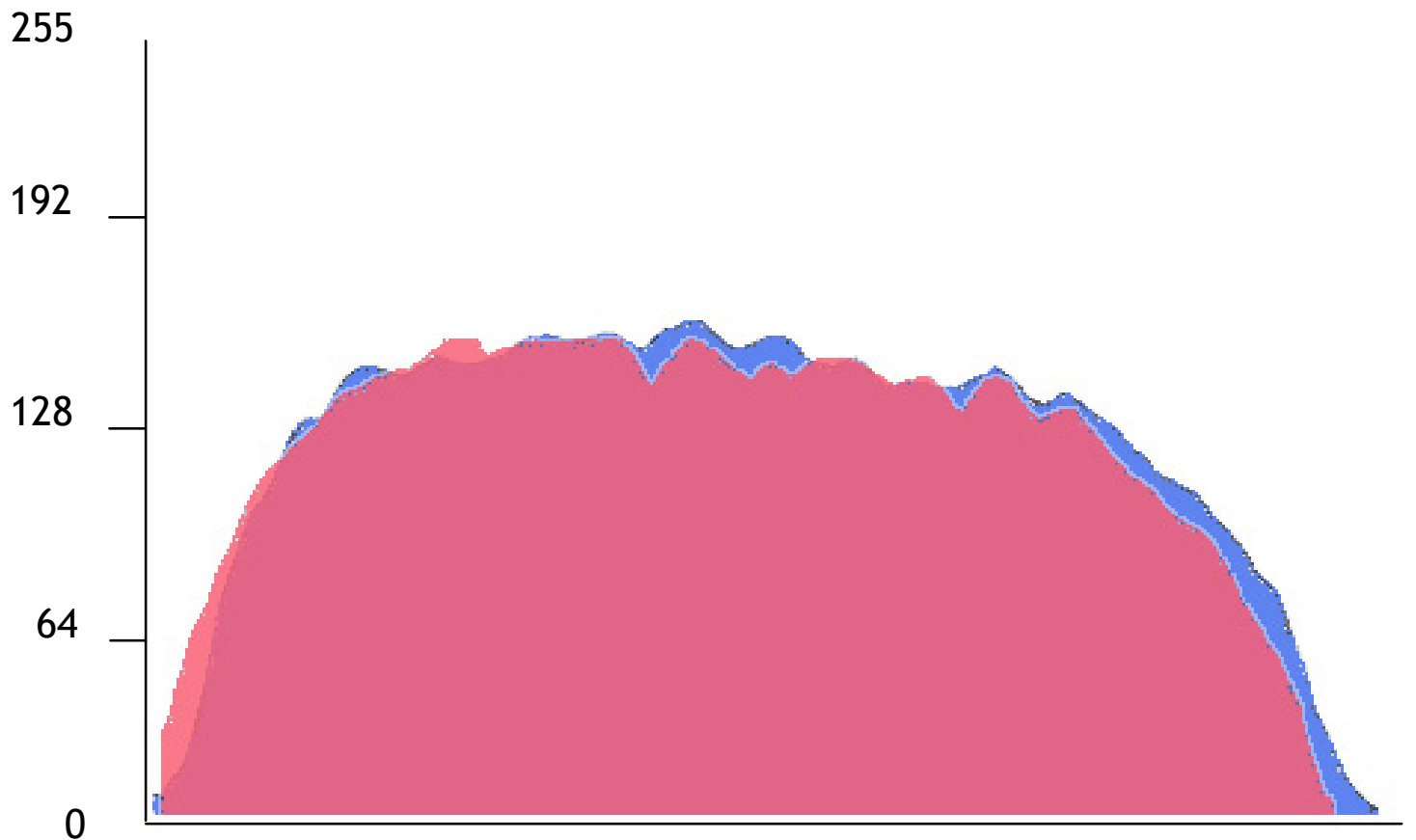

Figura R20 Perfil densitométrico para AT180.

El perfil densitométrico de las bandas de western blotting para AT180 demuestra claramente dos perfiles muy semejantes en los ratones KO para IRS-2 (color rojo) y en los animales WT (color azul) (blanco=0, negro= 255). 


\section{Análisis post-mortem de la existencia de Tau-fosforilada. Presencia}

de AT8.

La proteína AT8, producto de la fosforilación de Tau, aumentó en los animales Knock out para IRS-2 con respecto a los animales wilde type.

Mediante western blotting se comprobó la presencia de una banda amplia y muy intensa de esta proteína en los lisados de cerebro de los knock out (figura R21).

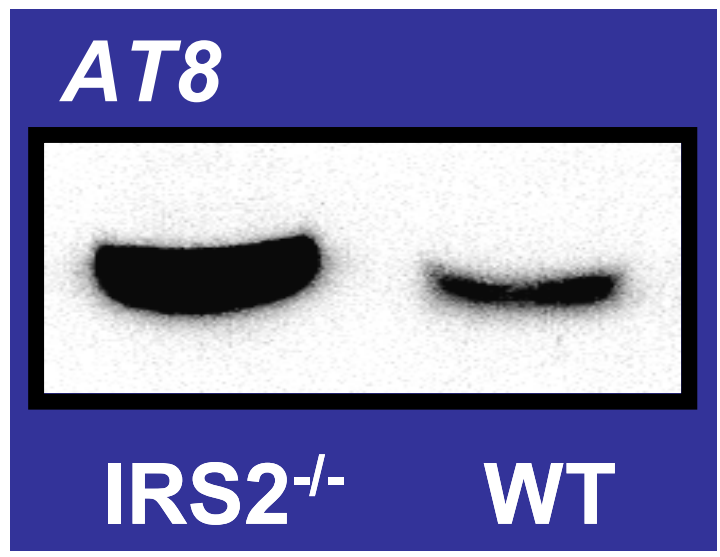

Figura R21 Western blotting de lisados de cérebro para AT8.

Aspecto que presentaban las bandas de western blotting para AT18 en los lisados de cerebro de ratones knock out para IRS-2 (IRS2-/-) y los de los wilde type (WT).

Una vez calculados los valores medios de los niveles de gris y el área ocupada por las bandas de western de ambos grupos de animales, se apreció una diferencia significativa ( $<0.001$, para el área y $p<0.05$ para los niveles de gris) entre ambos grupos de animales, lo que demostraba cuantitativamente que los cerebros de los ratones knock out para IRS-2 tenían aumentada la proteína AT8 (figura R22).

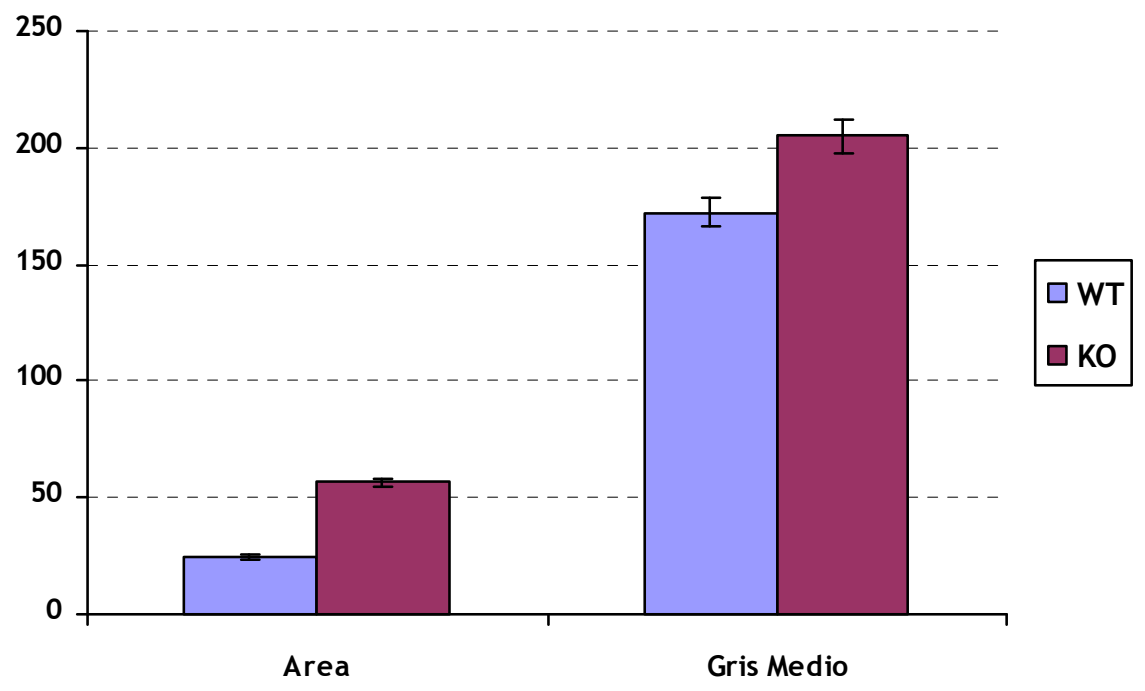

Figura R22 Área ocupada por las bandas de Western blotting y niveles medios de gris para AT8.

El área ocupada por la banda de los animales knock out para IRS-2 (KO) fue significativamente mayor $(p<0.001)$ que la ocupada en los animales wilde type (WT). Los niveles medios de gris fueron mayores $(p<0.05)$ en los animales knock out que en los wilde type. 
Al analizar densitométricamente las bandas del western se observaron perfiles diferentes entre los knock out y los wilde type. A excepción de la parte medial de la banda, donde los niveles de gris fueron claramente superiores en los animales knock out, la intensidad de nivel de gris fue muy parecida en ambos grupos de tratamiento. Sin embargo, mientras que el perfil en los animales knock out mostraba un aspecto de meseta en los niveles altos, el perfil en los wilde type manifestaba variaciones con dientes de sierra, sobre todo en la parte media de la banda.

Todo ello es indicativo de una distribución más homogénea de la proteína y de la existencia de mayor cantidad de AT8 en los animales knock out que en los wilde type (figura R23).

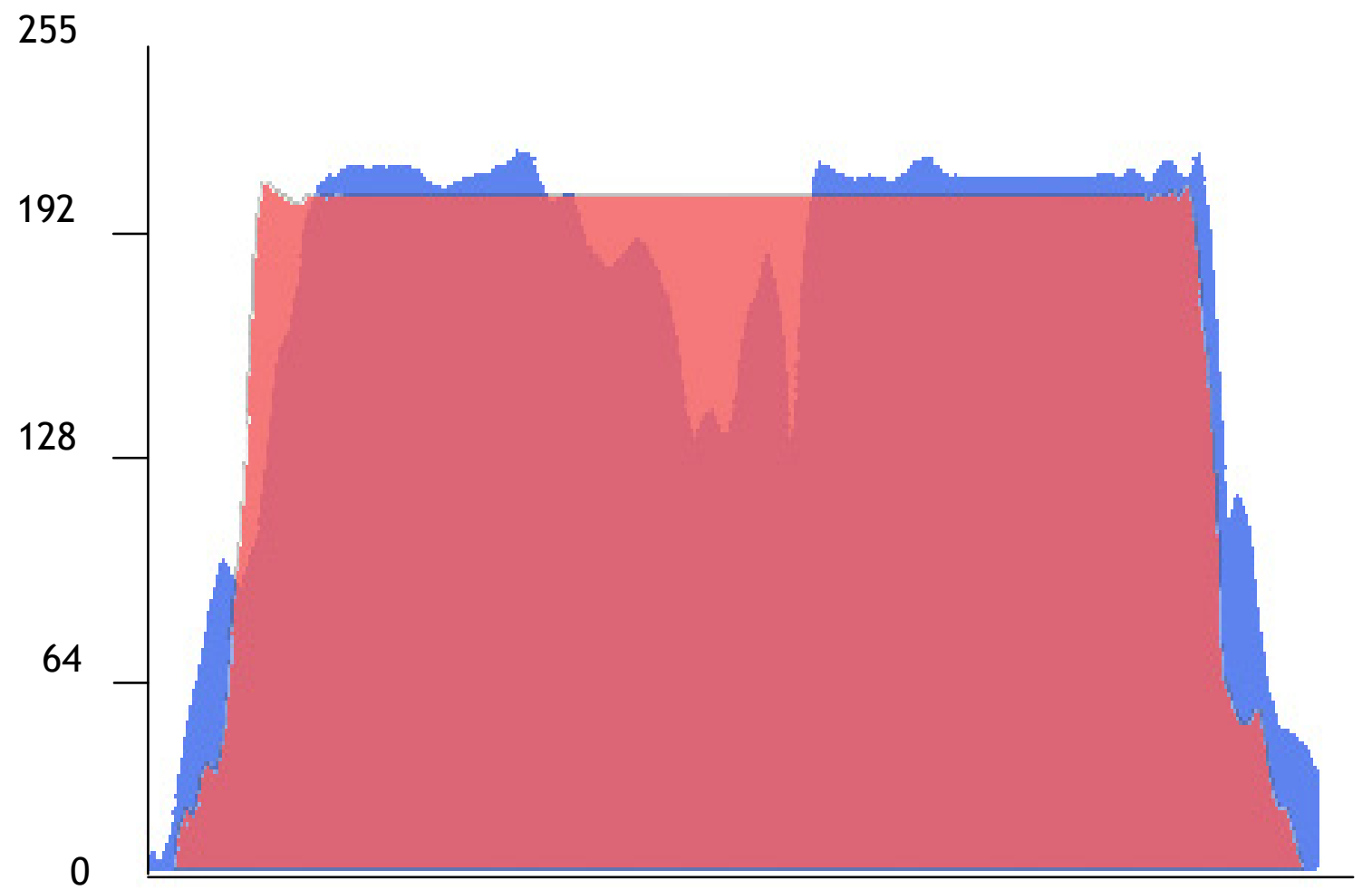

Figura R23 Perfil densitométrico para AT8.

El perfil densitométrico de las bandas de western blotting para AT8 demuestra claramente que los niveles de gris en la banda correspondiente a los ratones KO para IRS-2 (color rojo) fueron mayores y más homogéneos que los observados en los animales WT (color azul) (blanco=0, negro $=255$ ). 


\section{Análisis post-mortem de la presencia de Tau fosforilada me- diante inmunocitoquímica.}

\section{Animales Wilde Type.}

En los ratones wilde type, apenas se apreció la presencia de Tau fosforilada mediante inmunocitoquímica.

Las imágenes R24 y R25 están tomadas en cerebros de animales wilde type, en particular, de la corteza somatosensorial primaria (CSS1) y el giro dentado del hipocampo (GD), en ellas se observa que la reacción inmunocitoquímica para la Tau fosforilada (flechas) es prácticamente inapreciable.
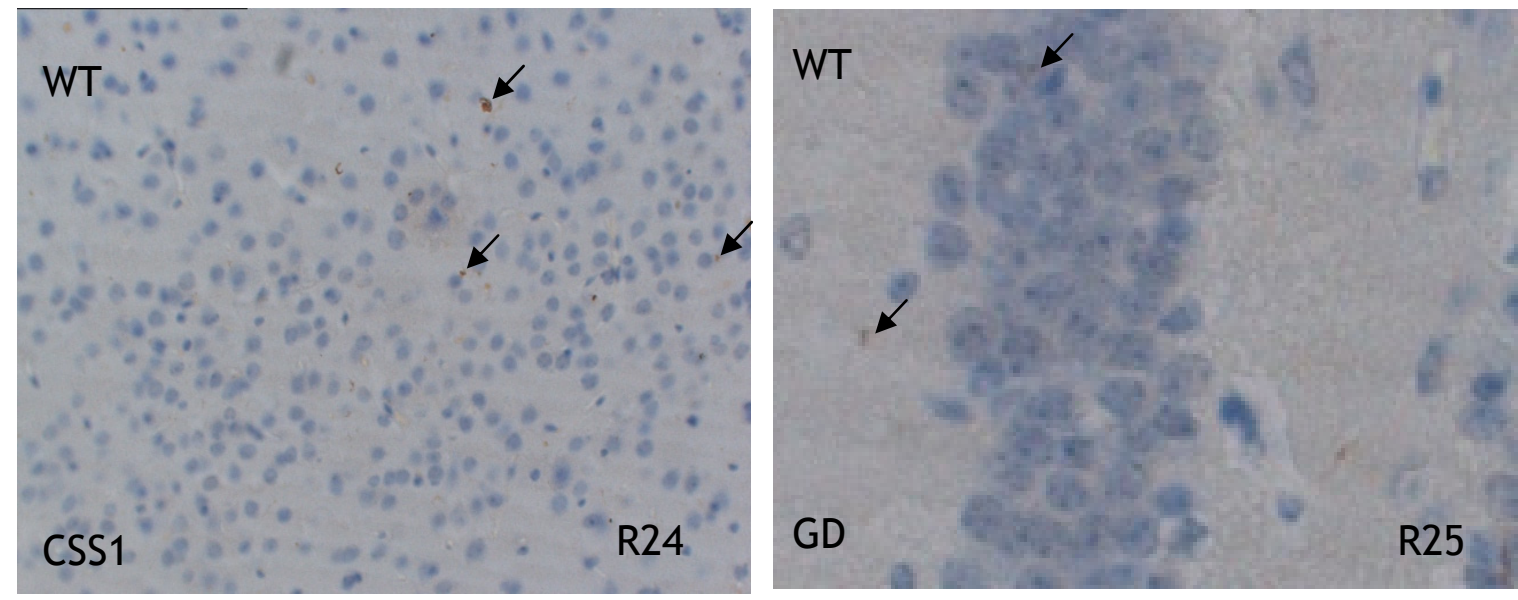

Figuras R24 y R25 Inmunocitoquímica para Tau fosforilada en cerebros wilde type. Imágenes tomadas en la corteza somatosensorial primaria (CSS1) y el giro dentado del hipocampo (GD).

Destaca que apenas hay depósitos reactivos. En ambas, las flechas señalan los muy escasos puntos de reacción a Tau fosforilada.

\section{Animales Knock Out.}

Al contrario de lo que ocurría en los ratones wilde type, en los cerebros de los ratones knock out para IRS-2 la reacción inmunocitoquímica a Tau fosforilada fue muy evidente.

Sin embargo, los patrones de reacción no fueron iguales en todos los animales, presentando, de unos a otros, dos patrones muy distintos que afectaron a varias regiones del cerebro.

Las imágenes R26 y R27 muestran los dos patrones de reacción observados en la corteza somatosensorial primaria (CSS1) y las figuras R28 y R29 muestran esos mismos patrones en el hipocampo.

Un patrón estaba más localizado en los somas neuronales y, aunque existe reacción en el neuropilo adyacente, ésta no es exagerada. 
El segundo patrón presenta una intensidad de reacción mucho más fuerte y afecta al neuropilo adyacente y a los somas neuronales.

En ambos casos, junto a las neuronas positivas a Tau se aprecia gran cantidad de neuronas que no presentaban reacción.
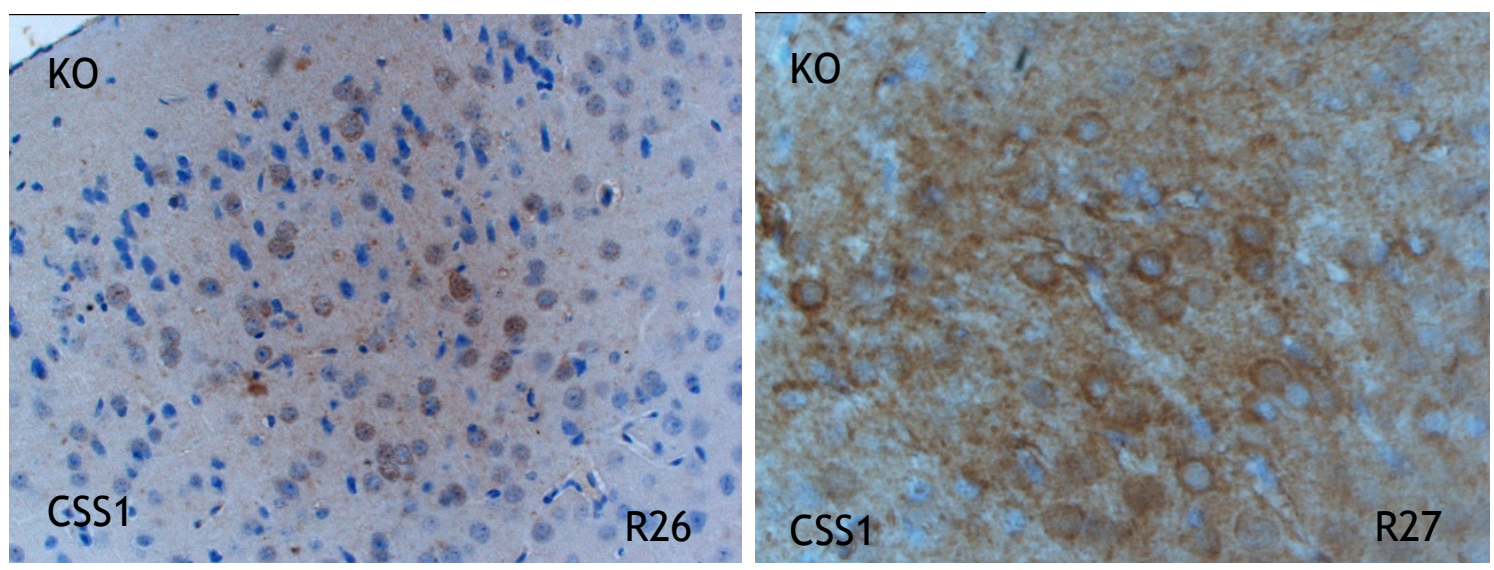

Figuras R26 y R27 Inmunocitoquímica para Tau fosforilada en cerebros knock out. Imágenes tomadas en la corteza somatosensorial primaria (CSS1).
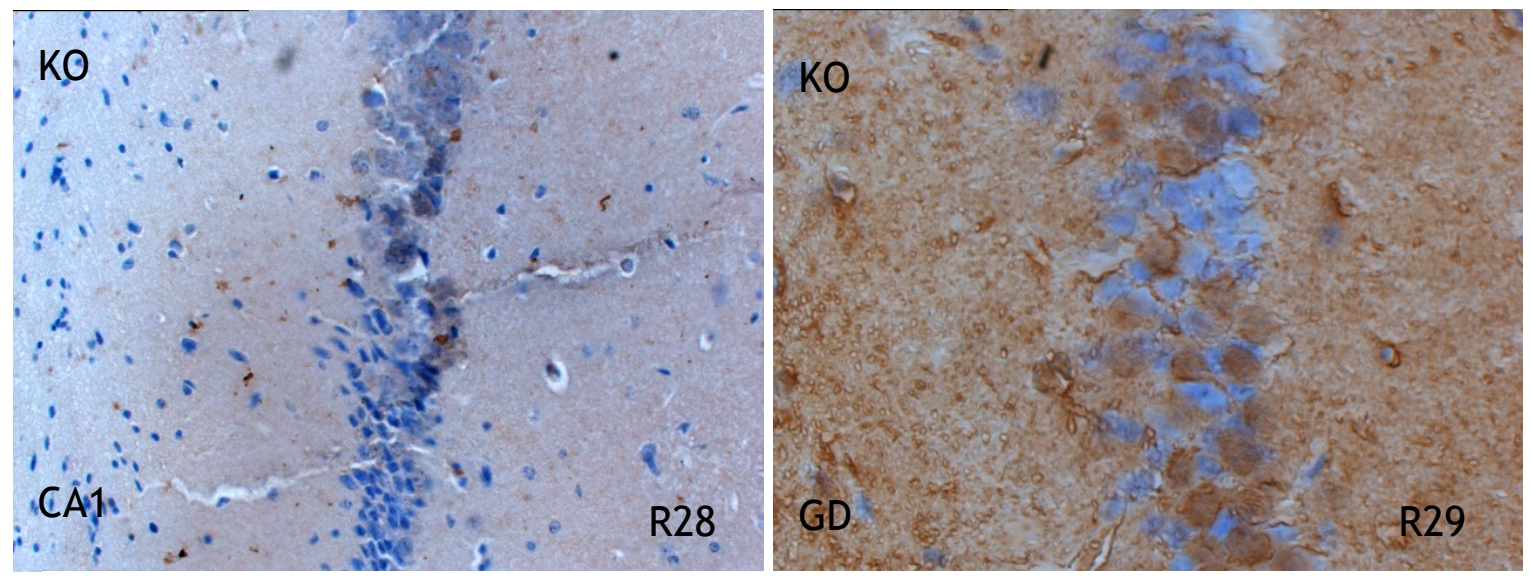

Figuras R28 y R29 Inmunocitoquímica para Tau fosforilada en cerebros knock out. Imágenes tomadas en el hipocampo región 1 del asta de amón (CA1) y giro dentado (GD). 


\section{Análisis post-mortem de la presencia de depósitos de ami- loide y amiloidosis vascular. Tinción de Rojo Congo.}

\section{Animales Wilde Type.}

Al estudiar con la tinción de rojo congo los cerebros de los ratones wilde type, tal y como muestran las imágenes adyacentes correspondientes al giro dentado (Figura R30) y a la corteza entorrinal ( $\mathrm{Fi}$ gura R31), no apareció ningún tipo de tinción, indicativo de la no existencia de amiloidosis o depósitos amiloideos en los cerebros de estos animales.

Figura R30 Imagen panorámica tomada en el giro dentado del cerebro de un ratón wilde type.

En ella se puede apreciar que no existe coloración, lo que sugiere que no hay depósitos amiloides o amiloidosis vascular.
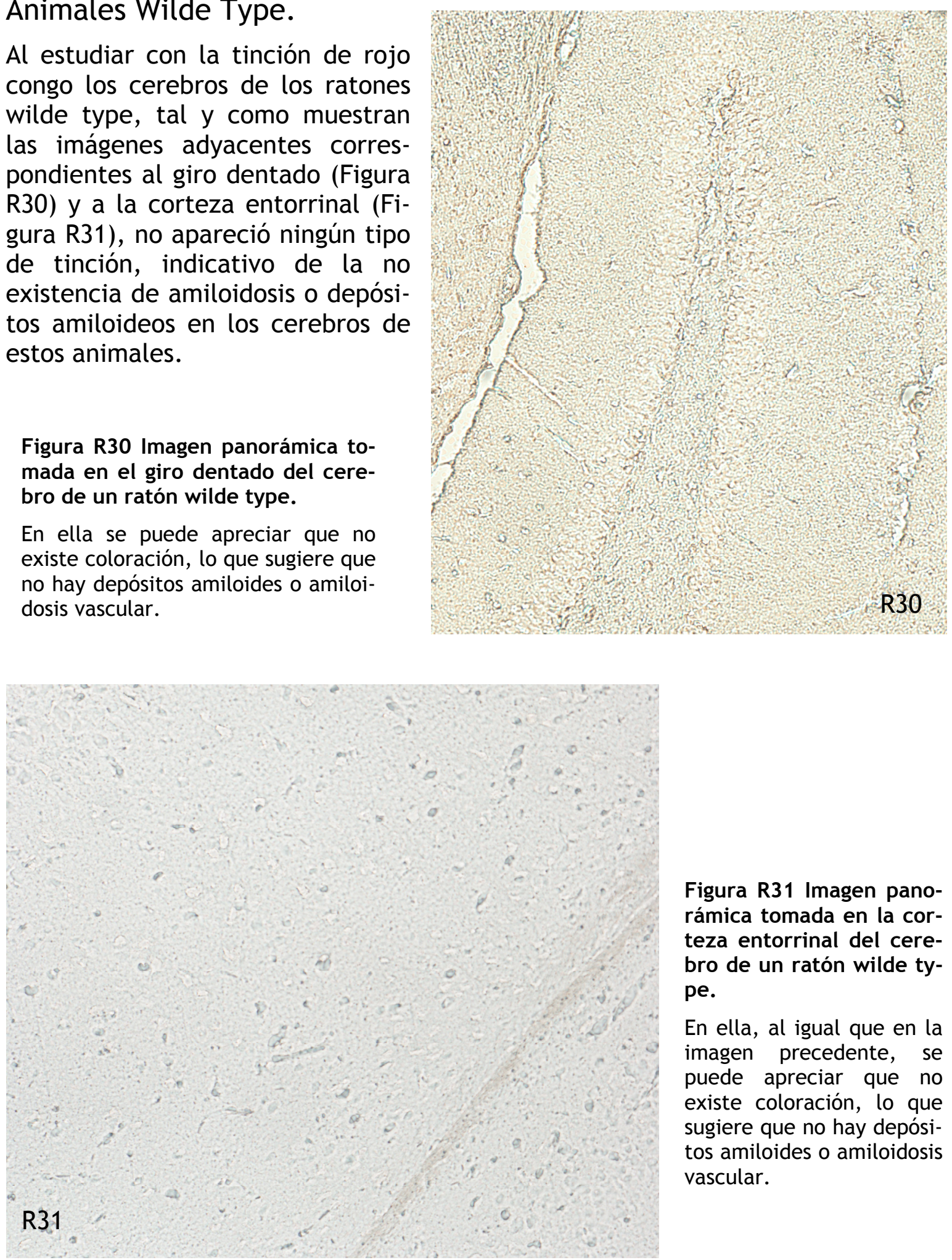

Figura R31 Imagen panorámica tomada en la corteza entorrinal del cerebro de un ratón wilde type.

En ella, al igual que en la imagen precedente, se puede apreciar que no existe coloración, lo que sugiere que no hay depósitos amiloides o amiloidosis vascular. 


\section{Animales Knock Out.}

Loa animales knock out para IRS-2 al contrario que los wilde type, presentaron depósitos de rojo congo distribuidos por diferentes partes del encéfalo. A continuación se muestran las más llamativas.

En el hipocampo aparecieron depósitos de rojo congo que afectaban a la capa granular del giro dentado y a la capa piramidal del asta de Amón, en las regiones CA1, CA2 y CA3 (Figura R32)
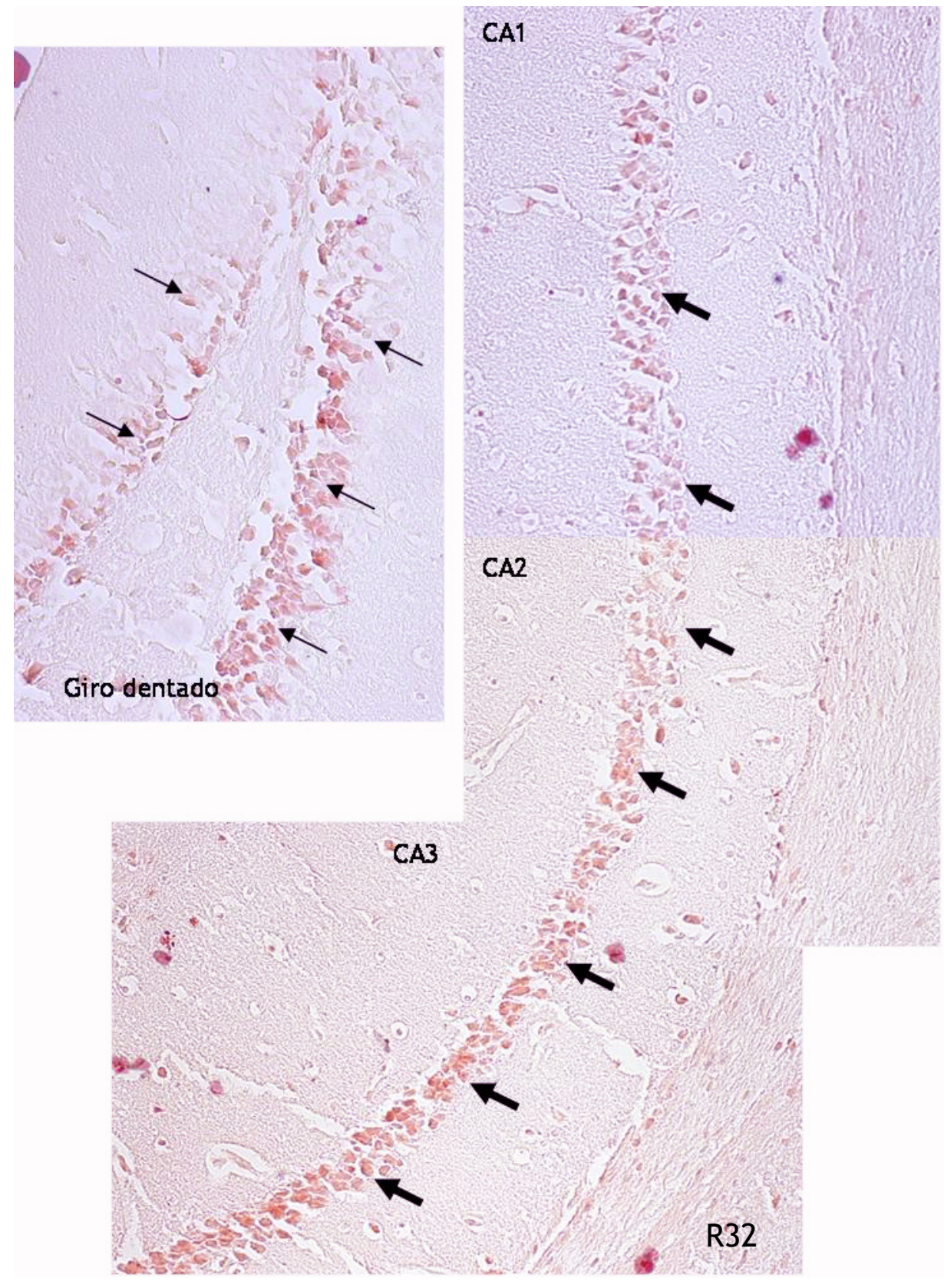

Figura R32 Imagen panorámica tomada en la corteza entorrinal del cerebro de un ratón knock out.

Las imágenes muestran de forma clara la tinción positiva con rojo congo. Apareció de forma principal en la capa granular del giro dentado (flechas finas) y en la capa piramidal del asta de amón, en las regiones CA1, CA2 y CA3 (Flechas gruesas). 
En el lóbulo temporal, la tinción positiva al rojo congo se localizó preferentemente en la corteza ectorrinal (figura R33) y en el complejo amigdalino, afectando a la porción póstero-lateral (figura R34), la región basal lateral (figura R35) y en la pósteroventral (figura R36) de dicho complejo.

Figura R33 Imagen panorámica tomada en la corteza ectorrinal del cerebro de un ratón

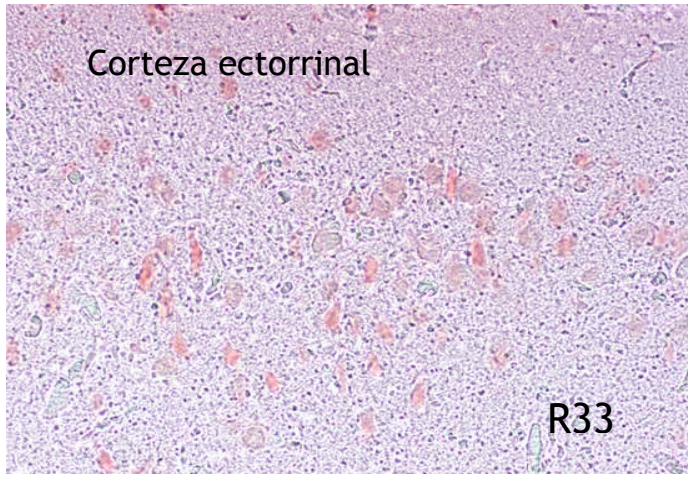
knock out.

La imagen muestra de forma clara la tinción positiva con rojo congo.

En otras regiones de la corteza cerebral se observaron depósitos en la corteza somatosensorial primaria (figura R37), la corteza auditiva (figura R38) y la corteza visual primaria (figura R39).
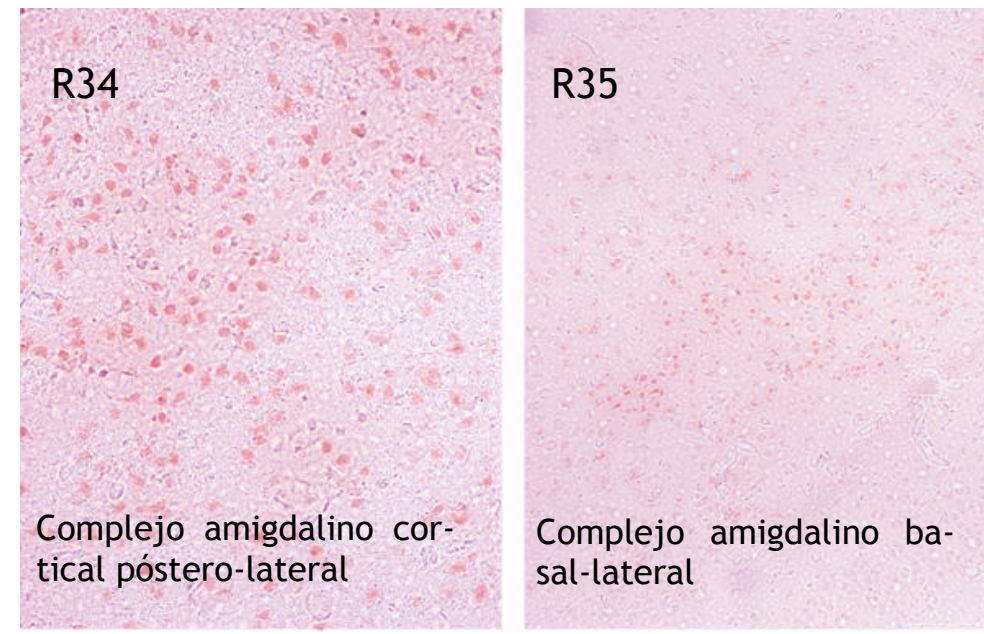

\section{R36}

Núcleo amigdalino medial póstero-ventral

Figuras R34, R35 y R36 Imágenes panorámicas tomadas en el complejo amigdalino del cerebro de un ratón knock out. Las imágenes muestran de forma clara la tinción positiva con rojo congo.
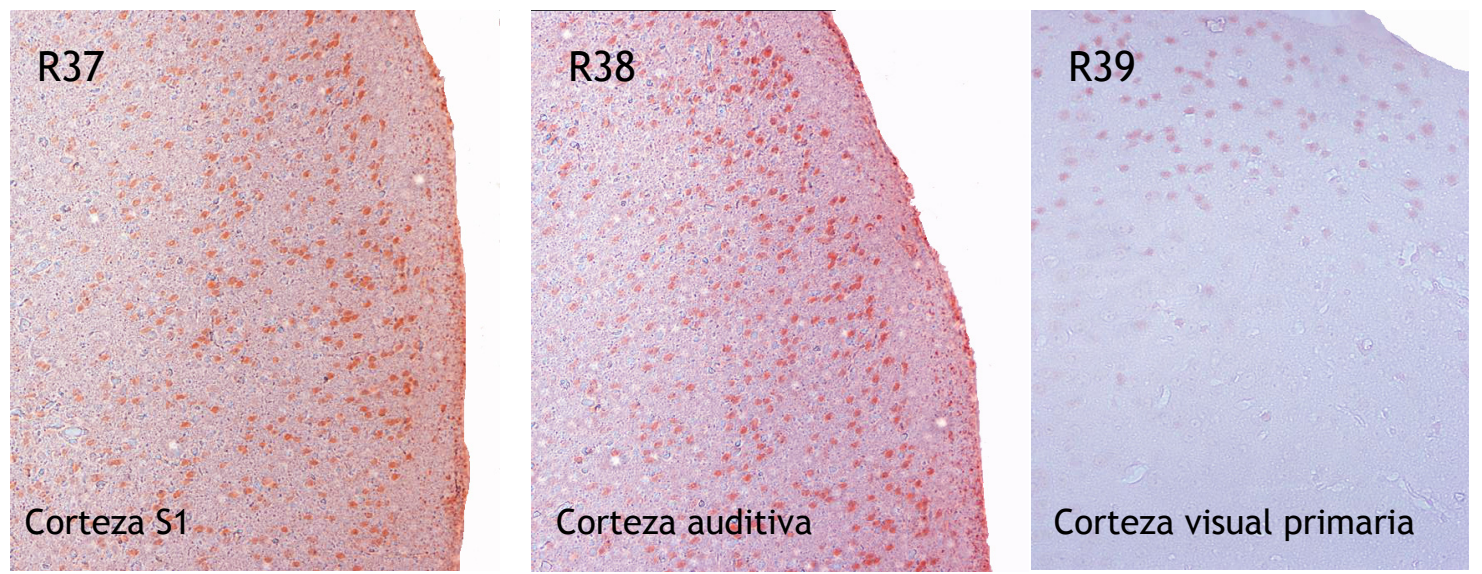

Figuras R37, R38 y R39 Imágenes panorámicas tomadas en diferentes regiones de la corteza cerebral sensitiva. Las imágenes muestran de forma clara la tinción positiva con rojo congo. 


\section{Análisis post-mortem de la presencia de $\beta$-amiloide.}

Puesto que en el cribaje previo con rojo congo detectamos la presencia de tinción positiva en distintas zonas del encéfalo, lo que sugería un proceso degenerativo con depósitos de amiloide, y los resultados de western blotting e inmunocitoquímica hacían presumir una neurodegeneración por hiperfosforilación de Tau, una tauopatía, era lógico presuponer que el proceso neurodegenerativo podría acompañarse de depósitos de $\beta$-amiloide.

Por ello, el siguiente paso en el estudio fue realizar un estudio inmunocitoquímico del encéfalo de los ratones, empleando un anticuerpo anti- $\beta$-amiloide y comparar los resultados obtenidos en los wilde type frente a los knock out para IRS-2.

Realizado el estudio, pudimos comprobar que los ratones knock out para IRS-2 presentaron positividad.

Animales Wilde Type.

Las figuras R40 a R42 muestran una composición de microfotografías tomadas en varias zonas encefálicas de ratones wilde type. En ellas puede observarse la ausencia de reacción inmunocitoquímica a $\beta$-amiloide.
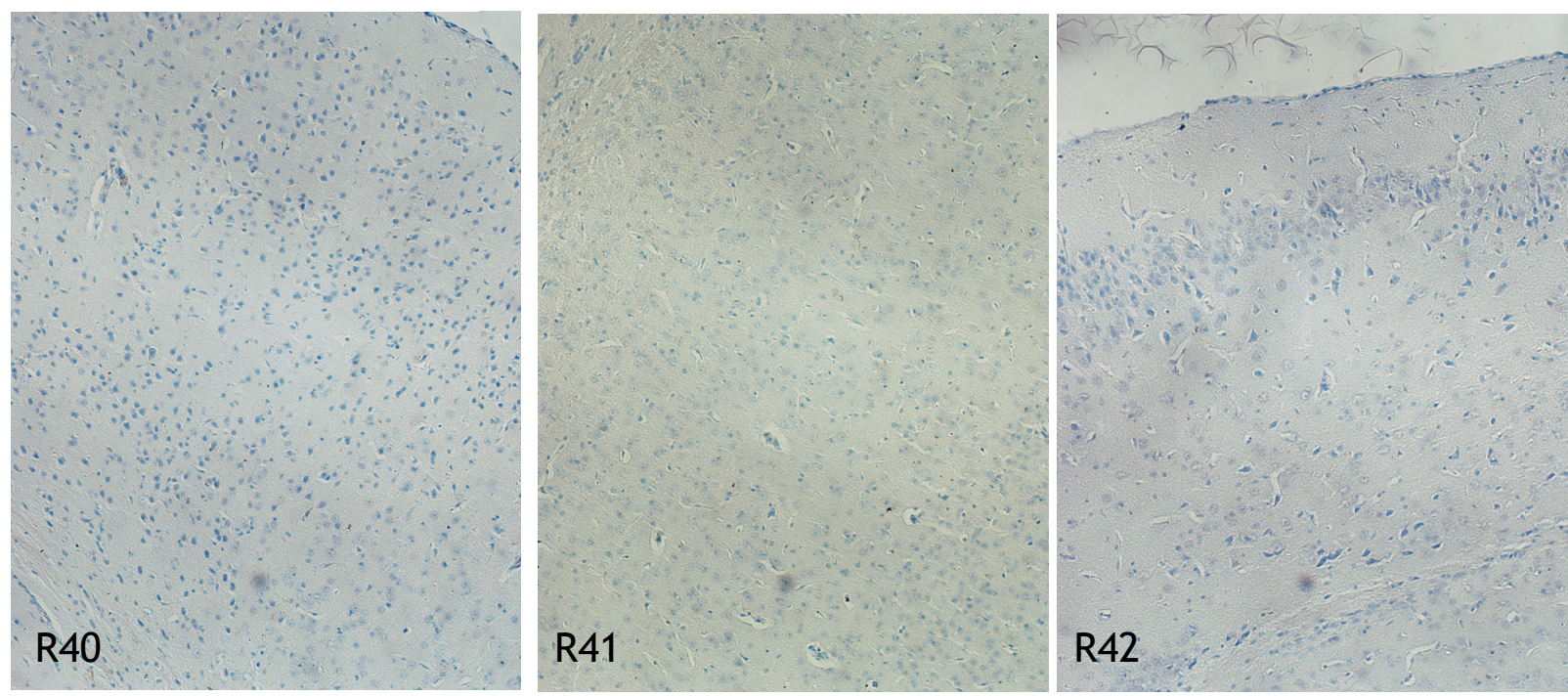

Figuras R40, R41 y R42. Inmunocitoquímica para $\beta$-amiloide en el encéfalo de ratones Wilde type.

R40, corteza motora primaria; R41, corteza somatosensorial primaria; R42, corteza entorrinal. 


\section{Animales Knock Out.}

En los ratones knock out, los depósitos de $\beta$-amiloide detectados mediante inmunocitoquímica afectaron a diferentes zonas encefálicas que iremos exponiendo a continuación de forma detallada.

Los resultados obtenidos al analizar los depósitos de $\beta$-amiloide fueron más selectivos que los encontrados en el estudio con rojo congo. De forma que todas las regiones que presentaron positividad con el rojo congo, mostraron reacción positiva a $\beta$-amiloide, pero además algunas regiones encefálicas en las que fue difícil asegurar positividad para rojo congo, presentaron clara inmunorreactividad a $\beta$-amiloide.

Una de esas regiones fue la zona basal de la corteza frontal que presentó positividad a $\beta$-amiloide, con depósitos en el tubérculo olfativo y en sus proximidades (flechas en la figura R43).

Otra región cortical frontal en la que fue difícil discriminar si había o no positividad a rojo congo, pero que en cambio presentó positividad a $\beta$-amiloide fue el área motora primaria de la corteza frontal.

Como muestran las figuras R44 y R45, la corteza motora primaria de los ratones knock out para IRS-2 presentó depósitos extracelulares (flechas).

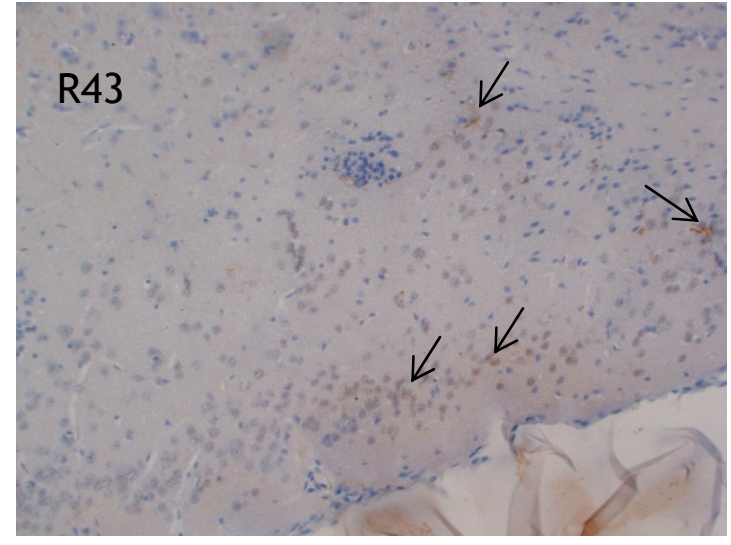

Figura R43 Inmunocitoquímica para $\beta$ amiloide en el tubérculo olfativo de ratones knock out para IRS-2.

Las flechas indican depósitos positivos intra y extracelulares.
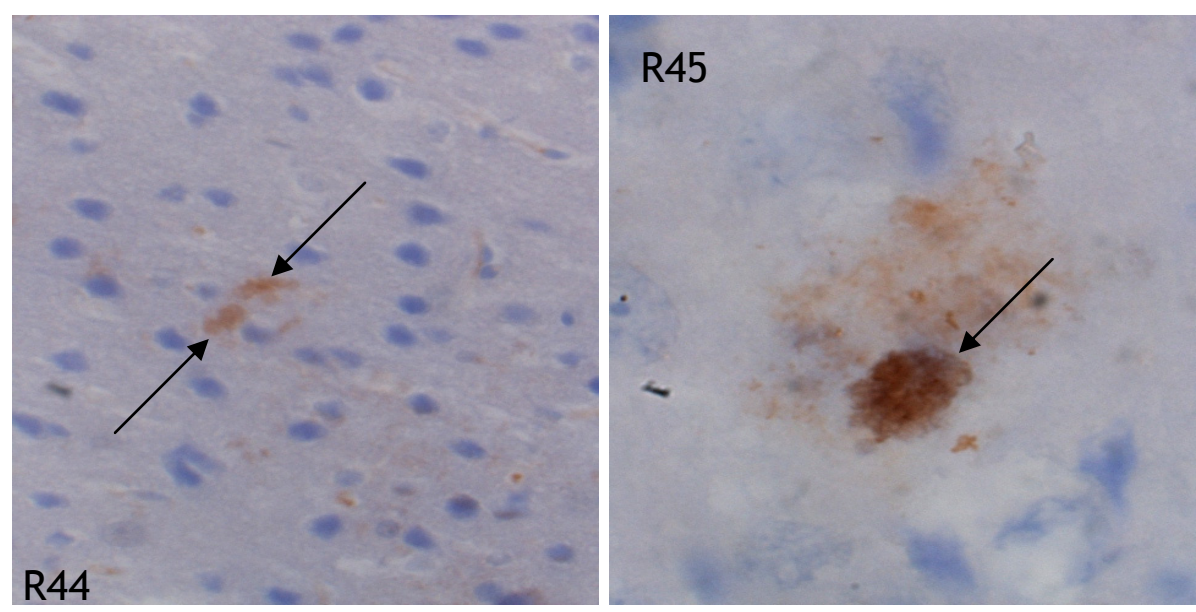

Figuras R44 y R45 Inmunocitoquímica para $\beta$-amiloide en la corteza motora primaria del encéfalo de ratones knock out para IRS-2.

Las flechas señalan los depósitos de $\beta$-amiloide extracelulares. 
Estos animales también presentaron depósitos de $\beta$-amiloide en otras regiones corticales, como la corteza somatosensorial primaria con depósitos extracelulares (flecha en figuras R46 a R48).

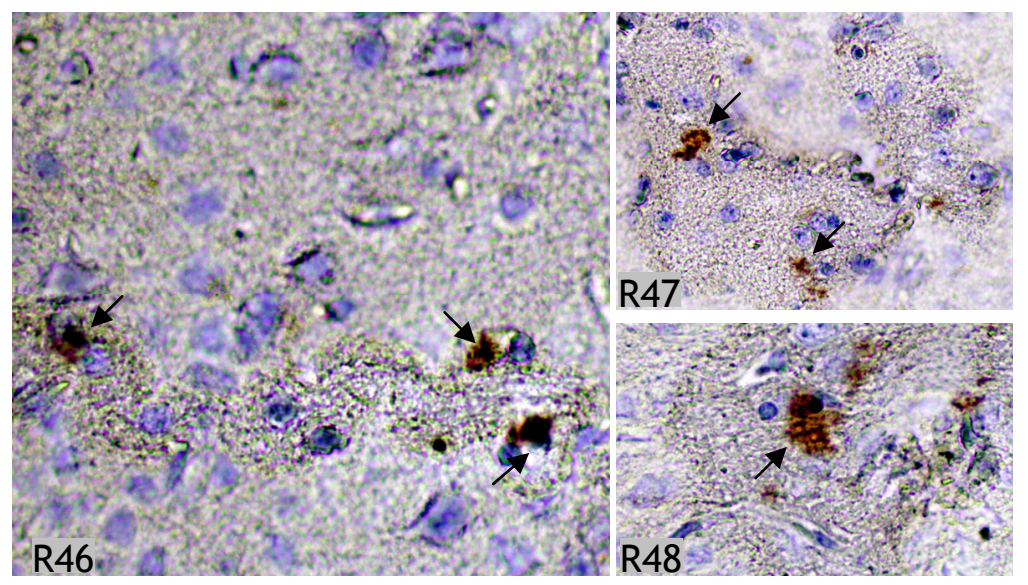

Figuras R46, R47 y R48. Inmunocitoquímica para $\beta$-amiloide en la corteza somatosensorial primaria de ratones knock out para IRS-2.

Las flechas señalan depósitos extracelulares de $\beta$-amiloide.

La corteza somatosensorial secundaria (figuras R49 y R52) con depósitos intra y extracelulares, la corteza piriforme (figura R50) con depósitos generalizados que ocupan regiones enteras de la corteza, la corteza entorrinal (figura R51) con depósitos intensamente reactivos.
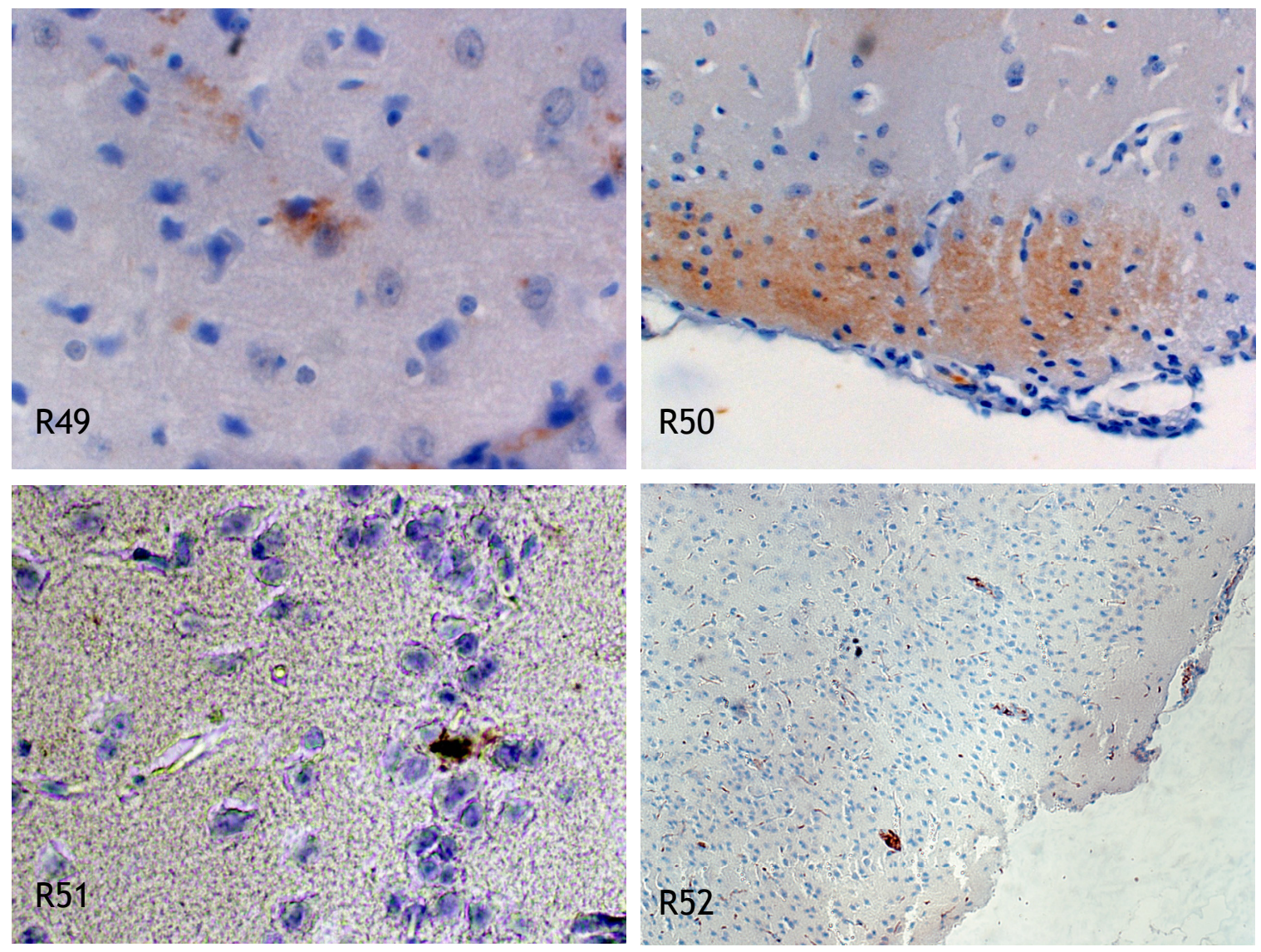

Figuras R49, R50, R51 y R52. Inmunocitoquímica para $\beta$-amiloide en diferentes regiones de la corteza cerebral de ratones knock out para IRS-2. 
En el hipocampo se observaron depósitos en el giro dentado (figura R53) con depósitos extracelulares, en las capas piramidales de las regiones CA1 (figura R54) y CA2 (figura R55), con depósitos intracelulares, y en la capa polimorfa de la región CA3 (figura R56) en la que los depósitos eran principalmente extracelulares.
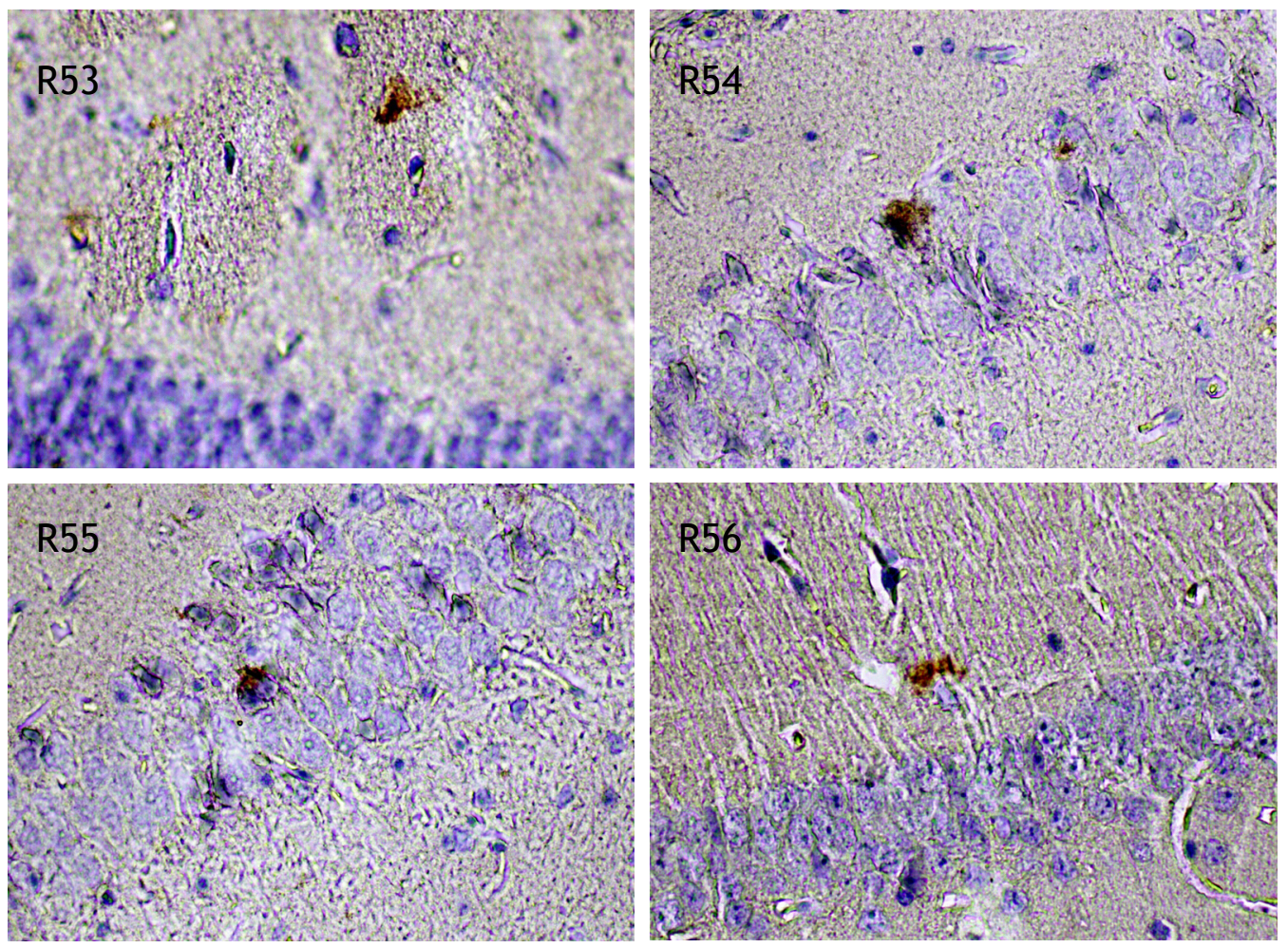

Figuras R53, R54, R55 y R56. Inmunocitoquímica para $\beta$-amiloide en diferentes regiones del hipocampo de ratones knock out para IRS-2.

Otras dos regiones que presentaron inmunorreactividad a $\beta$-amiloide fueron la región póstero-lateral del complejo amigdalino (figura R57), y en ganglios basales, en el caudado-putamen (figura R58).
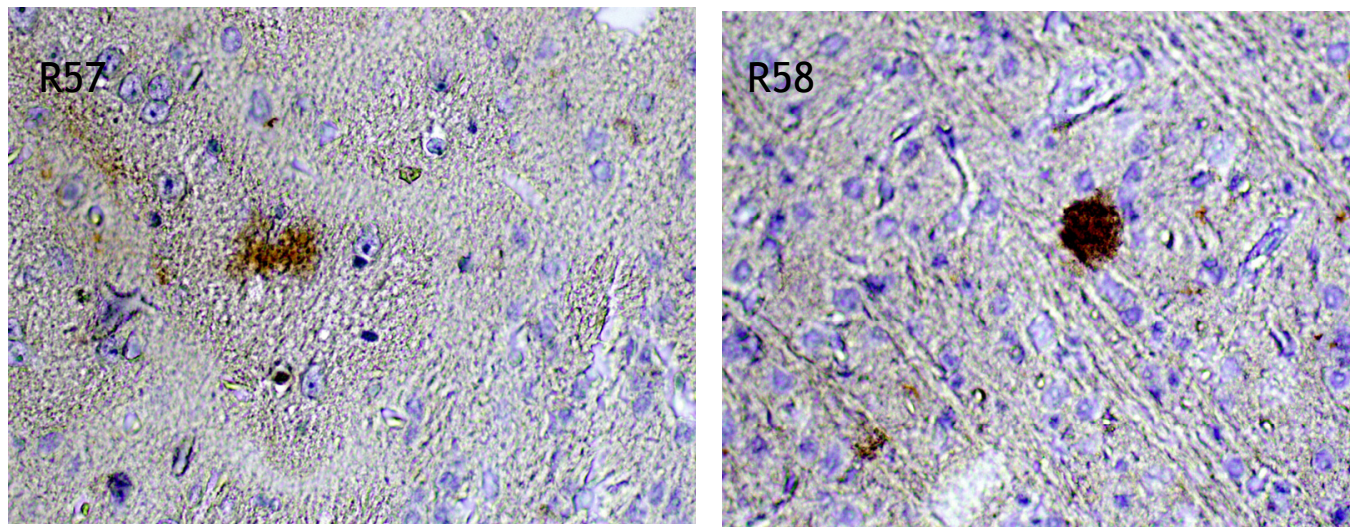

Figuras R57 y R58. Inmunocitoquímica para $\beta$-amiloide en la región póstero-lateral del complejo amigdalino (R57) y en el caudado-putamen de ratones knock out para IRS-2 (R58). 
En los ratones knock out para IRS-2 que presentaron hidrocefalia, que describiremos a continuación, se detectó la presencia de $\beta$-amiloide perivascular en los plexos coroideos del agujero de Monro (figura R59).

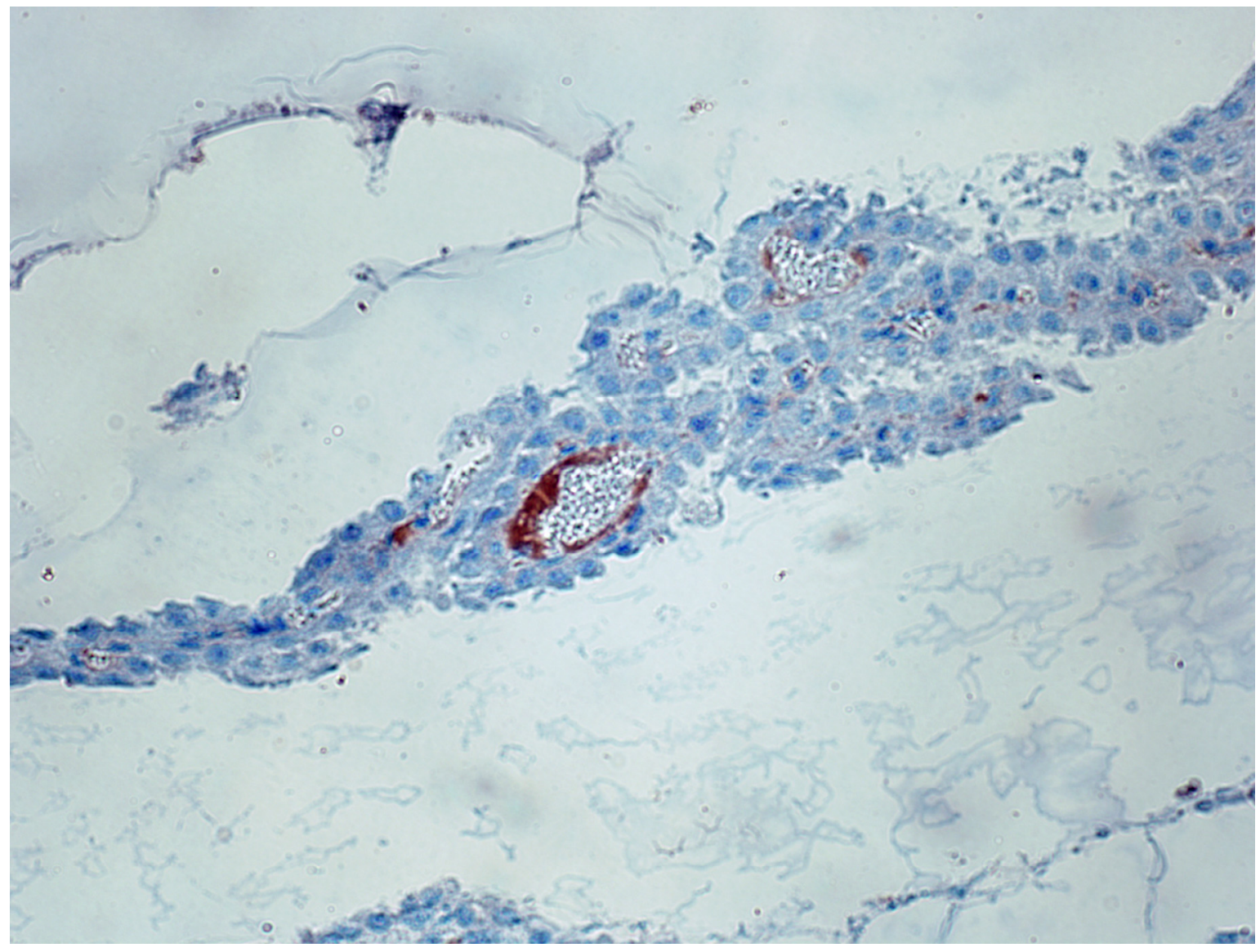

Figuras R59. Inmunocitoquímica para $\beta$-amiloide en animales hidrocefálicos.

En estos animales, se observó mediante inmunocitoquímica depósitos de $\beta$-amiloide perivascular en los plexos coroideos del agujero interventricular de Monro. 


\section{Análisis post-mortem de la dilatación ventricular. Estudio histológico.}

Cinco de los ratones knock out para IRS-2 estudiados presentaron una clara hidrocefalia en el momento de su sacrificio, con un vertido ostensible de líquido cefalorraquídeo en el momento de la apertura del cráneo.

Ratones wilde type.

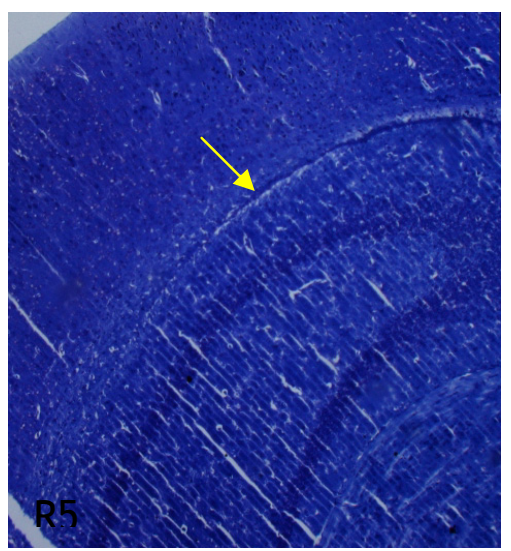

Como era de esperar, en estos animales, la tinción con violeta de cresilo no puso de manifiesto ninguna alteración llamativa en el interior de los ventrículos cerebrales, que presentaban paredes ependimarias muy próximas entre sí, tal y como se muestra en la figura R60.

Figura R60. ventrículo lateral en la prolongación téporo-parietal, violeta de cresilo.

La flecha señala la hendidura ventricular

\section{Ratones knock out.}

El estudio histológico permitió comprobar la existencia de variaciones considerables en el tamaño de los ventrículos cerebrales al comparar los animales wilde type con los knock out. Las variaciones más notables, morfológicas y morfométricas, aparecieron en el acueducto mesencefálico o de Silvio, el ventrículo medio y los ventrículos laterales. Afectando también a las cisternas meníngeas. La figura R61 muestra la dilatación del acueducto de Silvio de uno de estos animales.
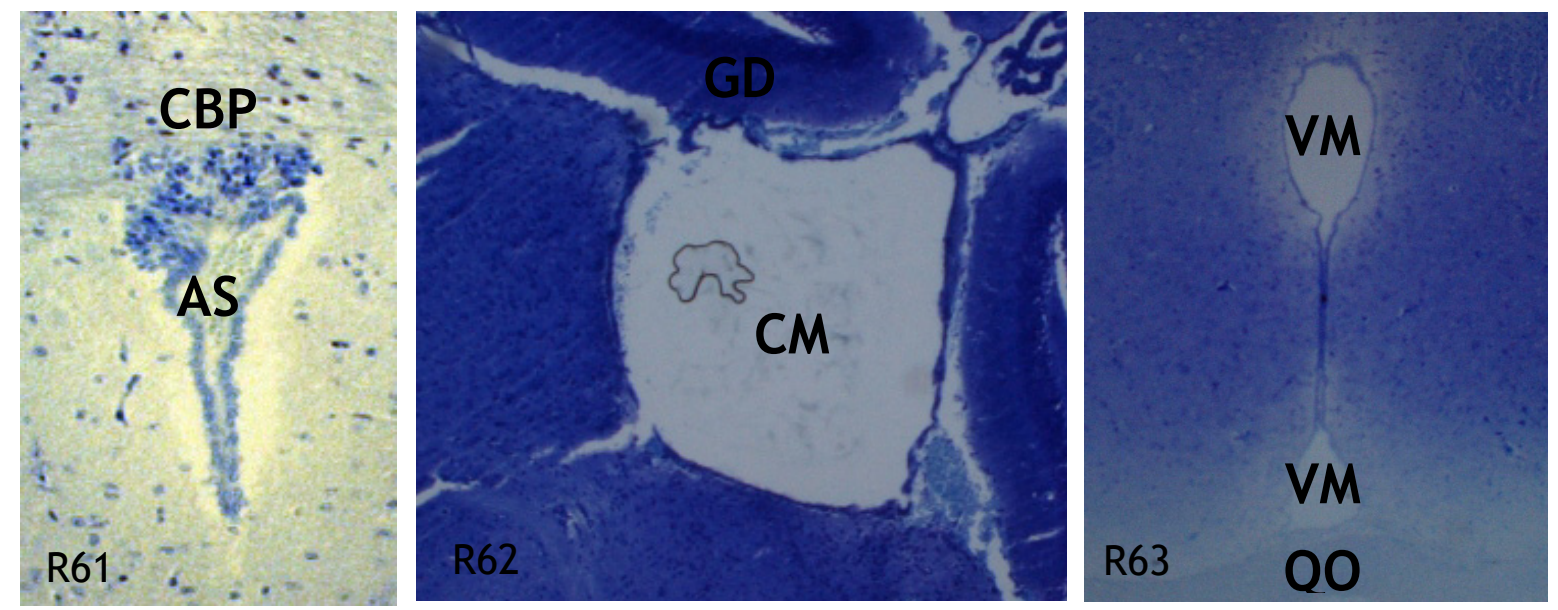

Figura R61. Acueducto de Silvio. Figura R62 Cisterna magna. Figura R63 Ventrículo medio. Las micrografías fueron obtenidas en cerebros de ratones knock out para IRS-2 que presentaban hidrocefalia manifiesta.

CBP: comisura blanca posterior, AS: acueducto de SIlvio, CM: cisterna magna, GD: giro dentado, VM: ventrículo medio, QO: quiasma óptico. 
La figura R62 muestra la cisterna magna de uno de estos animales, considerablemente dilatada.

La figura R63 muestra el ventrículo medio o tercer ventrículo de un ratón knock out, también con una dilatación considerable. La observación de una dilatación no homogénea de este ventrículo nos hizo considerar diferentes diámetros dorsoventrales para realizar el estudio morfométrico del ventrículo en las imágenes de resonancia magnética de los animales que no presentaban hidrocefalia manifiesta.

Las dilataciones más importantes se observaron en los ventrículos laterales, si bien es de resaltar que fue en estos ventrículos en donde aparecieron mayores variaciones de unos ratones a otros.

La figura R64 muestra el patrón de dilatación ventricular observado en la comunicación interventricular (agujero de Monro) entre el ventrículo medio y los ventrículos laterales, en la localización estereotáxica c.

La dilatación ventricular llega a hacer que las estructuras neuroanatómicas, como el fórnix, que se aprecia claramente en la figura R64, pierdan su normal disposición y relaciones.
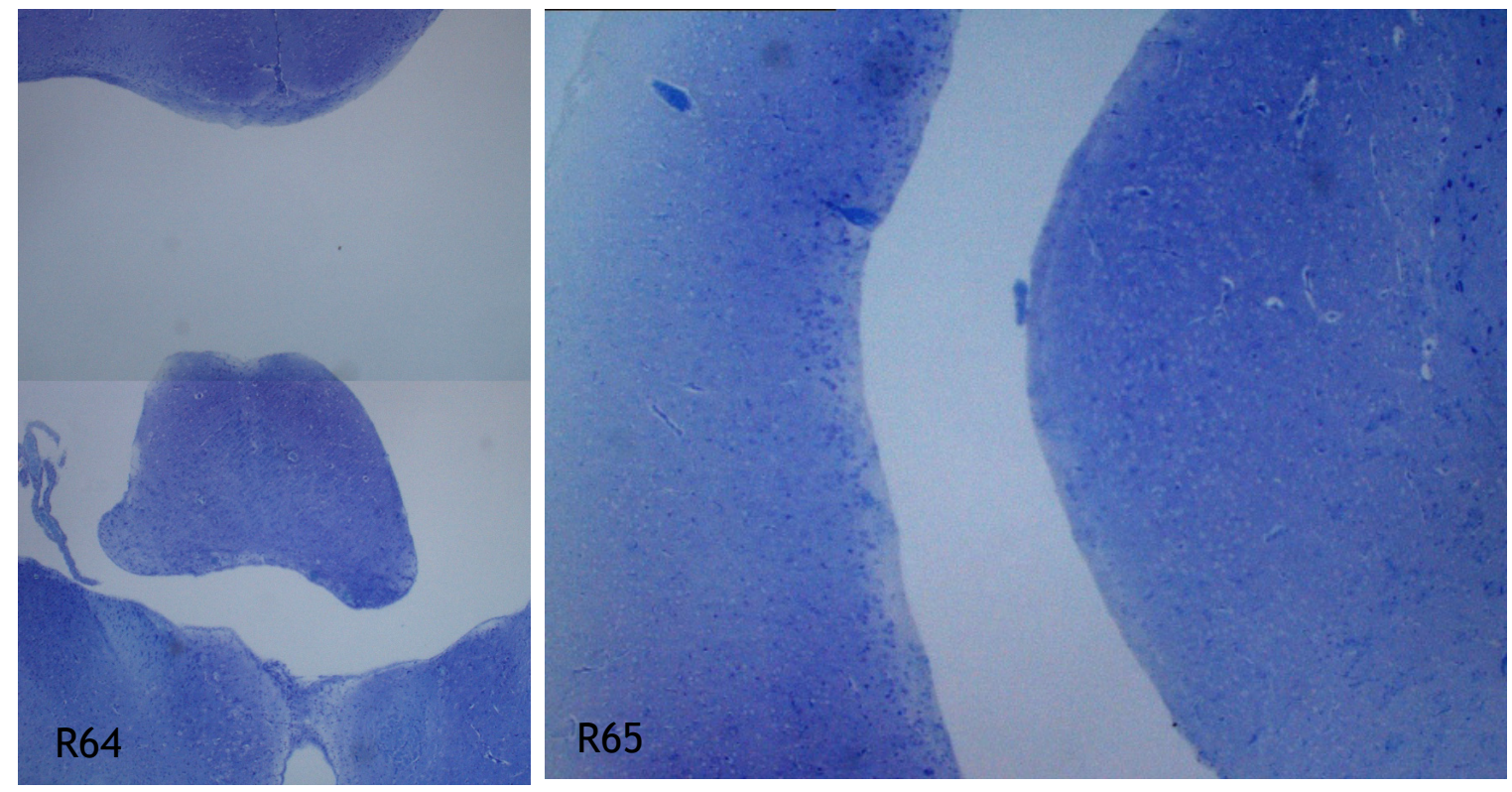

Figura R64. Comunicación interventricular o agujero de Monro, violeta de cresilo. Figura R65. Ventrículo lateral en la prolongación témporo-parietal, violeta de cresilo.

La figura R65 muestra el ventrículo lateral distendido en su prolongación témporo-parietal.

La gran dilatación de los ventrículos laterales se puede observar en la composición de micrografías que se presenta como figura R66, en la que se compara, señalando con flechas, la dilatación del ventrículo lateral en los ratones knock out (KO) frente a los wilde type (WT). Esta imagen es un claro exponente de como, tras la necropsia, el estudio histológico demostró la gran dilatación ventricular. 

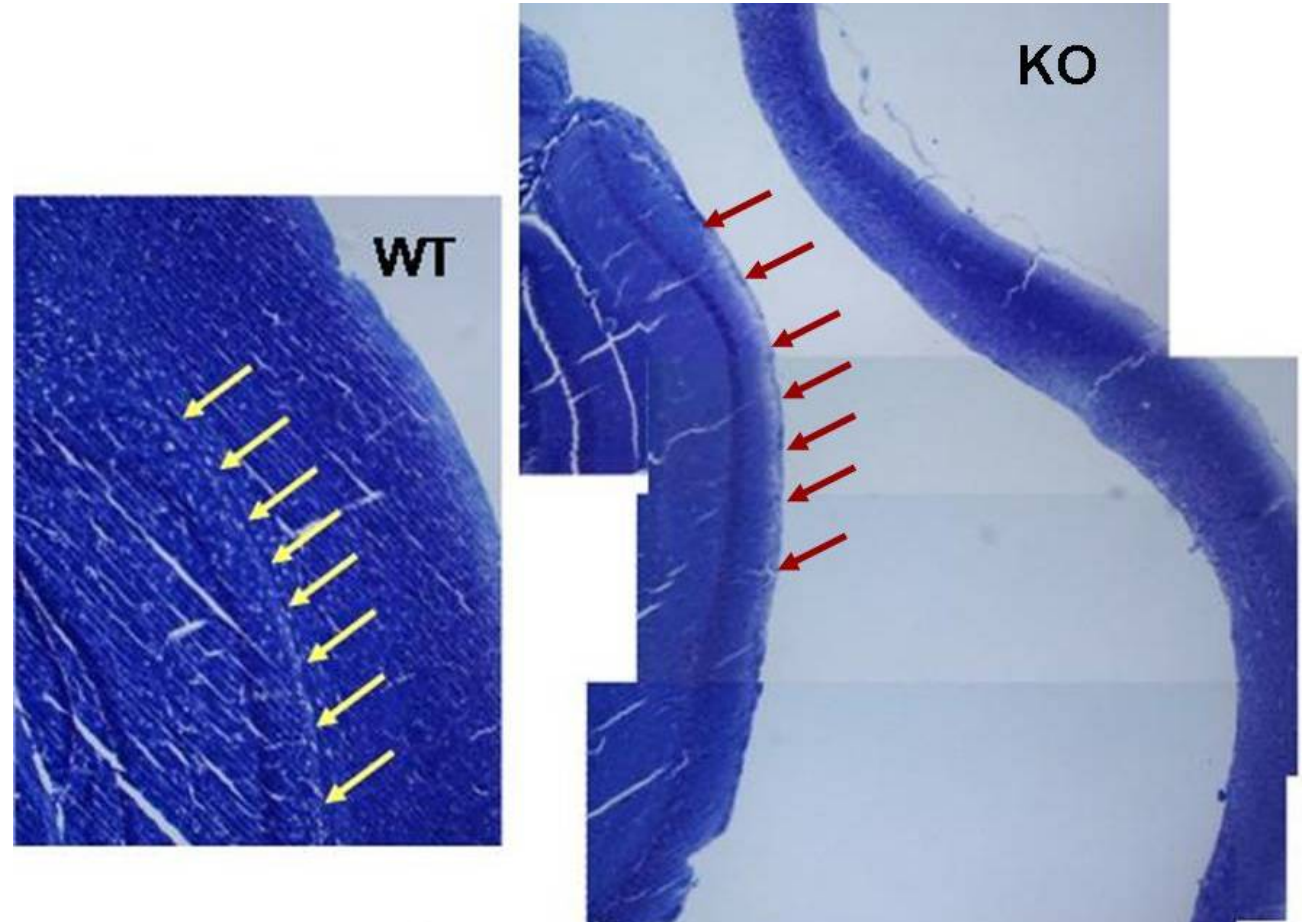

R66

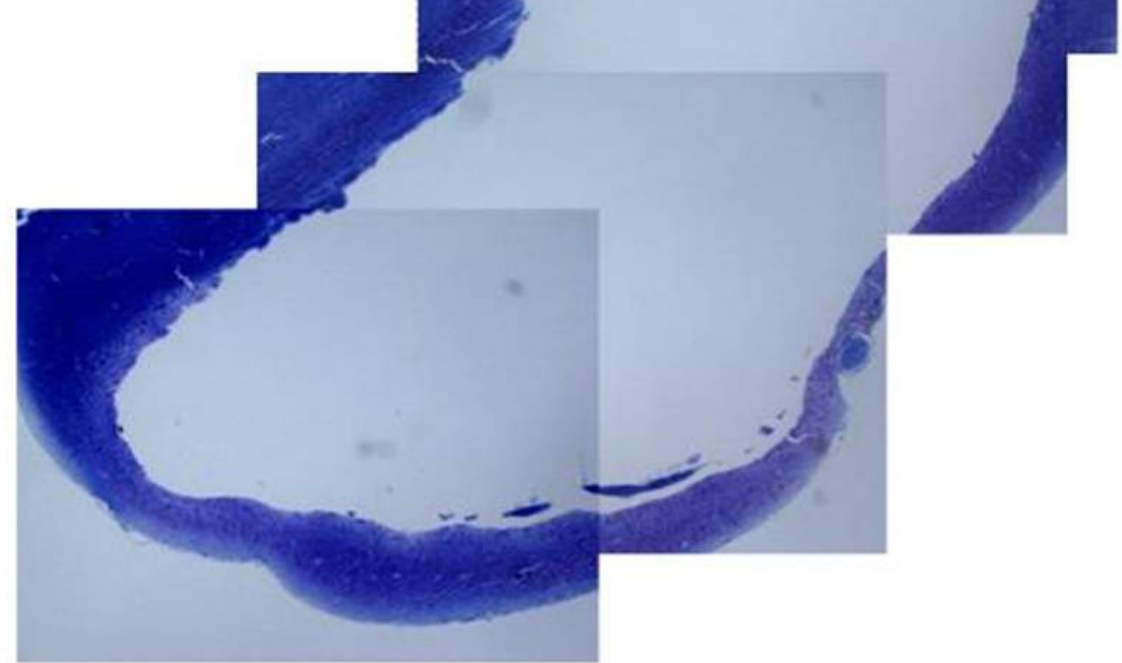

Figura R66. Tinción de violeta de cresilo realizada sobre cortes frontales del cerebro en la región $c$.

Permite comparar la gran dilatación ventricular observada en los ratones knock out para IRS-2 (KO) que presentaron hidrocefalia frente a los wilde type (WT).

Puesto que estos animales se salían de la norma, representaban un 10\% de los animales estudiados y no pertenecían al grupo de animales estudiados con resonancia magnética, fueron considerados para el estudio histológico como un grupo aparte y sus encéfalos no se consideraron para el estudio morfométrico, ya que como podrá comprobarse más adelante las variaciones del tamaño ventricular fueron más que evidentes. 


\section{Análisis postmortem de la reacción glial en los ratones Knock Out hidrocefálicos.}

La extrema delgadez del tejido nervioso y del neuropilo de la corteza cerebral y el tálamo y ganglios basales en las regiones próximas a los ventrículos dilatados, que se han mostrado en el apartado anterior, sugería que junto a un proceso neurodegenerativo se estuviera induciendo un proceso de tipo inflamatorio por la hipertensión endocraneal causada por la hidrocefalia.

Para comprobar las reacciones que se producían indagamos la existencia o no de una gliosis reactiva mediada por astrocitos.

Para ello, a estos animales se les realizó un estudio inmunocitoquímico para la proteína fibrilar glial ácida (GFAP).

Tras realizar este studio, se comprobó que la encrucijada entre el ventrículo medio y el ventrículo lateral mostró un claro aumento de positividad a GFAP en el tálamo y, aún mayor en la estría medular; como demuestran las figuras R67 y R68, respectivamente.
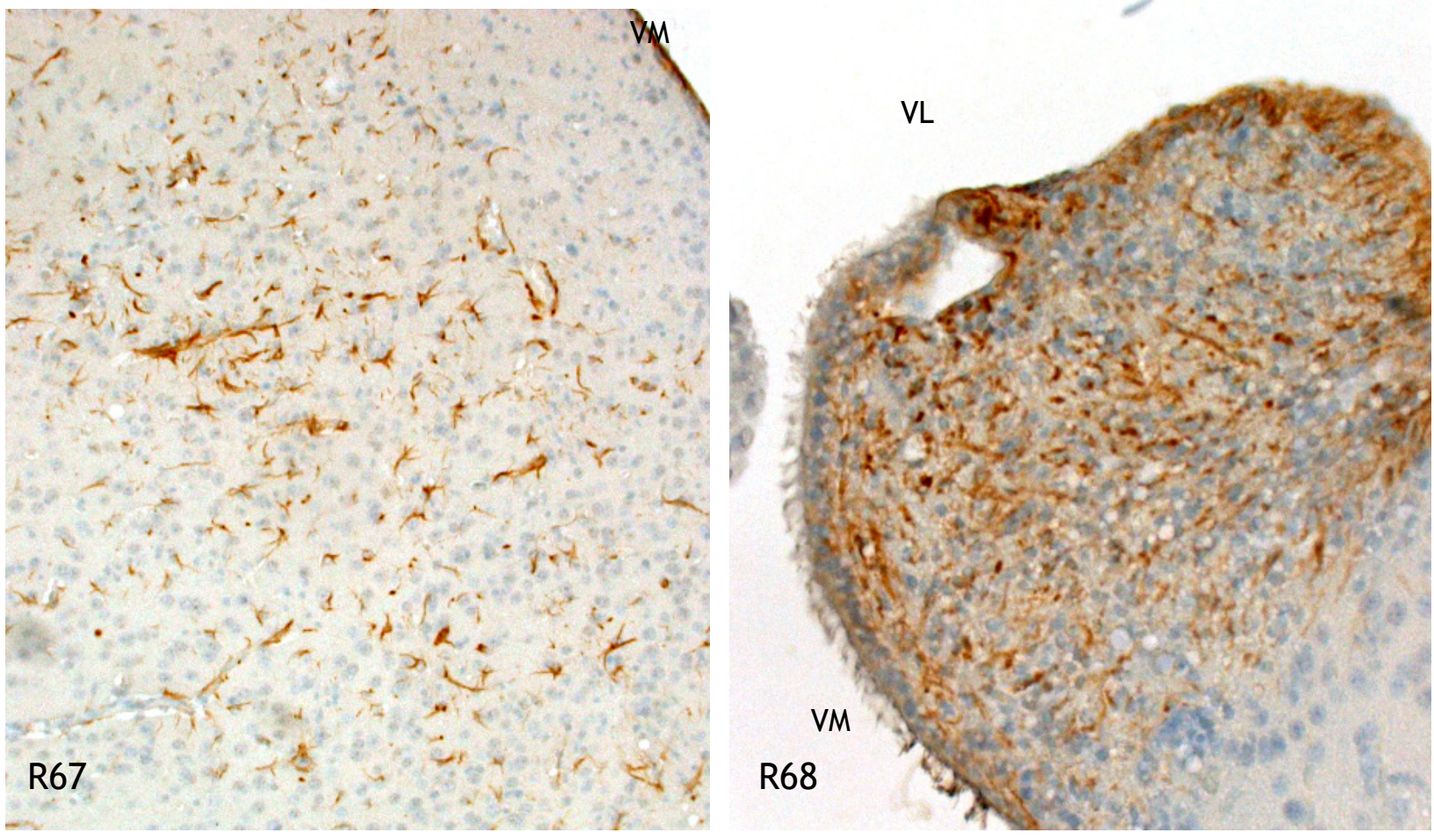

Figuras R67 y R68. Micrografías obtenidas del tálamo (R67) y de la estría medular (R68) en animales knock out para IRS-2 tras la detección inmunocitoquímica de GFAP.

VM: ventrículo medio, VL: ventrículo lateral 
Lo mismo ocurrió al analizar la porción basal del ventrículo lateral (figura R69) o la corteza ectorrinal, zona más adelgazada de la corteza cerebral (figura R70).
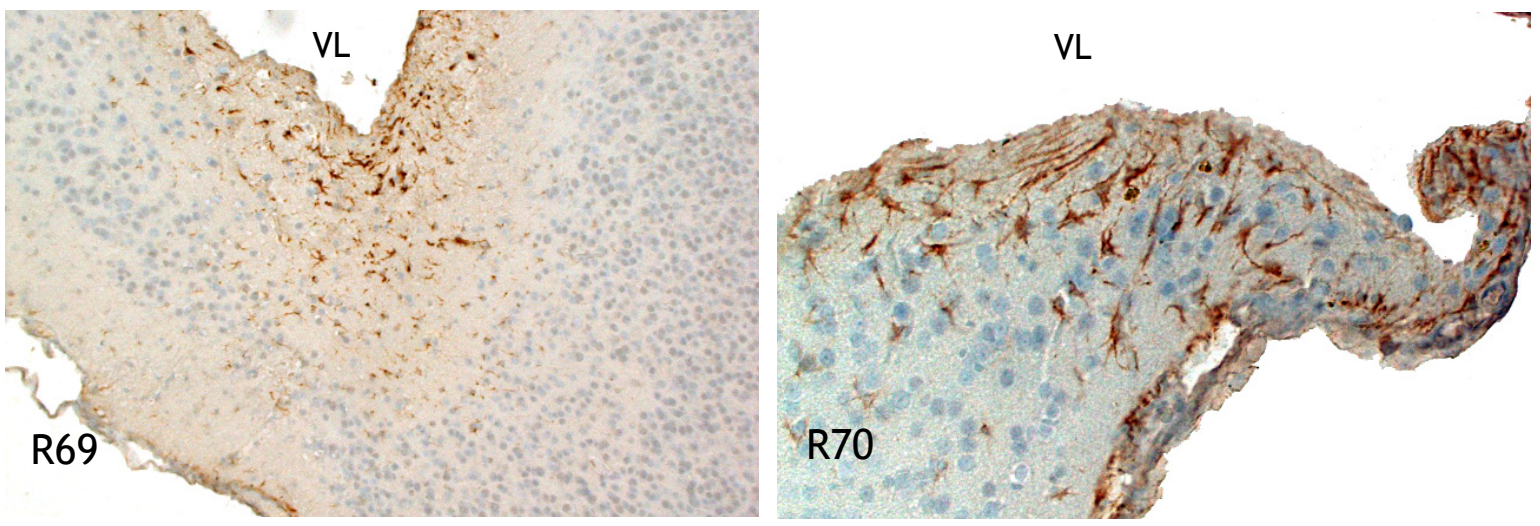

Figura R69 y R70. Inmunocitoquímica para GFAP en la porción basal del neuropilo adyacente al ventrículo lateral y en la porción más atrofiada y adelgazada de la corteza cerebral, la coretza entorrinal e insular.

$\mathrm{VL}$ : ventrículo lateral.

Un detalle que llamó poderosamente la atención fue la aparición de gliosis reactiva en el hipocampo de estos animales, en zonas que no estaban próximas a ningún ventrículo cerebral, como muestran las figuras R71.

La figura R72 muestra la gliosis reactiva en el hipocampo de un ratón knock out que no presentó hidrocefalia.

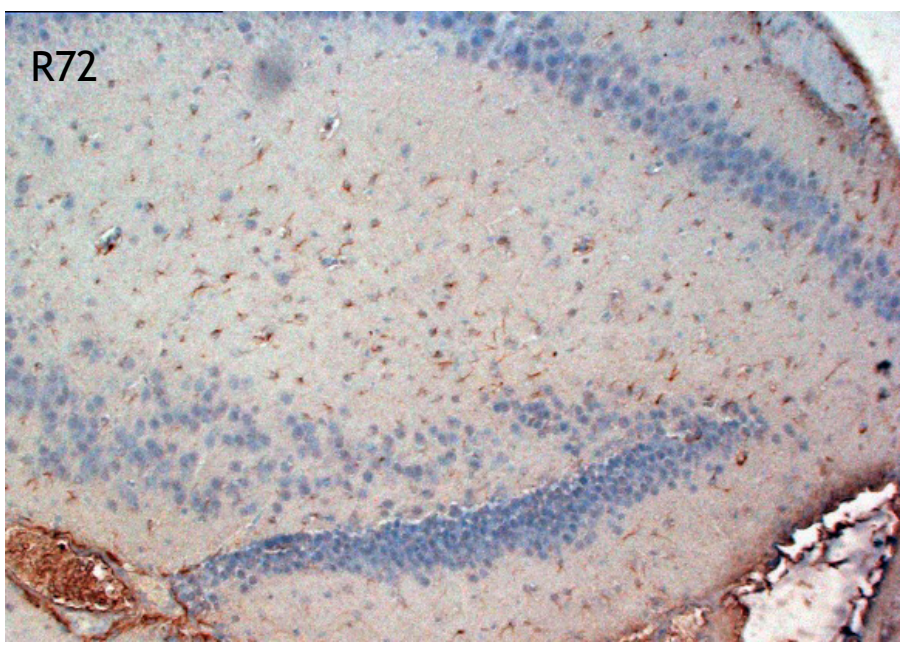

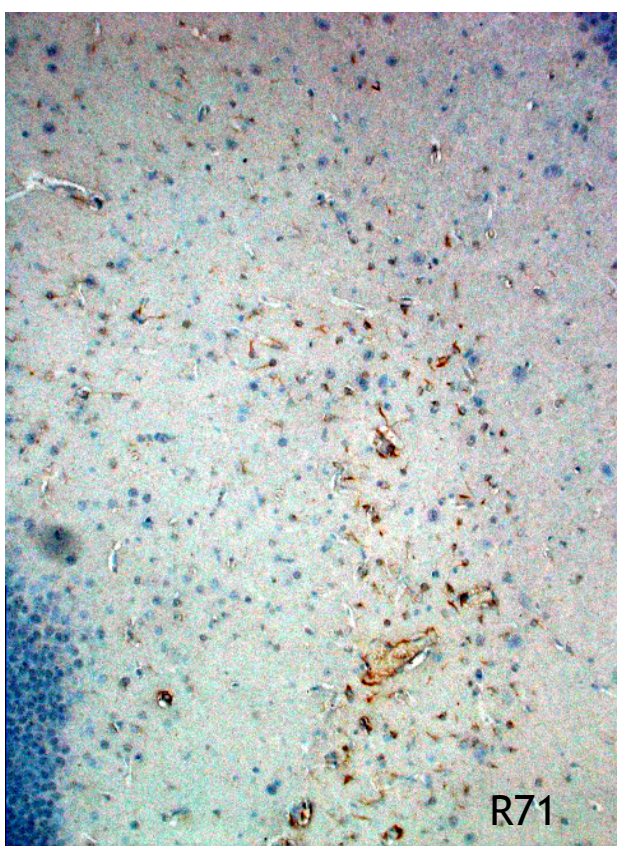

Figuras R71 y R72. Reacción inmunocitoquímica a GFAP en el hipocampo de los animales knock out a IRS-2. 


\section{Estudio morfométrico histológico del Hipocampo.}

En el estudio morfométrico de los grosores corticales, se han excluido todos los ratones que presentaban hidrocefalia severa, para evitar posibles efectos derivados de la hipertensión endocraneal.

Tras realizar el análisis del grosor del giro dentado, se comprobó que los ratones knock out para IRS-2 (figura R74) presentaron un grosor total significativamente menor $(p<0.01)$ al observado en los wilde type (figura R73), estos hallazgos como puede comprobarse en la figura R75 afectaron de forma semejante a la porción dorsal y a la porción ventral del giro dentado.
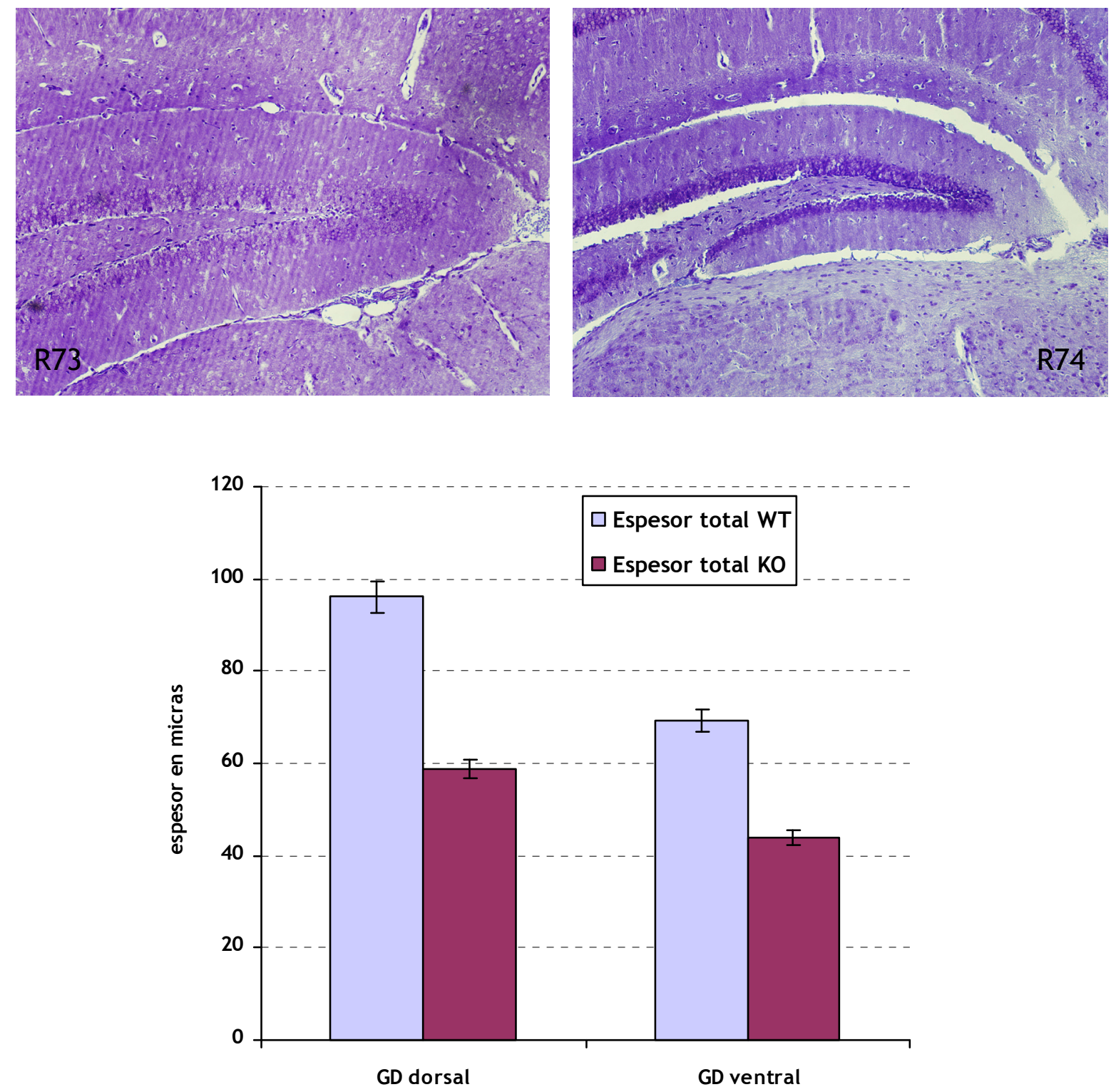

Figuras R73 a R75. Giro dentado.

R73, giro dentado de un ratón wilde type. R74, giro dentado de un ratón knock out para IRS-2. R75, Gráfica que muestra las diferencias observadas al analizar el grosor de las dos partes del giro dentado en los ratones estudiados. 
De forma semejante a lo que ocurrió en el giro dentado, al analizar sucesivamente cada una de las regiones del asta de Amón, se comprobó que en los ratones knock out para IRS-2 los grosores fueron significativamente menores $(p<0.01)$ en todas las zonas analizadas en esta estructura: CA1, CA2 y CA3 (figuras R76 a R80).
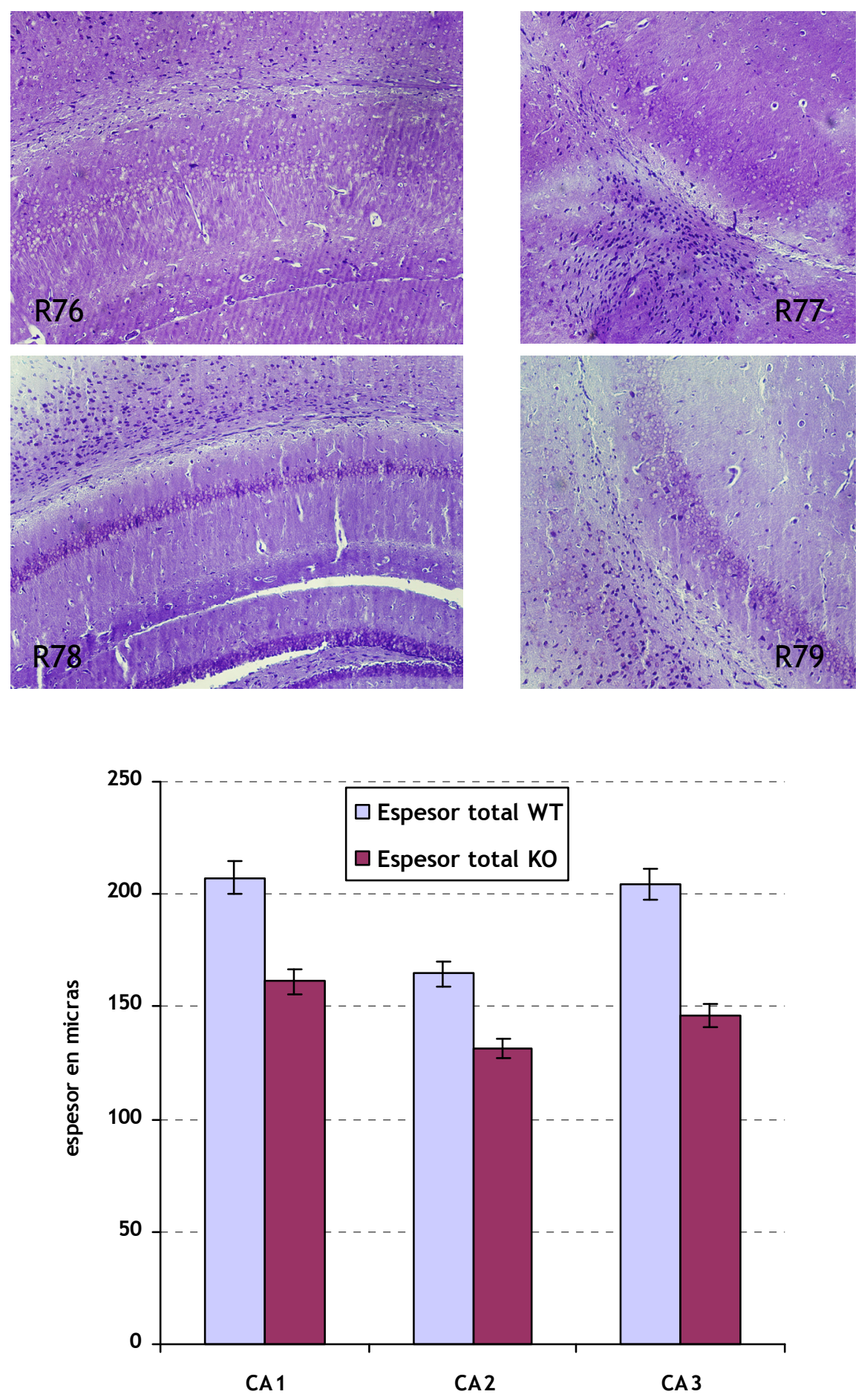

Figuras R76 a R80. Asta de Amón.

R76: CA1 de un ratón wilde type. R77: CA2 de un ratón wilde type. R78: CA1 de un ratón knock out para IRS-2. R79: CA2 de un ratón knock out para IRS-2. R80: Gráfica que muestra las diferencias observadas al analizar el grosor de CA1, CA2 y CA3. 
Considerando sólo el estrato piramidal (capa de células piramidales), estrato plexiforme en la región CA3, de las diferentes regiones del hipocampo analizadas, en todas, el grosor de dicho estrato fue siempre significativamente menor $(p<0.01)$ en los hipocampos de los ratones knock out para IRS-2 que en de los ratones wilde type (figura R81).

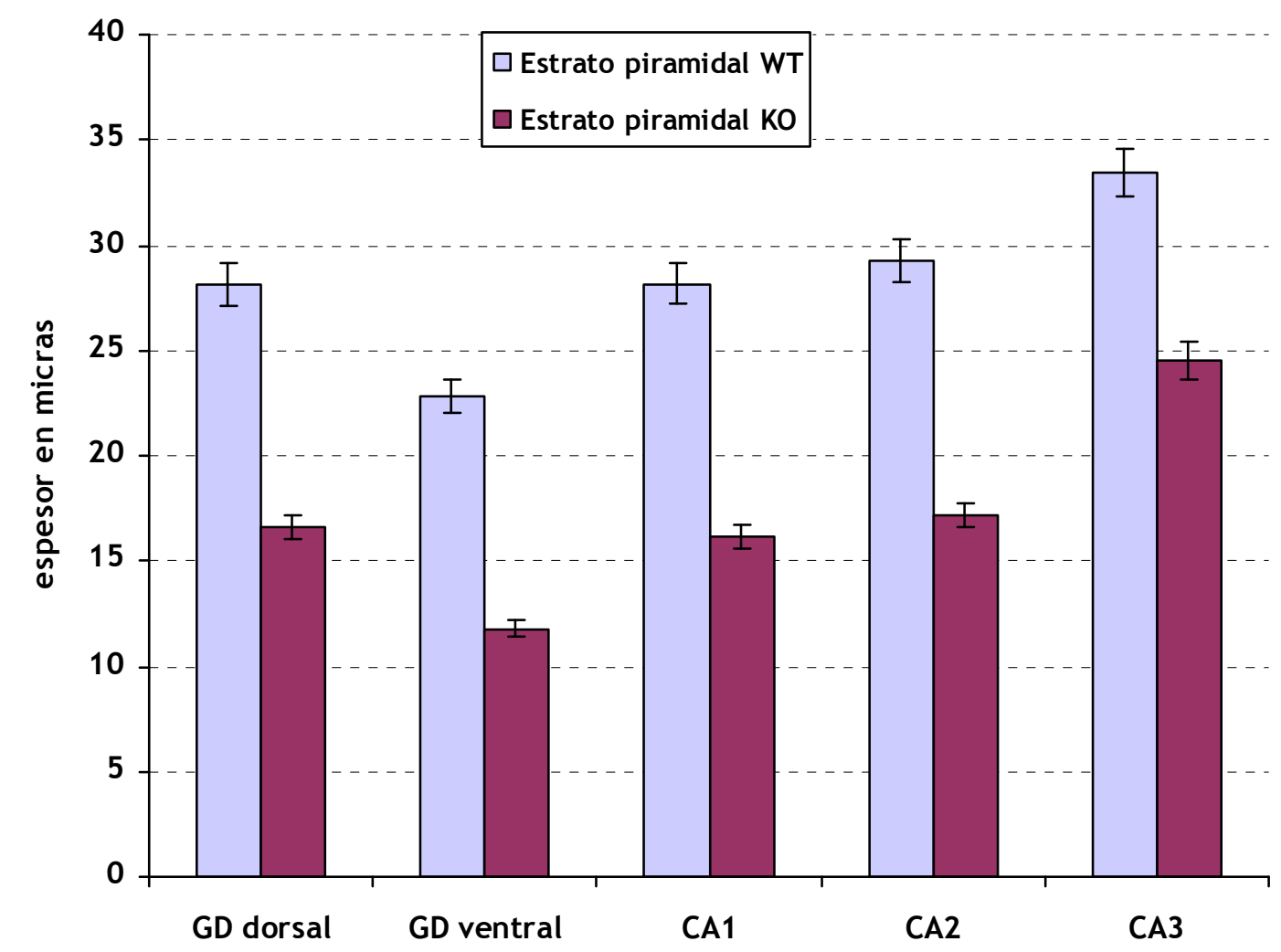

Figura R81. Gráfica que resume el espesor, expresados en micras, del estrato piramidal en las diferentes regiones del hipocampo analizadas: GD, giro dentado; Asta de Amón: CA1, CA2 y CA3 (estrato plexiforme).

\section{Estudio morfométrico histológico de la Corteza Entorrinal.}

Al analizar el espesor de la corteza entorrinal, se comprobó que dicho espesor fue significativamente menor $(p<0.05)$ en los ratones knock out para IRS-2 que en los ratones wilde type (figura R82).

Figura R82. Gráfica que muestra los valores encontrados al analizar el espesor (em micras) de la corteza entorrinal.

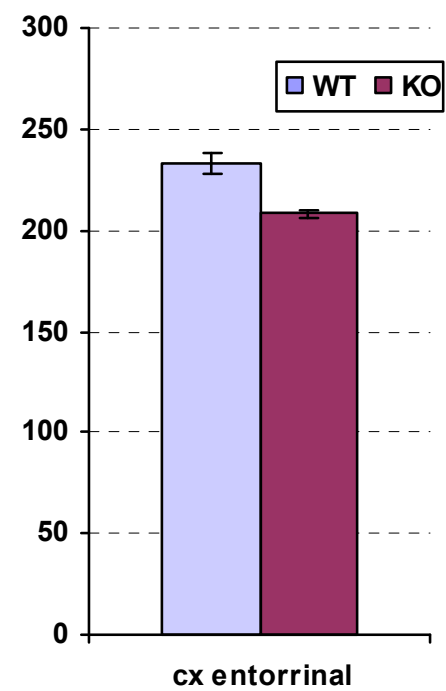




\section{Estudio in vivo con Resonancia Magnética.}

\section{Tamaño ventricular}

\section{Secciones coronales.}

\section{Cuarto ventrículo.}

Como puede apreciarse en las figuras R83 y R84, correspondientes a resonancias magnéticas de cortes coronales de la protuberancia, y en la figura R85, gráfica que resume los valores morfométricos de las áreas, en milímetros cuadrados, y el perímetro en milímetros del cuarto ventrículo, los ratones knock out presentaron un área y un perímetro significativamente mayores $(\mathrm{p}<0.01)$ que los ratones wilde type.
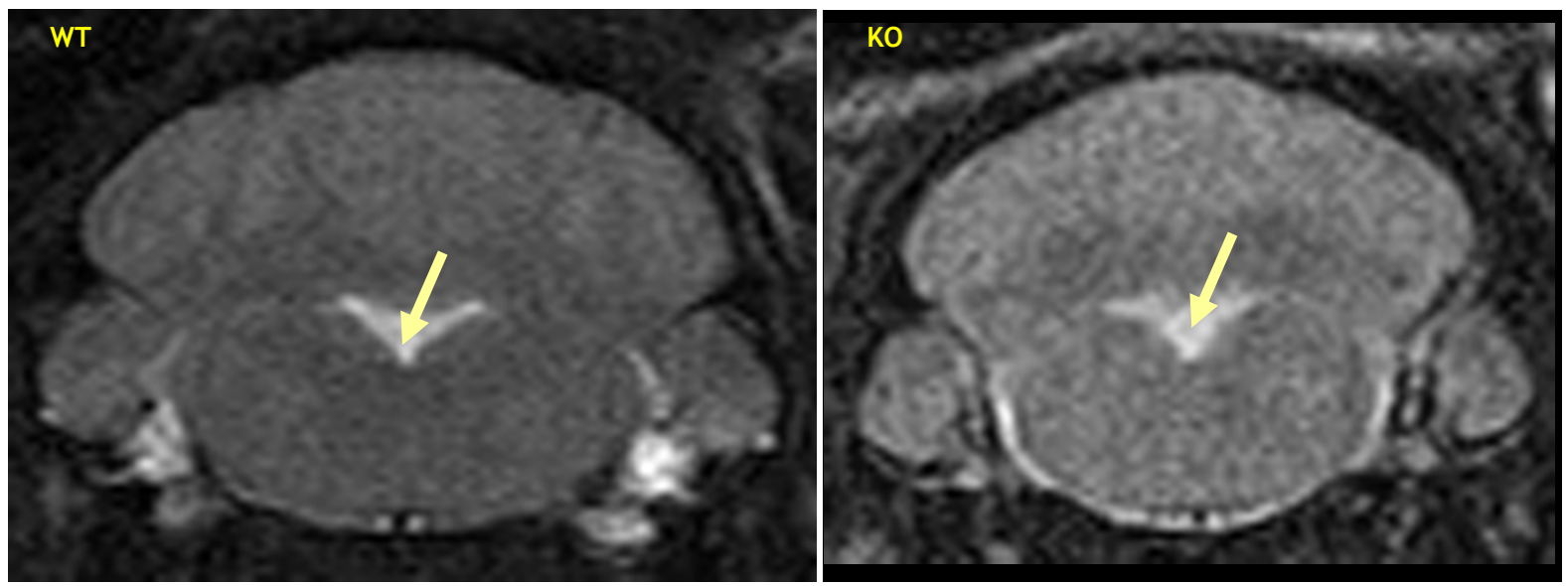

Figura R83 y R84. Resonancias magnéticas que afectan a la protuberancia. WT: wilde type, KO: knock out para IRS-2. Las flechas señalan el cuarto ventrículo.

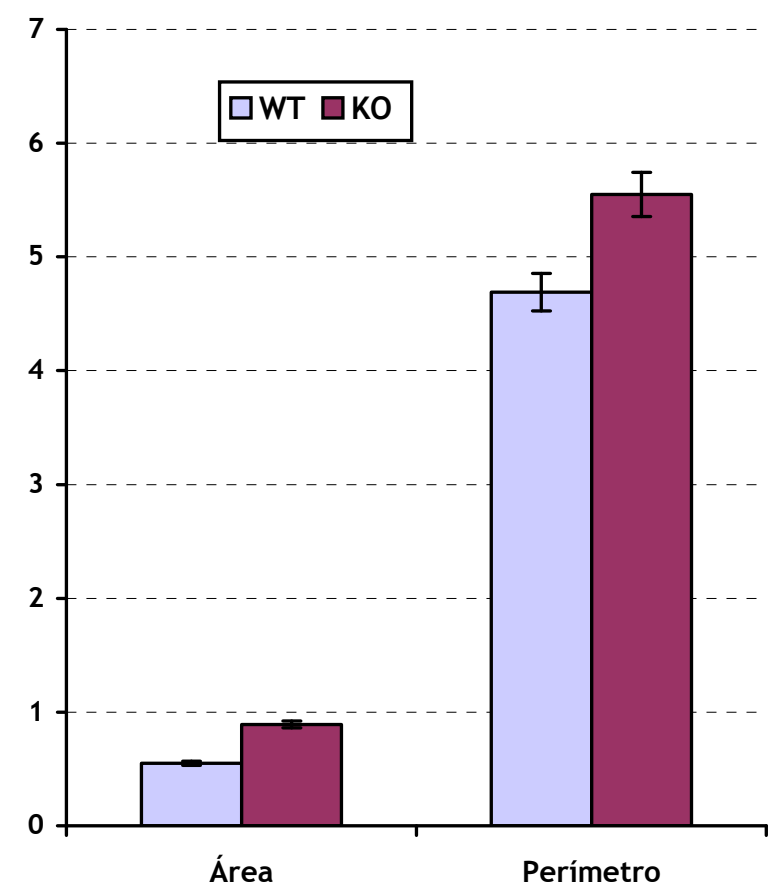

Figura R85. Morfometría del cuarto ventrículo.

La gráfica R85 muestra los valores medios y el error estándar de la media observados al medir el área y el perímetro del cuarto ventrículo en los ratones wilde type (WT) y knock out para IRS-2 (KO). 
Al analizar los diámetros transversal y dorso-ventrales de los mismos cortes de resonancia, puede apreciarse, como se muestra en la gráfica de la figura R86, la existencia de un aumento para todos ellos en los ratones knock out para IRS-2 con respecto a los ratones wilde type, siendo más significativo en el transversal $(p<0.01)$ y las zonas media e intermedia del dorso-ventral $(p<0.05)$.

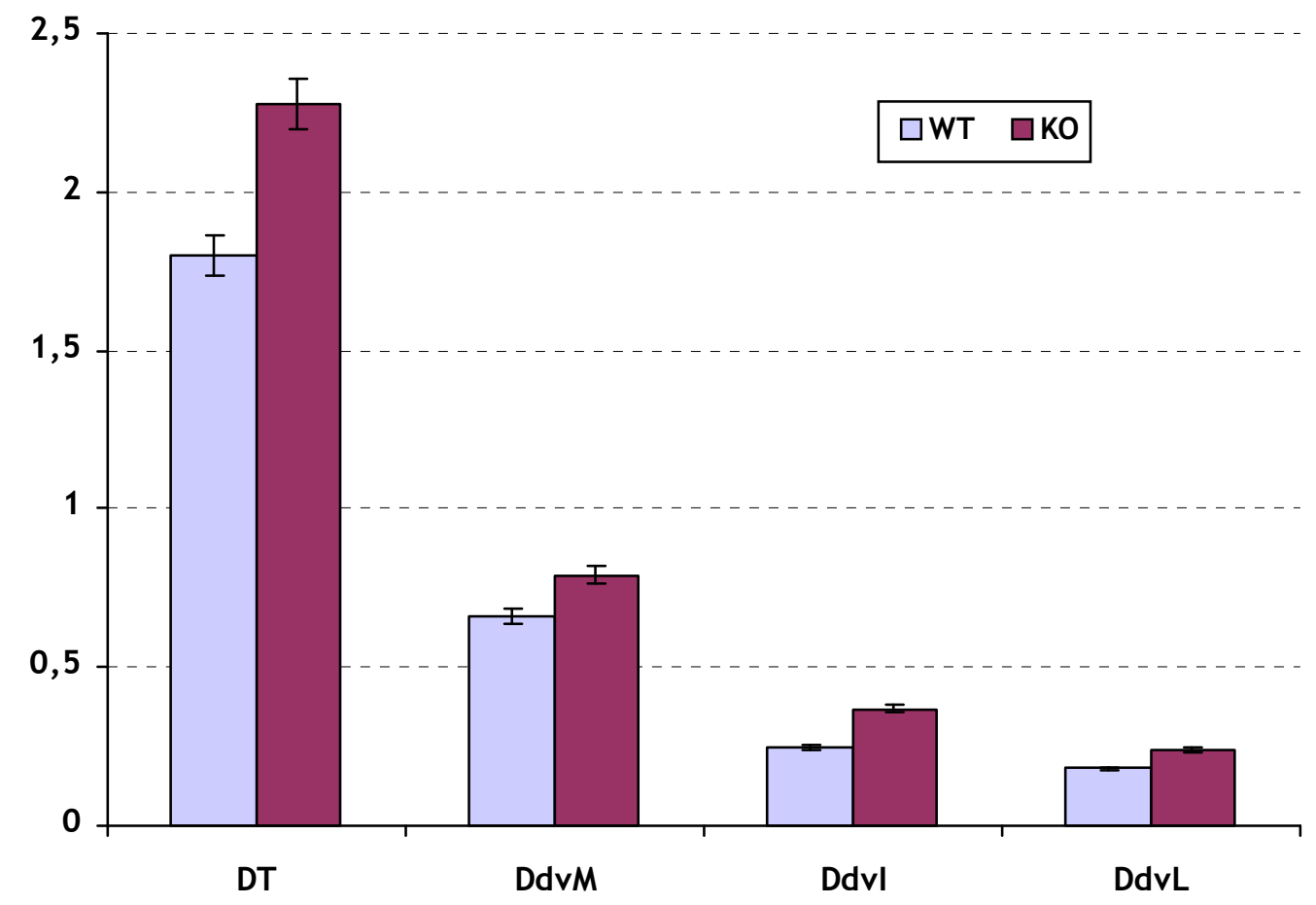

Figura R86. Morfometría del cuarto ventrículo.

La gráfica R86 muestra los valores medios y el error estándar de la media, en milímetros, observados al estudiar los diámetros transversal (DT), dorso-ventral medio (DdvM), dorsoventral intermedio ( $\mathrm{Ddvl}$ ) y dorso-ventral lateral ( $\mathrm{DdvL}$ ) del cuarto ventrículo en los ratones wilde type (WT) y knock out para IRS-2 (KO). 


\section{Acueducto mesencefálico}

Como puede apreciarse en las figuras R87 y R88, correspondientes a resonancias magnéticas de cortes coronales del mesencéfalo, y en la figura R89, gráfica que resume los valores morfométricos de las áreas, en milímetros cuadrados, y el perímetro en milímetros del acueducto mesencefálico, los ratones knock out presentaron un área y un perímetro muy parecido al observado en los ratones wilde type, aunque ambos de mayor tamaño.
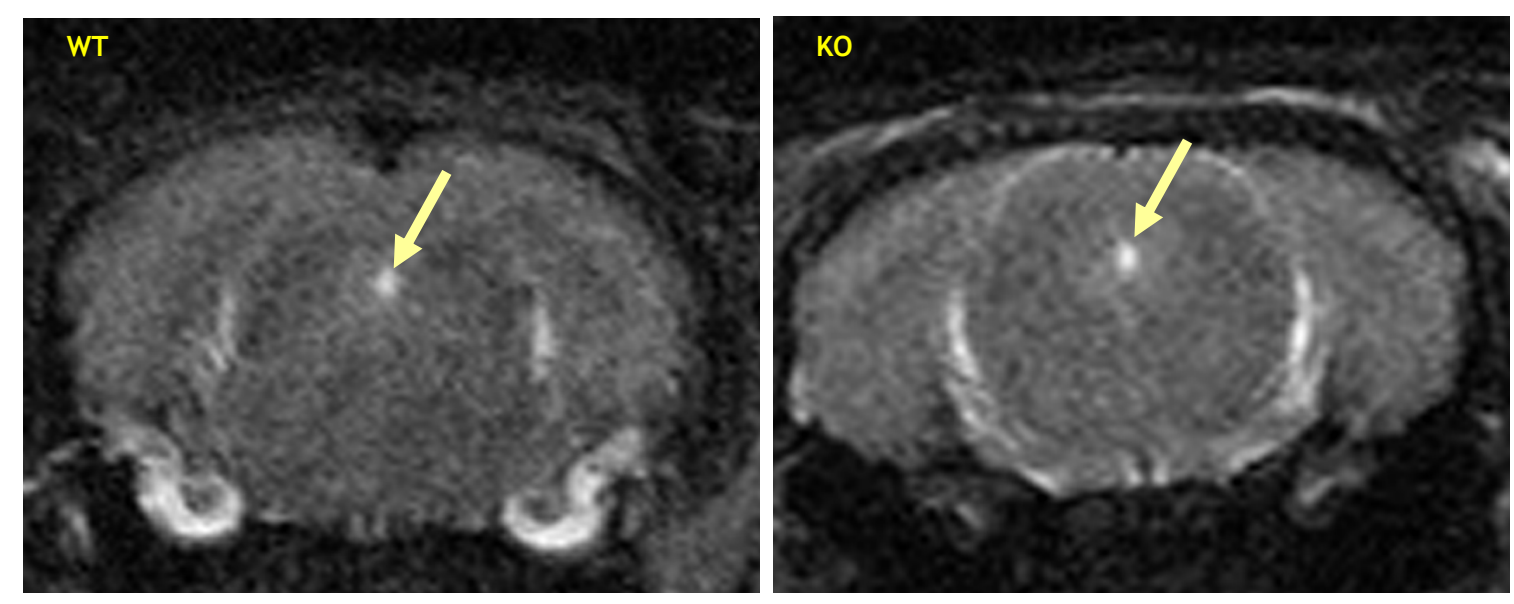

Figuras R87 y R88. Resonancias magnéticas que afectan al mesencéfalo. WT: wilde type, KO: knock out para IRS-2. Las flechas señalan el acueducto mesencefálico.

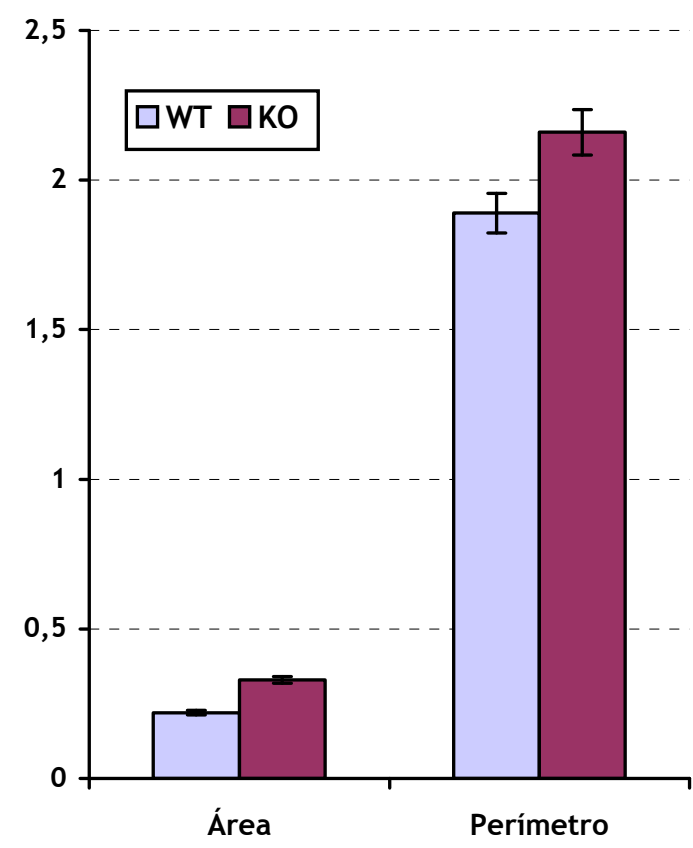

Figura R89. Morfometría del acueducto mesencefálico.

La gráfica R89 muestra los valores medios y el error estándar de la media observados al medir el área y el perímetro del acueducto mesencefálico en los ratones wilde type (WT) y knock out para IRS-2 (KO). 
Al analizar los diámetros del acueducto mesencefálico de los mismos cortes de resonancia, puede apreciarse, como se muestra en la gráfica de la figura R90, que aparecieron variaciones significativas entre los ratones knock out para IRS-2 y los ratones wilde type para el diámetro dorso-ventral $(p<0.01)$, pero no para el diámetro transversal.

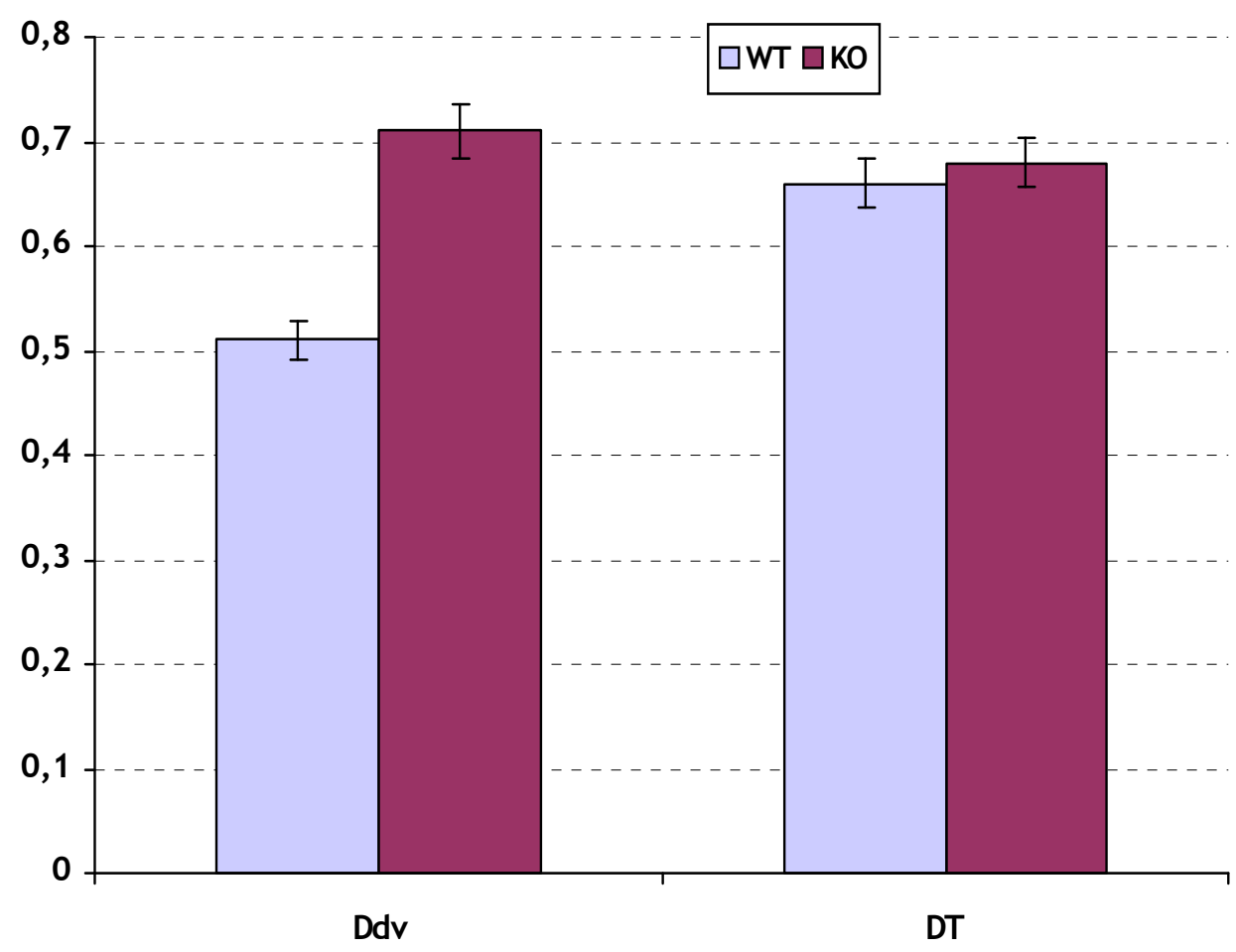

Figura R90. Morfometría del acueducto mesencefálico.

La gráfica R90 muestra los valores medios y el error estándar de la media, en milímetros, observados al medir los diámetros dorso-ventral (Ddv) y transversal (DT) del acueducto mesencefálico, en los ratones wilde type (WT) y knock out para IRS-2 (KO). 


\section{Ventrículo medio. Proyección a.}

Como puede apreciarse en las figuras R91 y R92, correspondientes a resonancias magnéticas de cortes coronales del encéfalo, y en la figura R93, gráfica que resumen los valores morfométricos de las áreas, en milímetros cuadrados, y el perímetro en milímetros del ventrículo medio (flechas), los ratones knock out presentaron un área muy parecido al observado en los ratones wilde type y un perímetro superior, pero no estadísticamente significativo.
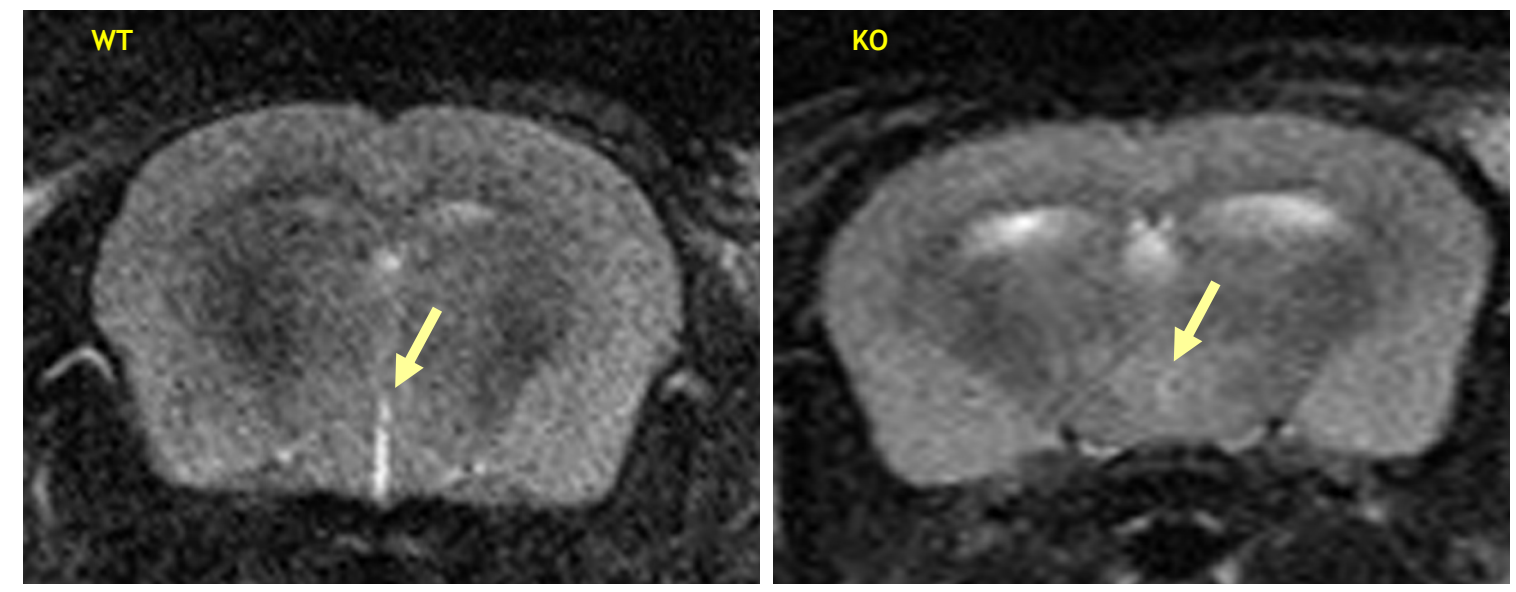

Figuras R91 y R92. Resonancias magnéticas que afectan al enecéfalo, plano de proyección estereotáxica a. WT: wilde type, KO: knock out para IRS-2. Las flechas señalan el ventrículo medio.

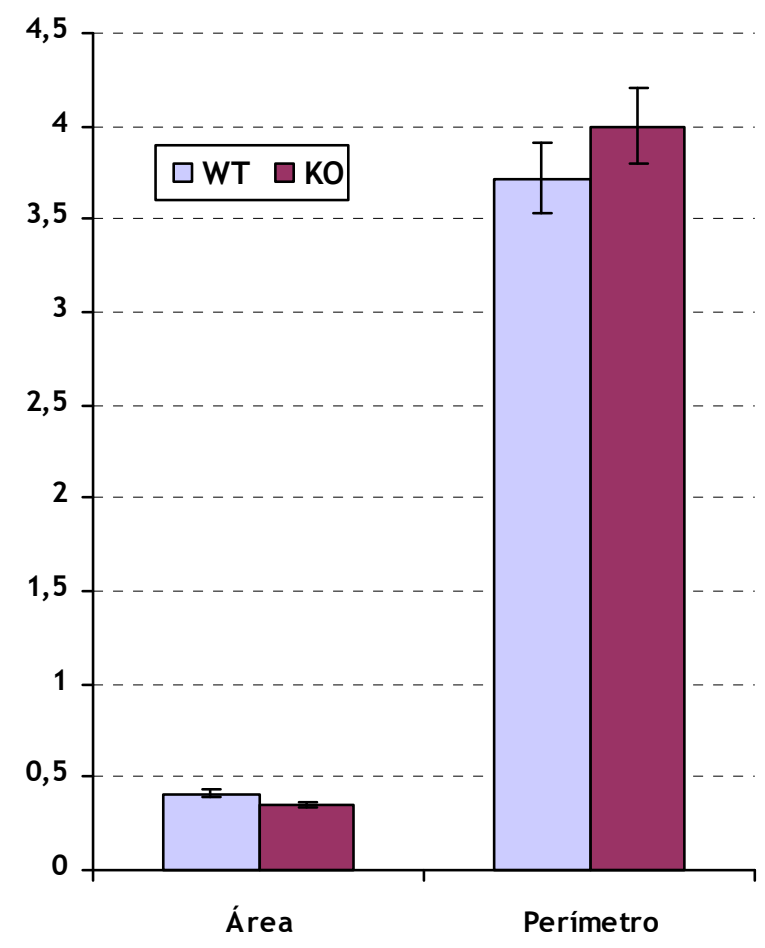

Figuras R93. Morfometría del ventrículo medio.

La gráfica R93 muestra los valores medios y el error estándar de la media observados al medir el área y el perímetro del ventrículo medio en la proyección a en los ratones wilde type (WT) y knock out para IRS-2 (KO). 
Al analizar el diámetro longitudinal y los diámetros transversales, de los mismos cortes de resonancia, puede apreciarse, como se muestra en las gráficas de la figuras R94 y R95, que no aparecieron variaciones significativas entre los ratones knock out para IRS-2 y los ratones wilde type, salvo para el diámetro transversal inferior, que fue significativamente mayor en el knock out $(p<0.01)$.
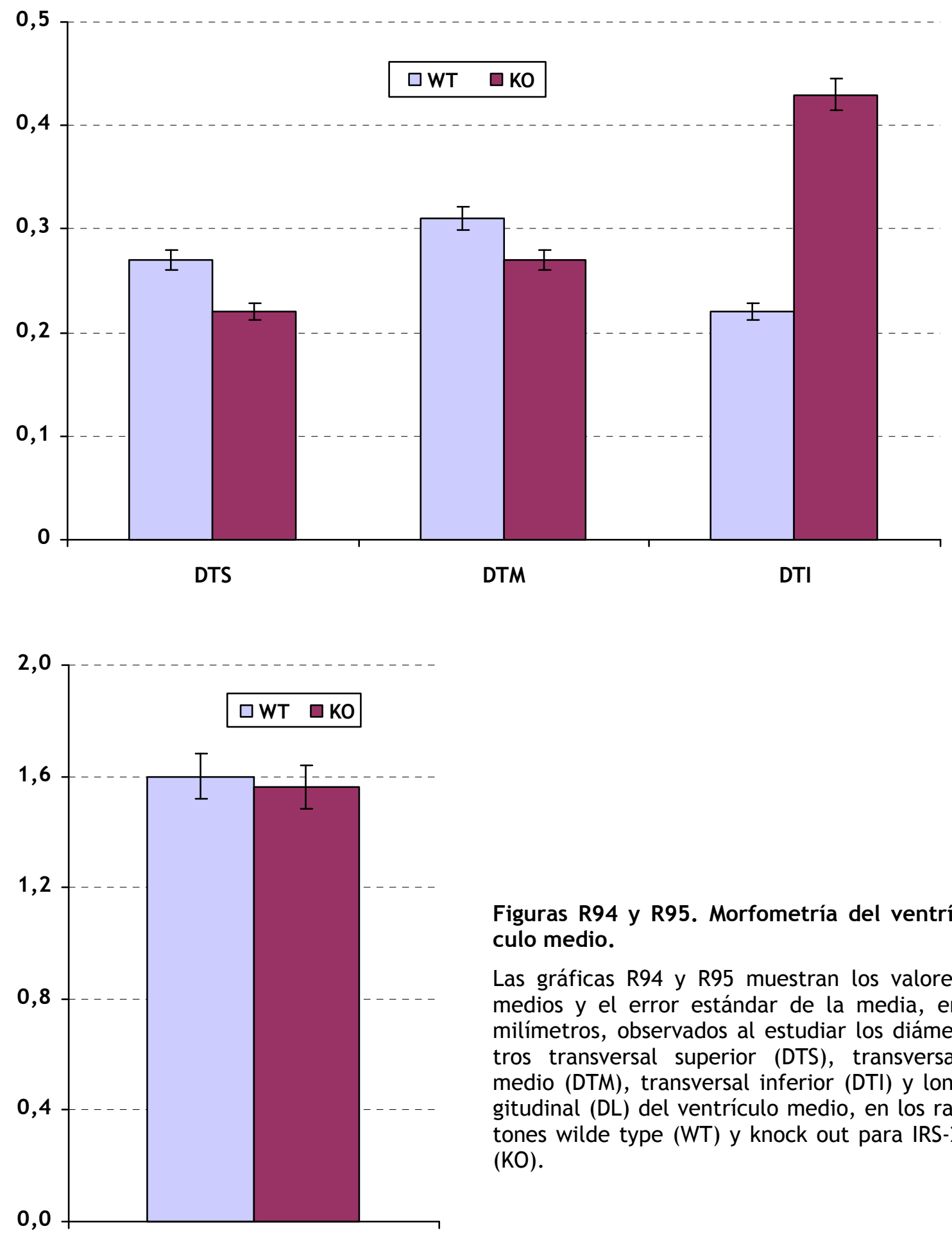

Figuras R94 y R95. Morfometría del ventrículo medio.

Las gráficas R94 y R95 muestran los valores medios y el error estándar de la media, en milímetros, observados al estudiar los diámetros transversal superior (DTS), transversal medio (DTM), transversal inferior (DTI) y longitudinal (DL) del ventrículo medio, en los ratones wilde type (WT) y knock out para IRS-2 (KO).

$\mathrm{DL}$ 


\section{Ventrículo medio. Proyección b.}

Las figuras R96 y R97, muestran resonancias magnéticas de cortes coronales del encéfalo, localización b, y la figura R98 resume los valores morfométricos de las áreas, en milímetros cuadrados, y el perímetro en milímetros del ventrículo medio. Los ratones knock out presentaron áreas y perímetros similares a los observados en los ratones wilde type, aunque ligeramente mayores.
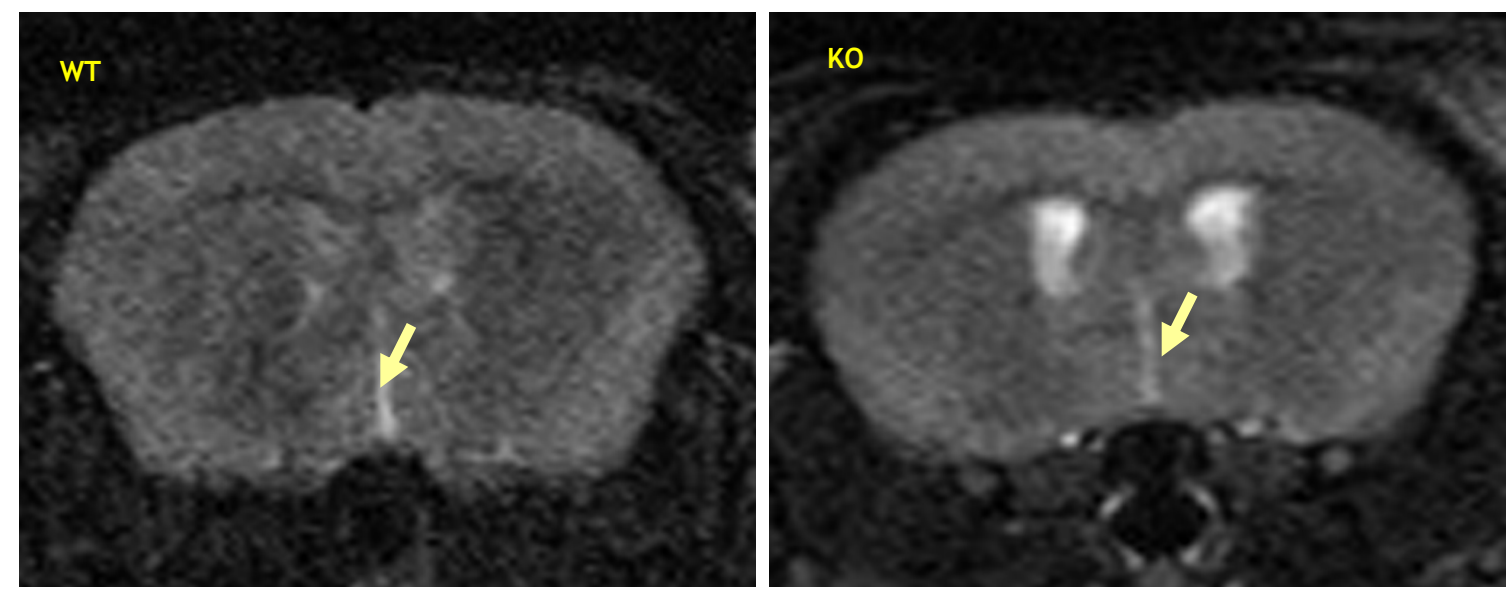

Figuras R96 y R97. Resonancias magnéticas que afectan al enecéfalo, plano de proyección estereotáxica b. WT: wilde type, KO: knock out para IRS-2. Las flechas señalan el ventrículo medio.

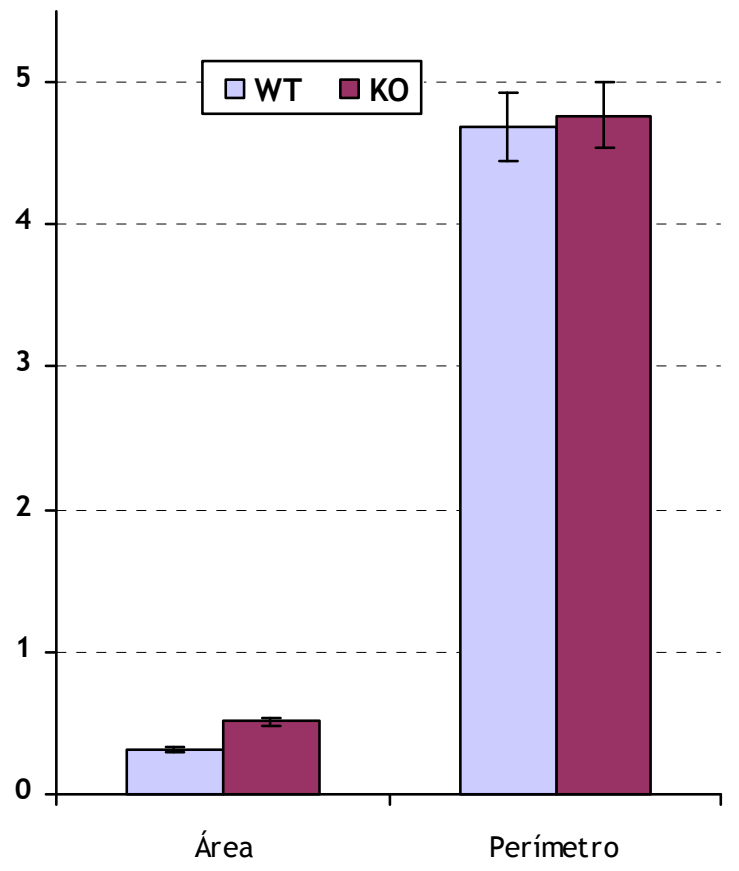

Figura R98. Morfometría del ventrículo medio.

La gráfica R98 muestra los valores medios y el error estándar de la media observados al medir el área y el perímetro del ventrículo medio en la proyección b en los ratones wilde type (WT) y knock out para IRS2 (KO). 
Al analizar los diámetros de los mismos cortes de resonancia, puede apreciarse, como se muestra en las gráficas de las figuras R99 y R100, que todos los diámetros medidos son mayores en los ratones knock out para IRS-2, siendo la diferencia más significativa en los diámetros transversales en la zona superior, DTS, y media, DTM $(p<0.01)$.
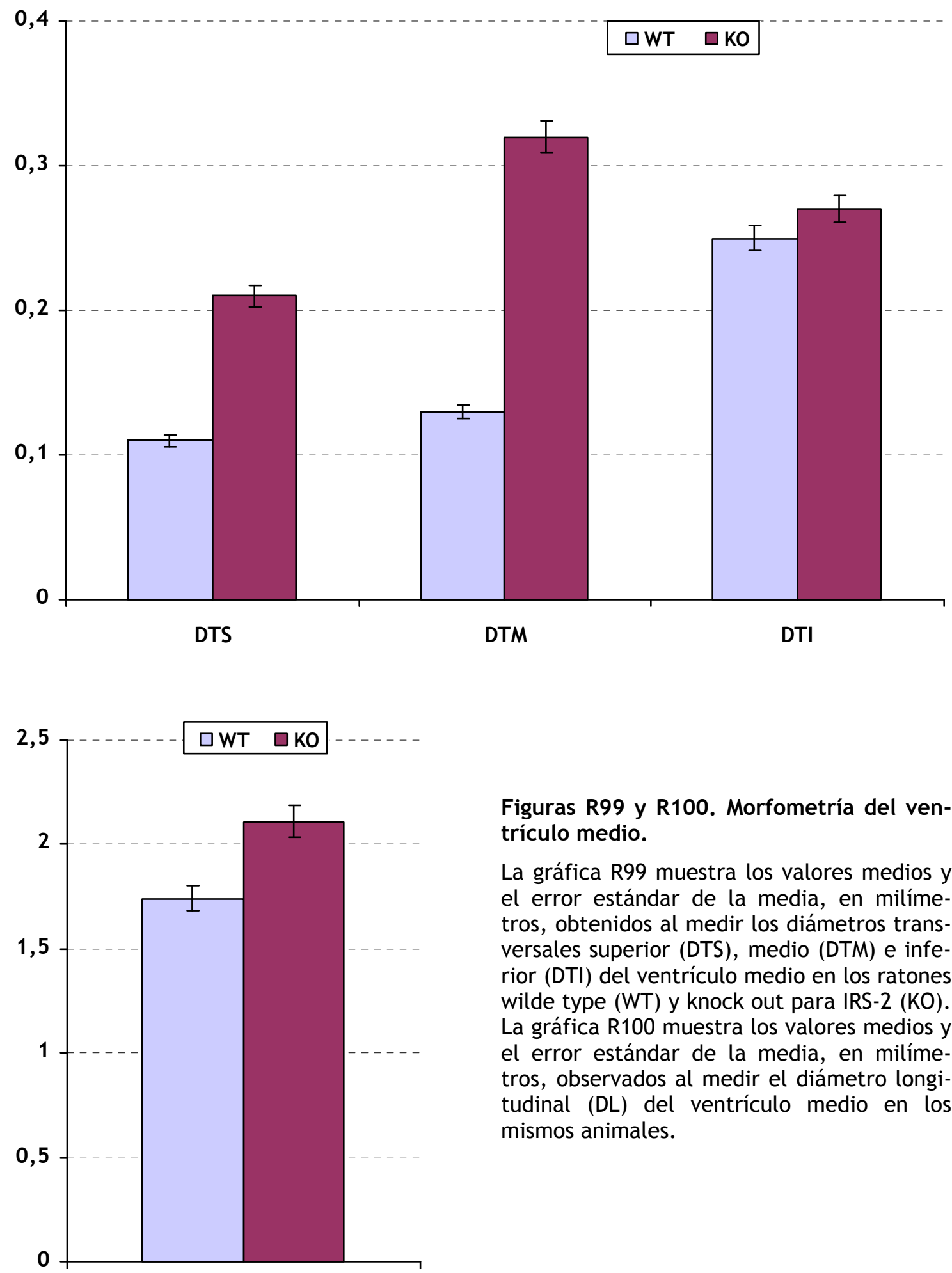

Figuras R99 y R100. Morfometría del ventrículo medio.

La gráfica R99 muestra los valores medios y el error estándar de la media, en milímetros, obtenidos al medir los diámetros transversales superior (DTS), medio (DTM) e inferior (DTI) del ventrículo medio en los ratones wilde type (WT) y knock out para IRS-2 (KO). La gráfica R100 muestra los valores medios y el error estándar de la media, en milímetros, observados al medir el diámetro longitudinal (DL) del ventrículo medio en los mismos animales.

DL 


\section{Ventrículo medio. Proyección c.}

Como puede apreciarse en las figuras R101 y R102, correspondientes a resonancias magnéticas de cortes coronales del encéfalo, localización c, y en la figura R103, gráfica que resume los valores morfométricos de las áreas, en milímetros cuadrados, y el perímetro en milímetros del ventrículo medio (flechas), los ratones knock out presentaron un comportamiento similar al obtenido en la localización $\mathrm{b}$, con aumento no significativo del área y del perímetro del ventrículo medio frente a los ratones wilde type.
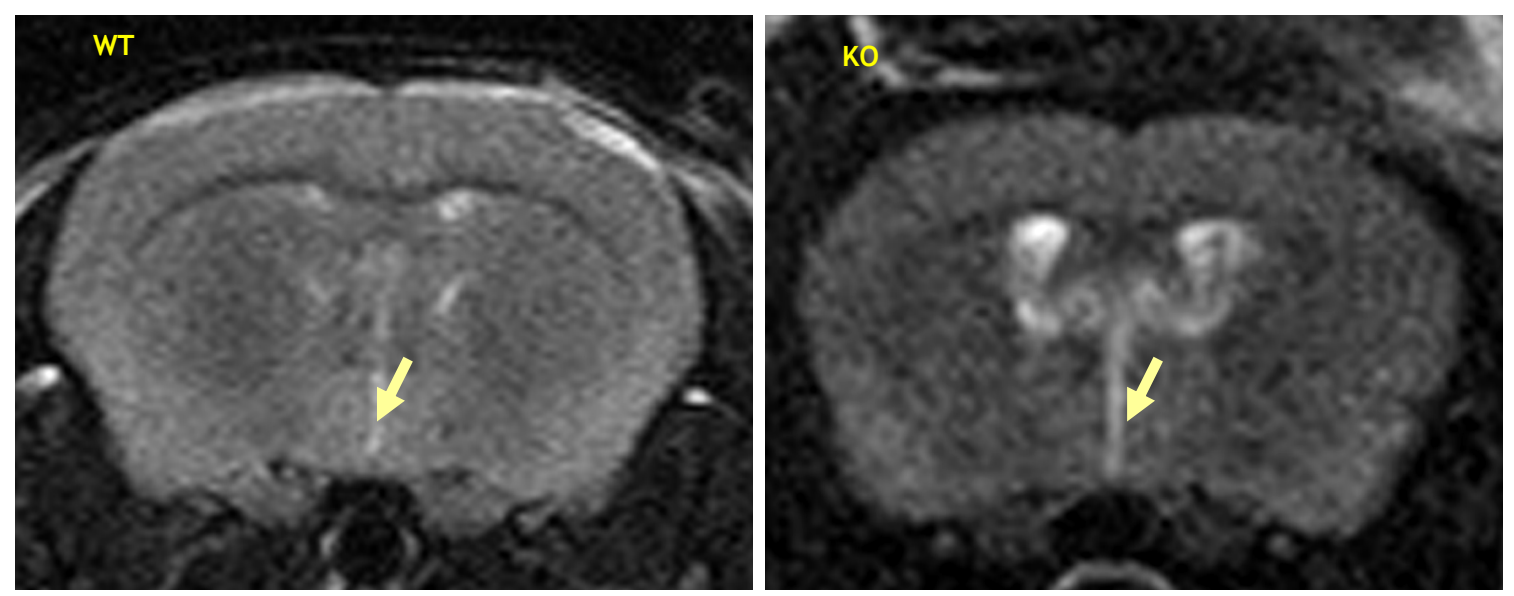

Figuras R101 y R102. Resonancias magnéticas que afectan al encéfalo, plano de proyección estereotáxica c. WT: wilde type, KO: knock out para IRS-2. Las flechas señalan el ventrículo medio.

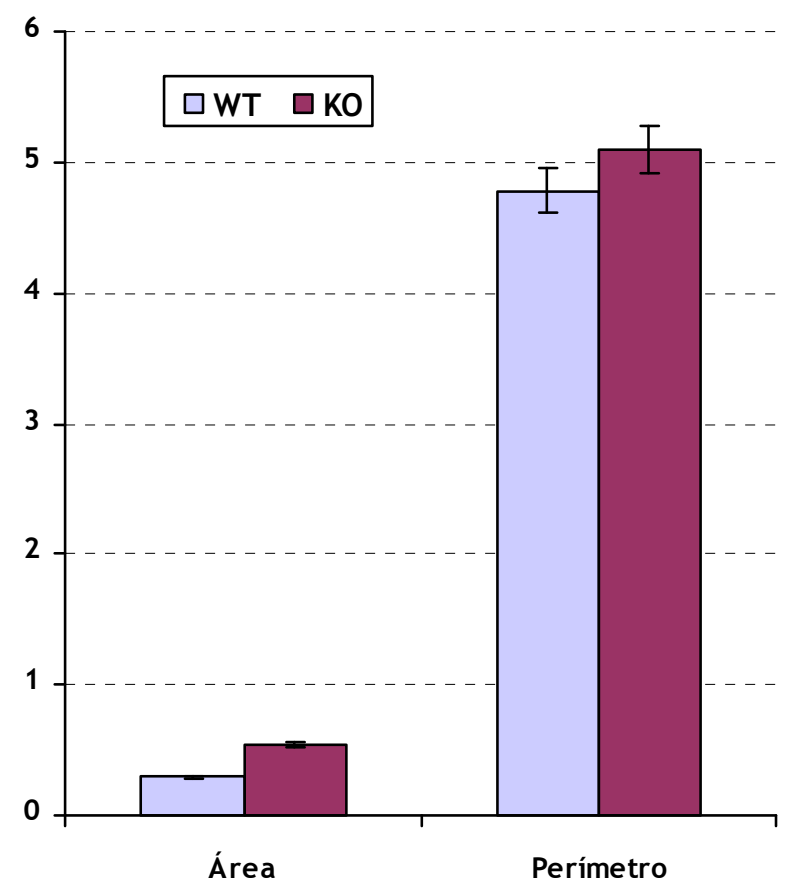

Figura R103. Morfometría del ventrículo medio.

La gráfica R103 muestra los valores medios y el error estándar de la media observados al medir el área y el perímetro del ventrículo medio en la proyección c en los ratones wilde type (WT) y knock out para IRS-2 (KO). 
El diámetro longitudinal de los ratones KO fue ligeramente mayor que el de los WT $(p<0.05)$. De igual manera que en la proyección $b, y$ a diferencia de la a, los diámetros transversales superior (DTS) y medio (DTM) fueron significativamente mayores en los ratones knock out $(p<0.01$ y $p<0.05$, respectivamente), y poco significativo en el diámetro transversal inferior (DTI).
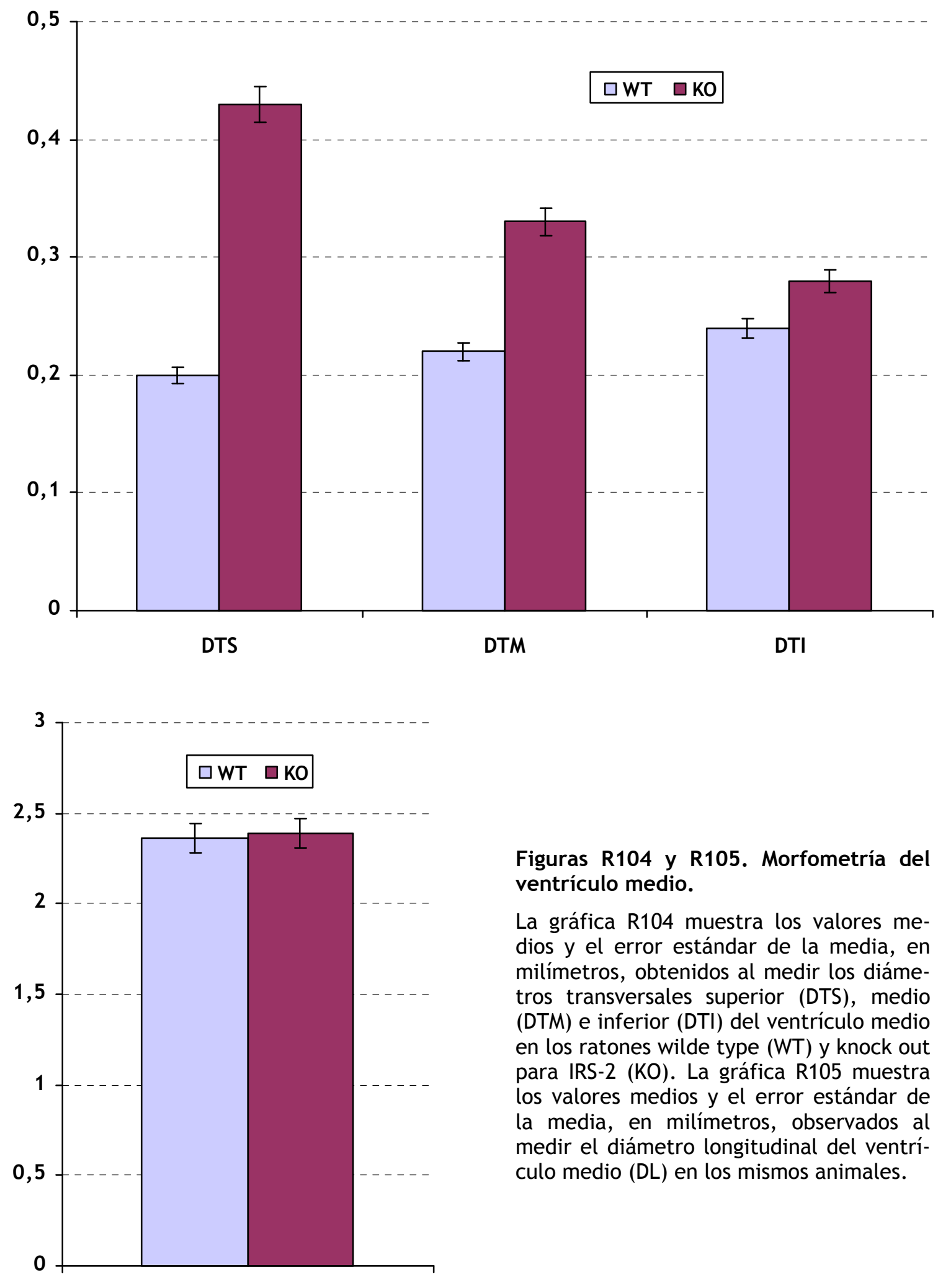

Figuras R104 y R105. Morfometría del ventrículo medio.

La gráfica R104 muestra los valores medios y el error estándar de la media, en milímetros, obtenidos al medir los diámetros transversales superior (DTS), medio (DTM) e inferior (DTI) del ventrículo medio en los ratones wilde type (WT) y knock out para IRS-2 (KO). La gráfica R105 muestra los valores medios y el error estándar de la media, en milímetros, observados al medir el diámetro longitudinal del ventrículo medio (DL) en los mismos animales.

DL 


\section{Ventrículo lateral. Proyección a.}

Las figuras R106 y R107, correspondientes a resonancias magnéticas de cortes coronales del encéfalo, proyección estereotáxica a, y la figura R108, gráfica que resume los valores morfométricos de las áreas, en milímetros cuadrados, y el perímetro en milímetros del ventrículo lateral (flechas), muestran que los ratones knock out presentaron un área $(p<0.01)$ y un perímetro $(p<0.05)$ significativamente mayores que el observado en los ratones wilde type.
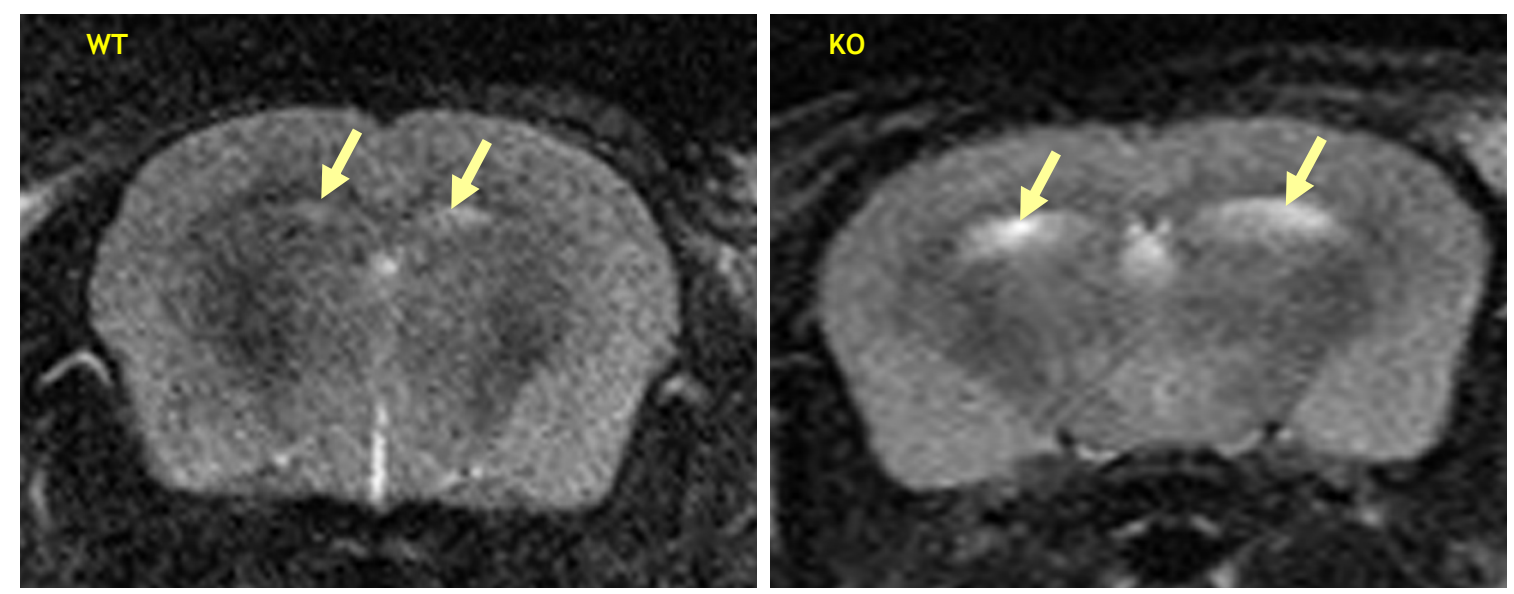

Figuras R106 y R107. Resonancias magnéticas que afectan al encéfalo, plano de proyección estereotáxica a. WT: wilde type, KO: knock out para IRS-2. Las flechas señalan el ventrículo lateral.

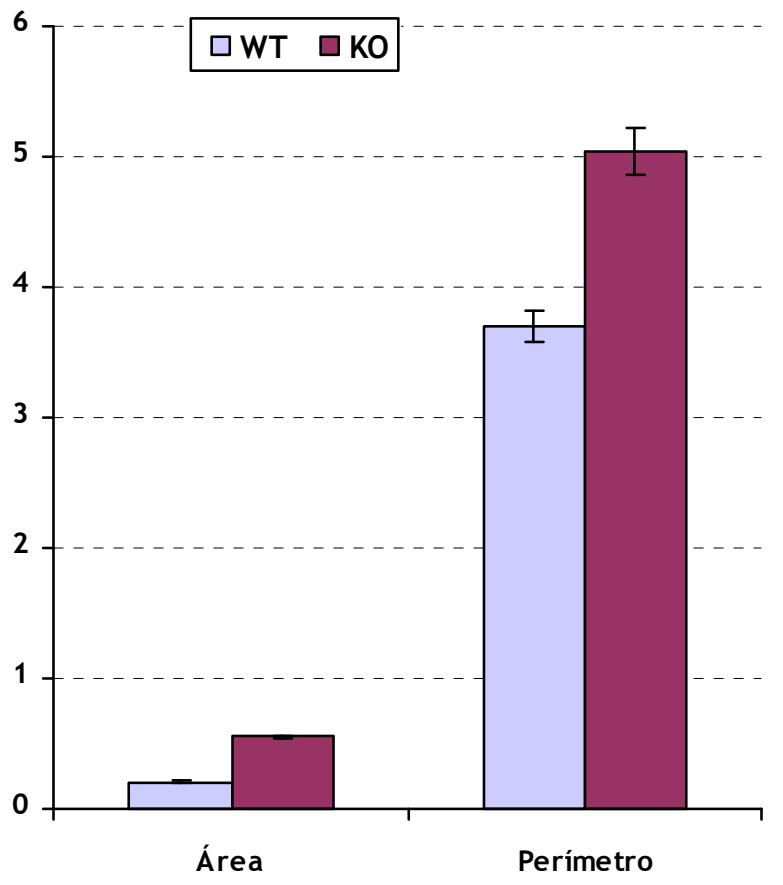

Figura R108. Morfometría del ventrículo lateral.

La gráfica R108 muestra los valores medios y el error estándar de la media observados al medir el área y el perímetro del ventrículo lateral en la proyección a en los ratones wilde type (WT) y knock out para IRS-2 (KO). 
En la gráfica R109 y R110 se muestra que el diámetro longitudinal (DL) y los diámetros transversales medial (DTM), medial lateral (DTML), lateral medial (DTLM) $y$ lateral (DTL), en los ratones KO fueron significativamente mayores $(p<0.01)$ que en los de los ratones WT.
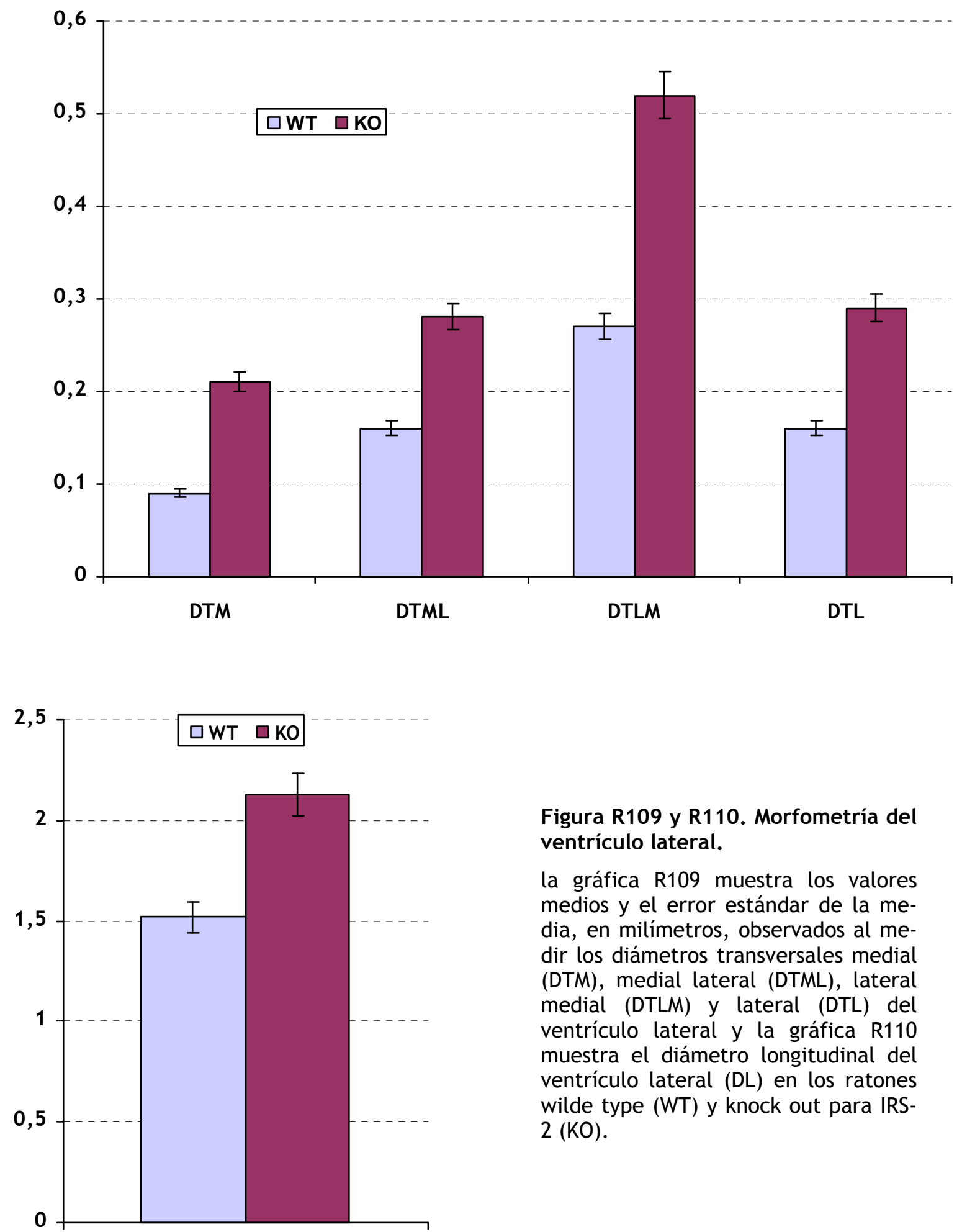

Figura R109 y R110. Morfometría del ventrículo lateral.

la gráfica R109 muestra los valores medios y el error estándar de la media, en milímetros, observados al medir los diámetros transversales medial (DTM), medial lateral (DTML), lateral medial (DTLM) y lateral (DTL) del ventrículo lateral y la gráfica R110 muestra el diámetro longitudinal del ventrículo lateral $(D L)$ en los ratones wilde type (WT) y knock out para IRS2 (KO). 


\section{Ventrículo lateral. Proyección b.}

Se aprecia en las figuras R111 y R112, correspondientes a resonancias magnéticas de cortes coronales del encéfalo, proyección estereotáxica $b$, el aumento del ventrículo lateral (flechas) en el ratón knock out para IRS-2. La figura R113, gráfica que resume los valores morfométricos de las áreas, en milímetros cuadrados, y el perímetro en milímetros del ventrículo lateral, confirma que los ratones knock out presentaron un área $(p<0.01)$ y un perímetro $(p<0.05)$ significativamente mayores que el observado en los ratones wilde type.
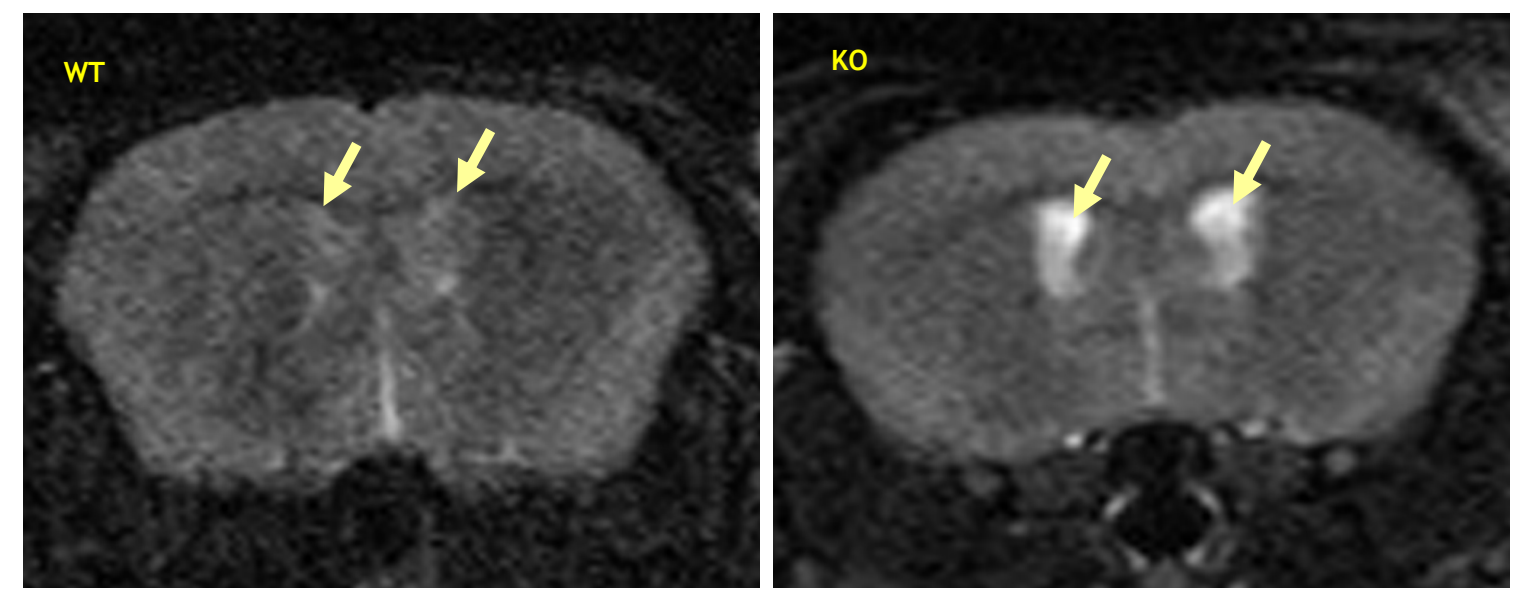

Figuras R111 y R112. Resonancias magnéticas que afectan al encéfalo, plano de proyección estereotáxica b. WT: wilde type, KO: knock out para IRS-2. Las flechas señalan el ventrículo lateral.

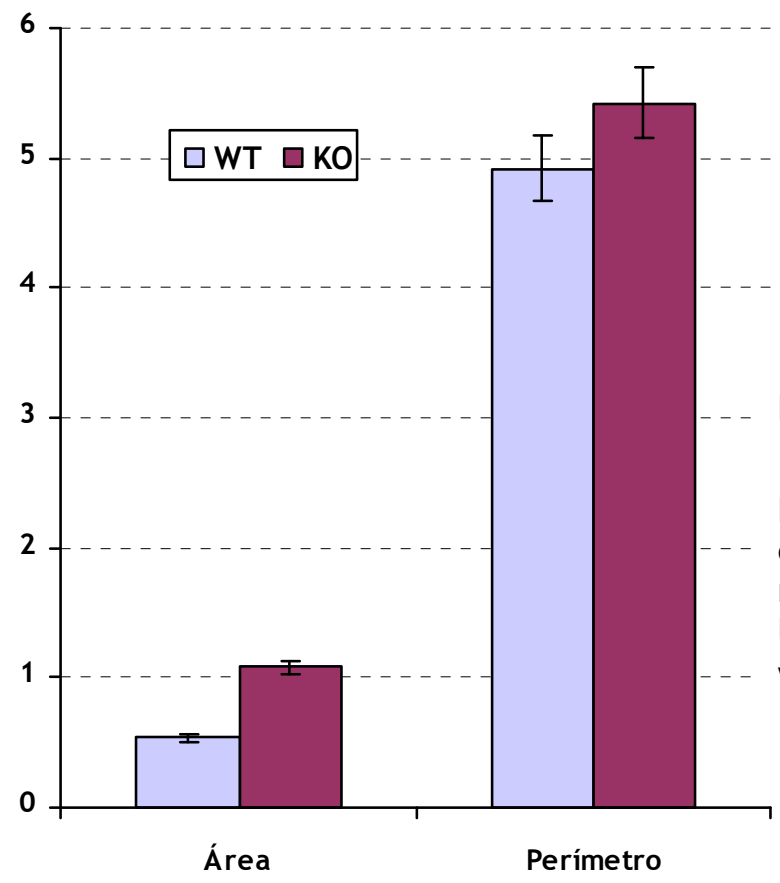

Figura R113. Morfometría del ventrículo lateral.

La gráfica R113 muestra los valores medios y el error estándar de la media observados al medir el área y el perímetro del ventrículo lateral en la proyección $b$ en los ratones wilde type (WT) y knock out para IRS-2 (KO). 
El diámetro dorso-ventral en la localización b de los ratones KO fue ligeramente mayor que el de los WT, aunque sin significación estadística. Todos los diámetros transversales fueron mayores de forma significativa $(p<0.01)$ en los ratones knock out frente a los wilde type (figuras R114 y R115).
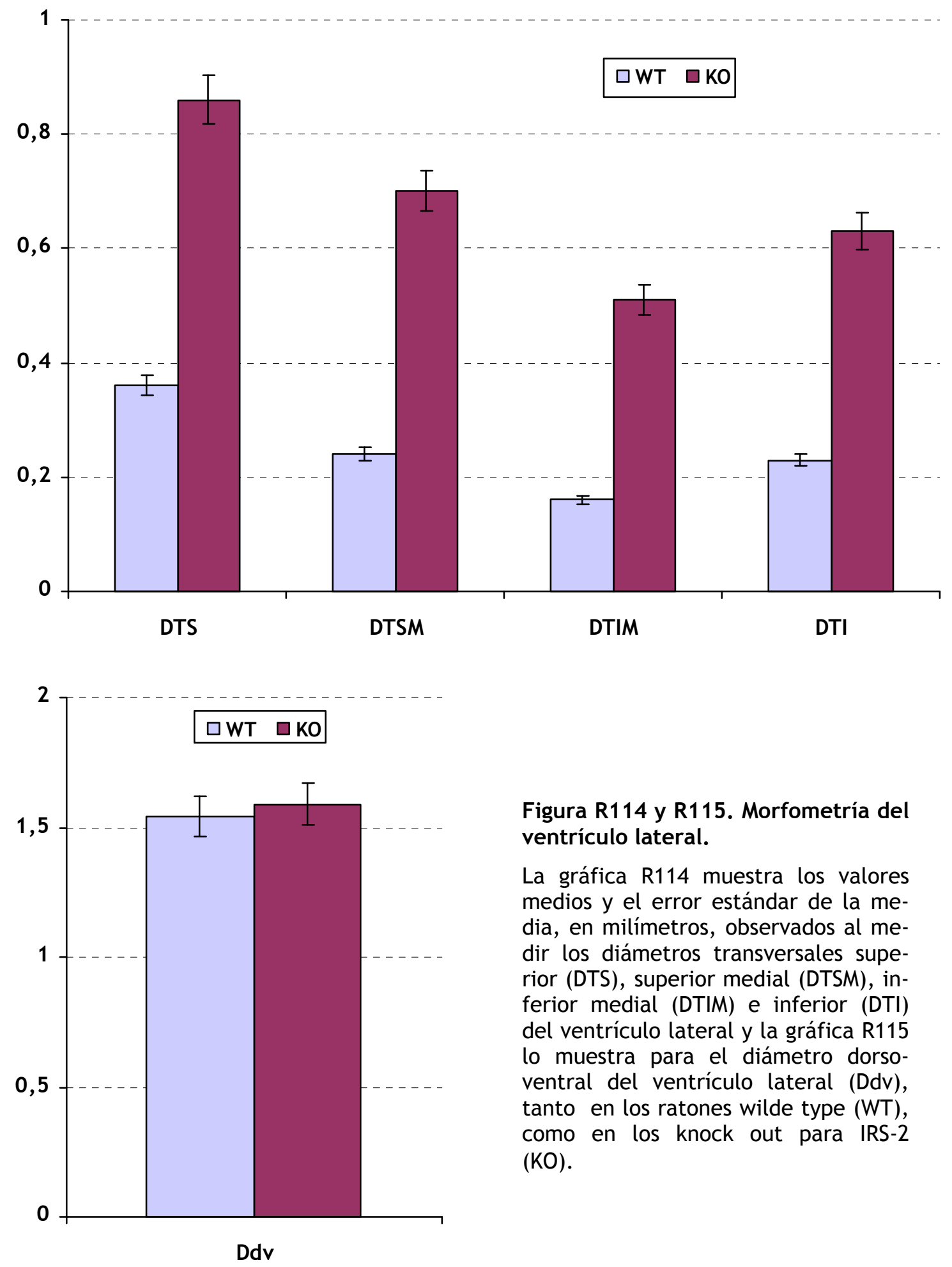

Figura R114 y R115. Morfometría del ventrículo lateral.

La gráfica R114 muestra los valores medios y el error estándar de la media, en milímetros, observados al medir los diámetros transversales superior (DTS), superior medial (DTSM), inferior medial (DTIM) e inferior (DTI) del ventrículo lateral y la gráfica R115 lo muestra para el diámetro dorsoventral del ventrículo lateral (Ddv), tanto en los ratones wilde type (WT), como en los knock out para IRS-2 (KO). 


\section{Ventrículo lateral. Proyección c.}

El ventrículo lateral de los animales con la deleción para IRS-2 presentan un claro aumento del ventrículo lateral, tal y como puede apreciarse en las imágenes R116 y R117. La gráfica de la figura R118 muestra los valores morfométricos de las áreas, en milímetros cuadrados, y el perímetro en milímetros del ventrículo lateral, siendo el área $(\mathrm{p}<0.01)$ y el perímetro $(\mathrm{p}<0.05)$ significativamente mayores para los ratones knock out que para los ratones wilde type.
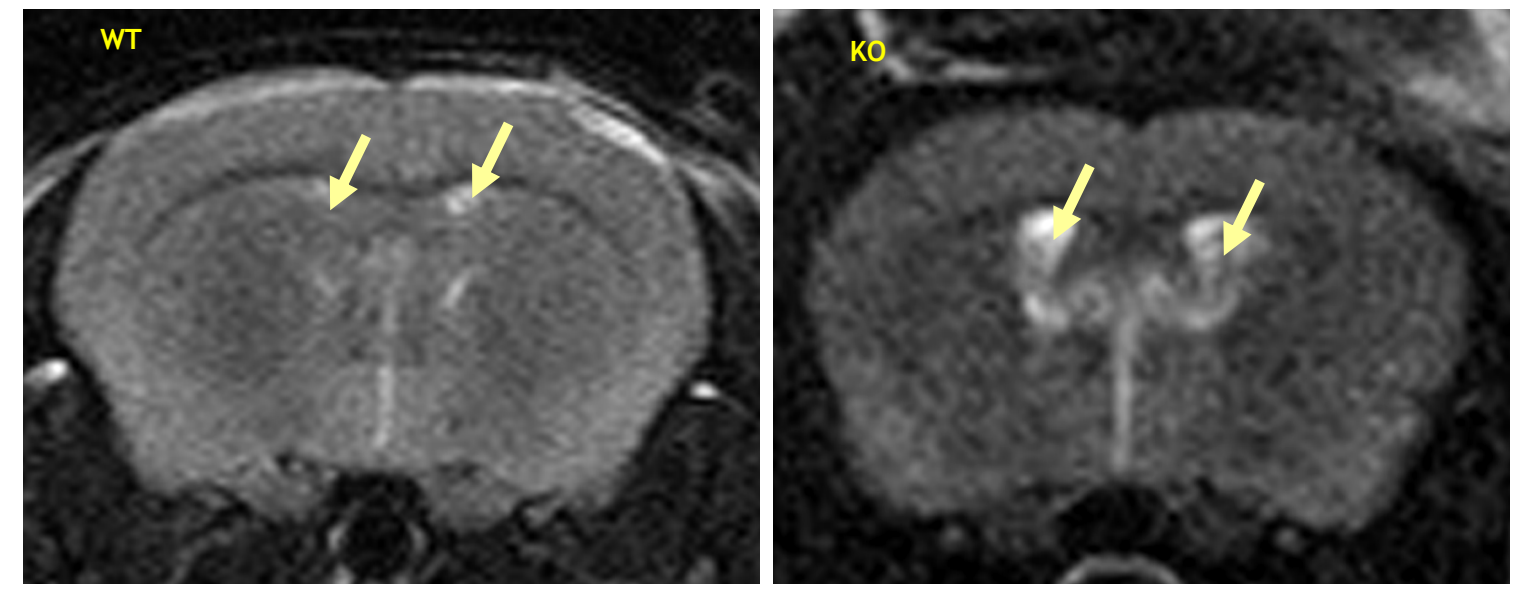

Figuras R116 y R117. Resonancias magnéticas que afectan al encéfalo, plano de proyección estereotáxica c. WT: wilde type, KO: knock out para IRS-2. Las flechas señalan el ventrículo lateral.

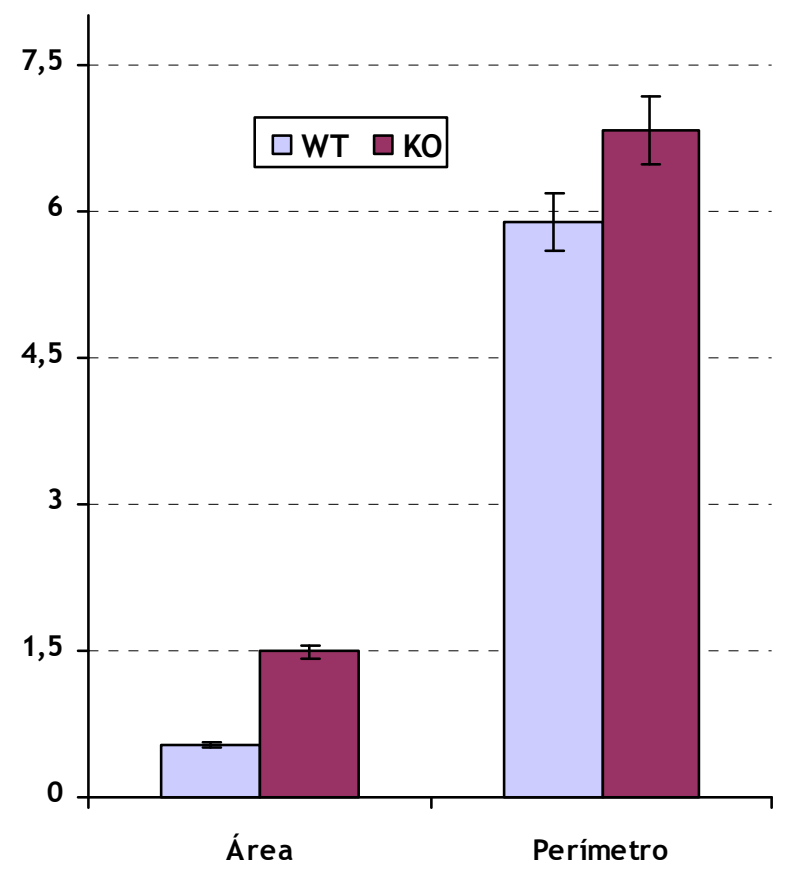

Figura R118. Morfometría del ventrículo lateral.

La gráfica R118 muestra los valores medios y el error estándar de la media observados al medir el área y el perímetro del ventrículo lateral en la proyección c en los ratones wilde type (WT) y knock out para IRS-? (KO) 
Como resumen, las gráficas inferiores (figuras R119 y R120), todos los diámetros estudiados eran mayores en los animales knock out. Si bien la diferencia observada en el diámetro dorso-ventral no fue significativa, sí lo fue para los diferentes diámetros transversales: $p<0.001$ para el transversal superior, $p<0.01$ para el transversal superior medial e inferior medial y $p<0.005$ para el transversal inferior.
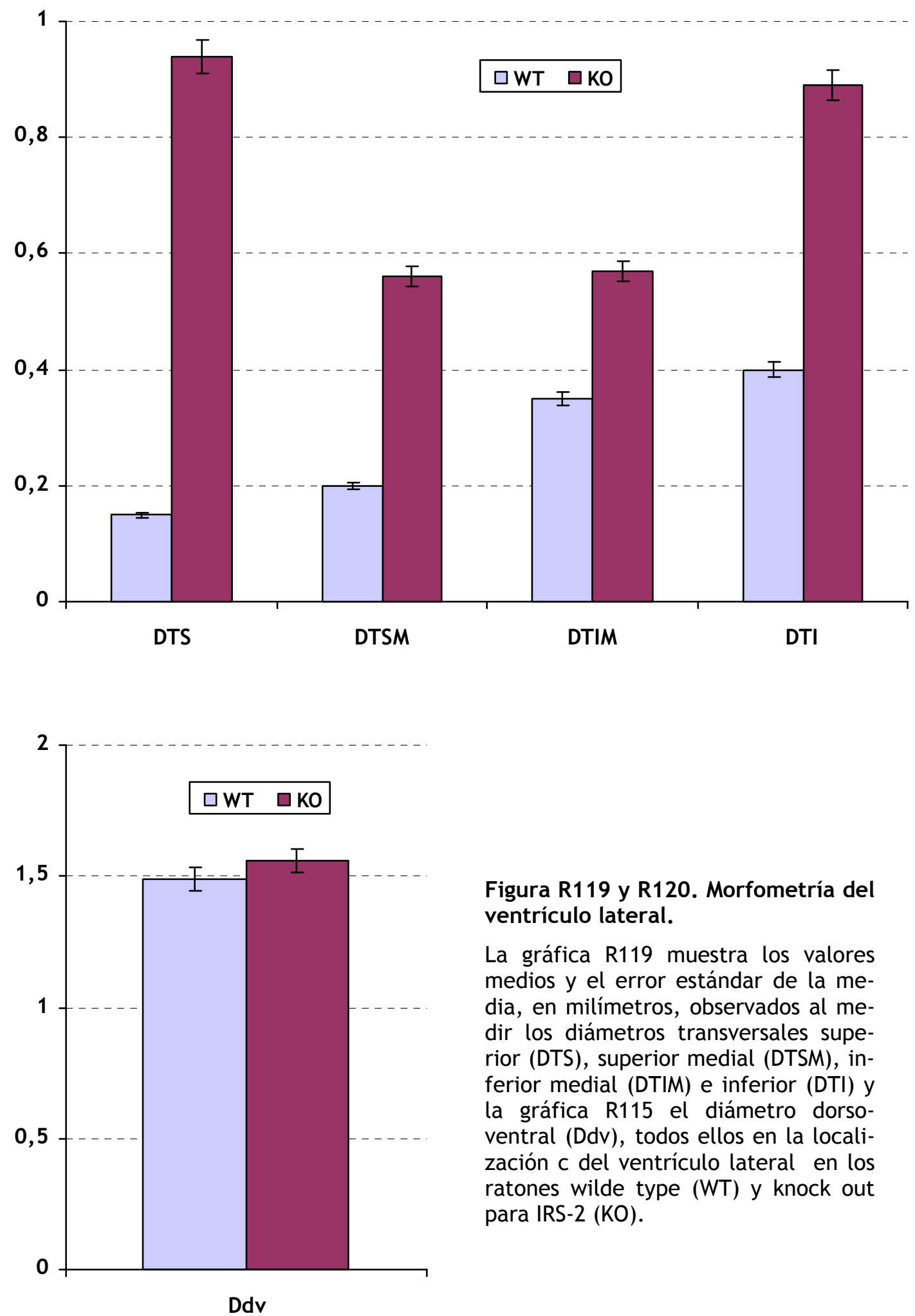

Figura R119 y R120. Morfometría del ventrículo lateral.

La gráfica R119 muestra los valores medios y el error estándar de la media, en milímetros, observados al medir los diámetros transversales superior (DTS), superior medial (DTSM), inferior medial (DTIM) e inferior (DTI) y la gráfica R115 el diámetro dorsoventral (Ddv), todos ellos en la localización $\mathrm{c}$ del ventrículo lateral en los ratones wilde type (WT) y knock out para IRS-2 (KO). 
Secciones axiales.

\section{Ventrículo medio.}

Las imágenes R121 y R122, que corresponden a resonancias magnéticas de secciones axiales del encéfalo, permiten comparar el ventrículo medio de ratones wilde type y knock out pata IRS-2. Los valores morfométricos de las áreas, en milímetros cuadrados, y del perímetro, en milímetros (figura R123) confirman que son significativamente mayores en los animales knock out que en los wilde type, área $p<0.001$; perímetro $p<0.01$.

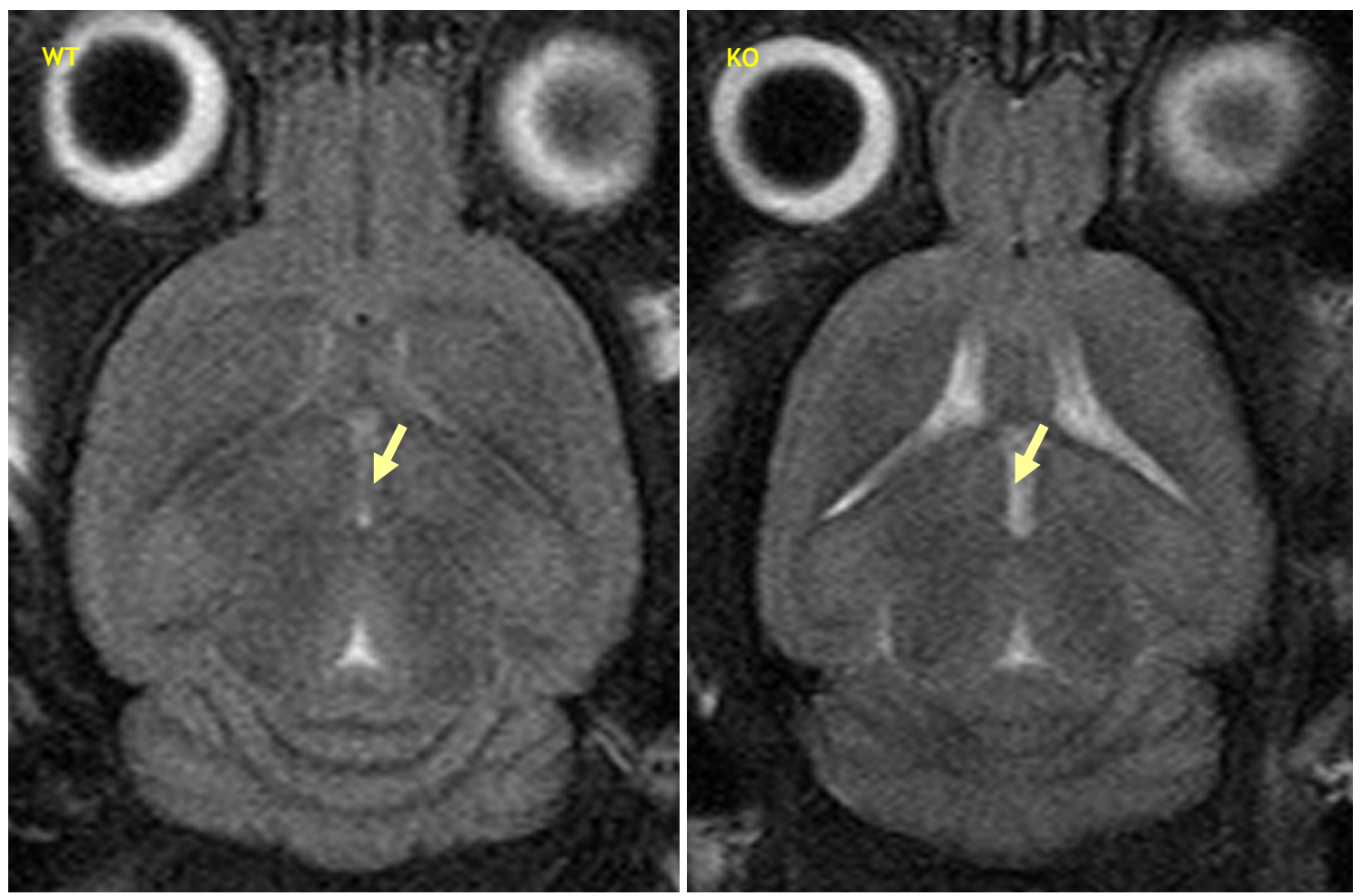

Figuras R121 y R122. Resonancias magnéticas tomadas en cortes horizontales o axiales del encéfalo. WT: wilde type, KO: knock out para IRS-2. Las flechas señalan el ventrículo medio.

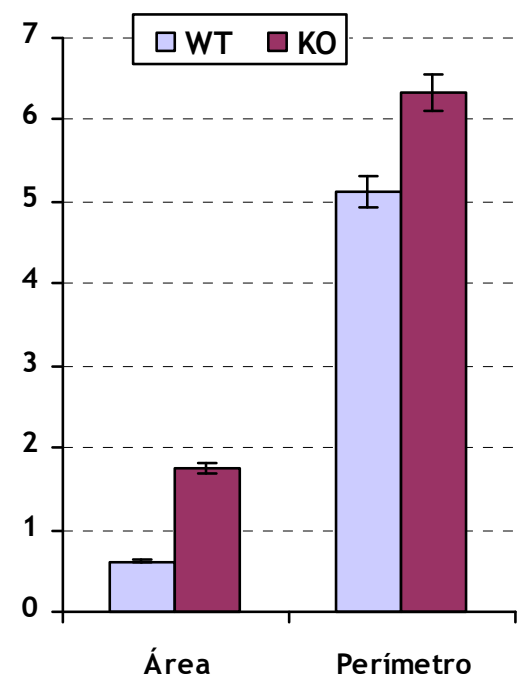

Figura R123. Morfometría del ventrículo medio.

La gráfica R123 muestra los valores medios y el error estándar de la media observados al medir el área y el perímetro del ventrículo medio en los ratones wilde type (WT) y knock out para IRS-2 (KO). 
La gráfica de la figura R124 muestra todos los diámetros estudiados, evidenciándose que fueron mayores en los animales knock out $(p<0.01)$, siendo más significativas las diferencias observadas en los diámetros transversales, $p<0.001$, sobre todo en el medio y posterior.

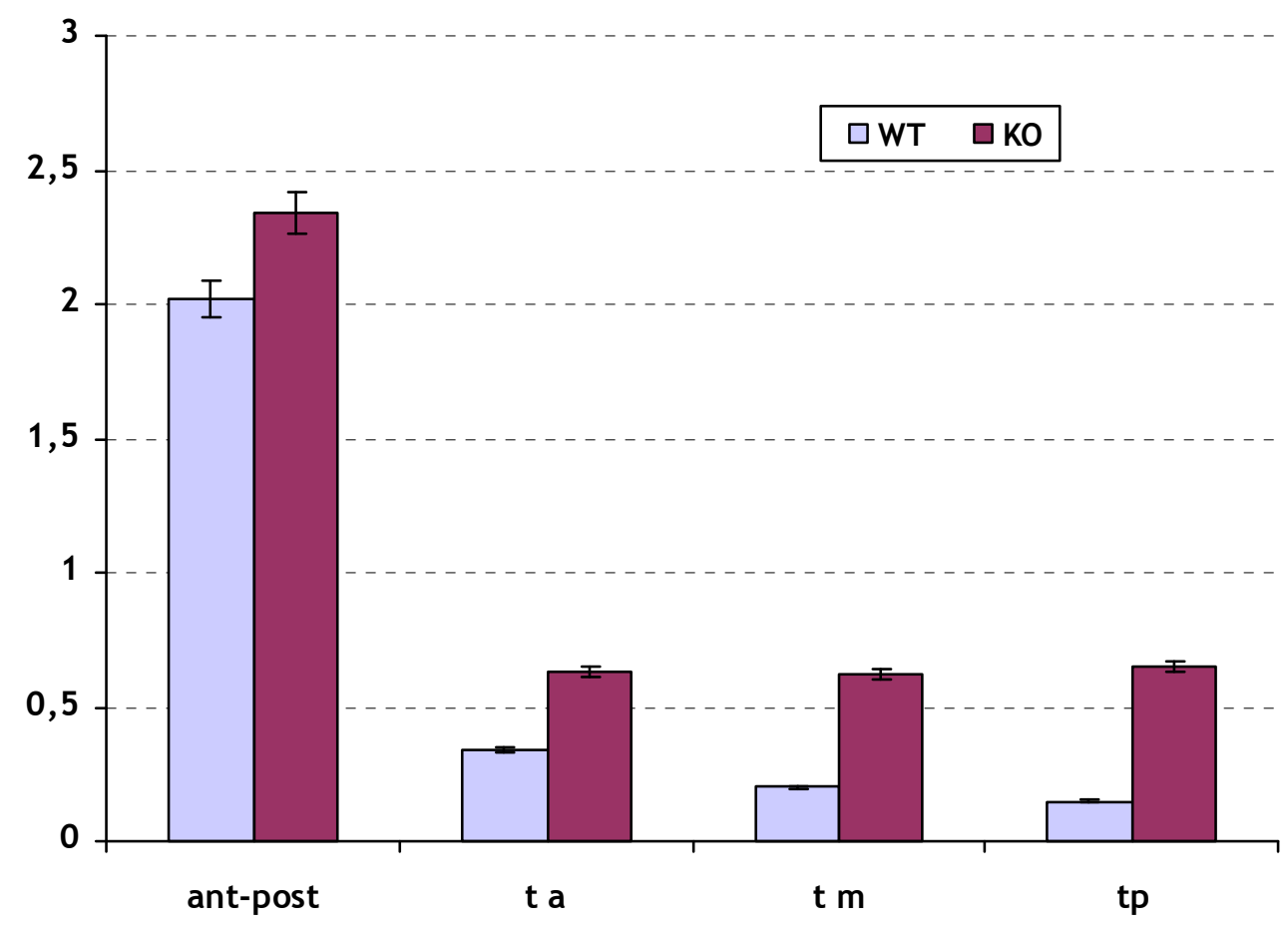

Figura R124. Morfometría del ventrículo medio.

La gráfica R124 muestra los valores medios y el error estándar de la media, en milímetros, observados al medir los diámetros antero-posterior (ant-post), transversal anterior (ta), transversal medio $(\mathrm{tm})$ y transversal posterior $(\mathrm{tp})$ del ventrículo medio en los ratones wilde type (WT) y knock out para IRS-2 (KO). 


\section{Ventrículo lateral.}

En las imágenes R125 y R126 se indican con flechas los ventrículos laterales sobre imágenes de resonancia magnética de secciones axiales del encéfalo, realizadas en ratones wilde type y knock out pata IRS-2. Los valores morfométricos de las áreas, en milímetros cuadrados, y del perímetro en milímetros (figura R127) confirman lo observado sobre las imágenes, siendo significativamente mayores en los animales knock out que en los wilde type, área $p<0.001$; perímetro $\mathrm{p}<0.01$.
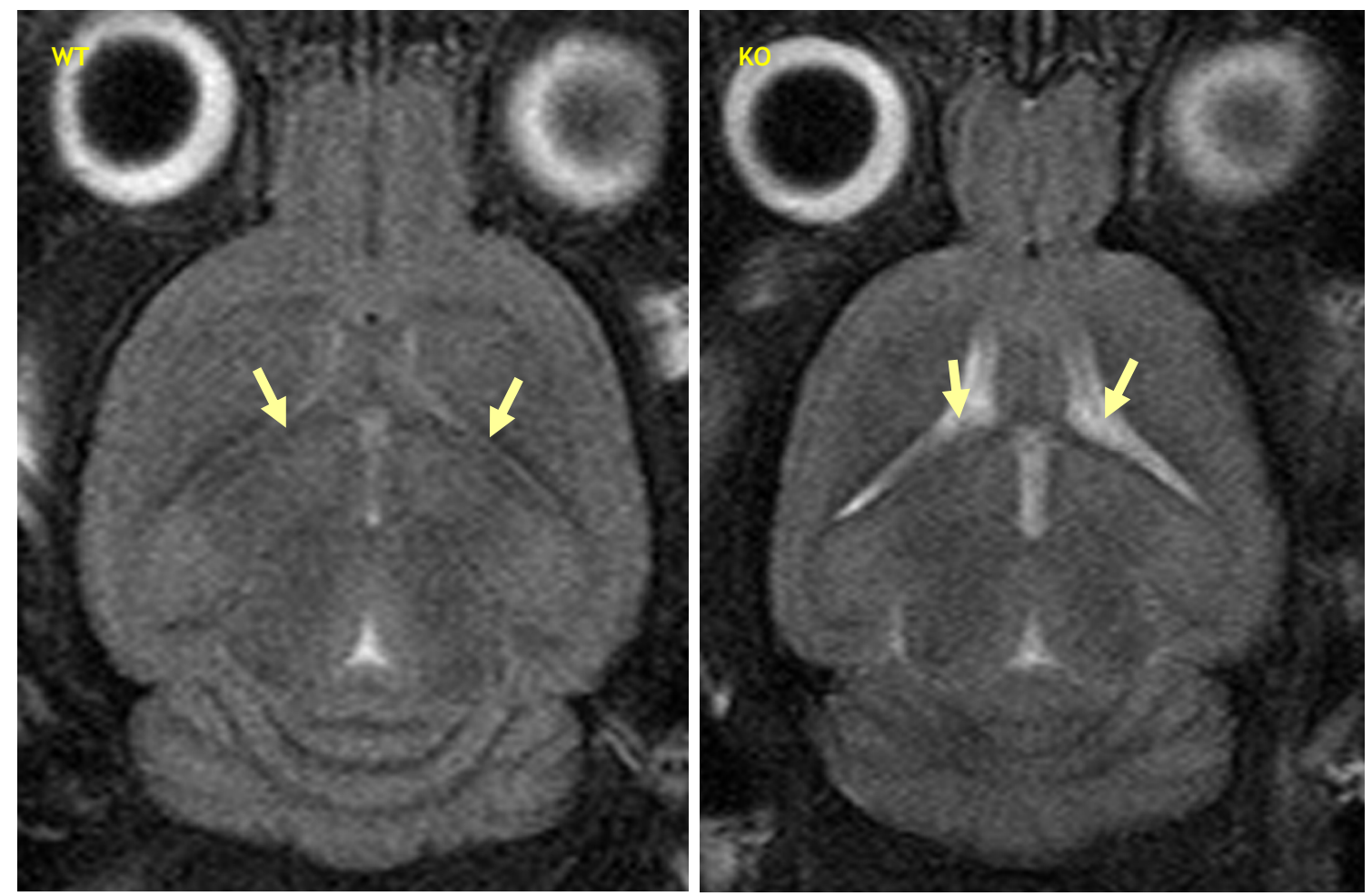

Figuras R125 y R126. Resonancias magnéticas tomadas en cortes horizontales o axiales del encéfalo. WT: wilde type, KO: knock out para IRS-2. Las flechas señalan el ventrículo lateral.

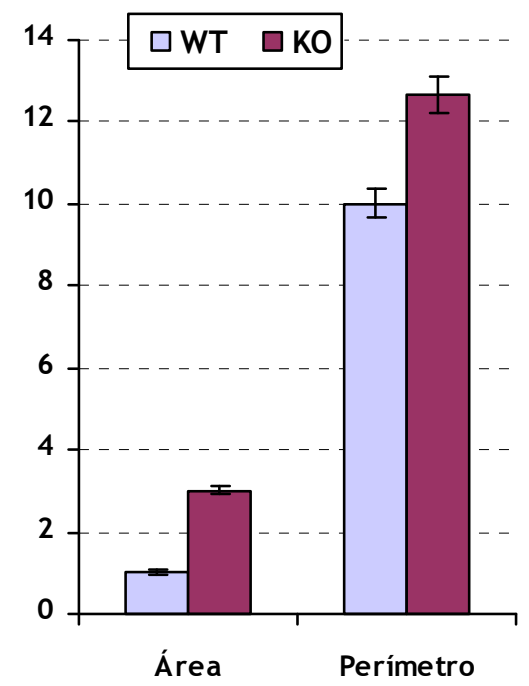

Figura R127. Morfometría del ventrículo lateral.

La gráfica R127 muestran los valores medios y el error estándar de la media observados al medir el área y el perímetro del ventrículo lateral en los ratones wilde type (WT) y knock out para IRS-2 (KO). 
Los diámetros medidos en el ventrículo lateral son todos mayores en los animales knock out frente a los wilde type (al menso $p<0.05$ ). Se resumen estas diferencias en las figuras R128 y 129. Las diferencias más significativas se apreciaron en el diámetro céfalo-caudal $(p<0.01)$ y en los diámetros transversales en las zonas frontal y encrucijada $(\mathrm{p}<0.005)$.
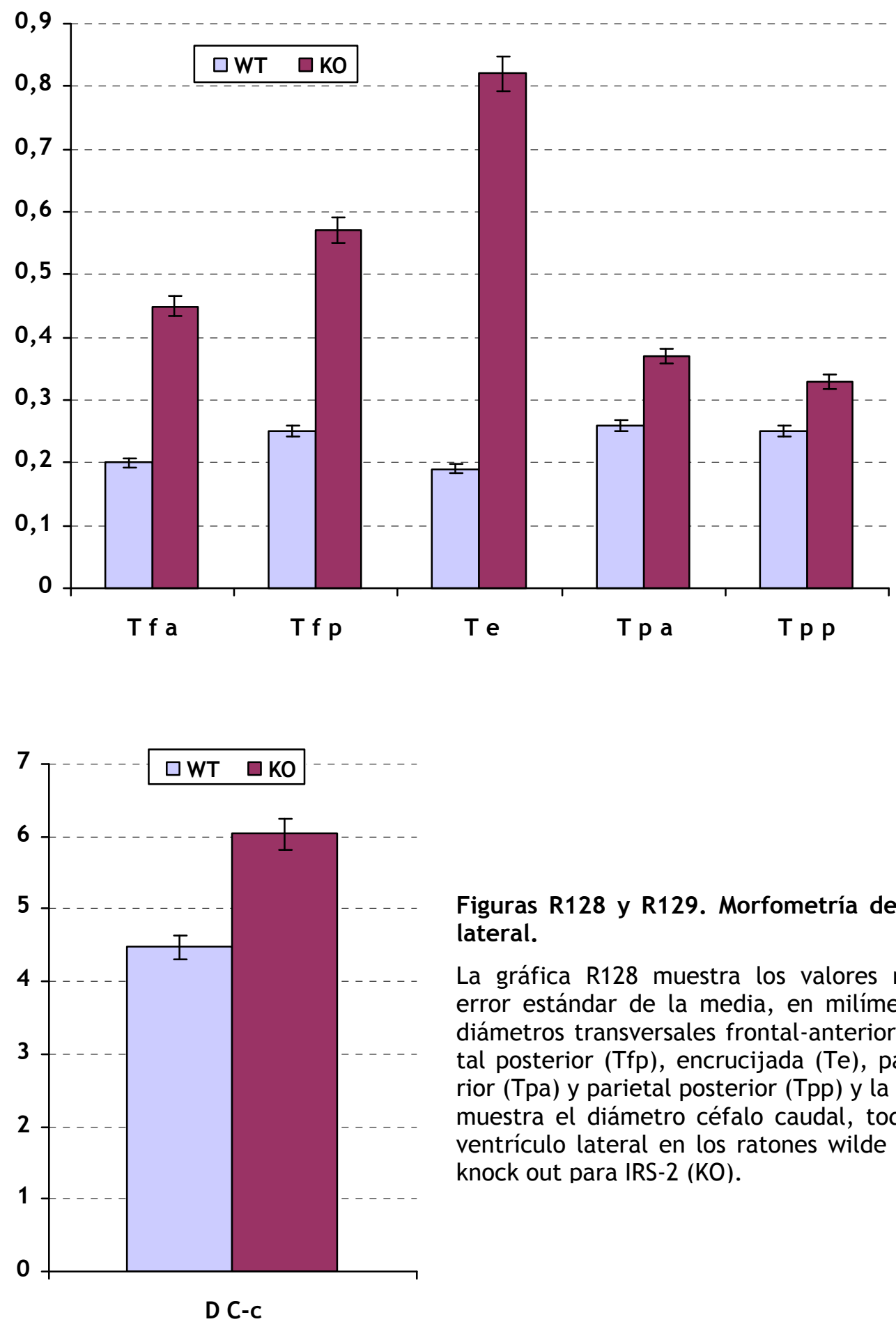

Figuras R128 y R129. Morfometría del ventrículo lateral.

La gráfica R128 muestra los valores medios y el error estándar de la media, en milímetros, de los diámetros transversales frontal-anterior (Tfa), frontal posterior (Tfp), encrucijada (Te), parietal anterior (Tpa) y parietal posterior (Tpp) y la gráfica R129 muestra el diámetro céfalo caudal, todos ellos del ventrículo lateral en los ratones wilde type (WT) y knock out para IRS-2 (KO). 


\section{Cisterna magna.}

Analizando las imágenes de resonancia magnética de secciones axiales del encéfalo, realizadas en ratones wilde type y knock out pata IRS-2, figuras R130 y R131, donde se indican con flechas la cisterna magna, se observa un aumento de la misma en los ratones KO. Esta observación se confirma con los valores morfométricos de las áreas, en milímetros cuadrados, y del perímetro en milímetros presentados en la figura R132, siendo significativamente mayores en los animales knock out que en los wilde type, área $p<0.001$; perímetro $p<0.01$.
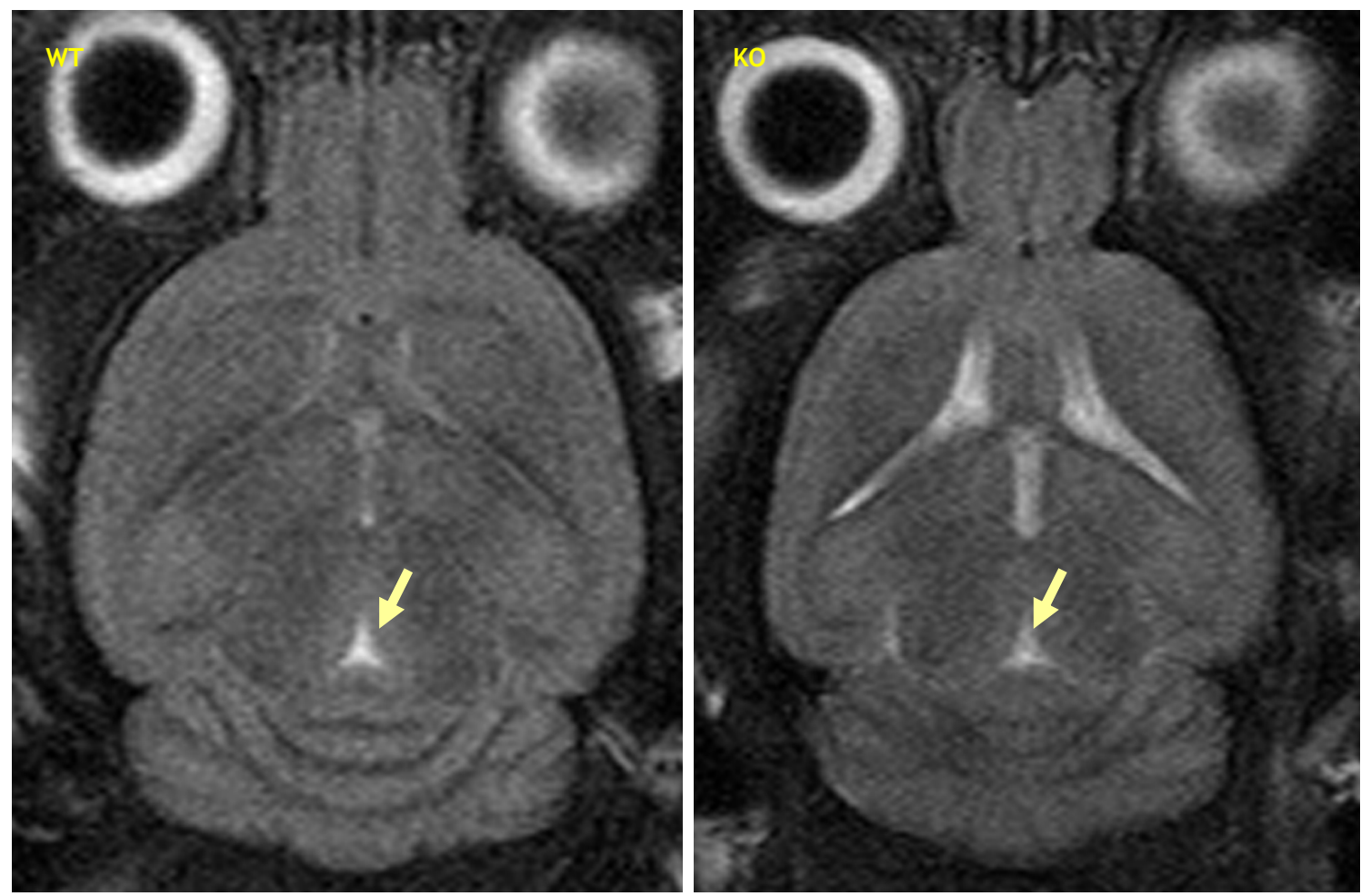

Figuras R130 y R131. Resonancias magnéticas tomadas en cortes horizontales o axiales del encéfalo. WT: wilde type, KO: knock out para IRS-2. Las flechas señalan el ventrículo lateral.

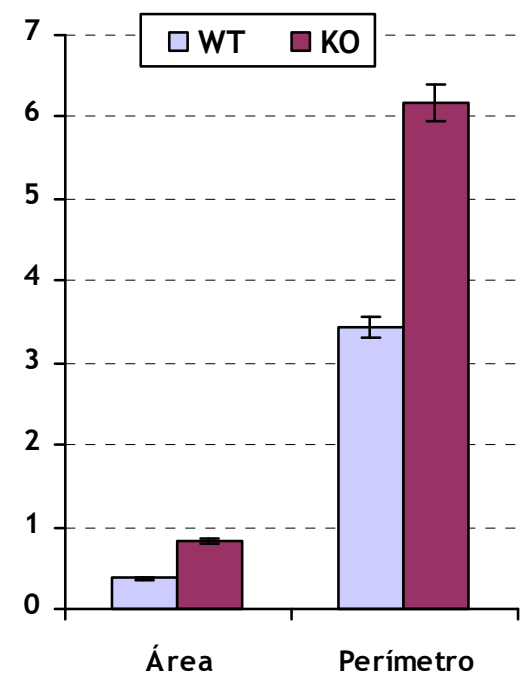

Figura R132. Morfometría de la cisterna magna.

La gráfica R132 muestra los valores medios y el error estándar de la media observados al medir el área y el perímetro de la cisterna magna en los ratones wilde type (WT) y knock out para IRS-2 (KO). 
La gráfica de la figura R133, que resume los valores de los diámetros medidos en la cisterna magna, indica que en los animales knock out, tanto el diámetro antero-posterior $(\mathrm{p}<0.01)$, como el transversal $(\mathrm{p}<0.01)$ son significativamente mayores frente a los wilde type.

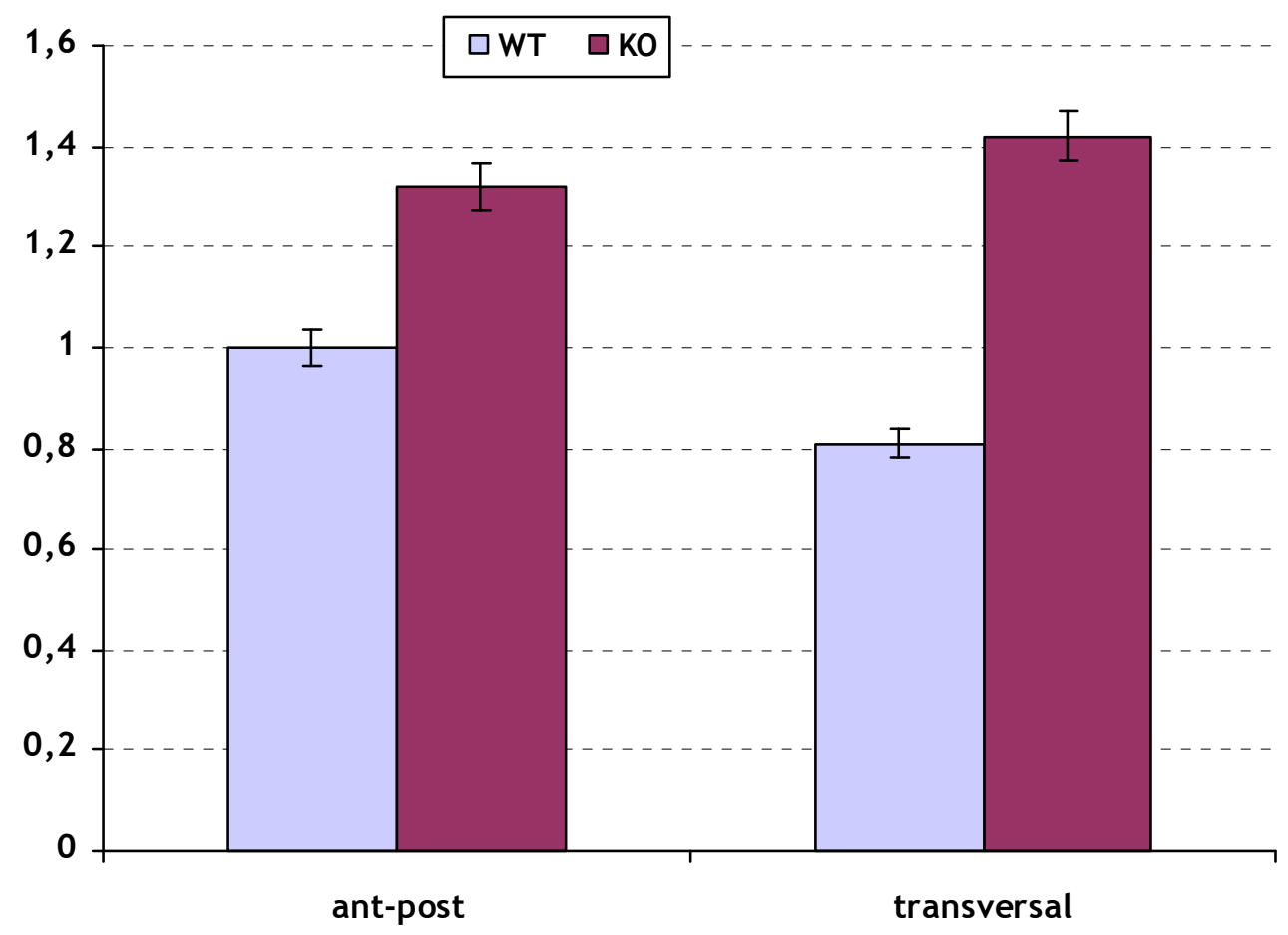

Figura R133. Morfometría de la cisterna magna.

La gráfica R133 muestra los valores medios y el error estándar de la media, en milímetros, observados al medir los diámetros antero-posterior (ant-post) y transversal de la cisterna magna en los ratones wilde type (WT) y knock out para IRS-2 (KO). 


\section{II. Áreas y perímetros encefálicos.}

El aumento de las cavidades ventriculares analizadas hasta el momento y la disminución de las diferentes zonas corticales, que se expondrán posteriormente, en los ratones knock out para IRS-2 frente a los wilde type, producen una disminución del área y del perímetro totales del encéfalo en dichos animales.

Se han medido sobre imágenes de resonancia magnética de cortes coronales del encéfalo en las localizaciones $a, b$ y c. Los resultados se presentan resumidos en las gráficas de las figuras R134, R135 y R136, las áreas en milímetros cuadrados y los perímetros en milímetros.

No se observan importantes diferencias entre los valores del área y del perímetro en las diferentes localizaciones dentro de cada grupo de animales. Sin embargo, sí se aprecia en la comparativa entre grupos que en los ratones knock out el área y el perímetro son significativamente menores, $\mathrm{p}<0.01$, respecto a los wilde type, en las tres localizaciones.
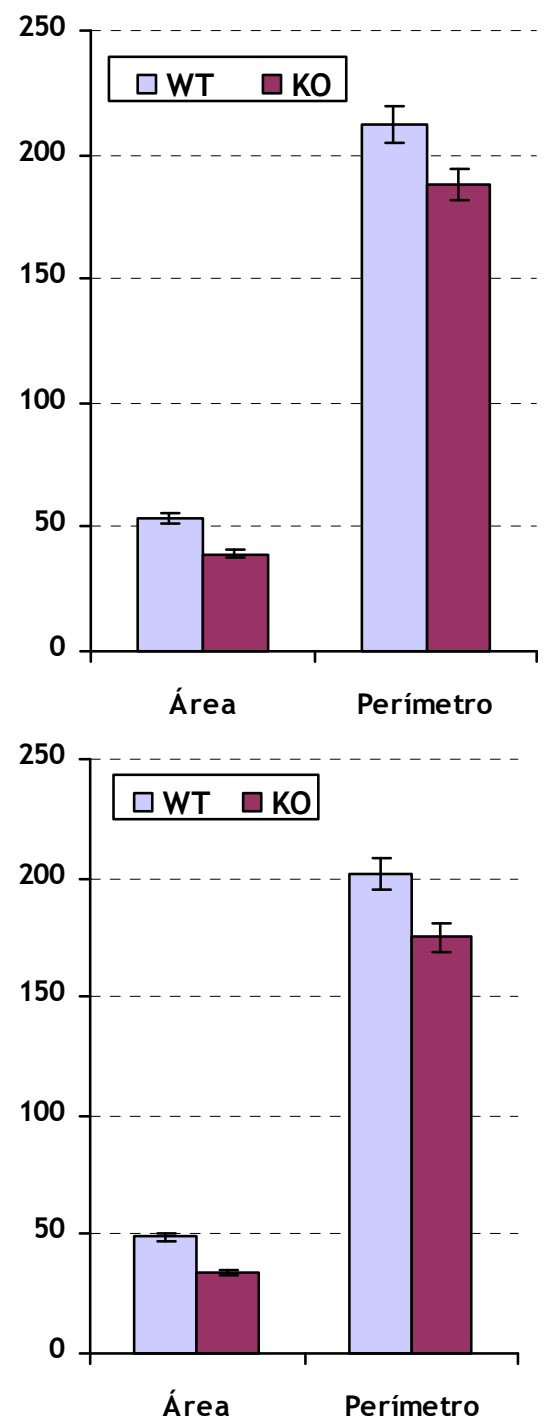

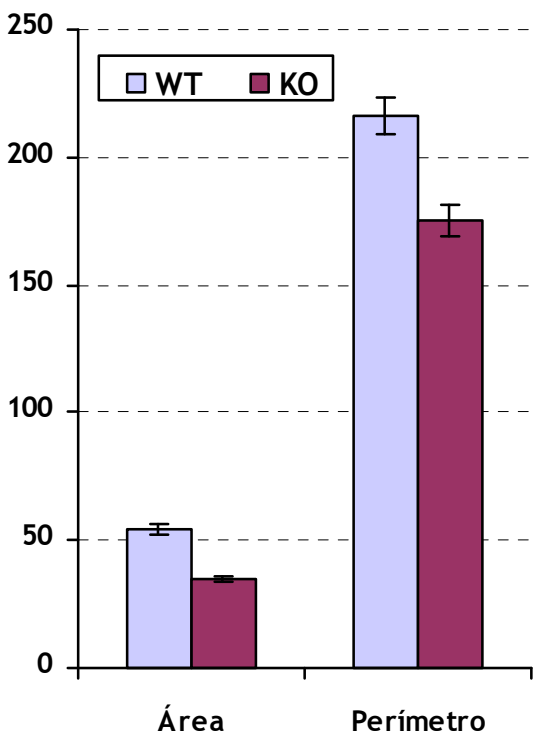

Figuras R134, R135 y R136. Morfometría del encéfalo.

La gráficas muestran los valores medios y el error estándar de la media observados al medir el área y el perímetro total del encéfalo en las proyecciones estereotáxicas a, figura R134; b, figura R135; y c, figura R136, en los ratones wilde type (WT) y knock out para IRS-2 (KO). 


\section{Espesor de la Corteza Cerebral en cortes axiales.}

\section{Hendidura interhemisférica.}

Como puede observarse en la figura R137 (montaje fotográfico que se presenta a modo de ejemplo) y en la gráfica R138, la altura de la hendidura interhemisférica en un corte axial del encéfalo de los ratones knock out para IRS2 fue significativamente menor $(p<0.05)$ que la observada en los ratones wilde type, para ambas localizaciones b y $c$.

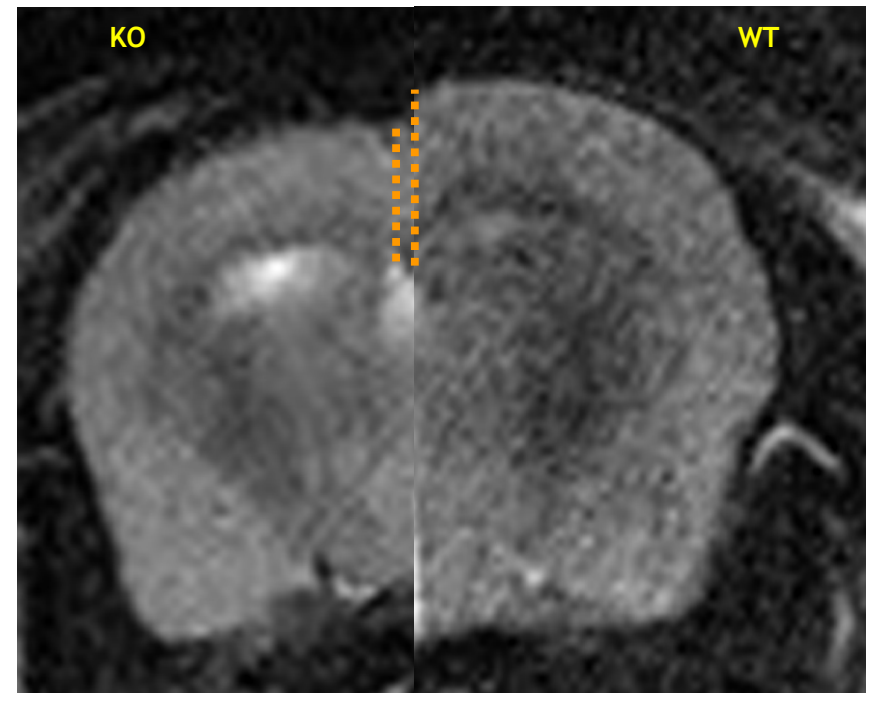

Figura R137. Montaje fotográfico que muestra la variación en la altura de la hendidura interhemisférica (línea naranja), observable con resonancia magnética.

WT: wilde type, KO: knock out para IRS-2.

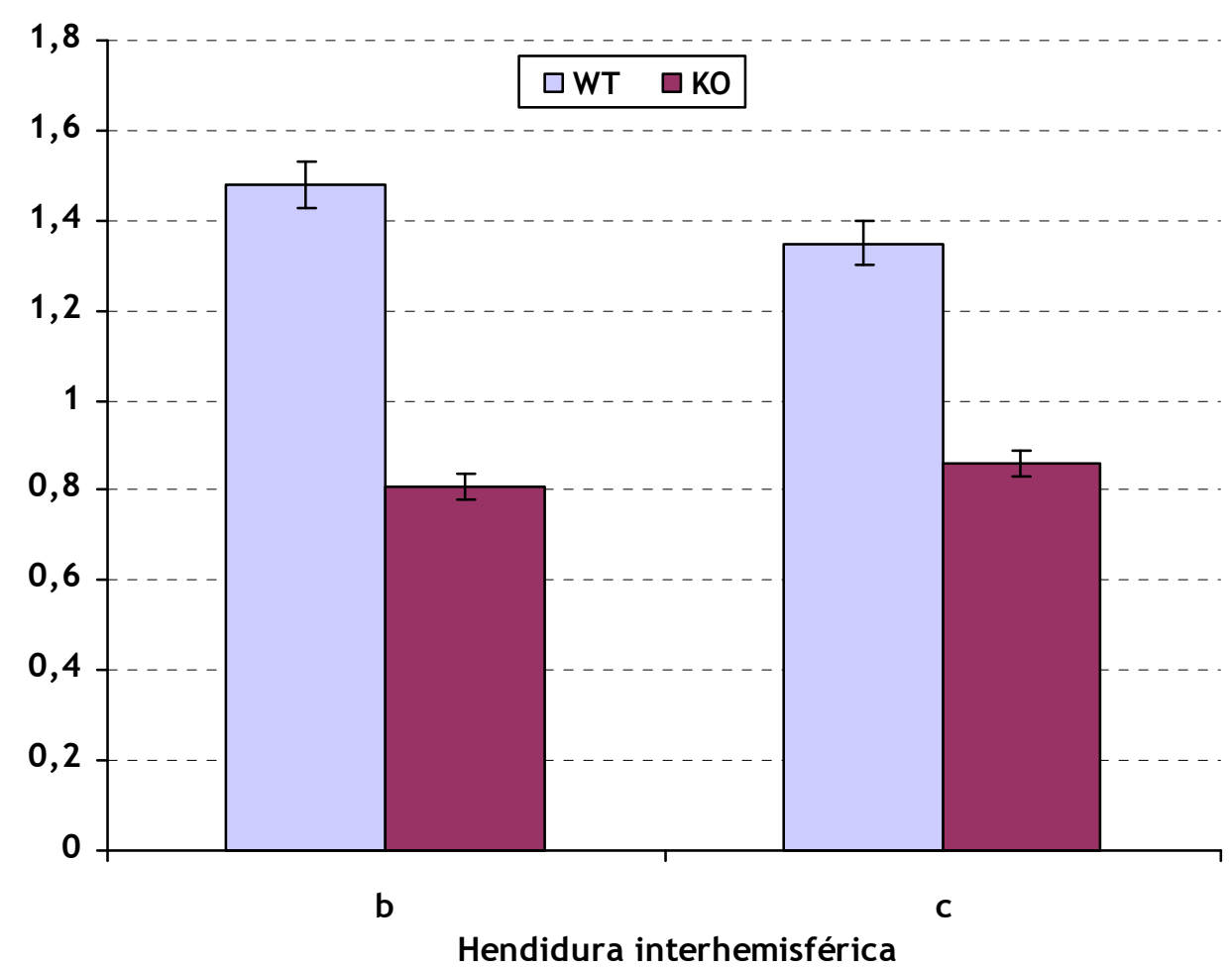

Figura R138. Gráfica que resume las diferencias observadas al medir, en milímetros, la altura de la hendidura interhemisférica en las localizaciones b y c.

WT: wilde tvpe, KO: knock out para IRS-2. 


\section{Corteza cingular.}

Los resultados morfométricos obtenidos (figura R139) muestran que el grosor de la corteza cingular fue significativamente menor $(p<0.05)$ en los ratones knock out para IRS-2 que en los ratones wilde type, siendo más apreciable en la localización $b$.

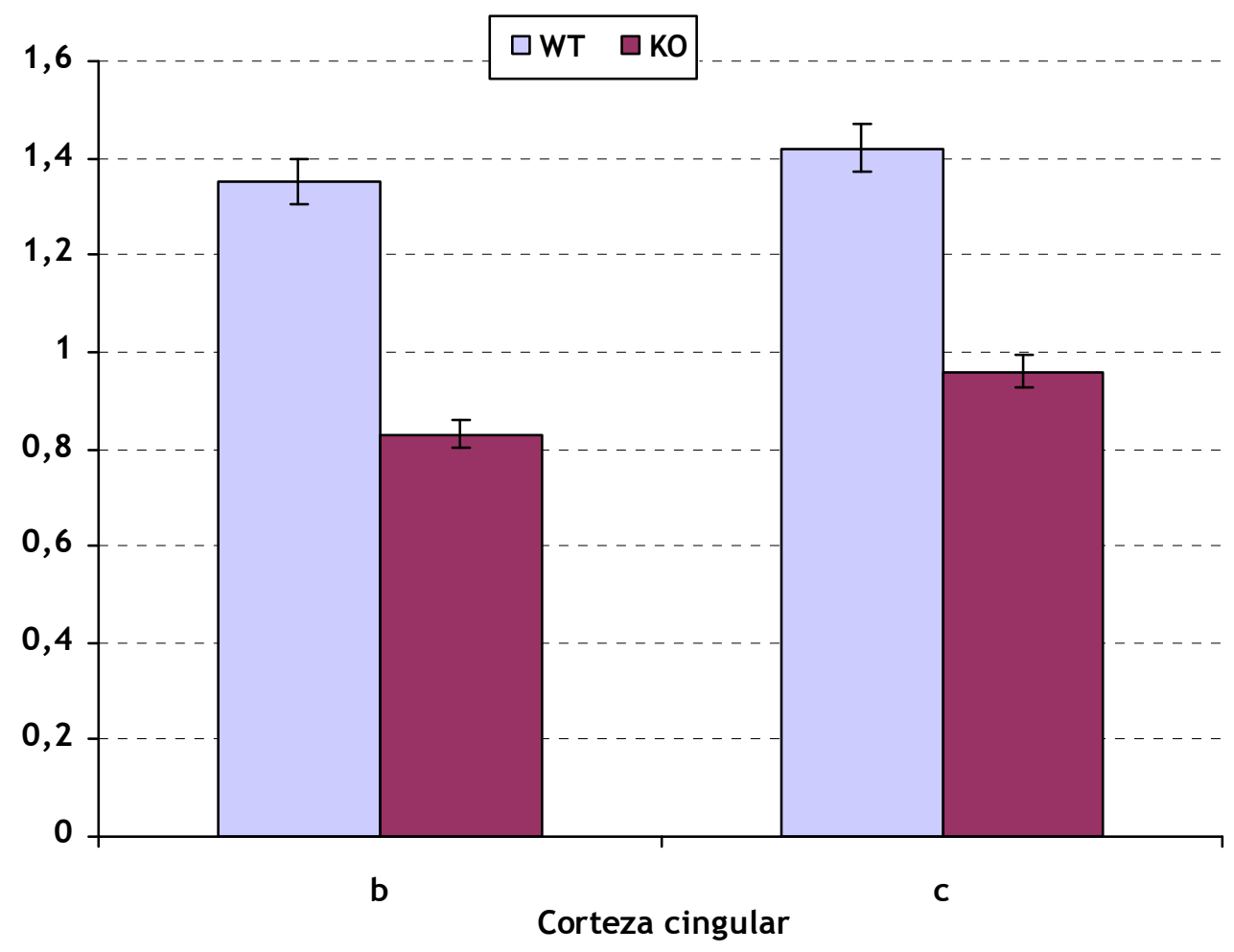

Figura R139. Gráfica que muestra las diferencias de grosor, medido en milímetros, de la corteza cingular en las localizaciones b y c.

WT: wilde type, KO: knock out para IRS-2. 


\section{Corteza motora.}

El análisis morfométrico, recogido en las figuras R140 y R141, demuestra que en todas las zonas de la corteza motora el grosor de la misma fue significativamente menor $(p<0.05)$ en los ratones knock out de IRS-2 que en los ratones wilde type.

Las diferencias más destacables se observaron en la corteza motora secundaria de la localización c donde las diferencias entre los valores medios alcanzaron un nivel de significación de $\mathrm{p}<0.01$.
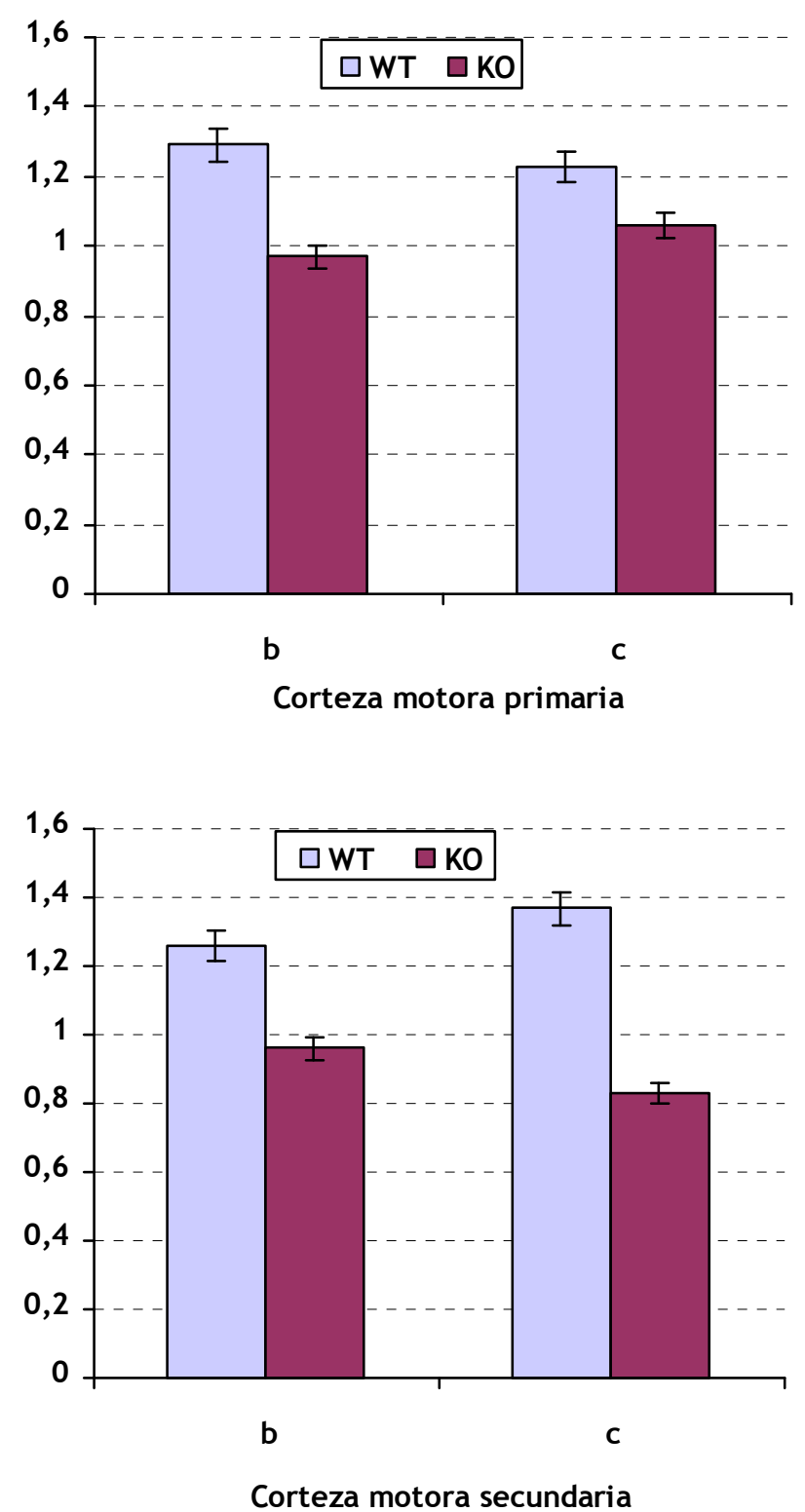

Figuras R140 y R141. Gráficas que muestran las diferencias de grosor, medido en milímetros, en las diferentes zonas de la corteza motora.

WT: wilde type, KO: knock out para IRS-2. 


\section{Corteza somatosensorial (SS).}

En esta región del cerebro, el grosor de la corteza somatosensorial primaria fue significativamente menor en los ratones knock out de IRS-2 que en los ratones wilde type.

Como se resume en la gráfica de la figura R142, esta diferencia de tamaño se observó principalmente en la corteza somatosensorial primaria en la localización $b$ donde alcanzó un grado de significación de $p<0.01$. Las diferencias observadas en la zona cortical relacionada con la proyección c, aun siendo significativas $(p<0.05)$ fueron menores que en el resto de la corteza primaria.

El comportamiento para la corteza somatosensorial secundaria, mostrado en la figura 143, siguió una tendencia similar que en la corteza somatosensorial primaria entre los ratones knock out y los wilde type, aunque con diferencias menos significativas en la localización c.

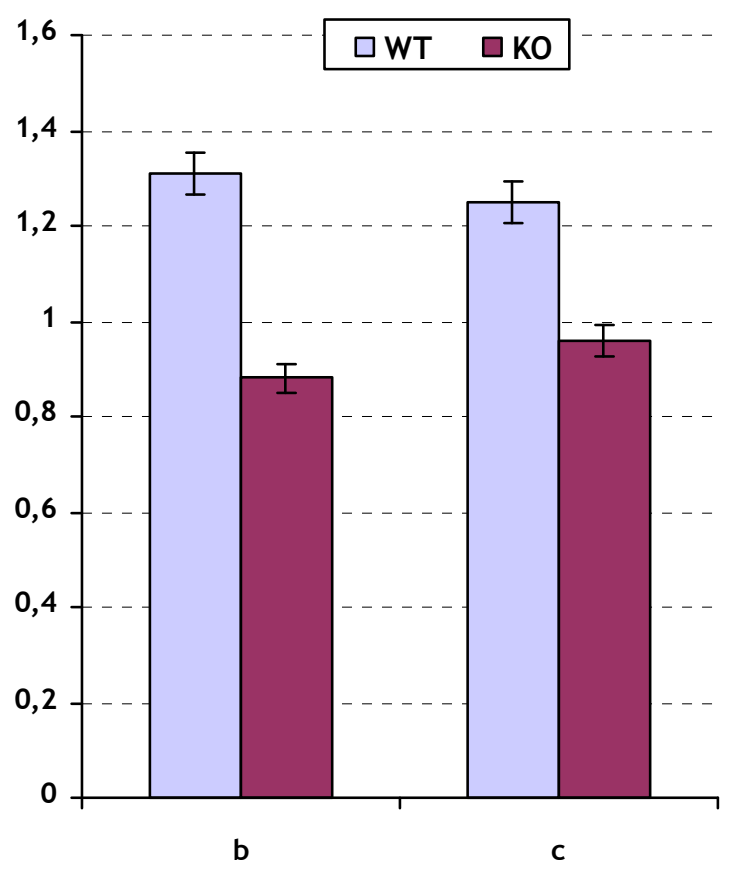

Corteza somatosensorial primaria

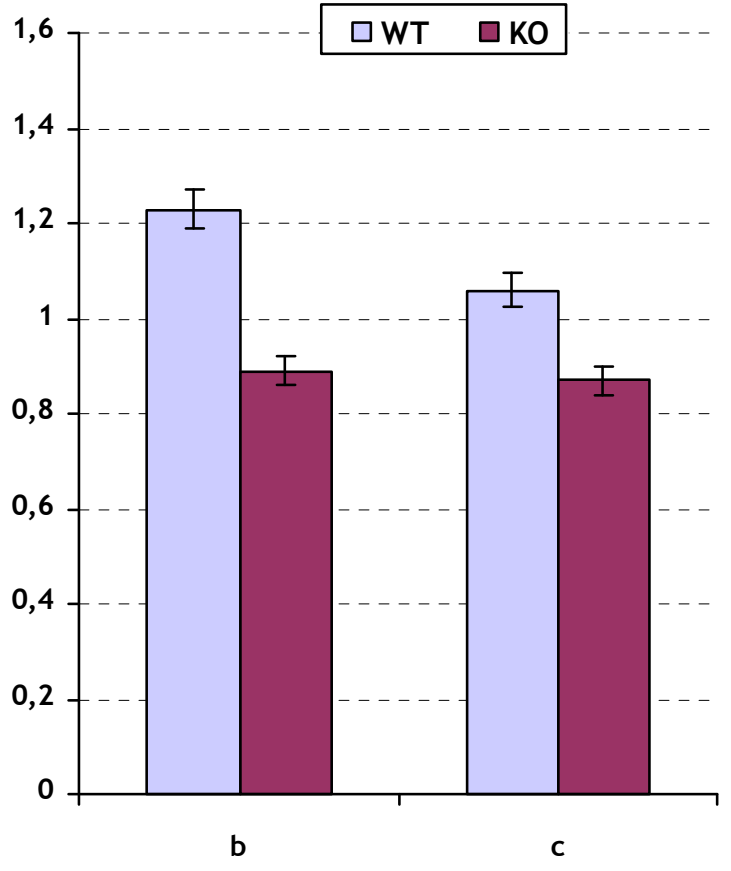

Corteza somatosensorial sec undaria

Figura R142 y R143. Gráficas que muestran las diferencias de grosor, medido en milímetros, en la corteza somatosensorial primaria y secundaria.

WT: wilde type, KO: knock out para IRS-2. 


\section{Corteza insular}

El grosor de la corteza insular también fue significativamente menor $(\mathrm{p}<0.01)$ en los ratones knock out de IRS-2 que en los ratones wilde type.

Como expresan las gráficas de la figura R144, no se apreciaron grandes diferencias entre los resultados de las proyecciones b y c, dándose un comportamiento muy similar.

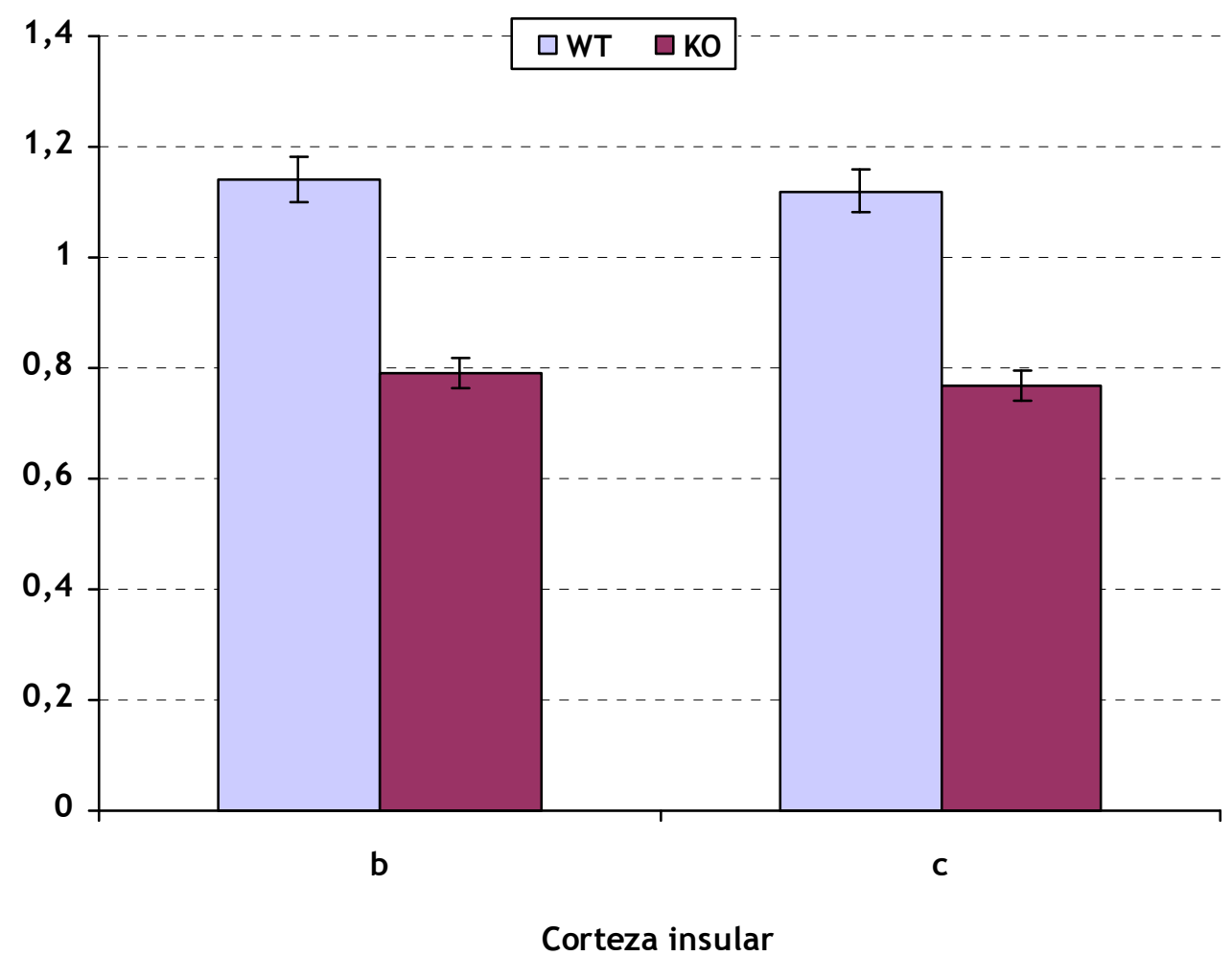

Figura R144. Gráfica que muestra las diferencias de grosor, medido en milímetros, de la corteza insular, en las localizaciones b y c.

WT: wilde type, KO: knock out para IRS-2. 


\section{Corteza entorrinal}

Los resultados morfométricos obtenidos (figura R145) muestran que el grosor de la corteza entorrinal fue significativamente menor $(p<0.01)$ en los ratones knock out para IRS-2 que en los ratones wilde type.

Además los resultados son muy similares en ambas localizaciones b y c.

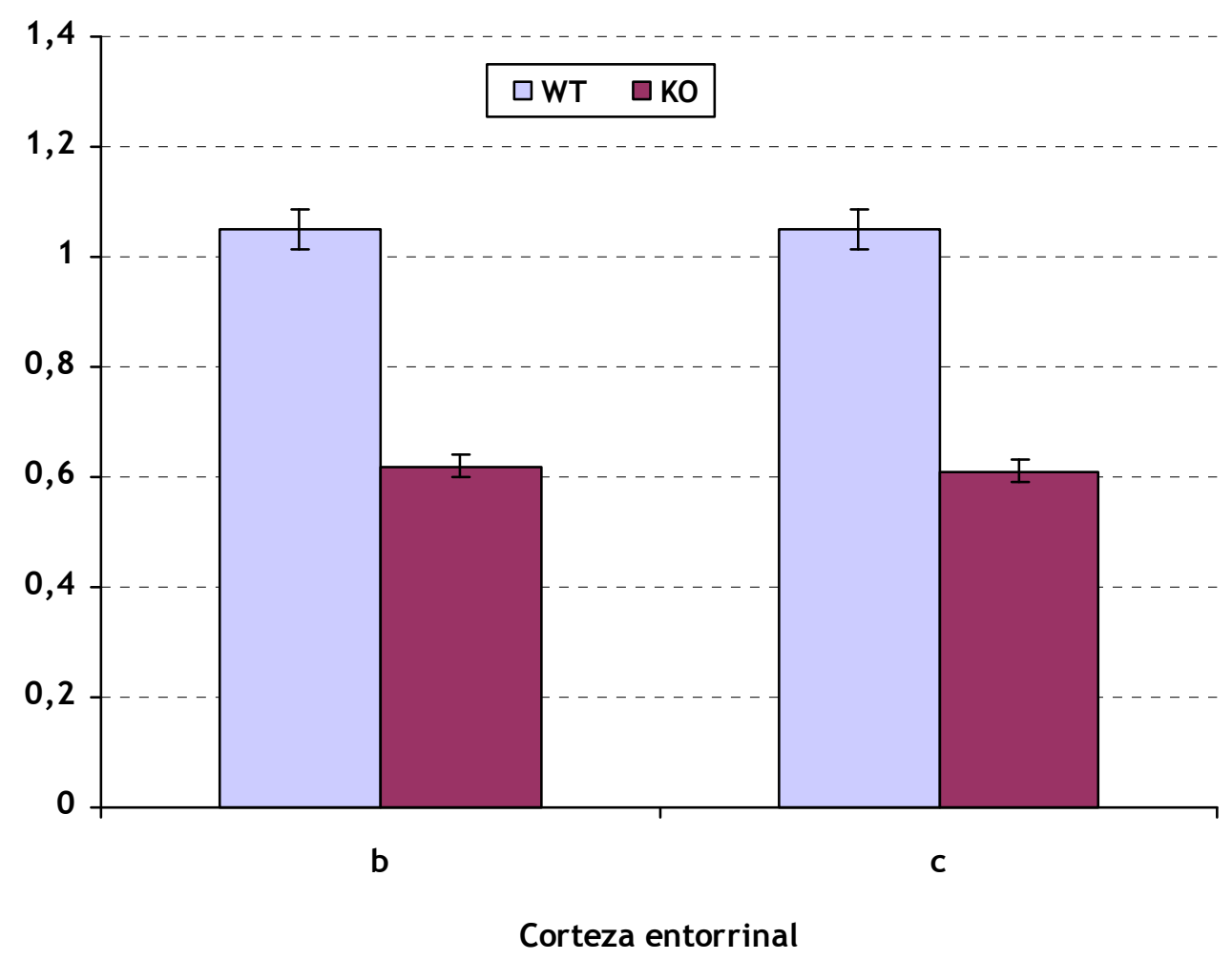

Figura R145. Gráfica que muestra las diferencias de grosor, medido en milímetros, de la corteza entorrinal, en las localizaciones b y c.

WT: wilde type, KO: knock out para IRS-2. 


\section{Hipocampo.}

La región hipocampal presentó una disminución en su grosor tanto en la dirección dorso-ventral como transversal.

En la figura R146, que resume los valores morfométricos, se aprecia que la diferencia fue más significativa en la dorso-ventral $(p<0.05)$.

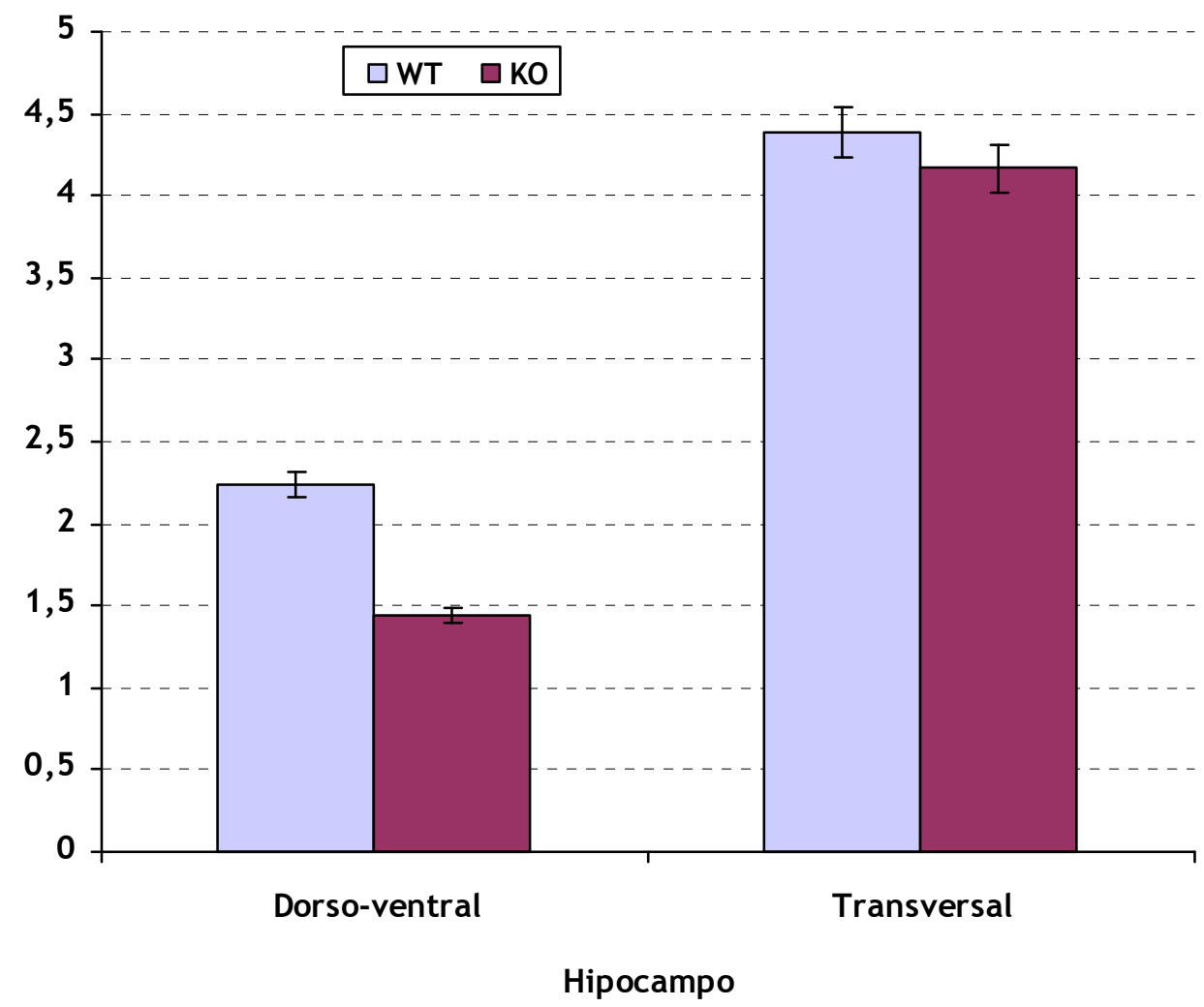

Figura R146. Gráfica que muestra las diferencias de grosor, medido en milímetros, en el hipocampo.

WT: wilde type, KO: knock out para IRS-2. 


\section{Diámetros de los Ganglios Basales en cortes axiales.}

\section{Estriado (caudado-putamen)}

La figura R147 muestra los valores medios de los grosores de la zona del estriado, medidos en milímetros. Es llamativa la disminución que se dio en los grosores que presentaron los ratones knock out para IRS-2 (KO) frente a los ratones wilde type (WT) según la dirección dorso-ventral.

Aunque también fue menor el grosor en la dirección transversal, ésta fue menos significativa que en la dirección dorso-ventral $(p<0.01)$.

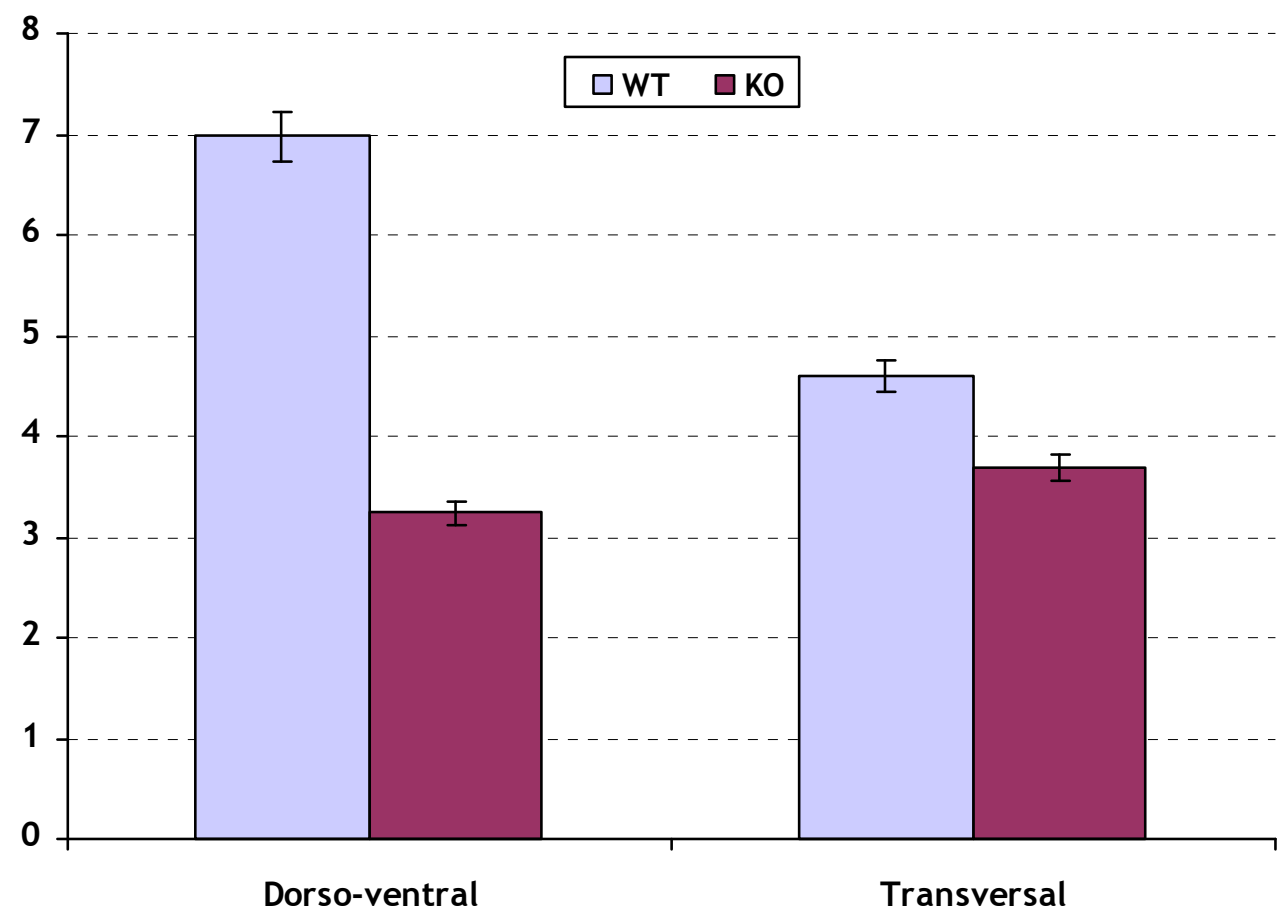

Estriado (caudado-putamen)

Figura R147. Gráfica que muestra las diferencias de grosor, medido en milímetros, en el estriado.

WT: wilde type, KO: knock out para IRS-2. 
Discusión 


\section{Comentarios relacionados con la metodología empleada.}

\section{Inmunocitoquímica.}

Hemos utilizado para el estudio inmunocitoquímico los métodos de la EstreptoAvidia-Biotina Peroxidasa (Stav-Pox) y el de la Peroxidasa Antiperoxidasa (PAP).

Son consideradas técnicas sándwich porque necesitan de tres sueros o tres complejos de reacción para su realización.

Para la PAP se precisa un primer antisuero (procedente generalmente de ratón o conejo) contra el antígeno que se quiere estudiar; un segundo antisuero (obtenido fundamentalmente de cabra o cerdo) anti-inmunoglobulina (fracción Fc) del primario; y un tercer antisuero que se consigue cuando se inmuniza a ratones o conejos con la peroxidada del rábano picante y al que se le conjuga peroxidasa. Resulta así un complejo soluble, con tres moléculas de peroxidada y dos inmunoglobulinas. Se denomina PAP.

La Stav-Pox es una variante del anterior, aunque más moderna y específica. Emplea un primer antisuero (procedente de ratón o conejo) contra el antígeno que se desea estudiar, semejante a la PAP pero normalmente de 5 a 10 veces más diluido; un segundo antisuero (obtenido generalmente de cabra o cerdo) antiinmunoglobulina (fracción Fc) del primario y que lleva incorporado a su brazo largo varias moléculas de Biotina (proteína de alta afinidad por las inmunoglobulinas); y, finalmente, un complejo de Estrepto-Avidina conjugado con varias moléculas de peroxidada, que se une a la Biotina (por la alta afinidad de Estrepto-Avidina por la Biotina).

Para la conservación de la morfología y de la antigenicidad es fundamental el proceso de fijación. Las características de las reacciones inmunocitoquímicas después del empleo de fijadores diferentes han sido analizados por muchos autores, como Nakane y col. (1989), Hall y col. (1990), Landerbg y Ross (1991), Golick y Rice (1992).

En nuestro estudio hemos utilizado una solución fijadora ampliamente experimentada en nuestro laboratorio, como demuestran gran número de publicaciones sobre el estudio inmunohistoquímico de la hipófisis y del hipotálamo (Carretero y col., 1989, 1990, 1991, 1992a, 1992b, 1995a, 1995b, 1997; Montero y col., 1990; Gil, 1992; Rubio y col., 1992, 1994; Sánchez y col., 1993).

Así comprobamos que, aun cuando la cantidad de la proteína o del péptido fuera pequeña, dicha solución se revelaba como un excelente fijador para el estudio inmunocitoquímico de Tau fosforilada, GFAP y del péptido $\beta$-amiloide en el ratón.

Los controles que hemos realizado están enmarcados dentro de los clásicamente descritos: test de dilución (Sternberger, 1979; Petrusz y col., 1976), test de sustitución de reactivos (Hutson y col., 1979; Forssmann y col., 1981) y, el más común de todos, test de preabsorción (Hutson y col., 1979; Buffa y col., 1979; Forssmann y col., 1981).

En nuestro estudio, al sustituir los sueros anti-Tau, anti-GFAP o anti- $\beta$-amiloide por tampón de ensayo o por suero normal de conejo o de ratón, obtuvimos como resultado la abolición total del producto de la reacción. 
Realizamos controles de dilución tanto para obtener la concentración más adecuada del primer antisuero como para eliminar tinciones de fondo y otras reacciones; después de un meticuloso test de dilución comprobamos que la dilución óptima del suero específico fue de 1:500 para Tau, de 1:800 para GFAP y de 1:350 para $\beta$-amiloide.

Con inmunocitoquímica, también se pueden detectar enzimas intracelulares mediante inmunohistoquímica, como hemos hecho en nuestro laboratorio con la Aromatasa P450 (Carretero y col., 1999a; 1999b), con un protocolo semejante al empleado en nuestro estudio.

La mayoría de los estudios para detectar $\beta$ amiloide y su localización cerebral se han basado en el uso de inmunohistoquímica. Los resultados indican que es el precursor más que el $\beta$-amiloide lo que se detecta intracelularmente cuando se usan los anticuerpos 4G8, 6E10 y $82 \mathrm{E} 1$.

Más allá, los resultados de tinción variaron cuando se utilizaron estrategias de pretratamientos. Se detectó $\beta$-amiloide intracelular con anticuerpos directamente a la C-término de $\beta$-amiloide (neoepitopo) en sujetos con Alzheimer. La carencia de inmunoreactividad intracelular en sujetos no dañados, cuando se usa anticuerpos contra neoepitopos, puede deberse a la falta o bajo nivel de la proteína de manera que es indetectable al nivel de luz del microscopio por el método inmunohistoquímico (Aho y col., 2010). Aunque los fragmentos amiloides solubles, en sí mismos, antes de que se produzca la agregación del amiloide en placas, tienen efectos perjudiciales sobre la función cerebral, estos efectos son reversibles $\mathrm{y}$, por lo tanto, lo más probable es que no provoquen muerte neuronal. La neurodegeneración vista en los cerebros de la enfermedad de Alzheimer lo más probable es que sea de efecto en sentido descendente, ligada a procesos tales como la activación de la respuesta inmune y la producción de radicales libres. Estos resultados sugieren que el tratamiento en los estados muy tempranos de la enfermedad de Alzheimer podría prevenir la degeneración neuronal irreversible posterior (Hölscher y col., 2007).

Morfometría y cuantificación celular.

El problema de la valoración morfológica subjetiva de la actividad celular quedó resuelto tras la aplicación de métodos cuantitativos morfométricos y estereológicos. Estos métodos han evolucionado a lo largo de los años. En sus inicios, hace prácticamente treinta años, se empleaban métodos manuales. En la actualidad, el empleo de los ordenadores y la digitalización de imágenes permite hacer análisis automáticos en los que el operador no interfiere en la medida.

Alrededor de 1850, el geólogo francés Delesse y el microscopista inglés Sorby enunciaron, independientemente, el principio de que el promedio de un área fraccional de un tipo particular de componente en una sección tomada de un cuerpo sólido es directamente proporcional a la fracción de volumen de ese componente dentro del cuerpo sólido original.

Estos autores llegaron a esta conclusión por un proceso intuitivo, pero los esfuerzos de expertos en geometría integral y probabilidad han demostrado en varias ocasiones la validez del principio de Delesse (Crofton, 1877; Delthiel, 1926; Bonnesen y Fenchel, 1934; Blaschke, 1949). 
Mayhew y Cruz Orive (1973) transformaron el principio de Delesse mediante la consideración de un modelo de esfera concéntrica (toscamente similar a una célula) y consiguieron formulaciones bastante claras de esta relación.

Otros autores también han dejado claro que las ecuaciones usadas en estereología son mera manifestación de un área mucho más amplia de las matemáticas, que se ha denominado geometría multidimensional (Miles, 1972) o simplemente probabilidad geométrica (Little, 1974).

La estereología, término acuñado por la Sociedad Internacional de Estereología en 1961, está basada en la probabilidad geométrica, y permite la evaluación de estructuras tridimensionales por extrapolación de mediciones realizadas en secciones bidimensionales. Tras la aplicación de axiomas estereológicos a mediciones realizadas en secciones bidimensionales, se consigue la medida de volumen, superficie, número de tejidos y componentes celulares con microscopía óptica o electrónica (Rohr y col., 1978).

Los métodos estereológicos son aquellos que se usan para derivar información tridimensional a partir de la consideración de imágenes bidimensionales. En sentido amplio, esto incluirá métodos de reconstrucción tridimensional usando secciones seriadas, así como métodos cuantitativos extrapolables tratados con determinaciones numéricas. Este último concepto ha sido denominado estereología cuantitativa (Underwood, 1970).

Existen bastantes revisiones y artículos que han tratado más a fondo estos temas y, entre ellos, destacamos los de Loud y col., (1965), Weibel y col., (1966), Weibel (1969), Elias y col., (1971), Weibel y Bolander (1973) y Elias y Hide (1980).

Los parámetros abiertos a estudio por los métodos estereológicos incluyen volúmenes y áreas de superficie de componentes fraccionarios, volúmenes medios y áreas de superficie medias de diferentes partículas o células dentro de un tejido, así como el tamaño y número de las mismas. Estos volúmenes, áreas, números y tamaños pueden ser estimados a partir de células o tejidos, o bien a partir de porciones de los mismos.

En estereología estricta, los valores para un componente dado son expresados como densidades que relacionan su volumen, superficie o número con la unidad de volumen de una superficie de referencia dada. En morfometría simple, los valores se expresan como la media aritmética de una población de valores que resulta de tratar estadísticamente las áreas o números referidos a áreas o a poblaciones totales de un parámetro concreto.

Los efectos de tratamientos experimentales sobre la estructura celular y el curso a lo largo del tiempo de distintos eventos morfológicos, pueden ser constatados de forma precisa por medio del volumen, superficie o número de células o de sus organelas. Con ello se evitan en gran medida los aspectos subjetivos y se pueden obtener datos cuantitativos fiables y comparables. Por ello, los métodos estereológicos y morfométricos representan un avance importante en la microanatomía y en la investigación básica morfológica en neuroendocrinología.

En nuestro laboratorio, han sido empleados en numerosas ocasiones técnicas y métodos estereológicos o morfométricos con gran eficacia y precisión. 
La validez del empleo de la morfometría y la densitometría en el análisis de resonancia magnética, utilizado por primera vez en nuestro laboratorio está bien soportado en la literatura y es de uso reciente, tal y como recogemos a continuación y en el subapartado de "Resonancia Magnética y Diagnóstico de la Enfermedad de Alzheimer y otras enfermedades neurodegenerativas".

Los pacientes con probable enfermedad de Alzheimer y la forma amnésica del deterioro cognitivo leve a menudo muestran varios tipos de déficit neuropsicológicos. Estas deficiencias a menudo se relacionan con la atrofia cortical, inducida por la degradación neuronal. Por ello, estudios recientes tratan de correlacionar si los diferentes patrones anatómicos de la atrofia cortical se asocian con déficits neuropsicológicos específicos. Para ello, una vez determinados los déficits neuropsicológicos se procede a cuantificar la atrofia cortical midiendo el espesor de la capa cortical de las diferentes partes del cerebro usando para ello imágenes de resonancia magnética. Diferentes regiones específicas del cerebro que presentan adelgazamiento cortical se asocian con disfunciones cognitivas que incluyen: contar hacia atrás, memoria verbal y gráfica, denominación y fluidez, copia de dibujos, inhibición de respuesta y atención selectiva. Sin embargo, hay otras funciones que no se asocian con focos específicos de la atrofia cortical: contar hacia delante, parte de lectura de palabras de la prueba de Stroop, reconocimiento de palabras e imágenes. Lo que sugiere que la atrofia con adelgazamiento cortical, en lugares anatómicos específicos, es un marcador patológico para formas específicas de disfunción cognitiva (Ahn y col., 2011).

Particularmente en nuestro estudio hemos aplicado la morfometría para la medición del grosor de la corteza cerebral, de los diámetros ventriculares y de los diámetros del hipocampo y el estriado, en las imágenes obtenidas con resonancia magnética.

Empleo de ratones genéticamente modificados para el estudio de la Enfermedad de Alzheimer.

Los animales trasgénicos, principalmente ratones, han sido y están siendo empleados para el estudio de los cambios patológicos de la enfermedad de Alzheimer; sin embargo, hasta ahora, la mayoría de los animales empleados tienen modificada la expresión regulable de Tau (Mocanu y col., 2008) o son animales que hiperexpresan $\beta$-amiloide.

En nuestro estudio empleamos un modelo diferente en el que no se induce la aparición artificial de la enfermedad de Alzheimer, sino que ésta acontece como consecuencia de un proceso endocrino-metabólico, parcialmente ligado a la edad como es la diabetes tipo II. 


\section{Resonancia Magnética y Diagnóstico de la Enfermedad de Alzheimer y otras enfermedades neurodegenetivas.}

La mayor ventaja del empleo de la resonancia magnética, en combinación con diferentes métodos de análisis de datos, es que proporciona herramientas para investigar alteraciones en la estructura y función del cerebro in vivo.

Los análisis con resonancia magnética convencional o funcional se han utilizado mucho en el estudio de las enfermedades neurodegenerativas, con un gran énfasis en el análisis visual y morfo-estereológico tridimensional de los procesos que acontecen en la enfermedad de Alzheimer, de cara a su diagnóstico, a esclarecer los estadios evolutivos de la enfermedad y a tratar de establecer criterios de pronóstico.

Para ello se han estudiado cohortes de pacientes con enfermedad de Alzheimer y se han contrastado con sujetos neurológicamente normales, con pacientes de otras enfermedades neurodegenerativas como enfermedad de Parkinson, corea de Hungtington, etc. Incluso se ha analizado la influencia de la edad y el sexo.

La alta resolución espacial, sensibilidad, y especificidad de la imagen por resonancia magnética (por ejemplo, la resolución: $0,8 \mathrm{~mm}$ isotrópico; sensibilidad: $80-94 \%$, especificidad: $60-100 \%$ ) han hecho que sea una poderosa herramienta para identificar alteraciones estructurales y atrofia cerebral con mediciones volumétricas de todo el cerebro (Frisoni, 2001; Kochunov y col., 2005).

Con avanzados programas informáticos, en la resonancia magnética el neocórtex del cerebro puede ser automáticamente subdividido en 32 regiones de interés basadas en circunvoluciones por cada hemisferio, incluyendo la sustancia gris, la sustancia blanca, y los volúmenes del hipocampo (Desikan y col., 2010; 2009; Yang y col., 2011). La pérdida de sustancia gris también se puede determinar midiendo el espesor cortical de la materia gris.

En nuestro estudio por resonancia magnética del cerebro de ratones hemos analizado en la transición fronto-parietal el grosor cortical del córtex frontal, del cortex parietal, del lóbulo temporal medial, del hipocampo y de algunos núcleos basales. Esta terminología es la empleada en la Neuroanatomía Humana, ya que la disposición topográfica en el ratón no guarda paralelismo exacto, debido a la lisencefalia y menor desarrollo evolutivo del encéfalo del ratón con respecto al humano. A modo de ejemplo, la corteza entorrinal que se localiza en el lóbulo temporal medial en humanos, es claramente superficial y lateral en el ratón.

Una de las diferencias claramente notables entre nuestro estudio en ratones y los estudios generalmente realizados en humanos es que, menos escasas excepciones en las que se analizan áreas de Brodman aisladas o mapeos encefálicos (Apostolova y Thomson, 2008), nuestro estudio no analiza lóbulos en general, sino que dentro de cada uno de ellos particulariza el tipo de corteza: motora, somatosensorial, etc. Siendo el primero en establecer estas distinciones, al igual que el primero que analiza mediante resonancia magnética los cambios que acontecen en el encéfalo del ratón durante un proceso de neurodegeración con lesiones y alteraciones bioquíomico-metabólicas semejantes a las que se aprecian en humanos en la enfermedad de Alzheimer. 
En la atrofia grave de la enfermedad de Alzheimer establecida clínicamente, junto a la pérdida de sustancia gris cortical, la reducción de los volúmenes de la sustancia gris y blanca subcortical, y las alteraciones del hipocampo, aparece la expansión de los espacios ventriculares y de la separación de los surcos cerebrales por rellenarse con líquido cefalorraquídeo (Thompson y col., 2004; 2007).

En nuestro estudio hemos podido comprobar que el análisis morfométrico de los ventrículos cerebrales es un parámetro muy útil en el análisis del grado de desarrollo de la neurodegeneración. No así el de los surcos ya que la lisencefalia del cerebro del ratón impide este análisis, por ello se han analizado otros espacios subaracnoideos como la cisterna magna.

El deterioro cognitivo leve, en particular el de tipo amnésico, es el concepto más reciente utilizado para describir el estado intermedio entre el envejecimiento saludable y la enfermedad de Alzheimer. Por ello, este grupo de pacientes es muy utilizado en el estudio con resonancia magnética para establecer paralelismos y etapas evolutivas entre el individuo sano y la enfermedad de Alzheimer.

Por otro lado, se ha hecho especial hincapié en determinar las zonas cerebrales más dañadas y cómo el cerebro avanza en su degeneración según progresa la enfermedad.

En 1989 se publicó el primer estudio demostrando que estimaciones cualitativas de la atrofia del hipocampo en deterioros cognitivos leves predicen su evolución hacia la enfermedad de Alzheimer (de Leon y col., 1989).

Este hallazgo ha sido reproducido posteriormente (de Leon y col., 1993; Visser y col., 1999) y más recientemente, las predicciones de progresión de la enfermedad de Alzheimer se demostraron analizando el volumen del hipocampo (Jack y col., 1999; Wolf y col., 2003) y la perfusión del hipocampo (Johnson y col., 1998). Estos primeros estudios también demostraron que el predominio de la atrofia del hipocampo aumentaba con la edad y era muy común en los dos procesos (de Leon y col., 1997; Köhler y col., 1998).

Posteriormente, se comprobó que la reducción del tamaño de la corteza entorrinal sirve para discriminar entre el deterioro cognitivo leve y el envejecimiento (Du y col., 2001; Dickerson y col., 2001; Xu y col., 2000; Juottonen y col., 1998; Bobinski y col., 1999; Toledo-Morrell y col., 2000) y predecir con precisión la futura progresión de sujetos con deterioro cognitivo leve hacia enfermedad de Alzheimer (Dickerson y col., 2001; Toledo-Morrell y col., 2000; Killiany y col., 2000; de Leon y col., 2001).

Los estudios postmortem mediante resonancia del hipocampo en el envejecimiento, el detrioro cognitivo leve, la enfermedad de Alzheimer y la hidrocefalia de presión endocraneal normal han puesto de manifiesto que el análisis cualitativo y la reducción de tamaño del hipocampo, con especial mención al giro dentado, y del lóbulo temporal lateral, son predictivos de la enfermedad de Alzheimer cuando aparecen en el deterioro cognitivo leve (de Leon y col., 1989, 1993, 1997; Narkiewicz y col., 1993; Convit y col., 1993, 2000; Bobinski y col., 1993; George y col., 1990; Golomb y col., 1993; Holodny y col., 1998; Jack y col., 1999, 2002, 2005; Grundman y col., 2002; Farlow y col., 2004; DeCarli y col., 2007). 
El patrón general de los cambios estructurales en las imágenes por resonancia magnética en pacientes con deterioro cognitivo leve y los pacientes con enfermedad de Alzheimer observado al inicio ha sido descrito por numerosos autores (Baron y col., 2001); Bozzali y col., 2006; Chetelat y col., 2005; Hamalainen y col., 2008; 2007, Hirata y col., 2005; Jack y col., 2008; Karas y col., 2008; Pennanen y col., 2005; Saykin y col., 2006; Frisoni y col., 2002; Busatto y col., 2003; Good y col., 2002; Grossman y col., 2004; Karas y col., 2003; de Leon y col., 2004; 2007; Devanand y col., 2007; 2008; Dickerson y col., 2001; Eckerstrom y col., 2008; Jack y col., 1997; 1998a; 2000; Killiany y col., 2000; Modrego, 2006; Stoub y col., 2005; Tanna y col., 1991; Wang y col., 2006; Colliot y col., 2008; Du y col., 2007; Apostolova y col., 2006b), el primer cambio evolutivo del deterioro cognitivo hacia la enfermedad e Alzheimer es la atrofia global y específica del lóbulo temporal medial (Mizuno y col., 2000; Bozzali y col., 2006; Chetelat y col., 2005; Hamalainen y col., 2007; Karas y col., 2008; Kinkingnehun y col., 2008; Whitwell y col., 2007a; 2007b; 2008; de Leon y col., 2004; 2007; Devanand y col., 2007; 2008; Dickerson y col., 2001; Eckerstrom y col., 2008; Jack y col., 2000; 2004; 2005; Killiany y col., 2000; Modrego, 2006; Stoub y col., 2005; de Toledo y col., 2004; Tapiola y col., 2008).

Los pacientes con deterioro cognitivo que evolucionan hacia la enfermedad de Alzheimer presentan un patrón de cambios atróficos casi equivalente a los observados en pacientes con enfermedad de Alzheimer un año antes de cumplir con los criterios clínicos de la enfermedad y el grado de neurodegeneración de las estructuras del lóbulo temporal medial es el mejor marcador de imagen por resonancia magnética previo a la evolución inminente hacia la enfermedad de Alzheimer, siendo el descenso del volumen hipocampal (el izquierdo más que el derecho) la característica estructural más importante (Risacher y col., 2009).

La alteración del lóbulo temporal medial y de la función cortical póstero-medial pueden ser signos indicativos de deterioro cognitivo leve que evolucionará hacia una enfermedad de Alzheimer clínica (Pihlajamäki y col., 2009).

Los pacientes con deterioro cognitivo leve muestran menor volumen entorrinal, sin diferencias en el hipocampo o la región póstero-medial, que los individuos normales. Los pacientes con enfermedad de Alzheimer presentan una pérdida importante de volumen en la corteza entorrinal, hipocampal y póstero-medial en relación con los pacientes con deterioro cognitivo leve o los individuos normales (Miettinen y col., 2011). Estos hallazgos demuestran que la atrofia entorrinal y la disfunción cortical postero-medial son las características iniciales del pródromo de la enfermedad de Alzheimer y preceden a la atrofia del hipocampo y la corteza póstero-medial.

Los estudios realizados con resonancia magnética en humanos, se han corroborado con estudio histopatológicos hallándose una importante correlación entre los volúmenes determinados desde la imagen por resonancia magnética y los histológicos. Por otro lado, las medidas del volumen del hipocampo basadas en la histología o en imagen por resonancia magnética se asocian significativamente con el número de las neuronas del hipocampo.

Aunque los límites entre la sustancia gris y la blanca de las corteza entorrinal y la perirrinal se delimitan mal en las imágenes de resonancia magnética, se han descrito estudios semejantes a los ya indicados para el hipocampo (Bobinski y 
col., 1999). Teniendo en cuenta que, además, los cambios en la corteza entorrinal pueden preceder a los cambios del hipocampo en sujetos cognitivamente normales en situación de riesgo para futuros deterioros cognitivos leves.

En una constante búsqueda de parámetros que ayuden a la mejora del diagnóstico de la enfermedad de Alzheimer, se han realizado estudios que tratan de relacionar los cambios estructurales y funcionales de diferentes estructuras cerebrales basados en el estudio de imágenes por resonancia magnética, por ejemplo, del hipocampo y de la corteza entorrinal. Además, se puede valorar el grado de activación del hipocampo mientras se realizan pruebas de codificación y recuperación de parejas formadas por palabras e imágenes. Se ha descrito (Jauhiainen y col., 2009) que las alteraciones volumétricas de la corteza entorrinal es el parámetro que mejor discrimina, por lo que la evaluación de la atrofia entorrinal, además de los criterios diagnósticos vigentes, parece prometedor en la identificación de la enfermedad de Alzheimer prodrómica.

Se han descrito variaciones morfométricas del hipocampo derecho al izquierdo en pacientes con enfermedad de Alzheimer. Este hecho se ha asociado a que existiendo interconectividad entre ambos hipocampos, el izquierdo ha sido asociado al recuerdo libre y al recuerdo libre retardado de la información verbal; mientras que el hipocampo derecho se encuentra asociado al recuerdo y al recuerdo retardado de la localización espacial de los ítems verbales (de ToledoMorrell y col., 2000).

También se ha apuntado la posibilidad de que diferencias pre-determinadas interindividuales en el volumen del hipocampo en humanos puedan determinar la vulnerabilidad para los daños cognitivos o psicopatológicos relativos a la edad a lo largo de la vida (Lupien y col., 2007).

Aunque la edad y la enfermedad de Alzheimer afectan a la atrofia del hipocampo, ambos parámetros actúan de forma independiente en el volumen hipocampal. Esto sugiere que la atrofia del hipocampo es un indicador diagnóstico temprano que puede ser usado tanto para los casos de enfermedad de Alzheimer de inicio temprano como en los pacientes ancianos típicos (Risacher y col., 2009).

No obstante, los estudios limitados al hipocampo y la corteza entorrinal no permiten diferenciar entre la demencia fronto-temporal y la enfermedad de Alzheimer; pero sí con la esquizofrenia (Laakso y col. 2001).

Nuestros resultados, obtenidos en ratones, son comparables a los estudios relacionados en humanos en lo referente al volumen del hipocampo (Jack y col., 2008; Saykin y col., 2006; de Leon y col., 2004; 2007; Devanand y col., 2007; 2008; Dickerson y col., 2001; Eckerstrom y col., 2008; Jack y col., 1997; 1998a; 1999; 2000; Modrego, 2006; Wang y col., 2006; Colliot y col., 2008; Ridha y col., 2008), y la densidad de la sustancia gris del hipocampo (Karas y col., 2004; Trivedi y col., 2006; Saykin y col., 2006), y otras regiones (Karas y col., 2004; de Leon y col., 2004; 2007; Devanand y col., 2007; 2008; Dickerson y col., 2001; Jack y col., 1997; 1998a; Killiany y col., 2000; Modrego, 2006; Stoub y col., 2005; Tanna y col., 1991; Bouwman y col., 2007; Korf y col., 2004; Visser y col., 2002; de Toledo y col., 2004; Tapiola y col., 2008).

Igualmente, se aproximan a las conclusiones obtenidas, en humanos, por otros autores, utilizando medidas del hipocampo, de la amígdala, de la cor- 
teza entorrinal y otras estimaciones del volumen del lóbulo temporal medial (Bozzali y col., 2006; Chetelat y col., 2005; Hamalainen y col., 2007; Karas y col., 2008; Kinkingnehun y col., 2008; Whitwell y col., 2008; de Leon y col., 2004; 2007; Devanand y col., 2007; 2008; Eckerstrom y col., 2008; Fleisher y col., 2008; Jack y col., 2000; 2005; Killiany y col., 2000; Modrego, 2006; Stoub y col., 2005; Korf y col., 2004; de Toledo y col., 2004; Tapiola y col., 2008; Apostolova y col., 2006a).

Las características histopatológicas del cerebro de la enfermedad de Alzheimer, mediante resonancia magnética, se traducen en lesiones "positivas" tales como placas amiloides y angiopatía amiloide cerebral, ovillos neurofibrilares y respuestas gliales, y lesiones "negativas" como la pérdida neuronal y sináptica. Los estudios post-mortem mediante resonancia magnética han permitido establecer la progresión de la patología amiloide y la tauopatía, y, en consecuencia, el desarrollo de criterios diagnósticos que se utilizan actualmente en todo el mundo. Además, los estudios de correlación clínico-patológicos han sido cruciales para generar hipótesis sobre la fisiopatología de la enfermedad, al establecer que existe una continuidad entre el envejecimiento normal y la demencia de la enfermedad de Alzheimer, y que la acumulación de placa amiloide ocurre principalmente antes de la aparición de los déficits cognitivos, mientras que los ovillos neurofibrilares, la pérdida de neuronas y la pérdida sináptica en particular, son paralelos a la progresión del deterioro cognitivo. Estos datos neuropatológicos han sido ampliamente validados por estudios longitudinales in vivo usando modernos biomarcadores de imagen como el estudio del amiloide mediante tomografía por emisión de positrones y la imagen por resonancia magnética volumétrica (Serrano-Pozo y col., 2011a).

El uso combinado de medidas de imágenes obtenidas mediante resonancia magnética, que demuestran hiperamplitud de los espacios ocupados por el líquido céfalo-raquídeo, y el análisis de las proteínas presentes en el mismo también puede ser útil en el diagnóstico precoz y específico de la enfermedad de Alzheimer, así como para ayudar a entender mejor el curso de dicha enfermedad (de Leon y col., 2004).

Otro parámetro estudiado con resonancia magnética, en humanos, es la variación en el grosor cortical. Varios ámbitos cognitivos: la función ejecutiva, la memoria inmediata, y la velocidad atención/procesamiento, se hacen anormales en las personas con Alzheimer, pero su grado de alteración depende de la edad de instauración, siendo más acentuado cuanto más temprana es. Mediante resonancia magnética se ha comprobado que el adelgazamiento cortical es más acentuado cuanto más temprana es la enfermedad. Afectándose principalmente la corteza cingular posterior izquierda, la corteza temporal lateral derecha, y la corteza parietal bilateral y el grosor cortical en general (Stricker y col., 2011).

Existen evidencias que sugieren la existencia de una cierta heterogeneidad biológica en el progreso del deterioro cognitivo y de las lesiones cerebrales de unos individuos a otros (He y col., 2009). También se han descrito hallazgos que sugieren que la enfermedad vascular puede tener un curso más largo de deterioro cognitivo que la enfermedad de Alzheimer (Selnes y col., 2008). Estos resultados, sin embargo, deben ser interpretados con cautela porque las diferencias son relativas y, además, es posible que múltiples factores etiológicos de la enferme- 
dad puedan ocurrir a la vez en un individuo dado. Por ejemplo, tanto la enfermedad de Alzheimer como la enfermedad vascular son comunes en la edad avanzada, (Seshadri y col., 2006), pueden afectar a la cognición de una manera similar (Nordahl y col., 2005), y es probable que se combinen para ser la causa más común de demencia (Schneider y col., 2007). No obstante, el tratamiento de la enfermedad cerebrovascular ha demostrado que influye en la incidencia de demencia en poblaciones de alto riesgo (Hansson y col., 1999; Forette y col., 1998).

La validación histológica postmortem de los hallazgos obtenidos por resonancia magnética, semejante a la empleada por nosotros en este estudio, es un método aceptado por la comunidad científica y ensayado en humanos sobre pacientes con enfermedad e Alzheimer (Bobinski y col., 2000).

En relación con nuestro estudio, debemos comentar que la resonancia magnética también se ha empleado para analizar los efectos de la diabetes o las relaciones entre ellas y la neurodegeneración o su asociación con la patología vascular (Den Heijer y col., 2003). Comprobándose que los pacientes con diabetes mellitus tenían más atrofia del hipocampo y la amígdala en comparación con los individuos no diabéticos. Además, la resistencia a la insulina progresiva se asocia a una mayor atrofia de la amígdala. Estos hallazgos no guardan relación con las alteraciones vasculares sino con la diabetes en sí misma.

En nuestro estudio con los ratones knock out para IRS2 la atrofia del hipocampo es evidente; las variaciones en la amígdala no podemos descartarla, pero no se han incluido en el estudio por la enorme dificultad que entraña establecer en resonancia magnética de ratones los límites anatómicos del complejo amigdalino.

Aunque en principio podría haber sido interesante hacer un estudio en el tiempo de los animales analizados en nuestro trabajo para comprobar la evolución de las alteraciones observadas en la resonancia magnética, dos razones justifican el no haberlo hecho: en primer lugar pretendíamos establecer un diseño experimental que nos permitiera sentar las bases para estudios posteriores, $y$, en segundo lugar, estudios secuenciales hechos en humanos durante tres años demostraron que los cambios observados a nivel individual fueron pequeños, y dentro del rango de exactitud de las medidas, al menos en el hipocampo. Por lo tanto, una serie en el tiempo de resonancias del hipocampo no ofrece ninguna ventaja sobre un estudio único para apoyar el diagnóstico de enfermedad de Alzheimer (Laakso y col., 2000).

\section{Comentarios relacionados con los resultados obtenidos.}

La enfermedad de Alzheimer se caracteriza por la formación de dos importantes agregados de proteínas: placas seniles y ovillos neurofribilares, los cuales están involucrados en el proceso conducente a la progresiva degeneración neuronal y la muerte. Para esta enfermedad, la neurodegeneración es una condición patológica de las células, antes que un acelerador del envejecimiento. 
Las placas seniles se generan por la deposición en el cerebro humano de fibrillas del péptido $\beta$-amiloide, un fragmento que proviene del proceso proteolítico de la proteína precursora del amiloide.

Al igual que en el cerebro humano, el análisis inmunocitoquímico realizado en este estudio sobre los ratones knock out para IRS-2 confirman la presencia de depósitos $\beta$-amiloide en diferentes regiones cerebrales del mismo, frente a la ausencia en los cerebros de los ratones wilde type.

En su patogenia se ha implicado a la hiperfosforilación de la proteína Tau, que es el principal componente de los filamentos helicoidales apareados, que forman una red compacta de filamentos llamada ovillos neurofibrilares. Al estrés oxidativo, ya que existen suficientes evidencias de que constituye un factor importante en la modificación de los patrones normales de señalización de células neuronales, conduciendo a anormalidades bioquímicas y estructurales y neurodegeneración como la relatada para la patogénesis de la enfermedad de Alzheimer (Maccioni y col., 2001). A alteraciones inmunológicas como la presencia de anticuerpos para la proteína básica de la mielina, con niveles hasta 10 veces superiores a los encontrados en otros procesos neurológicos (Singh y col., 1992); el aumento en la producción de citoquinas como interleucinas 1, 2 y 6 . Otro hallazgo significativo de un posible fallo en el sistema inmune lo sugiere el que la inmunocitosis en sangre de sujetos sanos responde a la estimulación con $\beta$ amiloide, cosa que no ocurre en sujetos con enfermedad de Alzheimer (Singh, 1994). Además, se ha descrito la presencia de un anticuerpo específico anticerebral que se dio en el $57 \%$ de los pacientes con Alzheimer, siendo prácticamente inexistente en los individuos de control (Singh y col., 1986).

Analizaremos a continuación los hallazgos obtenidos por otros autores, contrastándolos con los obtenidos en nuestro estudio y relacionándolos con la posible resistencia a la insulina en el cerebro de los ratones knock out para IRS2.

Aunque hemos subdividido en subapartados temáticos esta parte de la discusión, la gran implicación que se da entre los agentes estudiados durante el desarrollo y evolución de la enfermedad de Alzheimer y su posible relación con la diabetes tipo II por resistencia periférica a la insulina, hace que la separación total por temas sea imposible ya que, de lo contrario, las explicaciones y hallazgos se harían probablemente incomprensibles.

\section{Fosforilación de Tau.}

La implicación de Tau en las enfermedades neurodegenerativas fue recogida excelentemente en su elegante revisión por Avila (2006). Las ideas principales de dicha revisión, a la que se incorporan hallazgos de otros autores y algunos matices, se recogen en este apartado.

La proteína Tau fue descubierta por primera vez como una proteína asociada a microtúbulos que disminuye la concentración de la tubulina, ésta se polimeriza para formar los microtúbulos en el cerebro (Weingarten y col., 1975).

La unión de Tau a los microtúbulos trae como consecuencia la estabilización de los microtúbulos ensamblados, permitiendo la extensión y estabilización de las neuritas (Caceres y Kosic, 1990; Drubin y col., 1986). 
Pero, Tau bloquea el transporte a través de microtúbulos y aumenta el estrés oxidativo (Ebneth y col., 1998; Stamer y col., 2002; Trinczek y col., 1999).

Aunque pudiera ocurrir que un equilibrio entre estos dos efectos sea necesario para el correcto transporte axonal a través de microtúbulos estables, es poco probable ya que la ausencia de Tau no provoca diferencias en el transporte (Dawson y col., 2001; Harada y col., 1994).

La identificación de Tau como un componente de los filamentos helicoidales apareados, típicos de la enfermedad de Alzheimer (Grundke-lqbal y col., 1986a) hizo que adquiriera un interés adicional.

Aunque nuestro estudio era principalmente morfométrico sobre imágenes de resonancia magnética, también se ha querido completar analizando la presencia o ausencia de tau fosforilada en los cerebros de los ratones knock out, por ser una característica típica de la enfermedad de Alzheimer humana, con el propósito de que los resultados pudieran potenciar la valía del ratón knock out para IRS2 como modelo para el estudio de la neurodegeneración del tipo enfermedad de Alzheimer. El análisis inmunocitoquímico reveló la presencia de tau fosforilada en diferentes áreas cerebrales.

Como ya hemos comentado con anterioridad, estos filamentos contribuyen a formar los ovillos neurofibrilares, agregados de proteínas que, junto con las placas seniles, son las estructuras aberrantes encontradas en los cerebros de los pacientes con enfermedad de Alzheimer (Alzheimer, 1911).

El interés por Tau se acrecentó cuando se supo que, muy probablemente, el principal componente de los filamentos era Tau (Montejo de Garcini y col., 1986; Goedert y col., 1988; Wischik y col., 1988), en una forma hiperfosforilada (Grundke-lqbal y col., 1986b). A la vez que la hiperfosforilación de Tau provocaba una disminución en la unión de Tau a los microtúbulos (Busciglio y col., 1995).

Diferentes isoformas de la proteína Tau se pueden expresar como el resultado del empalme de RNAs diferentes y cada una de estas expresiones tiene diferente grado de fosforilación (Himmler, 1989; Himmler y col., 1989). No obstante, todas las isoformas son capaces de polimerizarse en estructuras fibrilares (Goedert, 1999), tales como las presentes en la enfermedad de Alzheimer. Significativamente, los polímeros de Tau también se pueden encontrar en otros trastornos neurodegenerativos caracterizados por la presencia de agregados de fosfoTau, las llamadas tauopatías (Lee y col., 2001). Por lo tanto, las patologías asociadas con Tau están relacionadas con su fosforilación y su agregación, aunque como veremos más adelante también lo pueden estar con su fragmentación.

El término tauopatía se usa para definir un grupo de desórdenes neurodegenerativos en los que se cree que la hiperfosforilación de Tau y la agregación de ovillos neurofibrilares están directamente asociados con la muerte neuronal y el progreso de la enfermedad.

Se observan tres características principales en la patología de Tau: la hiperfosforilación de Tau, la desestabilización microtubular y la polimerización de Tau.

La fosforilación anormal de Tau tiene un papel directo en la desestabilización microtubular, no así la agregación de Tau. Sin embargo, la desregulación de qui- 
nasas tiene su importancia en el proceso de la enfermedad, ya que las quinasas GSK-3 y CDK-5 se han identificado como actores clave en los cerebros de los enfermos de Alzheimer. Las mutaciones en el gen de Tau asociadas con la enfermedad de Parkinson ligada al cromosoma 17 tienen influencia en la estabilidad microtubular, ensamblaje microtubular y la agregación de Tau. Además, la proporción entre diferentes isoformas de Tau es crucial para la célula, ya que una relación perturbada es suficiente para desencadenar la enfermedad. Muchas de estas mutaciones se han utilizado para generar modelos de ratón para estudiar los mecanismos que hay detrás de las tauopatías (Froelich-Fabre y Bhat, 2004).

La fosforilación de Tau en los residuos serina/treonina es una modificación que puede afectar a un total de 79 residuos de los 441 que posee la isoforma más larga de Tau en el sistema nervioso central (Goedert y col., 1989), y es la que ha sido más estudiada.

Las principales quinasas involucradas en las modificaciones de Tau y degeneración neuronal han sido divididas en dos grupos: proteín-quinasas que actúan sobre prolina o motivos prolin-serina/treonina, como son la proteín-quinasa activadora de mitógenos (MAP), la quinasa 3b de la glicógeno sintetasa (GSK3b), la quinasa Tau-tubulina, la qinasa ciclin-dependiente (cdk2 y cdk5), las quinasas activadas por estrés (SAPK); y las quinasas que fosforilan motivos distintos a prolin-serina/treonina, entre las que se incluyen la quinasa reguladora de afinidad a microtúbulos (MARK), la proteín-quinasa II dependiente de $\mathrm{Ca}^{2+} /$ calmodulina (CaMPKII), la proteín-quinasa dependiente de AMP cíclico (PKA) y la quinasa II de la caseína (García y Jay, 2002).

Cdk5 tiene un papel crítico en el desarrollo cerebral y la neurogénesis. La desregulación de esta kinasa como ocurre por la carga amiloide extracelular en la hiperfosforización de Tau, provoca una secuencia de eventos moleculares que conducen a la degeneración neuronal. Los inhibidores de Cdk5 y GSK3beta y los oligonucleótidos antisentido ejercen protección contra la muerte neuronal.

Cdk5 es una proteína importante para la regulación fina de eventos postraduccionales que originan cambios subcelulares en la organización del citoesqueleto. Dado su carácter multifuncional, al asociarse a otras proteínas celulares interactúa con el citoesqueleto y forma complejos supramoleculares. Cdk5 contribuye a la fosforilación de Tau humana en los residuos S202, T205, S235 y S404.

En la enfermedad de Alzheimer, por lo menos treinta residuos serina/treonina son fosforilados (Gong y col., 2005; Morishima-Kawashima y col., 1995) por dos tipos de quinasas: quinasas relacionadas con prolina, como GSK3, Cdk5, p38 o JNK; y quinasas no relacionadas con prolina, como PKA, PKC, CaMPKII o CKII (Goedert y col., 1997; Baudier y col., 1987; Correas y col., 1992; Drewes y col., 1992; Hanger y col., 1992; Imahori y col., 1997; Ishiguro y col., 1992; Lucas y col., 2001; Scott y col., 1993).

Por otra parte, parece que esta fosforilación regula a menudo la unión de Tau a los microtúbulos (Busciglio y col., 1995).

Entre las quinasas identificadas anteriormente, GSK3 juega un papel importante en la regulación de la fosforilación de Tau en condiciones patológicas experimentales (Perez y col., 2003; Noble y col., 2005). 
También hay evidencia de que la Tau pseudo-hiperfosforilada es tóxica para las células y que está asociada con la inducción de muerte celular por apoptosis (Brandt y col., 2005). De hecho, ya que la Tau fosforilada parece ser más resistente a la proteolisis por diferentes proteasas (Johnson y col., 1989; Shimura y col., 2004), esta fosfoTau podría acumularse en las neuronas, ejerciendo, de este modo, su influencia tóxica sobre la célula.

Una clase particular de enfermedad de Alzheimer, la enfermedad de Alzheimer familiar, se asocia con mutaciones en los genes APP, PS-1 y PS-2 (Price y col., 1998), que son responsables de la expresión de la proteína precursora de amiloide, y de las presenilinas 1 y 2 . El péptido precursor de amiloide, como su nombre indica, es la proteína precursora para el principal componente de las placas seniles, el péptido $\beta$ amiloide, mientras que PS-1 y PS-2 son los componentes de un complejo proteico que muestra la actividad proteolítica y que está implicado en la división del péptido precursor de amiloide para producir $\beta$ amiloide.

La hipótesis de la cascada de $\beta$-amiloide (Hardy y col., 2002), propone que la acumulación de $\beta$-amiloide puede ser aumentada por mutaciones en el péptido precursor que facilita su escisión en $\beta$-amiloide. Por otra parte, se ha sugerido que el incremento de las mutaciones funcionales podría aumentar la actividad del complejo de la proteasa en el que participan la PS-1 o la PS-2, aumentando así su actividad sobre el péptido precursor y la producción de $\beta$-amiloide. La acumulación de $\beta$-amiloide, a su vez, facilita la fosforilación de Tau por las quinasas como GSK3 (Alvarez y col., 1999).

Sin embargo, la validez de esta hipótesis ha sido cuestionada ya que isoformas de Tau patológicas (Tau fosforilada) pueden acumularse en ausencia de $\beta$ amiloide. De hecho, hay un trastorno neurológico que parece estar impulsado por mutaciones en PS-1 (Baki y col., 2004; Weihl y col., 1999), mutaciones que dan lugar a la hiperfosforilación de Tau en ausencia de los agregados de $\beta$ amiloide (Dermaut y col., 2004).

Por lo tanto, diferentes mutaciones en los genes asociados a la enfermedad de Alzheimer familiar, tales como PS-1, pueden producir una ganancia o pérdida de la función que facilita la fosforilación de Tau, la principal característica de la enfermedad de Alzheimer y otras tauopatías. También Tau está hiperfosforilada en otras tauopatías y en otros trastornos, como la demencia frontotemporal y el parkinson ligado al cromosoma 17, la parálisis supranuclear progresiva o la demencia corticobasal; las mutaciones en la proteína Tau parece que facilitan su propia fosforilación, agregación y la aparición de la enfermedad (Lee y col., 2001).

Independientemente de si es necesaria o no la participación de los agregados de $\beta$-amiloide para que ocurra la hiperfosforilación de tau, en los ratones knock out para IRS2 de nuestro estudio aparecen las dos patologías en las células neuronales cerebrales, sin que el ratón presente las mutaciones genéticas referidas anteriormente. Se deduce, por tanto, que éstas pueden ser consecuencia de un proceso que tiene que ver con la resistencia a la insulina.

El ensamblaje in vitro de Tau en polímeros fibrilares, parecidos a los filamentos helicoidales encontrados en el cerebro de pacientes con enfermedad de Alzheimer, fue descrito por primera vez en 1986 (Montejo y col., 1986), aunque se re- 
quiere una gran cantidad de Tau para producir la polimerización in vitro (Dawson y col., 2001; Montejo y col., 1986; Wille y col., 1992; Crowther y col., 1992).

La concentración mínima de Tau necesaria para su ensamblaje podría reducirse en presencia de inductores, un efecto que se ha atribuido a los sulfoglucosaminoglicanos, como la heparina, que facilitan la polimerización de Tau in vitro (Goedert y col., 1996; Perez y col., 1996).

Del mismo modo, los ácidos grasos como el ácido araquidónico o los productos de su peroxidación (Wilson y col., 1997) pueden inducir la polimerización de Tau in vitro (Perez y col., 2000), al igual que las quinonas (Santa-María y col., 2004).

La mínima región requerida para el auto-ensamblaje de Tau ha sido localizada en el motivo tercero de unión a la tubulina de la molécula de Tau (Perez y col., 1996; von Bergen y col., 2000) y junto a él, se ha implicado a dos péptidos en el ensamblaje: el péptido 1 que contiene los residuos 306-301 y que es capaz de auto-ensamblaje en la ausencia de cualquier compuesto añadido (von Bergen y col., 2000) y el péptiodo 2 que contiene los residuos 317-335 (Perez y col., 2000).

La caracterización de las variantes de Tau que carecen de cualquiera de estos péptidos puso de manifiesto que aunque el péptido 1 facilita el ensamblaje de Tau, no es esencial; mientras que la presencia del péptido 2 es un requisito indispensable para la polimerización de Tau en la presencia de quinonas (SantaMaria y col., 2006).

Se ha propuesto que Tau sólo se ensambla después de que estos dos péptidos sufren un cambio conformacional (Gamblin, 2005).

Experimentalmente, empleando ratones, se han realizado aproximaciones experimentales para tratar de imitar las tauopatías de la enfermedad de Alzheimer o la de la enfermedad de Parkinson ligada al cromosoma 17. En el primer modelo, se sobreexpresa la Tau humana en ratones que carecen de Tau endógena (Andorfer y col., 2005); mientras que, en el segundo modelo, se expresa en los ratones la Tau humana con algunas de las mutaciones encontradas en los pacientes con dicha enfermedad (Lim y col., 2001; Allen y col., 2002).

En ambos casos, se generaron los filamentos de Tau hiperfosforilada. En el modelo de ratón de la tauopatía correspondiente a la enfermedad de Alzheimer, la expresión de Tau humana fue impulsada por su propio promotor, mientras que en el modelo de Parkinson, Tau se expresó bajo diferentes promotores que controlan la expresión y la patología de la proteína Tau en las neuronas en diferentes localizaciones (Takashima y col., 1993).

Goedert (2005) ha sugerido que los cambios en el primer motivo de unión a tubulina de la molécula de Tau podrían estar relacionados con la aparición de la enfermedad de Pick, mientras que los cambios en el dominio C-terminal de la molécula de Tau podrían estar relacionados con la aparición de la enfermedad de Alzheimer. Los cambios en la relación de 4R/3R podría promover la aparición de otras tauopatías.

El descubrimiento de mutaciones en el gen Tau, las que provocan la aparición familiar del Parkinson ligado al crosoma 17, proporciona una evidencia de que 
los defectos en Tau son suficientes para causar enfermedades neurodegenerativas (Spillantini y col., 1998a; 1998b; Hutton y col., 1998; Poorkaj y col., 1998).

La tauopatía en la enfermedad de Alzheimer sigue un claro y específico camino cinético que no suele corresponder al que se encuentra en modelos animales. Hace algún tiempo, las diferentes etapas de la patología Tau en la enfermedad de Alzheimer fueron descritas por Braak y Braak (1991) y más recientemente, una descripción similar fue hecha por Delacourte y col. (1999).

La tauopatía se inicia en la corteza entorrinal, desde donde se extiende a las regiones vecinas, como el hipocampo; regiones en las que aparece la neurodegeneración. En el hipocampo, se ha encontrado una relación inversa entre el número de agredados y el número de neuronas que sobreviven (Cras y col., 1995; Fukutani y col., 1995; Bondareff y col., 1989), lo que sugiere que las neuronas que degeneran han desarrollado, previamente, los agregados de Tau. Lo que parece confirmarse en cultivos celulares (Khlistunova y col., 2006).

Los ratones knock out para IRS2 de nuestro estudio presentan tau fosforilada en diferentes regiones cerebrales como la corteza somatosensorial primaria y el hipocampo con diferentes patrones de manifestación. En estas regiones se produce la neurodegeneración comprobada por las mediciones realizadas en las imágenes de resonancia magnética. Por tanto, encontramos en estos ratones una relación directa entre la tauopatía y la hipertrofia de las áreas cerebrales en las que se produce.

La degeneración podría estar relacionada con el posible secuestro, por los agregados de Tau, de diferentes proteínas importantes para la función celular (Alonso y col., 1997; Hernandez y col., 2001).

La degeneración de las neuronas también podría dar lugar a la aparición de Tau extracelular no polimerizado, que podría encontrarse finalmente en el líquido cefalorraquídeo de pacientes con la enfermedad de Alzheimer (lqbal y col., 2005).

Se ha propuesto que neuronas que llevan lesiones neurofibrilares podrían sobrevivir durante largos períodos de tiempo y se ha sugerido que estos agregados pueden no ser tóxicos, sino que podrían proteger contra la degeneración de una manera similar a los agregados encontrados en la enfermedad de Huntington (Arrasate y col., 2004).

En consecuencia, los agregados de Tau podrían proteger frente a la neurodegeneración secuestrando el fosfoTau tóxico que se acumula en una neurona en condiciones patológicas (Lee y col., 2005).

Probablemente, ciertos agregados de Tau, más pequeños o modificados, en vez de las estructuras semejantes a filamentos helicoidales puede ser los que tengan efectos tóxicos como cabría deducirse de los hallazgos obtenidos desde diferentes laboratorios (Cleveland y col., 1977; Bird y col., 1999; Wittmann y col., 2001; Santacruz y col., 2005; Duff y Planel, 2005; Gómez-Ramos y col., 2006).

Se ha postulado que Tau, cuando no está vinculada a los microtúbulos, o está en forma modificada, es tóxico para las células neuronales.

En la enfermedad de Alzheimer, la patología Tau se inicia en la corteza entorrinal. Si la probabilidad de muerte de las neuronas en esta región fuera similar a 
la de otras regiones, se podría explicar la aparición de la patología Tau si las células de esta corteza tuvieran una menor proporción de su Tau ligado a microtúbulos, o en forma modificada. De hecho, ya se ha propuesto una menor afinidad de Tau a los microtúbulos de las neuronas entorrinales (Puig y col., 2005).

A través de la degeneración de estas neuronas, la proporción de Tau, no ligada a los microtúbulos o en forma modificada, que entra en el espacio extracelular aumentaría y podría interactuar y ser absorbida por otras neuronas. La consiguiente degeneración de estas neuronas liberaría de nuevo proteína Tau, y más Tau extracelular estará disponible para ejercer un efecto tóxico sobre otras neuronas. Este proceso puede repetirse periódicamente, estableciendo un tipo de reacción en cadena que podría dar lugar a la propagación de la patología Tau.

En nuestro estudio, mediante inmunocitoquímica hemos podido comprobar que algunos ratones knock out para IRS2 presentaban reacción intraneuronal, pero a la vez, el neuropilo adyacente, extracelular, era reactivo, lo que soporta claramente esta hipótesis.

En esencia, este modelo implica dos pasos: el inicio de la patología y su difusión. En la enfermedad de Alzheimer, la iniciación puede ser debida al efecto tóxico de $\beta$-amiloide, sobre todo si tenemos en cuenta la hipótesis de la cascada amiloide (Hardy y Selkoe, 2002). La distribución de los agregados de $\beta$-amiloide varía ampliamente entre diferentes regiones del cerebro (Braak y Braak, 1991) y la presencia de estos agregados en la corteza entorrinal podría promover la neurodegeneración local en una región donde también mutaciones de PS-1 aumentarían aún más la pérdida neuronal (Lazarov y col., 2006).

La velocidad a la que se extiende la patología Tau dependerá de la muerte neuronal promovida por la presencia de proteína Tau extracelular, tóxica para las neuronas.

En nuestro estudio inmunocitoquímico hemos podido comprobar como en la corteza somatosensorial y en el asta de Amón y el giro dentado del hipocampo, se observan neuronas cuyo citoplasma es claramente reactivo a Tau hiperfosforilada; y como hemos comentado anteriormente, rodeando a estas neuronas, en el neuropilo adyacente, hay inmunopositividad para Tau hiperfosforilada. Nuestros hallazgos evidencian que la ruta de actuación de Tau propuesta por otros autores, que se ha explicado anteriormente, tiene una base morfológica que la justifica y justificaría la neurodegeneración hipocampal. Como comentaremos más adelante, en esas mismas regiones hemos podido detectar positividad a rojo congo y la inmunopositividad a $\beta$ amiloide.

La agregación de Tau es tóxica y participa en la patogenia de la enfermedad de Alzheimer y de otras enfermedades neurodegenerativas que se acompañan de tauopatía, pero no está tan claro cuál de las formas agregadas de Tau es la especie tóxica (Rankin y Gamblin, 2008).

La proteína Tau se encuentra en los microtúbulos celulares contribuyendo a formar el armazón de la célula. La hiperfosforilación que se observa en la enfermedad de Alzheimer produce alteraciones de la forma celular que afectan a la sinapsis, originando la pérdida de las conexiones neuronales. 
Para la caracterización de las regiones de Tau hiperfosforiladas se utilizan sobre todo anticuerpos monoclonales que reconozcan sólo patrones de fosforilación específicos de la enfermedad. Se han identificado más de 30 sitios para fosforilación en serina y treonina (Porzig y col., 2007).

El empleo de anticuerpos para reconocer a la Tau hiperfosforilada, como el AT8 (Biernat y col, 1992), da lugar a protocolos metodológicos que permiten estudiar la gradual deposición de Tau hiperfosforilada según transcurre la enfermedad por sus diferentes estadios. (Braak y col., 2006)

Antes de la formación de los ovillos neurofibrilares en la corteza frontal, aparece fosfo-Tau/Ser396 en fracciones de enriquecimiento sináptico en los tramos entorrinal/transentorrinal, límbico y neocortical, indicando fosforilación temprana de Tau en la sinapsis. Estos niveles de fosforilación son muy elevados en las etapas avanzadas de la enfermedad (Muntané y col., 2008).

En la corteza temporal inferior posterior (área 37 de Brodmann), la mayoría de los ovillos neurofibrilares ocurren en las capas corticales II, III, V y VI, apareciendo como un parche o en modelo de racimo a lo largo de las capas corticales III y V y con las columnas de capas de células piramidales. La irregularidad de Tau, células intensamente etiquetadas con inmunoreactividad AT8 se agrupan principalmente en las capas III y V (Thangavel y col., 2008).

La corteza perirrinal (área 35) presenta ovillos neurofibrilares en el inicio de la enfermedad de Alzheimer. Se ha observado lesión inmunoreactiva de Tau que se extiende desde la región temporopolar (ínsula) hasta la corteza parahipocampal posterior. En su curso ántero-posterior, cubre el borde medial del surco colateral.

Aunque la lesión de Tau entra ligeramente en las regiones anterior y media de la corteza temporopolar y en la corteza ectorrinal (área 36) lateralmente, el área 35 está definida sin ambigüedad.

La patología temporal ventromedial, como la revelada por AT8, sugiere la presencia de una lesión relativamente amplia en estados tempranos de la enfermedad de Alzheimer implicando toda la corteza perirrinal y otras áreas nonisocorticales. Un estudio del equipo de Thangavel demuestra que estos pacientes exhiben células de inmunoreactividad AT8 en las cortezas temporopolar, hipocampo, perirrinal, entorrinal e insular (Thangavel y col., 2009).

En nuestro estudio, hemos comprobado el aumento de los productos de fosforilación de Tau mediante western blotting y su análisis morfo-densitométrico, principalmente de AT8. Además de la existencia de una cantidad mayor de esta proteína, su distribución en la banda es más homogénea en los ratones knock out para IRS2 que en los wilde type.

También se ha evidenciado la localización de Tau hiperfosforilada mediante el estudio inmunocitoquímico del hipocampo, y alteraciones morfométricas indicativas de atrofia cortical en las regiones cerebrales del ratón, que guardan equivalencias con las descritas por otros autores en humanos, y que han sido detalladas en los párrafos anteriores.

La aparición de Tau hiperfosforilada en la corteza somatosensorial primaria sugiere que en estos animales, el equivalente a la enfermedad de Alzheimer, 
está totalmente instaurada ya que las lesiones degenerativas de la corteza entorrinal y el hipocampo son muy manifiestas, incluso con gliosis reactiva y atrofia cortical, como comentaremos más adelante.

El proceso de hiperfosforilación de Tau se produce por una ruptura del equilibrio dinámico de regulación existente entre las proteínas fosfatasas y quinasas que actúan sobre Tau (Burack y Halpain, 1996).

Este desequilibrio se manifiesta en el ratón knock out para IRS2 al disminuir la presencia de diferentes fosfatasas desfosforiladoras, como las PP2A y $P P 2 B$, en las bandas de western blotting. En consonancia con ello, las bandas también indicaron disminución de la proteína Tau y aumento de las proteínas producto de la fosforilación de Tau.

La sobre-activación de Cdk5 en ratones transgénicos jóvenes no induce hiperfosforilación en sitios reconocidos por los anticuerpos AT8, AT100, PHF-1 y TG3, pero sí conduce a la inhibición de GSK3. Sin embargo, en animales transgénicos adultos se pierde la inhibición de GSK3 y se incrementa su actividad, coincidiendo con hiperfosforilación de Tau en los sitios AT8 y PHF-1 (Plattner y col, 2006).

Esta quinasa de Tau, en concreto su forma beta, fosforila muchos de los epitopos de Tau (Imahori y col, 1997). Su nivel de expresión y actividad están incrementados en el cerebro de enfermos de Alzheimer conforme aumenta la acumulación de ovillos neurofibrilares. La interrupción de la regulación de la actividad de GSK3 es la base de la hiperfosforilación de Tau en las tauopatías neurodegenerativas.

La búsqueda de inhibidores de la fosforilación de Tau, en concreto de inhibidores de GSK3, como el litio (Plattner y col, 2006), (Yoshida y col., 2006), es una buena aproximación terapéutica para la investigación, desarrollo y posterior comercialización de fármacos modificadores de la enfermedad de Alzheimer.

Además de Tau, las proteínas p53 también están asociadas con los trastornos neurodegenerativos. P53 induce fosforilación de Tau 2N4R humana en el epitopo de Tau-1AT8 en células HEK293a. Pero, Tau y p53 están separadas espacialmente dentro de la célula, localizándose Tau en el citoesqueleto y p53 en el núcleo. Por tanto, los efectos de la fosforilación de Tau y de p53 son indirectos (Hooper y col., 2007).

La valoración de la patología neurofibrilar relacionada con la enfermedad de Alzheimer requiere un procedimiento que permita la suficiente diferenciación entre los estados inicial, intermedio y final. La deposición progresiva de la proteína Tau hiperfosforilada en tipos neuronales de núcleos específicos o áreas es esencial para el proceso de la enfermedad. El protocolo, adaptando la selección y procesamiento de tejidos a las necesidades de las secciones (5-15 micras) de parafina embebida y la introducción de un robusto inmunoreactivo (AT8) para la proteína Tau hiperfosforilada, puede ser procesado automáticamente y, por tanto, tener una aplicación uniforme en el procedimiento por estados (Braak y col., 2006).

El epitopo de AT8 está alrededor del residuo 200, fuera de la región de las repeticiones internas y requiere la fosforilación de las serinas 199 y/o 202. Ambas son seguidas por una prolina, sugiriendo que la actividad kinasa pertenece a la familia de las kinasas dirigidas por prolinas. El epitopo de AT8 es casi coinciden- 
te con otro anticuerpo dependiente de fosforilación, TAU1, pero son complementarios ya que TAU1 requiere un epitopo desfosforilado (Biernat y col., 1992).

Un análisis inmunocitoquímico basado en estas premisas es el que hemos realizado en nuestro estudio para detectar Tau fosforilada, $\beta$-amiloide y GFAP.

Cada vez hay más evidencias sugiriendo que no sólo la hiperfosforilación, sino también la fragmentación de Tau juega un papel importante en la progresión de la enfermedad de Alzheimer (Gamblin y col., 2003; Yin y col., 2006; Zilka y col., 2006). La Tau truncada induce la apoptosis de las neuronas corticales in vitro (Chung y col., 2001) y, cuando se expresa en los animales transgénicos, da como resultado memoria espacial reducida y alteración de los reflejos (Hrnkova y col., 2007). En cultivos de neuronas corticales embrionarias tratadas con $\beta$-amiloide, la división de Tau precede a la apoptosis (Gamblin y col., 2003). Esto también indica que la fragmentación de terminales $\mathrm{N}$ y $\mathrm{C}$ induce la agregación de Tau tóxica en las células N2a (Wang y col., 2007). Aunque no está claro qué ocurre primero, si la hiperfosforilación de Tau o la división (Rissman y col., 2004; Mondragón-Rodríguez y col., 2008).

La fragmentación de Tau en ratones, a edades tempranas, presenta gran variabilidad, mientras que se observa más consistencia en la fosforilación de Tau (Kim y col., 2009). No obstante, otros autores defienden que la fragmentación de Tau es un evento temprano en la maraña patalógica de la enfermedad de Alzheimer precediendo a la hiperfosforilación en el cerebro de los animales transgénicos y los pacientes con enfermedad de Alzheimer (Rissman y col., 2004).

Nuestro estudio no aborda la solución a esta dicotomía temporal planteada, pero como el modelo de ratón utilizado desarrolla paulatinamente un proceso degenerativo semejante al de la enfermedad de Alzheimer, podría ser utilizado para analizar los cambios producidos a lo largo del tiempo, con el fin de responder a los interrogantes que se plantean en la actualidad.

\section{Amiloidosis y depósitos de $\beta$-amiloide.}

El péptido $\beta$-amiloide es un producto de la escisión de la proteína precursora $\beta$ amiloide que se ha detectado en el compartimento intracelular.

La aparición, según la edad, de los factores solubles derivados de la proteína precursora $\beta$-amiloide modula las rutas de señalización de PI3K/Akt/GSK-3ß. SA$\mathrm{AP} \alpha$ estimula y los oligómeros $\beta$-amiloide bloquean la supervivencia de la señal. Estos datos sugieren la existencia de una vulnerabilidad selectiva de grupos neuronales específicos en la enfermedad de Alzheimer (Jimenez y col., 2011).

La relación entre la fosforilación de Tau y la aparición de depósitos de $\beta$ amiloide sigue siendo controvertida, al igual que la relación entre las placas y los ovillos, no estando muy claro si son causa o consecuencia ni cual antece a cual.

El origen de los depósitos de $\beta$-amiloide podría ser periférico en principio (Wong y col., 1985); sin embargo, no hay evidencia de la existencia de una circulación del $\beta$-amiloide o de su precursor. 
Mountjoy y colaboradores (1982) fueron incapaces de encontrar la presencia de angiopatía amiloide en todos los casos de enfermedad de Alzheimer. En nuestro estudio, primero con rojo congo y luego con inmunocitoquímica para $\beta$-amiloide, hemos constatado la presencia de reacción perivascular que afecta de forma notable a los vasos contenidos en los plexos coroideos, lo que, en prinicpio, puede guardar relación con afectaciones en la barrera hematoencefálica.

En el mundo científico existe una falta de consenso con respecto a la correlación entre los sustratos patológicos de la neurodegeneración y el estado de demencia, en particular en los pacientes muy ancianos. La patología predominante es la relacionada con Tau y $\beta$-amiloide y las áreas ocupadas por ambas sustancias están fuertemente asociadas con la presencia de demencia. La esclerosis del hipocampo es un hallazgo específico en los pacientes con demencia. La demencia se asocia a una expansión de la patología incluyendo aumentos de Tau neocortical y placas de B-amiloide hipocampal, deposición de B-amiloide neocortical más abundante y esclerosis del hipocampo (Robinson y col., 2011).

Si analizamos detenidamente nuestros resultados inmunocitoquímicos, junto a la aparición de Tau hiperfosforilada en el neocórtex, como es el área somatosensorial primaria; hemos podido detectar depósitos de $\beta$-amiloide en muchas zonas encefálicas. Hemos encontrado depósitos del péptido en el hipocampo: giro dentado y regiones CA1, CA2 y CA3 del asta de Amón, corteza entorrinal, piriforme y ectorrinal; complejo amigdalino; corteza motora primaria y cortezas somatosensoriales primaria y secundaria. En todas esas zonas, hemos podido constatar también una reacción positiva al rojo congo, indicativa de la amiloidosis. Nuestros resultados sugieren que los ratones knock out para IRS2 presentan una patología típica de una enfermedad de Alzheimer bien desarrollada, que, en humanos, se acompañaría de demencia. Estos resultados implican que, como comentaremos en profundidad más adelante, la alteración de la ruta de señales intracelulares que se activan tras la activación del receptor insulínico es importante en la aparición de esta enfermedad neurodegenerativa.

En algunos casos y territorios cerebrales hemos detectado reacción intracelular para $\beta$-amiloide. Probablemente, tal y como se ha postulado previamente (Aho y col., 2010) esta reacción se deba a la presencia de la proteína precursora del péptido $\beta$-amiloide, más que a la presenia del péptido en sí mismo.

La patología relacionada con $\beta$-amiloide muestra un rango de lesiones que difieren cuantitativa y cualitativamente, probablemente porque pueda seguir una evolución temporal, por lo que las fases de aparición de depósitos puede ser útil al estudiar individuos sospechosos de padecer la enfermedad de Alzheimer (Alafuzoff y col., 2009).

Es posible que las variaciones individuales entre los ratones knock out observadas en nuestro estudio puedan ser debidas a este proceso de neurodegeneración secuencial en fases. 


\section{Proteína básica de la mielina.}

La proteína básica de la mielina interactúa con muchos ligandos diferentes, incluyendo lípidos, calmodulina, cationes divalentes, GTP y proteínas del citoesqueleto, como tubulina y actina. Se cree que la fijación de proteína básica de la mielina a tubulina y actina estabiliza su polimerización, lo cual es esencial para la formación de las vainas de mielina.

El gen codificador de la proteína básica de la mielina pertenece a una gran familia de genes reguladores del desarrollo llamado complejo Golli (genes del linaje oligodendrocítico). Miembros de esta familia están involucrados en la formación y mantenimiento de las vainas de mielina.

Hay cuatro isoformas predominantes de la proteína básica de la mielina: 21.5, $20.2,18.5$ y $17.2 \mathrm{kDa}$. En el feto y en los cerebros en desarrollo, predominan las isoformas 21.5, 20.2 y $17.2 \mathrm{kDa}$; mientras que en los cerebros adultos predominan las isomorfas 18.5 y $17.2 \mathrm{kDa}$.

Las patologías de la sustancia blanca pueden contribuir a la debilitación de la cognición en la vejez. La ralentización de la respuesta cognitiva y motora relacionada con la edad podría ser favorecida por los cambios en la sustancia blan$\mathrm{ca}$, tales como la cantidad de ubiquitina o la degeneración granular inmunoreactiva de la mielina.

La medida de la inmunoreactividad para ubiquitina y la proteina básica de la mielina (MBP) en la sustancia blanca frontal indica que ésta es significativamente menor en pacientes con enfermedad de Alzheimer frente a personas con suave o nulo daño cognitivo. Mientras que no aparece correlación entre ubiquitina en sustancia blanca y las medidas de pruebas cognitivas, la proteína básica de la mielina se correlaciona con todo el conjunto de la cognición, ya sea valorado con puntuaciones neurosicológicas, como con pruebas cognitivas cronometradas o con aquellas que reflejan las funciones frontales (Wang y col., 2004).

En los cuerpos amiloides de tejido cerebral de pacientes de Alzheimer al utilizar marcadores para proteínas oligodendrocíticas, como antisuero contra la proteína proteolípida básica de la mielina, galactocerebróxido y glicoproteína mielina/oligodendrocitas, se encuentran niveles elevados. Al contrario que al utilizar el marcador para microglia y macrófagos MRC OX-42. Además de amiloide y proteínas neuronales, una significativa proporción del contenido del cuerpo amiloide procede de oligodendrocitos y/o mielina. La degeneración de elementos neuronales/oligodendrocíticos puede preceder a la formación del cuerpo amiloide ya que éste es inmunoreactivo con anti-ubiquitina (Singhrao y col., 1994).

En la base de la patología de la enfermedad de Alzheimer, se encuentra la extensa desmielización axonal de la sustancia blanca, que provoca serias alteraciones de la conducción nerviosa y severos daños en las funciones cerebrales.

La presencia de anticuerpos para la proteína básica de la mielina es estadísticamente significativa. Mediante inmunoblotting, se ha demostrado su presencia en el $89 \%$ de los sueros de los pacientes con Alzheimer, frente a tan sólo en un $8 \%$ de sujetos sanos o con otros problemas cerebrales (Singh y col., 1992). Aunque no se sabe si los anticuerpos son un mecanismo patogénico o una consecuencia del proceso degenerativo. 
Los análisis bioquímicos de la sustancia blanca en pacientes con Alzheimer combinando cromatografía, inmunoensayos y Western, revelan aumento de las cantidades de $\beta$-amiloide 40 y 42 junto con descenso en las cantidades de la proteína básica de mielina, la proteína proteolipídica de mielina y 2',3' -cyclic nucleotide $3^{\prime}$-phosphodiesterasa. Además, los niveles de colesterol fueron significativamente inferiores mientras que el contenido total de ácido graso fue elevado (Roher y col., 2002).

Los hallazgos encontrados en nuestro estudio confirman los encontrados por otros autores. Mediante western blotting, hemos observado una clara disminución de la proteína básica de la mielina en los ratones knock out para IRS2. El análisis densitométrico de las bandas de western demostró que los niveles de la proteína fueron casi tres veces menores que los observados en los animales wilde type.

Estos resultados sugieren que la desmielinización y la ausencia de la proteína básica de la mielina guarda relación con los demás signos de neurodegeneración encontrados en nuestro estudio.

La relevancia de estos hallazgos podría estar en relación con el hecho de que, en experimentos con ratones transgénicos, se ha demostrado que la altura de las fibrillas y oligómeros relacionados con $\beta$-amiloide, en ausencia de la proteína básica de la mielina, son el doble que cuando persiste la proteína. Lo que sugiere que la proteína básica de la mielina podría inhibir la formación de fibrillas de $\beta$-amiloide restringiendo la formación de oligómeros y ralentizando el agrupamiento de las protofibrillas (Hoos y col., 2007).

\section{Atrofia Cortical y de los Ganglios de la Base en la Neurodegenera- ción.}

La atrofia cerebral global también se ha medido en una serie de estudios de deterioro cognitivo leve, dado que las tasas de aumento de la atrofia cerebral predicen la progresión de deterioro cognitivo leve a demencia, (Jack y col., 2005; Fox y col., 1999; Erten-Lyons y col., 2006). Es interesante señalar que en un estudio sobre imagen de resonancia magnética (He y col., 2009), el grupo de sujetos con daños cognitivos leves amnésicos de dominio múltiple (aMCI-M) presentaba una atrofia significativa en comparación con el grupo de sujetos con daños cognitivos leves amnésicos de dominio simple (aMCl-S). Esto es consistente con al menos un artículo anterior (Bell-McGinty y col., 2005) y con el presumible mayor avance de la enfermedad en el grupo aMCI-M.

Las imágenes de resonancia magnética de cortes frontales del cerebro de los ratones knock out para IRS2 permiten medir las áreas y perímetros globales. Nuestro estudio pone en evidencia que este ratón presenta una significativa atrofia cerebral global frente a los animales normales a la que contribuyen las atrofias específicas de las diferentes zonas corticales.

La enfermedad de Alzheimer se caracteriza histopatológicamente por la formación de las placas de B-amiloide y los ovillos neurofibrilares. La progresión de la patología de las placas y los ovillos, en esta enfermedad, se correlacionan estrechamente con la pérdida de neuronas y sinapsis (Braak y Braak, 1991). 
Estas pérdidas son más evidentes en la atrofia grave, incluyendo la pérdida de materia gris cortical, la reducción de los volúmenes de la materia gris y blanca subcortical, así como la expansión de los espacios ventriculares y de la separación de los surcos cerebrales por rellenarse con líquido cefalorraquídeo (Thompson y col., 2004; 2007).

En la enfermedad de Alzheimer, esta atrofia cerebral se localiza en la corteza límbica temporal medial en sus primeros estados. En etapas posteriores de la enfermedad, avanza a regiones de la corteza paralímbica y del neocórtex (Braak y Braak, 1991).

La corteza límbica temporal tiene un papel esencial en la memoria episódica. Como el deterioro de la memoria es de los primeros síntomas de la enfermedad de Alzheimer, la corteza límbica temporal (incluida la corteza entorrinal y el hipocampo) ha sido un objetivo atractivo para los estudios de neuroimagen estructural (Du y col., 2001; Callen y col., 2001; Jack y col., 1997; Xu y col., 2000; De Santi y col., 2001).

La imagen obtenida por resonancia magnética permite la realización de análisis estructurales in vivo de las diferentes zonas cerebrales. En nuestro estudio se han medido los grosores de diferentes zonas corticales. En todas ellas, con mayor o menor significatividad, el grosor cortical en los ratones knock out para IRS2 ha sido inferior que en los ratones wilde type. Por ejemplo, la hendidura interhemisférica llega a reducirse hasta un $45 \%$.

Aparece atrofia cortical en la corteza entorrinal y en el hipocampo, como en las primeras etapas de la enfermedad de Alzheimer, pero también se desarrolla en la corteza cingular; en la corteza motora, más elevada en la secundaria que en la primaria; en la corteza somatosensorial; y en la corteza insular.

Dada la importancia de la atrofia del hipocampo y de la corteza entorrinal, se ha realizado un estudio morfométrico histológico de estas zonas. Los resultados obtenidos corroboran lo visto a través de la resonancia magnética. Tanto los grosores de la parte del giro dentado como del asta de amón fueron significativamente menores en los ratones knock out para IRS2. Incluso, considerando sólo el estrato piramidal de las diferentes regiones del hipocampo analizadas, el grosor de dicho estrato fue siempre menor es estos ratones. De igual manera, la corteza entorrinal también es de menor espesor.

Así pues, no hay duda de que el ratón knock out para IRS2 desarrolla modificaciones estructurales de su corteza cerebral muy semejantes a las que acontecen en los cerebros humanos que padecen la enfermedad de Alzheimer y que han sido descritas a lo largo de este trabajo. Como hemos indicado, aunque la atrofia cortical es generalizada en el cerebro del ratón, merece destacarse la ocurrida en el hipocampo, región específica en la enfermedad de Alzheimer.

Los ganglios basales son núcleos de sustancia gris que se localizan por debajo de las estructuras corticales y centro oval del telencéfalo. Su participación en la regulación del acto motor es notable y muchos procesos neurogenerativos, enfermedad de Parkinson, síndromes coreicos, mioclonías, etc, están relacionados con su lesión. 
Auqnue no se han establecido patrones que relacionen directamente la presencia de patología en los ganglios basales durante el desarrollo de la enfermedad de Alzheimer, los ratones knock out de nuestro estudio presentan una disminución importante del diámetro de los ganglios basales en la zona del estriado (caudado-putamen). En futuros análisis trataremos de comprobar si estas variaciones están vinculadas a la enfermedad de Alzheimer o son resultado del proceso de menor desarrollo cerebral que presentan los animales knock out para IRS2.

\section{Gliosis reactiva asociadas a Neurodegeneración. Hallazgos Histológi-} cos. Dilatación Ventricular.

Las células neurogliales son fundamentales para el control de la homeostasis del cerebro y representan el sistema de defensa intrínseco cerebral. Por lo tanto, todas las formas de neuropatología implican inevitablemente a la glía dentro del proceso.

Los astrocitos son células gliales especializadas que superan en más de cinco veces al número de neuronas, cubren todo el sistema nervioso central (SNC) y ejercen muchas funciones complejas esenciales para su salud. Si bien pueden permanecer en estado quiesciente durante largos periodos de tiempo, pueden modificar su comportamiento en respuesta a diversas señales provenientes del entorno celular.

Responden a todo tipo de ataques al sistema nervioso central a través de un proceso llamado astrogliosis reactiva. Al inducirse siempre que hay daño cerebral, se ha convertido en una característica patológica de las lesiones estructurales del sistema nervioso central y ha sido utilizada como un índice para valorar el daño neuronal subyacente. Los estudios realizados al respecto están dejando claro que la astrogliosis reactiva no es un simple fenómeno de todo o nada, sino que recoge los cambios, continuos y finamente graduados, que se dan en respuesta a contextos regulados por eventos de señalización específica.

Estos cambios van desde alteraciones reversibles en la expresión génica y la hipertrofia celular con preservación de los dominios celulares y de la estructura del tejido, hasta la formación de largas y duraderas cicatrices con reordenamiento de la estructura del tejido. Cada vez hay más evidencias de un papel importante de la astrogliosis reactiva en los desórdenes del sistema nervioso central a través de la pérdida de las funciones normales de los astrocitos o de la ganancia de efectos anormales (Sofroniew y Vinters, 2010).

Las enfermedades neurodegenerativas, en general, interrumpen la conectividad dentro de los circuitos cerebrales que afectan a los contactos neurona-neurona, glia-neurona y glia-glia. En este sentido, los estudios inmunohistoquímicos indican que en la enfermedad de Alzheimer hay efectos diferenciales sobre las poblaciones astrogliales dependiendo de su asociación con las placas, explicando la progresiva interrupción de la conectividad entre redes neuronales y los desequilibrios de los neurotransmisores que subyacen debajo de las deficiencias amnésicas y cognitivas observadas en la enfermedad (Olabarria y col., 2010). 
Se producen aumentos aislados de proteína fibrilar glial ácida, conocida normalmente como GFAP, en pacientes con demencia, tipo Alzheimer o multiinfarto, o siringomielia. Como el sistema nervioso central de estos pacientes es muy rico en astrocitos fibrilares, conteniendo grandes cantidades de GFAP, esta proteína puede ser usada como herramienta diagnóstica para estas enfermedades (Noppe y col., 1986).

A través de un análisis inmunocitoquímico se comprobó la presencia de la proteína fibrilar glial ácida (GFAP) en diferentes regiones del encéfalo del ratón knock out para IRS2. En los ratones hidrocefálicos se registró aumento de esta proteína en zonas próximas a los ventrículos lateral y medio, como la encrucijada entre ambas o la zona basal del ventrículo lateral y las cortezas ectorrinal e insular.

Esta reacción glial, que en principio pudiera ser consecuencia de un proceso inflamatorio causado por la hipertensión craneal y la dilatación ventricular, sin embargo, también se observó en zonas no próximas a los ventrículos, como el hipocampo, incluso en animales no hidrocefálicos.

Además de la astrogliosis, los procesos neurodegenerativos desencadenan otra reacción glial, la activación microglial, por ello, la tendencia actual es considerar a las enfermedades neurodegenerativas como procesos ante todo gliodegenerativos, en los que las células gliales determinan la progresión y el resultado de un proceso neuropatológico (Heneka y col., 2010).

La inflamación local mediada por microglía, la astrogliosis, la infiltración de células inmunes, la activación de la inmunidad adaptativa y las reacciones cicatriciales en el sistema nervioso central, que acompañan a las enfermedades neurodegenerativas graves y progresivas, avanzan por la expresión de citocinas, moléculas de adhesión, proteasas, y otros mediadores de la inflamación, productos liberados desde la activación microglial.

Debido a que el daño neuronal activa de forma inmediata a la microglía es posible que los mediadores liberados por ésta sean los responsables de la astrogliosis reactiva que responde al daño neuronal. Esto sugiere que la supresión de la sobreactivación microglial podría atenuar la asrogliosis de forma efectiva (Zhang y col., 2010).

Diferentes señales extrínsecas dirigen la activación microglial hacia fenotipos neuroprotectores o neurotóxicos bajo condiciones patológicas. Las proteínas quinasas activadas por mitógenos (MAPKs) son una familia de proteínas quinasas serina/treonina responsables de la mayoría de las respuestas celulares a las citocinas y a las señales externas de estrés, y son cruciales para la regulación de la producción de mediadores de la inflamación (Harper y LoGrasso, 2001).

La activación glial crónica en enfermedades neurodegenerativas contribuye a la disfunción neuronal y a la pérdida de neuronas a través de la producción de moléculas neuroinflamatorias. La activación de la glía en co-cultivos por lipopolisacáridos induce la muerte apoptótica de las neuronas. Las MAPKs probadas, p38, JNK, ERK1/2, se activan en las células gliales y en las neuronas después del tratamiento con lipopolisacáridos. Los inhibidores de la p38 y JNK bloquean parcialmente la muerte de las neuronas en los co-cultivos tratados con lipopolisacá- 
ridos, mientras que no es así con un inhibidor de la vía de ERK1/2 (Xie y col., 2004).

En el cerebro con enfermedad de Alzheimer, la interacción de la microglía con las fibrillas $B$-amiloide conduce a su activación fenotípica y la consiguiente producción de quimiocinas, citocinas neurotóxicas y las especies reactivas de oxígeno y de nitrógeno que son perjudiciales para el sistema nervioso central.

Medios condicionados obtenidos de cultivos microgliales expuestos a $\beta$-amiloide inducen apoptosis de las células del hipocampo. Este efecto pro-apoptótico no se observa en cultivos de hipocampo expuestos a medios condicionados obtenidos de cultivos gliales mixtos (astrocitos y microglía) que han sido expuestos a $\beta$ amiloide. La microglía expuesta a $\beta$-amiloide responde con cambios morfológicos reactivos, inducción de iNOS, producción elevada de óxido nítrico y disminución del metabolismo reductivo. Todas estas respuestas se atenúan por la presencia de los astrocitos. Sin embargo, esta modulación de los astrocitos no se observa cuando las células gliales son expuestas a factores proinflamatorios, aisladamente o en combinación con $\beta$-amiloide (von Bernhardi y Eugenín, 2004).

En nuestro estudio los ratones knock out presentan gliosis reactiva en el hipocampo, probablemente como consecuencia a la exposición de $\beta$-amiloide.

Estudios dirigidos a analizar la respuesta astrocitaria a la inyección de $\beta$ amiloide han puesto de manifiesto una activación astrocitaria, basada en los cambios morfológicos y la sobrerregulación de la proteína ácida glial fibrilar, que se localiza allí donde se deposita el péptido (Perez y col., 2010). Este hecho podría estar relacionado con que los astrocitos y la microglía son capaces de degradar potencialmente los depósitos neurotóxicos de $\beta$-amiloide típicos de la patología de la enfermedad de Alzheimer (Pihlaja y col., 2011).

Se puede, por tanto, asignar a la microglía un papel neuroprotector por su capacidad para fagocitar partículas B-amiloide y limpiar formas solubles de Bamiloide. Estas células tienen un papel integral en la reparación tisular y en la inflamación, y actualmente se está viendo que son capaces de facilitar una respuesta más compleja a los patógenos por cambiar su estado de activación (Mandrekar-Colucci y Landreth, 2010).

Sin embargo, hay evidencias que sugieren que la reacción glial está más en relación con la Tau hiperfosforilada y los ovillos neurofibrilares que con los depósitos de $\beta$-amiloide.

Aunque la cantidad de amiloide alcanza una meseta poco después de la aparición de los síntomas de la enfermedad de Alzheimer, la astrocitosis y la microgliosis aumentan de forma lineal durante todo el curso de la enfermedad. Por otra parte, las respuestas gliales correlacionan positivamente con la cantidad de ovillos, mientras que la astrocitosis correlaciona negativamente con el grosor cortical. Sin embargo, ninguna de las dos correlaciona con la cantidad de amiloide. Las respuestas gliales aumentan linealmente alrededor de donde existen placas y en las proximidades de los ovillos. Estos resultados indican que la progresión de la astrocitosis y microgliosis diverge de la correspondiente a la deposición amiloide, argumentando en contra de una relación directa entre las células gliales y las placas (Serrano-Pozo y col., 2011b). 
El análisis de la proliferación de células en la corteza de ratones transgénicos que desarrollan lesiones tipo enfermedad de Alzheimer, a diferentes edades, indica que la deposición de placa amiloide aumenta la proliferación de la microglía alrededor de las placas, pero no afecta a la proliferación de células precursoras oligodendrocitos corticales. No se encontró evidencia para la proliferación inducida por daño de astrocitos reactivos o para una neurogénesis redirigida desde la zona subventricular. La proliferación de la microglía contribuye a su rápida acumulación alrededor de las placas y puede desempeñar un papel limitante en la expansión de la placa (Kamphuis y col., 2012).

Como se ha indicado en varias ocasiones a lo largo de este trabajo, la acumulación de Tau fosforilada está estrechamente relacionada con los mecanismos celulares que ocurren en las enfermedades neurodegenerativas, en particular en la enfermedad de Alzheimer. Varios estudios, en la última década, están analizando la relación entre las reacciones gliales y la Tau hiperfosforilada.

En las tauopatías humanas, los marcadores Iba 1- y complejo histocompatible mayor (MHC) clase II-positivo de microglía activada se incrementaron en regiones de acumulación de Tau fosforilada (AT8). La inmunoreactividad del receptor barrendero de clase A (SRA) estuvo presente en algunas microglías activadas, incluyendo microglía fagocítica en la enfermedad de Alzheimer. Además, el análisis de inmunofluorescencia doble bajo microscopio confocal mostró microglía activada en la vecindad de células AT8 positivas. (Sasaki y col, 2008).

En ese mismo estudio se compararon los daños humanos con los presentados por ratones transgénicos con mutación Tau. Se observó que en éstos la inmunopositividad de AT8 estaba exactamente asociada con el número de microglía Iba1 positiva en el área cortical, pero la microglía asociada a Tau mostró excepcional inmunoreactividad para el antigen MHC clase II y SRA.

Los ratones knock out para IRS2 de nuestro estudio muestran incremento de la activación glial en el hipocampo, corteza ectorrinal e insular, zonas donde se produce también un aumento de los productos de la fosforilación de Tau, como AT8.

La apoptosis o muerte celular programada es un mecanismo por el cual la neurona auto-digiere activamente su esqueleto, organelas y DNA, manteniendo la integridad de la membrana plasmática, hasta desintegrarse en pequeñas vesículas o cuerpos apoptóticos que son fagocitados por células vecinas.

La tinción TUNEL, que localiza el cambio apoptótico, muestra significativamente densidad alta en los núcleos neuronales en la corteza entorrinal, el cuerno amonis (CA) y la corteza parietal. En todas las regiones, esta densidad tiene correlación directa significativa con los núcleos de las neuronas positivas en AT8, AT180 y Tau2, difiriendo según las regiones cerebrales. Los sitios de fosforilación de Tau, 159-163 y 202-205, están asociados probablemente con la apoptosis neuronal y los cambios apoptóticos son consecuencia de la fosforilación anormal de Tau (Kobayashi y col, 2003).

Aunque una de las causas de la muerte neuronal sea la hiperfosforilación de Tau, hay indicios de que las neuronas corticales pueden también degenerarse sin desarrollar cambios del citoesqueleto en la neocorteza de pacientes con enfermedad de Alzheimer, aunque sí disminuyen su tamaño (Van de Nes y col, 2008). 
El daño neuronal podría guardar relación con una señal extracelular, la molécula $\mathrm{S} 100 \mathrm{~B}$, altamente expresada por los astrocitos reactivos asociados a los depósitos de $\beta$-amiloide. La activación aumentada y prolongada de los astrocitos tiene un impacto perjudicial sobre la supervivencia neuronal, habiéndose señalado a la S100B derivada de astrocitos como una molécula candidata a ser responsable de este efecto perjudicial. Además, la sobre-expresión de S100B actúa acelerando la patología de la enfermedad de Alzheimer (Mori y col., 2010).

Diversos resultados obtenidos en modelos trasgénicos para la enfermedad de Alzheimer, parecen sugerir que la asociación entre la inflamación cerebral y la neurodegeneración ocurre en áreas específicas del cerebro, especialmente en el hipocampo (Belinson y Michaelson, 2009); ello podría guardar relación con rutas de señal extracelular, como por ejemplo la entrada de calcio en la célula, en respuesta a los depositos adyacentes de $\beta$ amiloide, que induce aumentos de GFAP en los astrocitos (Chow y col., 2010).

Los ratones con hidrocefalia, analizados histológicamente, confirman una importante inflamación de los ventrículos cerebrales. Los incrementos mayores se obtuvieron en el acueducto de Silvio, en las cisternas meníngeas y en los ventrículos medio y lateral, destacando sobre los demás, la dilatación del ventrículo lateral.

En los animales sin hidrocefalia, utilizados para el estudio morfométrico a través de resonancia magnética, se confirma la dilatación de las cavidades analizadas anteriormente. El ventrículo lateral vuelve a presentar el mayor aumento frente a los ratones normales.

Se deduce, por tanto, que la dilatación no se debe a un efecto del aumento de la presión intracraneal por la hidrocefalia, sino que es consecuencia de las reacciones gliales que se desencadenan en el proceso neurodegenerativo que ocurre en el ratón knock out para IRS2.

Sin embargo, aunque se encuentra gliosis en zonas limítrofes con los ventrículos dilatados, también aparece en zonas del hipocampo alejadas de los mismos y donde hay hipertrofia, por lo que se debe producir muerte neuronal por otros procesos no neuroinflamatorios.

También se ha descrito reacción glial, astrocitos y microglía, inducida por estrés oxidativo en el hipocampo de ratas modelo de enfermedad de Alzheimer (Arif y col., 2009; Cerpa y col., 2010), que se asocian, además, al resto de las características de la enfermedad, como el deterioro cognitivo, la acumulación de Bamiloide, la astrogliosis, la pérdida sináptica y la activación de las caspasas en el cerebro (McManus y col., 2011).

\section{Diabetes tipo II, IRS2 y Neurodegeneración.}

La diabetes melitus tipo 2 ha sido identificada como un factor de riesgo para la enfermedad de Alzheimer, en la que es frecuente que esté dañada la señalización de la insulina, contribuyendo a los procesos neurodegenerativos. La insulina y el péptido 1 similar a glucagón (GLP-1) mejoran la plasticidad sináptica en el hipocampo. La forma de GLP-1 resistente a la proteasa (Val $\left.{ }^{8}-\mathrm{GLP}-1\right)$ previene los 
efectos neurodegenerativos inducidos por la administración de $\beta$-amiloide (Gault y Hölscher, 2008; Abbas y col, 2009). Los pacientes diabéticos tipo 1 y tipo 2 tienen hasta el doble de riesgo de desarrollar la enfermedad de Alzheimer (Ott y col., 1999; Leibson y col., 1997).

Una potencial estrategia que ayuda a la prevención de los procesos neurodegenerativos en la enfermedad de Alzheimer es la normalización de la señalización de la insulina en el cerebro (McClean y col., 2010).

La diabetes y la enfermedad de Alzheimer comparten muchas características comunes, como señalización de insulina dañada, aumento de los niveles de colesterol y aumento de la incidencia de trastornos metabólicos (Li y col., 2007). Sobre las dos características patológicas más importantes de la enfermedad de Alzheimer, las placas de $\beta$-amiloide extracelulares y los ovillos neurofibrilares intracelulares de Tau hiperfosforilada, Kim y colaboradores (2009) sugirieron que la desregulación de Tau, su fosforilación y/o división, puede ser el factor clave que lleva al aumento en la incidencia de la enfermedad de Alzheimer en pacientes diabéticos.

Se ha abierto, por tanto, una importante línea de trabajo que trata de esclarecer si la neurodegeneración es dependiente de la hiperglucemia y los trastornos vasculares, encefalopatía y angiopatía diabética, o si la relación tiene que ver con las rutas de señal intracelular, tras la activación por insulina o IGF-1 del receptor insulínico en las neuronas.

Tanto la diabetes de tipo 1 como la de tipo 2 se caracterizan por niveles elevados de glucosa en sangre (Sullivan y col., 2007; Edwards y col., 2008), y la hiperglucemia se asocia con problemas de rendimiento cognitivo (Cox y col., 2005).

Además, la diabetes tipo 2 implica hiperinsulinemia y resistencia a la insulina en el contexto del síndrome metabólico, lo que se refiere a un conjunto de factores de riesgo metabólico y vascular como la obesidad, la dislipidemia, la hipertensión y la inflamación (Biessels y col., 2005; Milionis y col., 2008).

En contraste, el principal defecto de la diabetes tipo 1 (insulino-dependiente diabetes mellitus) es la deficiencia de la insulina causada por la destrucción mediada por autoinmunidad de células $\beta$ del pancreas (Stephenson y col., 1994).

Las diferencias entre los dos tipos de diabetes, falta de insulina (tipo I) versus falta de respuesta a la insulina (tipo II) parecen guardar relación con un mayor y severo déficit de aprendizaje y memoria en los ancianos con diabetes tipo 2 en comparación con los diabéticos tipo 1 (Brands y col., 2005; Strachan y col., 1997; Cox y col., 2005).

Los resultados experimentales también demuestran que los ratones diabéticos tipo 2 presentan patología Tau más grave: aumento de fosforilación y fragmentación de Tau; en comparación con los animales con diabetes tipo 1: menos fosforilación y ausencia de fragmentación de Tau (Freude y col., 2005).

Las ratas que desarrollan diabetes de aparición espontánea (Sima y col., 2000) muestran una mayor expresión de proteína precursora de amiloide, $\beta$-secretasa, y $\beta$-amiloide, así como hiperfosforilación de Tau, con cambios más severos en el modelo animal diabético tipo 2 (Li y col., 2007). Las discrepancias de estos hallazgos con los obtenidos por otros autores (Jolivalt y col., 2008) probable- 
mente se deban a diferencias metodológicas por no analizar los residuos Ser396 de la Tau, o al empleo de diferentes cepas de animales.

Los ratones knock out para IRS2 estudiados, aun teniendo niveles de glucemia $e$ insulinemia dentro de los parámetros normales, desarrollaron depósitos $\beta$ amiloide y tau hiperfosforilada, producidos por fallo en el receptor insulínico, similares a los propuestos por otros autores en estudios con ratones diabéticos.

La disfunción de la señalización de la insulina cada vez parece relacionarse más con la fisiopatología de la enfermedad de Alzheimer:

La hiperglucemia y la señalización de la insulina deteriorada son características comunes de la enfermedad de Alzheimer y la diabetes (Gasparini y col., 2002, Zhu y col., 2005).

La señalización de la insulina juega un papel crítico en el metabolismo de $\beta$ amiloide (Adlerz y col., 2007, Carro y col., 2002) y Tau (Cheng y col., 2005; Schubert y col., 2003; Schechter y col., 2005).

La señalización anormal de insulina afecta al desarrollo de las placas amiloides y los ovillos neurofibrilares, así como a los consecuentes déficits de aprendizaje y de memoria (de la Monte y col., 2005; Watson y col., 2004).

La insulina regula la fosforilación de Tau en cultivos neuronales (Hong y col., 1997; Lesort y col., 2000) e in vivo (Cheng y col., 2005; Schubert y col., 2003; Schechter y col., 2005), en consecuencia influyendo en el desarrollo de los ovillos neurofibrilares.

La fosforilación de Tau se incrementa en los residuos Ser396 y Ser202 en cerebros de ratón IGF-I-nulo (Cheng y col., 2005).

White y sus colegas (White y col., 1992) demostraron un aumento de ovillos neurofibrilares, con Tau hiperfosforilada, en el hipocampo de los ratones knock-out para IRS-2, que muestra los signos patológicos típicos de diabetes tipo 2.

Este estudio corrobora la presencia de los ovillos neurofibrilares con tau hiperfosforilada en la región del hipocampo como una característica patológica de los ratones knock-out para IRS2. Además se ha puesto de manifiesto esta patología en otras regiones corticales, como la corteza somatosensorial primaria.

Por lo tanto, en las condiciones de la diabetes, la señalización de la insulina deteriorada junto con la hiperglucemia puede aumentar la fosforilación de Tau y la división posterior. Estos cambios pueden contribuir al aumento del riesgo de Alzheimer en pacientes diabéticos.

Los resultados obtenidos a partir de ratones sugieren una secuencia temporal de la hiperinsulinemia/hiperglucemia, la hiperfosforilación de Tau, y la división final de Tau en los animales diabéticos. Podría ocurrir que la fosforilación de Tau se produzca antes que la aparición de productos de degradación de Tau en un modelo de ratón de tauopatía humano (Delobel y col., 2008) y en cultivos neuronales (Amadoro y col., 2011). 
Por lo tanto, la hiperfosforilación de Tau, combinada con su fragmentación, puede contribuir a alcanzar la patología de Tau más severa en los cerebros de animales con diabetes tipo 2 (Kim y col., 2009).

Experimentalmente, la administración de streptotocina a ratones induciendo en ellos una diabetes tipo 1 (Tam y col., 2004; Kellogg y col., 2005), se acompaña de hiperfosforilación de Tau (Clodfelder-Miller y col., 2006; Planel y col., 2007; Jolivalt y col., 2008). Esta hiperfosforilación no aparece si se administra insulina (Clodfelder-Miller y col., 2006; Planel y col., 2007) o si la streptotocina se administra a dosis bajas (Kim y col., 2009) y sostenidas, lo que implica que no cae la insulina endógena, estos resultados sugieren que es la hipoinsulinemia, más que la hiperglucemia, la que juega un papel más importante en el aumento de la progresión de la enfermedad de Alzheimer en la diabetes tipo 1.

La duda de si la diabetes tipo 2 aumenta el riesgo de aparición de la enfermedad de Alzheimer como consecuencia de una vasculopatía diabética, o si la diabetes influye directamente en el desarrollo de la neuropatología de dicha enfermedad, quedó resuelta cuando Den Heijer y colaboradores (2003) demostraron que la diabetes tipo 2 se asocia con la atrofia del hipocampo y la amígdala, independientemente de la patología vascular, lo que parecía sugerir que la diabetes tipo 2 influye directamente en el desarrollo de la neuropatología de Alzheimer.

La razón más probable de que la diabetes tipo 2 sea un factor de riesgo para la enfermedad de Alzheimer está en la desensibilización observada de los receptores de insulina cerebrales. La insulina actúa como un factor de crecimiento en el cerebro, participando en la reparación y diferenciación neuronal, y en la formación de dendritas. GLP-1 que facilita la liberación de insulina en condiciones de niveles altos de azúcar en sangre, también actúa como un factor de crecimiento similar a la insulina y protege a las neuronas de los efectos tóxicos (Hölscher, 2010b).

Algunos de los análogos de las incretinas GLP-1 y GIP (péptido insulinotrópico dependiente de glucosa) pueden cruzar la barrera sanguínea cerebral y desarrollar un efecto neuropreotector y mejorar la cognición al invertir los daños inducidos por $\beta$-amiloide en la plasticidad sináptica. En los modelos de ratones para la enfermedad de Alzheimer, los análogos de GLP-1, Val ${ }^{8} \mathrm{GLP}-1$ y liraglutida, previenen los daños en la memoria y el bloqueo de la plasticidad sináptica en el cerebro (Hölscher, 2010a; Hunter y Hölscher, 2012).

El GLP-1 reduce la formación de placas $\beta$-amiloide, reduce la reacción inflamatoria cerebral, protege a las neuronas del stress oxidativo, reduce el crecimiento externo neurítico, y protege la plasticidad sináptica (Hölscher, 2011).

El proceso inicial que puede desencadenar la cascada de acontecimientos neurodegenerativos en la enfermedad de Alzheimer podría ser el deterioro de la señalización del factor de crecimiento así como la desensibilización temprana del receptor insulínico (Hölscher, 2011).

En todos estos procesos parecen intervenir de forma importante las proteínas de sustrato de receptor insulínico, las IRS, imprescindibles para la activación de las rutas de señal intracelular en respuesta a la unión de insulina o IGF-1 al receptor insulínico. 
Las señales de la insulina y la IGF-1 son coordinadas por fosforilación de la tirosina de las proteínas de sustrato de receptor de insulina IRS1 e IRS2 (White, 2002).

La mayoría de los estudios revelan que IRS1 es el sustrato receptor de la insulina que lidera la estimulación del transporte de glucosa en los músculos y el tejido adiposo, mientras que en el hígado IRS1 y IRS2 tienen funciones complementarias en cuanto a la señalización y el metabolismo de la insulina (Thirone y col., 2006).

La rama IRS2 de la ruta de señalización de la insulina/IGF es un elemento común en la respuesta de insulina periférica y en el crecimiento y función de las células $\beta$ pancreáticas. Los fallos en la señalización de IRS2 podrían explicar la pérdida eventual de hiperinsulinemia durante prolongados períodos de resistencia a la insulina periférica. El extenso papel de la IRS1 y IRS2 en el crecimiento y supervivencia celular revela una vía reguladora común uniendo desarrollo, crecimiento somático, fertilidad, proliferación neuronal y envejecimiento a los mecanismos básicos utilizados por los vertebrados para la detección de nutrientes (White, 2002).

La señalización de IRS-2 media la acción de la insulina periférica y la función de las células $\beta$ pancreáticas, de manera que su pérdida causa diabetes en el ratón. Por otro lado, la ruptura del gen de IRS-2 reduce la proliferación de neuronas cerebrales alrededor del $50 \%$, lo que disocia el crecimiento cerebral del crecimiento corporal dependiente de IRS-1. Además, la presencia de ovillos neurofibrilares conteniendo Tau fosforilada acumulados en el hipocampo de ratones IRS-2 knock-out ancianos, sugiere que la señalización de IRS-2 es neuroprotectora. Por lo tanto, la desregulación de de la rama IRS-2 de la cascada de señalización de la insulina/IGF revela una conexión molecular entre la diabetes y la enfermedad neurodegenerativa (Schubert y col., 2003).

Es evidente que el ratón con el que hemos trabajado al cual le falta la proteína sustrato del receptor insulínico, IRS2, necesaria para la activación de las rutas de señal intracelular en respuesta a la unión de insulina o IGF-1 al receptor insulínico, presenta las caracterísiticas del deterioro neuronal similar al de la enfermedad de Alzheimer, como la atrofia cortical generalizada.

Aunque los ratones todavía no presentan índices de insulina y glucosa fuera de lo normal, sí se aprecia un ligero aumento de los mismos respecto a los wilde type. Se apunta, por tanto, la posibilidad de una tendencia hacia futura diabetes en el ratón, pero los daños neurodegenerativos parecen ser previos a la misma. De cualquier manera, parece que la concomitancia de las dos enfermedades es indiscutible actualmente.

Antes del comienzo de la diabetes, el factor de transcripción de homeodominio $\mathrm{Pdx} 1$ se reduce en los islotes de ratones IRS2 ${ }^{-1}$, mientras que se expresa de forma normal en islotes de ratones wild type o IRS $1^{-\%}$, que no desarrollan diabetes. Mientras que los ratones machos IRS2 ${ }^{-/} \mathrm{Pdx}^{+/+}$desarrollaron diabetes entre las 8 y 10 semanas, los ratones con haploinsuficiencia para Pdx1 produjo diabetes en ratones IRS2 ${ }^{\%}$ recién nacidos. En constraste, la expresión transgénica de Pdx1 restaura la masa y función de las células $\beta$ en ratones IRS $2^{-1-}$ y promueve la tole- 
rancia a la glucosa a lo largo de la vida, ya que estos ratones no desarrollan diabetes al menos hasta los 20 meses (Kushner y col., 2002).

IRS2 está decisivamente involucrada en la sensibilidad a la leptina (Kubota y col., 2004) y en el crecimiento y la regulación de la masa de las células $\beta$ y de las neuronas hipotalámicas a través de la homeostasis energética (Choudhury y col., 2005).

Algunos efectos terapéuticos a corto plazo del agonista de receptor para GLP-1 pueden ser independientes de IRS-2, pero los efectos a largo plazo sobre el crecimiento y supervivencia de células $\beta$ están mediados por la rama IRS-2 de la cascada de señalización Insulina/IGF (Park y col., 2006).

La obestatina actúa sobre el páncreas endocrino promoviendo la supervivencia de las células $\beta$ en los islotes y estimulando la expresión de los principales genes reguladores de las células $\beta$, ya que incrementa el cAMP y activa la quinasa relacionada con la señal del medio extracelular (ERK1/2) y la fosfatidilinositol 3quinasa (PI 3-quinasa)/Akt; su efecto antiapoptótico es bloqueado por inhibición de la señalización de adenil ciclase/cAMP/proteína quinasa A (PKA), PI 3quinasa/Akt, y ERK1/2. Además, sobrerregula GLP-1R mRNA y la expresión y fosforilación de IRS-2 (Granata y col., 2008).

Los ratones con deficiencia en la actividad de CREB, causada por la expresión de un transgen A-CREB dominante-negativo en las células $\beta$ pancreáticas, desarrollan diabetes secundaria a apoptosis de dichas células. A-CREB interrumpe severamente la expresión de IRS-2, un componente de la ruta de señalización de insulina que se muestra ser un objetivo directo para la acción en vivo de CREB. Como la inducción de IRS2 por cAMP mejora la activación de la quinasa de supervivencia Akt en respuesta a la insulina y al IGF-1, aparece un nuevo mecanismo por el cual las rutas de oposición cooperan en promover la supervivencia de las células (Jhala y col., 2003).

Los niveles normales de glucemia e insulinemia que presentan los ratones sugieren que la falta de IRS2 no produce la destrucción de las células $\beta$ pancreáticas reguladoras de dichas sustancias. Los cambios estructurales que se dan provienen de la resistencia a la insulina en las neuronas cerebrales provocado por el fallo en el receptor insulínico y no por hiperglucemia o hiperinsulinemia.

Las alteraciones en la señalización de insulina y IGF-1 son mecanismos que relacionan la hormona de crecimiento con el envejecimiento. El incremento de la longevidad ocurre en ratones con supresión selectiva del receptor IGF-1 en todos los tejidos o del receptor de insulina en la grasa. En ratones con supresión de IRS-1, reducida expresión de IRS2, o supresión selectiva de IRS-2 en el cerebro, la ruta de señalización IRS-PI3K-Akt-Foxo, que es compartida por IGF-1 e insulina, se implica específicamente en el control del envejecimiento (Bartke, 2008a).

La insulina controla la homeostasis de los nutrientes y del metabolismo por la cascada de señalización IRS-PI3K-AKT que se dirige a FOXO1 y mTOR. La mitocondria, al ser la principal plataforma metabólica, funciona mal durante la resistencia a la insulina en enfermedades metabólicas. Las mitocondrias generan de forma moderada especies reactivas de oxígeno que mejoran la sensibilidad de la insulina a la regulación redox de la tirosin-fosfatasa y el receptor insulínico. Sin 
embargo, la exposición crónica a elevados niveles de especies reactivas podría alterar la función mitocondrial y por tanto causar resistencia a la insulina (Cheng y col., 2010).

Estudios de las características fisiológicas y polimórficas de los genes relacionados con la insulina en personas excepcionalmente longevas sugieren un papel de la señalización de la insulina en el control del envejecimiento humano (Bartke, 2008b).

De forma similar a la dependencia insulínica de los tejidos metabólicamente activos como la grasa y el músculo, las neuronas también desarrollan resistencia a la insulina y por ello no pueden responder a las propiedades neurotrópicas de la insulina, produciendo daño neuronal y, en consecuencia, disfunción y diferentes estados de desarrollo de las enfermedades neurodegenerativas (Kim y Feldman, 2012).

En los resultados obtenidos se aprecia como la deficiencia de IRS2, que supone resistencia a la insulina de las neuronas cerebrales de los ratones knock out, produce una pérdida neuronal reflejada en la dilatación ventricular y la hipertrofia cortical de diferentes regiones del encéfalo.

Se han identificado neuronas conteniendo inmunoreactividad a IRS-2 en áreas del cerebro anterior, medio y posterior y tipos de células que son cruciales para el control del consumo de alimentos y la función autónoma. Por eso, analizando el papel que juega la señalización a través de IRS-2 en dichas áreas cerebrales se mejorará el conocimiento de los mecanismos subyacentes en la homeostasis energética normal y anormal (Pardini y col., 2006).

Además, la señalización de IRS2 puede modular también la progresión de otras enfermedades neurodegenerativas como la enfermedad de Huntington (Sadagurski y col., 2011).

IRS-1 e IRS-2 están involucrados en las rutas de señalización del factor neurotrópico derivado del cerebro (BDNF) que activa la fosfatidylinositol 3-kinasa (PI3-K), ya que en cultivos de neuronas corticales se fosforilan los residuos de tirosina uniéndose a PI3-K en respuesta a BDNF (Yamada y col., 1997).

IGF-1 aumenta la proliferación, inhibe la apoptosis y promueve la diferenciación de oligodendrocitos y sus células precursoras, indicando una importante función de la señalización del receptor IGF-1 (IGF-1R) en el desarrollo de la mielina. Por su parte, IRS-1 y IRS-2 sirven como proteínas adaptadoras de IGF-1R intracelular y están expresadas en neuronas, oligodendrocitos y sus precursores. Las señales mediadas por IGF-1R/IRS-2 son fundamentales para el momento adecuado de mielinización en vivo (Freude y col., 2008).

Hay hallazgos que parecen contradecir un papel fundamental para IRS2 en el desarrollo de la enfermedad de Alzhemier.

El trastorno IIS, señalización deteriorada de insulina por nula IRS2, en ratones Tg2576 que sobrexpresan el péptido precursor de amiloide humano, tiene efectos divergentes en los procesos patológicos, una reducción en los agregados de $\beta$ amiloide y un aumento de la fosforilación de Tau. Sin embargo, como estos efectos están acompañados de la mejora de los déficits de comportamiento, aparece un novedoso efecto protector de la interrupción de la señalización IRS2 en la enfermedad de Alzheimer (Killick y col., 2009). 
En cerebros de pacientes con la enfermedad de Alzheimer la expresión del receptor de insulina, del receptor de IGF-1 y de las proteínas IRS están infrareguladas. Por otro lado, en la patogénesis también se da la acumulación de productos de la ruptura del péptido precursor de amiloide. El estudio en ratones $\mathrm{nIR}{ }^{-1} \mathrm{Tg} 2576$ identifica la señalización del receptor de insulina como un potente regulador de la acumulación de $\beta$ amiloide en vivo. Pero la expresión disminuida, en exclusiva, de IGF-1R reduce la mortandad asociada a enfermedad de Alzheimer independientemente de la acumulación de $\beta$-amiloide y la transcripción mediada por Fox01 (Stöhr y col., 2011).

El deterioro de la señalización IGF-1/IRS-2 previene la muerte prematura y el retraso de la acumulación amiloide en modelos de ratones de la enfermedad de Alzheimer (Freude y col., 2009a).

IRS-2 podría actuar como un regulador negativo en la formación de la memoria por restringir la generación de espinas dendítricas (Irvine y col., 2011).

Sin embargo, hay otras muchas evidencias, además de las ya descritas con anterioridad, que asocian alteraciones en la ruta de señalización intracelular de insulina, mediada por IRS, con el establecimiento y desarrollo de procesos neurodegenerativos y, en particular, con la enfermedad de Alzheimer.

Estudios sobre modelos de ratones indican que el agotamiento de la dopamina nigrostriatal daña la señalización de insulina al disminuir IRS2 en el ganglio basal (Morris y col., 2008), lo que podría implicar a IRS2 en la enfermedad de Parkinson.

IRS2 también promueve la maduración y supervivencia de las células fotoreceptoras de la retina de ratones inmediatamente después del nacimiento (Yi y col., 2005).

La regulación de la fosforilación de IRS-1 puede modular los índices de apoptosis en el envejecimiento de la retina, potencialmente previniendo la activación del factor de crecimiento del endotelio vascular celular (Jiang y col., 2009).

La hiperactivación de la señalización de IGF1-R en animales transgénicos p44, los cuales muestran un envejecimiento acelerado, se caracteriza por un cambio temprano de TrkA a $p 75^{\mathrm{NTR}}$ y un incremento de la producción de $\beta$-amiloide en el cerebro (Costantini y col., 2006).

La SAPP $\alpha$ aumenta los niveles de expresión de varios genes neuroprotectores y protege los cultivos organotípicos hipocampales de la fosforilación de Tau, inducida por $\beta$-amiloide, y de la muerte neuronal. Los ratones con sobreexpresión de APP mutante poseen altos niveles de sAPP $\alpha$ y transtirretina y no desarrollan la fosforilación de Tau o la pérdida neuronal característica de la enfermedad de Alzheimer en humanos. El bloqueo de esta ruta provoca el aumento de $\beta$ amiloide, la fosforilación de Tau, y la pérdida neuronal y apoptosis dentro del campo neuronal CA1 del asta de Amón. Por lo tanto, la expresión elevada de transtirretina está mediada por SAPP $\alpha$ y protege al ratón $\mathrm{APP}_{\mathrm{Sw}}$ para que no desarrolle muchas de las neuropatologías observadas en la enfermedad de Alzheimer (Stein y col., 2004).

Se han descrito alteraciones específicas y significativas en el receptor de insulina, en el receptor IGF-1 y en sus proteínas sustrato IRS1 y IRS2 en la enfermedad 
de Alzheimer, habiéndose sugerido que las neuronas que degeneran en la enfermedad e Alzheimer pueden ser resistentes a la señalización IGF-1R/IR (Moloney y col., 2010).

Los análisis postmortem de cerebros de pacientes con la enfermedad de Alzheimer han asociado las alteraciones de los receptores y las IRS con la severidad de la neurodegeneración (Freude y col., 2009b).

Aunque IRS1 e IRS2 tienen una composición similar, la ruta de IRS2 es la responsable de los efectos de IGF1 en el tamaño del cerebro. Además, IRS2 protege al cerebro del envejecimiento producido por la acumulación de Tau fosforilada que podría, más adelante, formar ovillos neurofibrilares. Estos resultados son consistentes con el papel de IGF1 en la proliferación neuronal in vivo e in vitro (DiCicco-Bloom y Black, 1988; Zackenfels y col., 1995; Ye y col., 1996; Anlar y col., 1999; Dentremont y col ., 1999; Aberg y col., 2000; Pixley y col., 2000) y la capacidad de la insulina o del IGF-1 para reducir la fosforilación de Tau en neuronas cultivadas a través de un mecanismo dependiente de la PI3-quinasa (Hong y Lee, 1997). Dado que la señalización de IRS2 también media la acción de la insulina periférica y promueve la función de las células $\beta$ pancreáticas, la desregulación de la señalización IRS2 proporciona una base molecular para entender la relación entre la neurodegeneración y la resistencia a la insulina periférica y la diabetes (Gasparini y col., 2002).

En cultivos, la insulina y el IGF-1 promueven la proliferación, aumentan el crecimiento de las neuritas, y estimulan la síntesis de proteínas (Recio-Pinto y col., 1984; Mill y col., 1985; Fernyhough y col., 1989; Heidenreich y Toledo, 1989; Dudek y col., 1997).

La insulina y el IGF-1 promueven la supervivencia neuronal in vitro (Russell y col., 1998; Anlar y col., 1999). IGF-1 activa Akt para promover la fosforilación BAD y su asociación con la proteína 14-3-3 para liberar y activar Bcl-2 (Datta y col., 1997, Brunet y col., 1999).

La deficiencia de IGF-1 en las personas causa retraso mental y microcefalia, lo que sugiere que IGF-1 tiene un papel fundamental en el desarrollo del cerebro humano (Woods y col., 1996). La deficiencia parcial de IRS2 podría contribuir, al menos en parte, a la aparición de algunos tipos de microcefalia (Luo y col., 2000).

La señalización anormal de insulina podría contribuir a la demencia (Frolich y col., 1999; Blass y col., 2002; Gasparini y col., 2002; Hoyer, 2002). La activación de la maquinaria de señalización de la insulina puede ser importante para muchos aspectos de la función neuronal ya que en las neuronas piramidales prefrontales corticales, la señalización de la insulina promueve la transmisión GABAérgica que facilita el aprendizaje y la memoria (Ma y col., 2003).

Ratones euglucémicos Irs2-/-::Pdx1tg de edad, desarrollan ovillos neurofibrilares que contienen Tau fosforilada y que se acumulan en el hipocampo (Kushner y col., 2002), lo que sugiere que la pérdida de señalización de IRS2 en los tejidos periféricos y en el cerebro revela un posible mecanismo para vincular la resistencia a la insulina y la neurodegeneración sin diabetes (Hoyer, 2002).

Los resultados obtenidos en nuestro estudio apoyan esta idea. 
La fosforilación de Tau podría incrementarse por la relativa inactivación de PP2A en cerebros IRS2-/- (García y col., 2000).

Coincidiendo con lo anterior, en el análisis densitométrico de las bandas de Western Blotting de los ratones knock out para IRS2 de nuestro estudio fue notoria la disminución de las fosfatasas desfosforiladoras PP2A y el incremento de la fosforilación de tau.

Aunque no hay evidencias concluyentes, POR el hecho de que coincidan procesos inflamatorios en el cerebro de los knock out de IRS2, también se ha propuesto que la inhibición de la señalización IRS2 por la inflamación inducida por $\beta$-amiloide podría proporcionar un vínculo molecular entre estas características de la enfermedad de Alzheimer. 
Para concluir este capítulo de discusión, basándonos en todos los datos existentes en la literatura, muchos de los cuales han quedado reflejados con anterioridad, hemos tratado de aglutinar esquemáticamente qué es lo que ocurre en los ratones knock out para IRS2 y por qué estos animales pueden desarrollar un proceso neurodegenerativo que semeja la enfermedad de Alzheimer.

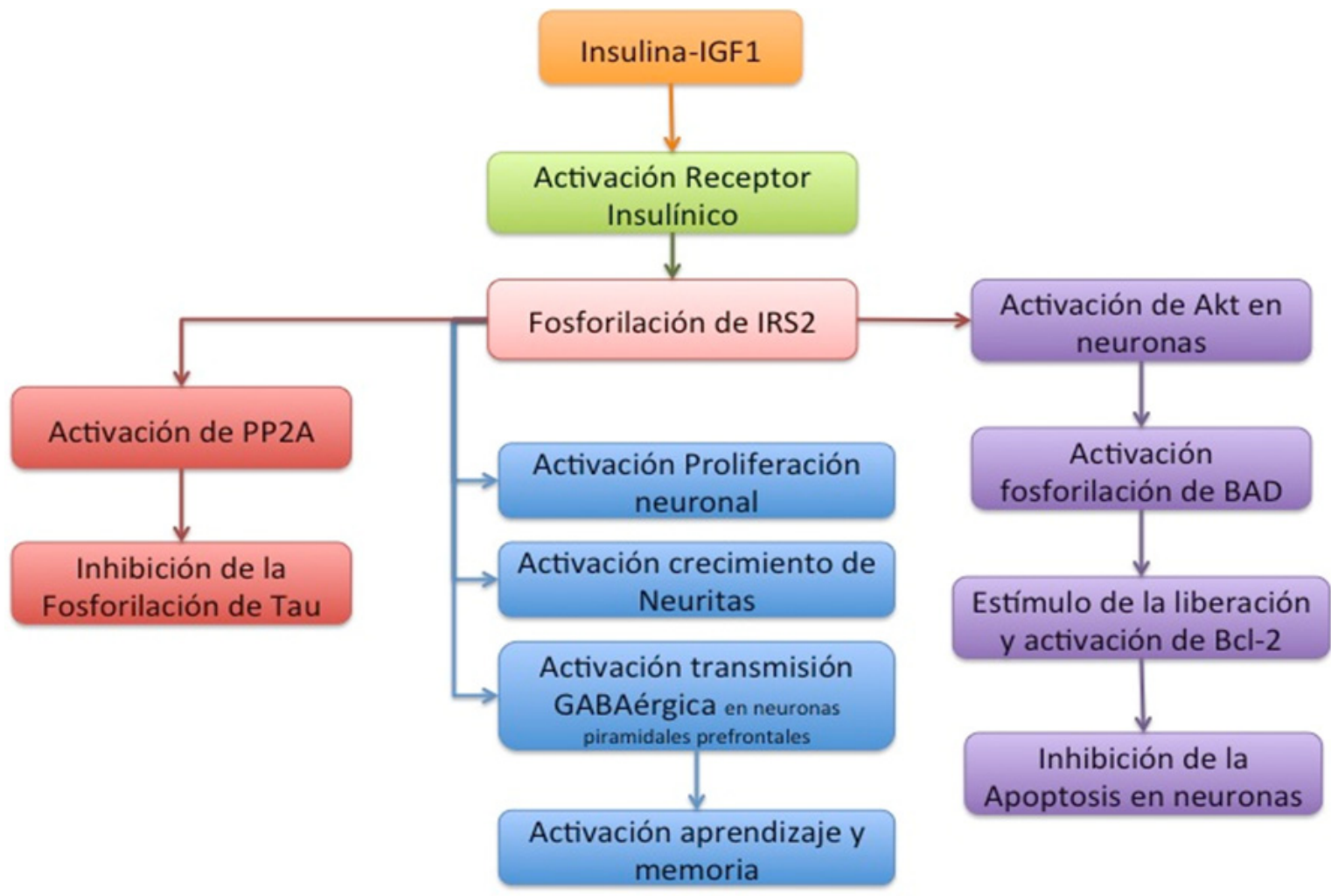

Figura D1. Acontecimientos neuronales consecuentes a la activación del receptor insulínico.

Como muestra el esquema de la Figura D1, la insulina o el IGF1 se unen a un receptor de mebrana y provocan la activación del receptor insulínico.

Ya dentro de la célula, la activación del receptor induce la fosforilación de IRS2.

Dicha fosforilación tiene como consecuencia la activación de PP2A, lo que inhibe la fosforilación de Tau.

Por otro lado, la fosforilación provoca la activación de Akt en neuronas, lo que fosforila BAD, que deja de formar dímeros con $\mathrm{Bcl}-2$, por lo que se induce el estímulo de la liberación y activación de $\mathrm{Bcl}-2$. Como Bcl-2 es una proteína antiapoptótica, a través de esta vía, se provoca la inhibición de la apoptosis neuronal.

La fosforilación de IRS2, además induce la activación de la proliferación neuronal, la activación del crecimiento de las neuritas y la activación del aprendizaje y la memoria a través de una activación en la transmisión GABAérgica en neuronas piramidales prefrontales.

Considerados globalmente todos estos hechos, podríamos decir que la activación del receptor insulínico y posterior fosforilación de IRS2 favorece el aprendizaje y la memoria, favorece la supervivencia neuronal y evita la toxicidad de Tau. 
Era lógico pues pensar que la ausencia de IRS2 podría tener como consecuencia la posible aparición de un proceso neurodegenerativo.

En la memoria y el aprendizaje, juegan un papel muy importante la participación de las hormonas insulina y factor de crecimiento insulínico tipo 1 (IGF-1). Estas dos hormonas son capaces de activar el receptor insulínico de la superficie de la célula neuronal, aunque la primera con mayor potencia que la segunda. Como este receptor es del tipo de actividad tirosina quinasa, al activarse produce la fosforilación del sustrato receptor insulínico tipo 2 (IRS-2).

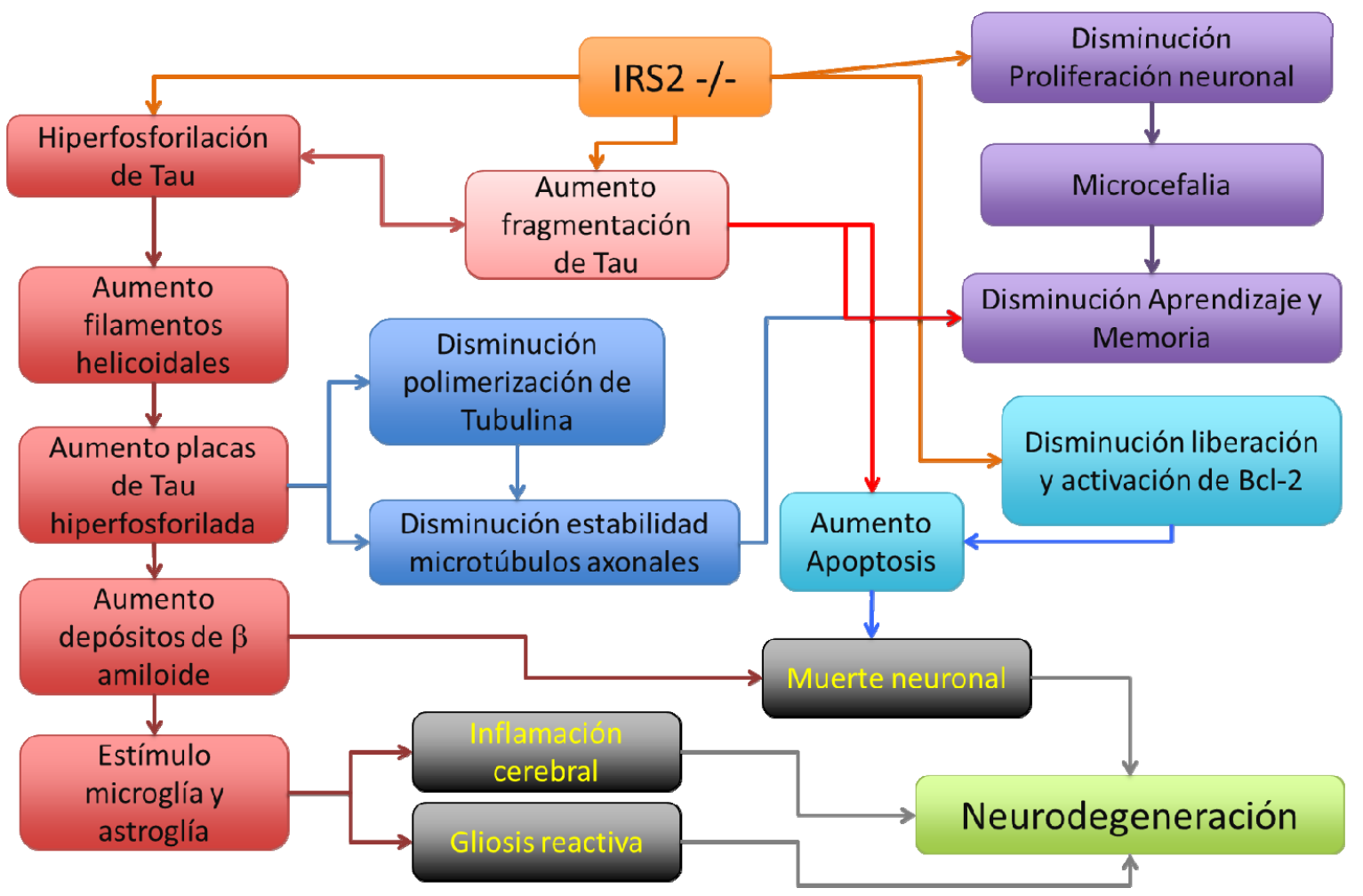

Figura D2. Acontecimientos intraneuronales o intraencefálicos que se sucederían teóricamente por la ausencia de IRS2 en los ratones knock out de nuestro estudio.

La figura D2 trata de resumir qué acontecimientos se suceden ante la ausencia de IRS2, como ocurre en los animales knock out de nuestro estudio.

Siguiendo la secuencia que empleamos para la explicación de la Figura D1, como se aprecia en la Figura D2, la ausencia de la fosforilación de IRS2 tiene como consecuencia la desaparición de la inhibición de la fosforilación de Tau lo que provocaría una hiperfosforilación de Tau.

Esta última traería consigo de forma secuencial el aumento de filamentos helicoidales, el aumento de placas con Tau hiperfosforilada, el aumento de depósitos de $\beta$-amiloide y el estímulo de la microglía y la astroglía. Todo ello conducente a una inflamación cerebral y a una gliosis reactiva que encaminaría el proceso hacia la neurodegeneración.

La ausencia de IRS2 y, consecuentemente, su no fosforilación provocarían un aumento en la fragmentación de Tau. Esta fragmentación se asociaría a la hiper- 
fosoforilación de Tau y se implicaría en la disminución del aprendizaje y la memoria.

La no fosforilación de IRS2 disminuiría la proliferación neuronal que conduciría a la microcefalia y ésta se asociaría a los déficits en aprendizaje y memoria.

Igualmente, provocaría un desenso en la liberación y activación de Bcl-2, lo que explicaría un aumento en la apoptosis. La apoptosis también se estimularía por la hiperfragmentación de Tau y por la disminución de la polimerización de tubulina y por la disminución de la estabilidad de los microtúbulos axonales, derivadas ambas de la hiperfosforilación de Tau.

\begin{abstract}
La tubulina es un heterodímero formado por dos subunidades que precisa de la proteína Tau para su polimerización. Cuando se ensamblan de forma organizada generan los microtúbulos del citoesqueleto celular. El aumento de los ovillos neurofibrilares de Tau fosforilada impide la polimerización de la tubulina y favorece la disminución de la estabilidad de los microtúbulos axonales. La pérdida de estas estructuras tubulares altera el transporte axonal de orgánulos y sustancias y, sobre todo, de la conducción del impulso nervioso. Todo ello incide en la disminución del aprendizaje y de la memoria, las manifestaciones cognitivas más evidentes de los pacientes con la enfermedad de Alzheimer.
\end{abstract}

El aumento de depósitos de $\beta$-amiloide y el aumento de la apoptosis implicarían un aumento de muerte neuronal y por tanto conduciría el proceso hacia la neurodegeneración.

La hipótesis que se plantea en el esquema de la Figura D2 se ha visto corroborada en gran parte en nuestro estudio, como muestra la figura D3.

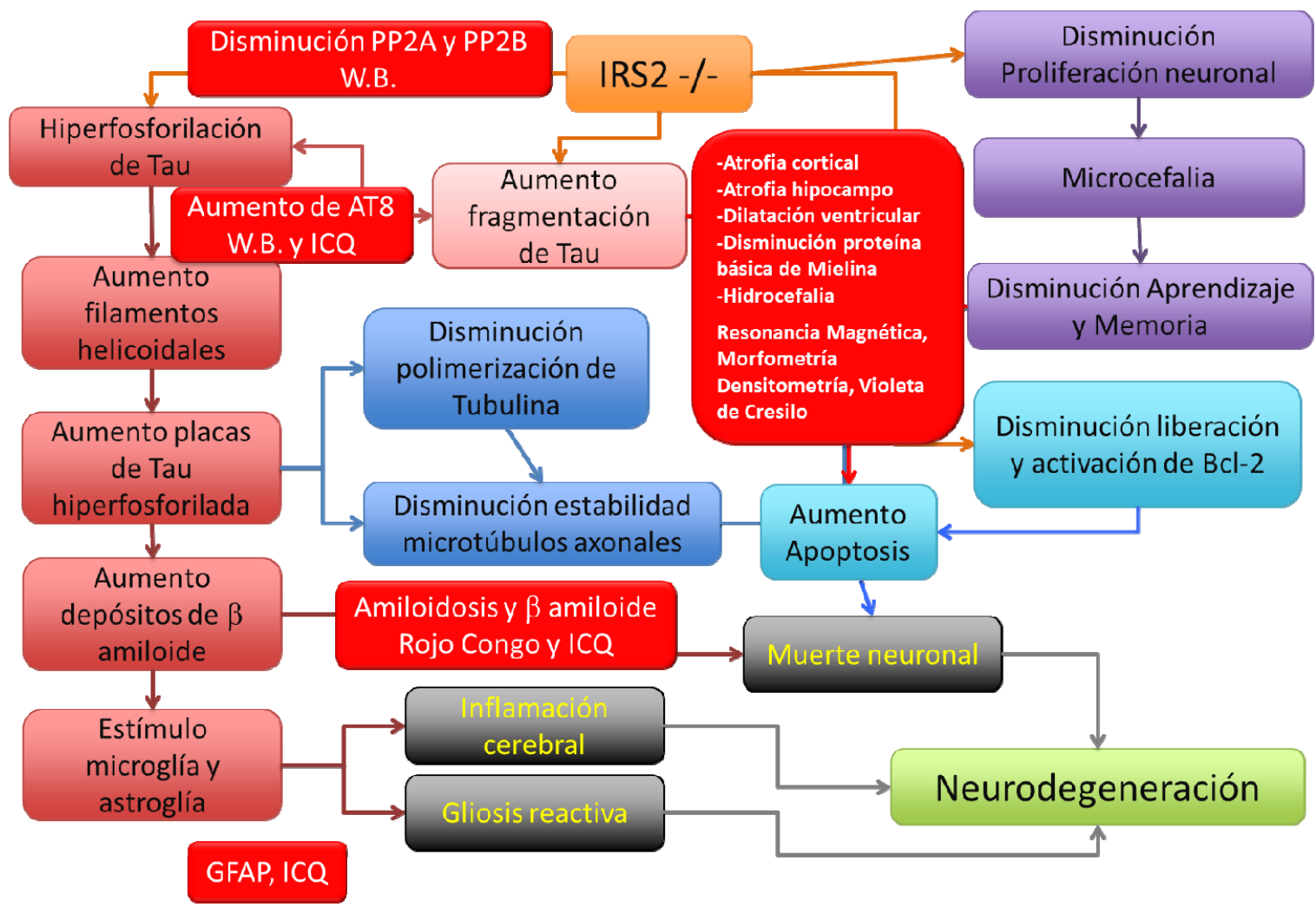

Figura D3. Hallazgos constatados en nuestro estudio que parecen confirmar la hipótesis planteada anteriormente y que recoge la figura D2. 
Mediante western blotting y densitometría hemos constatado la disminución de PP2A y PP2B.

Mediante western blotting y densitometría hemos constatado un aumeto de AT8 y mediante inmunocitoquímica el aumento de Tau1,2 fosforilada.

Mediante inmunocitoquímica hemos constatado el aumento de reacción a GFAP lo que implica un aumento de la glía astrocitaria.

Mediante histoquimia, rojo congo, e inmunocitoquímica hemos constatado la presencia de amiloidosis perivascular y depósitos del péptido $\beta$-amiloide.

A través del estudio morfológico histoquímico con violeta de cresilo y mediante imágenes de resonancia magnética, hemos constatado la presencia de atrofia cortical, atrofia del hipocampo, aumento de la dilatación ventricular (pudiendo llegar a hidrocefalias severas) y disminución de la proteína básica de la mielina (por western blotting). 
Conclusiones 
Después de analizar detenidamente los resultados obtenidos en los ratones que presentaban alteraciones en las rutas de señal intracelular, debidas a la carencia de la proteína de sustrato de receptor insulínico IRS2, por ser ratones knock out para el gen de IRS2, y compararlos con los descritos por otros autores, hemos llegado a las siguientes conclusiones:

Primera:

Los resultados obtenidos sugieren que todas las variaciones y alteraciones observadas en nuestro estudio se deben exclusivamente a la interrupción de la cascada de señales intracelulares que se activa por la fosforilación de la proteína de sustrato de receptor insulínico IRS2, puesto que:

Los animales empleados en nuestro estudio no eran hiperglucémicos, así que las alteraciones y variaciones observadas no pueden ser atribuidas en ningún caso a las lesiones vasculares o de otro tipo que se desarrollan como consecuencia de la hiperglucemia en los diabéticos.

Además, como presentan tasas sanguíneas de insulina que deben ser consideradas como normales, esas variaciones y alteraciones no se deben a la falta de activación del receptor insulínico por un déficit de insulina.

La determinación basal y postprandial de glucosa en sangre y la determinación postprandial de insulina en suero demuestran que no hay variaciones significativas entre los animales wilde type y los knock out para IRS2, entrando todos los valores observados dentro de rangos de normalidad.

Además, y puesto que, los niveles de insulina en sangre de los animales knock out para IRS2 fueron semejantes o superiores a los observados en los animales wilde type, las cascadas de señal intracelular que se activan por la fosforilación de otras proteínas de sustrato de receptor insulínico sí son posibles, y, presumiblemente, el receptor insulínico se activaba.

\section{Segunda:}

Al igual que había sido descrito por otros autores, los ratones knock out de IRS2 utilizados en el estudio presentaban una hiperfosforilación de Tau, principalmente asociada a AT8, a la vez que una disminución de enzimas desfosforiladoras y un descenso en la mielinización por disminución de la proteína básica de mielina.

Estas variaciones, observadas por western blotting, se constataron cuantitativamente mediante densitometría. Los perfiles densitométricos demuestran que en la mayoría de los casos las bandas de western blotting obtenidas en los ratones knock out no eran bandas homogéneas.

Estas alteraciones bioquímicas sugieren que los encéfalos de los ratones knock out de IRS2 pueden presentar patologías neurodegenerativas asociadas a hiperfosforilación de Tau, como ocurre en la especie humana con la enfermedad de Alzheimer.

\section{Tercera:}

Los ratones knock out para IRS2 presentan depósitos, principalmente extracelulares, del péptido $\beta$-amiloide, lo que sugiere que en su cerebro acontecen fenómenos neurodegenerativos que se asemejan a los que acontecen en 
humanos durante el desarrollo de la enfermedad de Alzheimer. Estos procesos afectan a la corteza cerebral y al hipocampo principalmente, aunque no exclusivamente.

La evidencia de los depósitos la hemos obtenido mediante el análisis inmunocitoquímico comparado entre ratones wilde type y knock out de la misma edad.

Cuarta:

El hipocampo de los ratones knock out a IRS2 presenta una clara atrofia que afecta de forma parecida al giro dentado, el asta de Amón (en sus diferentes regiones CA1, CA2 y CA3) con marcada atrofia del estrato piramidal (plexiforme en (A3) y a la corteza entorrinal de la circunvolución hipocampal.

Esta evidencia se ha obtenido mediante el estudio morfométrico postmortem de los cortes histológicos, excluyendo a los animales con hidrocefalia severa con la finalidad de que los resultados no quedaran enmascarados por un posible efecto de la hipertensión endocraneal.

Quinta:

Los ratones knock out para IRS2 desarrollan una dilatación ventricular manifiesta que afecta a los ventrículos laterales, el ventrículo medio, el acueducto de Silvio, el cuarto ventrículo y a la cisterna magna, de forma estadísticamente significativa. En algunos animales, se apreció una hidrocefalia severa, con líquido céfalo raquídeo a tensión.

Esta evidencia se ha obtenido mediante la visualización en el estudio histológico postmortem, el análisis morfométrico in vivo a partir de imágenes de resonancia magnética, $y$, en el momento del sacrificio, la hipertensión endocraneal se puso de manifiesto por la salida a presión del líquido céfalo-raquídeo en la apertura de la calota craneal.

Sexta:

Los fenómenos neurodegenerativos, principalmente en los ratones con hidrocefalia severa, aunque no exclusivamente, se acompañan de gliosis reactiva que afectaba a las zonas en la vecindad de los ventrículos cerebrales. Además, la gliosis reactiva fue evidente en otras zonas del encéfalo, como: el hipocampo, fundamentalmente en la capa molecular del giro dentado y de las regiones CA1, CA2 y CA3.

Estos hallazgos se evidenciaron mediante el estudio inmunocitoquímico postmortem con anticuerpos específicos contra la proteína fibrilar glial ácida que marca los astrocitos.

Séptima:

Los ratones knock out para IRS2 presentan una marcada atrofia cortical y atrofia del hipocampo, con disminuciones en el grosor y, en el caso del hipocampo, con disminución de los estratos neuronales del giro dentado y todas las regiones del asta de Amón.

Estos hallazgos los hemos constatado mediante morfometría de cortes histológicos postmortem y de imágenes de resonancia magnética obtenidas in vivo. 
Octava:

Los procesos neurodegenerativos corticales, observados en los animales knock out para IRS2, afectan de manera más manifiesta a la corteza cingular, la corteza motora secundaria, la corteza somatosensorial, la corteza insular y la corteza entorrinal.

Estos hallazgos se han constatado mediante morfometría de imágenes obtenidas in vivo mediante resonancia magnética.

Novena:

Los animales knock out para IRS2 presentaron, además, una disminución de tamaño de los ganglios basales, bien demostrado en el estriado, núcleos caudado y putamen globalmente considerados. Si bien no podemos asegurar que se deba al proceso neurodegenerativo en sí mismo, o a un menor desarrollo de estas estructuras.

Estos hallazgos se han constatado mediante morfometría de imágenes obtenidas in vivo mediante resonancia magnética.

Décima:

Los hallazgos obtenidos en nuestro estudio y las conclusiones que anteceden a ésta, sugieren que hemos estudiado un modelo experimental de ratón que permite el análisis de la instauración y progreso de un proceso neurodegenerativo en ratones, semejante al que acontece en la enfermedad de Alzheimer humana, sin la necesidad de inducir genéticamente acontecimientos individuales del proceso general de la enfermedad, como puede ser la inducción de la síntesis de $\beta$-amiloide.

Al contrario, se trata de un proceso neurodegenerativo que acontece como consecuencia de un fallo de señal intracelular, muy semejante al que acompaña a la resistencia periférica a la insulina, la diabetes tipo II; sin duda, la enfermedad endocrino-metabólica con mayor prevalencia en los países desarrollados y emergentes, al igual que la enfermedad de Alzheimer, como proceso nosológico neurológico.

El estudio mediante imágenes de resonancia magnética, acompañado del empleo de sencillos parámetros morfométricos, se corresponde con el análisis postmortem, y permite hacer un seguimiento de la evolución del proceso. Lo que podría ser muy útil para analizar la eficiencia de los posibles avances terapéuticos farmacológicos a lo largo del tiempo de evolución de la enfermedad y de la edad del animal, basándonos en que este modelo animal seguro que desarrollará, por sí mismo, la neurodegeneración al envejecer. 
Bibliografía 
Abbas T, Faivre E, Hölscher C. Impairment of synaptic plasticity and memory formation in GLP-1 receptor KO mice: Interaction between type 2 diabetes and Alzheimer's disease. Behav Brain Res, 205 (2009):265-271.

Aberg M, Aberg N, Hedbacker H, Oscarsson J, Eriksson P. Peripheral infusion of IGF-1 selectively induces neurogenesis in the adult rat hippocampus. J Neurosci, 20 (2000): 2896-2903.

Adlerz L, Holback S, Multhaup G, Iverfeldt K. IGF-1-induced processing of the amyloid precursor protein family is mediated by different signaling pathways. J Biol Chem, 282 (2007): 10203-10209

Ahn HJ, Seo SW, Chin J, Suh MK, Lee BH, Kim ST, Im K, Lee JM, Lee JH, Heilman KM, Na DL. The cortical neuroanatomy of neuropsychological deficits in mild cognitive impairment and Alzheimer's disease: a surface-based morphometric analysis. Neuropsychologia, 49 (2011): 3931-3945.

Aho L, Pikkarainen M, Hiltunen M, Leinonen V, Alafuzoff I. Immunohistochemical visualization of amyloid-beta protein precursor and amyloid-beta in extra- and intracellular compartments in the human brain. J Alzheimers Dis, 20 (2010): 1015-1028.

Alafuzoff I, Thal DR, Arzberger T, Bogdanovic N, Al-Sarraj S, Bodi I, Boluda S, Bugiani O, Duyckaerts C, Gelpi E, Gentleman S, Giaccone G, Graeber M, Hortobagyi T, Höftberger R, Ince P, Ironside JW, Kavantzas N, King A, Korkolopoulou P, Kovács GG, Meyronet D, Monoranu C, Nilsson T, Parchi P, Patsouris E, Pikkarainen M, Revesz T, Rozemuller A, Seilhean D, Schulz-Schaeffer W, Streichenberger N, Wharton SB, Kretzschmar H. Assessment of beta-amyloid deposits in human brain: a study of the BrainNet Europe Consortium. . Acta Neuropathol, 117 (2009): 309-320.

Allegri RF, Harris P, Feldman M, Taragano F, Paz J. Differential cognitive profiles of frontotemporal dementia and Alzheimer's disease. Rev Neurol, 27 (1998): 463-466.

Allen B, Ingram E, Takao M, Smith MJ, Jakes R, Virdee K, Yoshida H, Holzer M, Craxton M, Emson PC, Atzori C, Migheli A, Crowther RA, Ghetti B, Spillantini MG, Goedert M. Abundant tau filaments and nonapoptotic neurodegeneration in transgenic mice expressing human P301S tau protein. J Neurosci, 22 (2002): 9340-9351.

Alonso AD, Grundke-lqbal I, Barra HS, lqbal K. Abnormal phosphorylation of tau and the mechanism of Alzheimer neurofibrillary degeneration: sequestration of microtubuleassociated proteins 1 and 2 and the disassembly of microtubules by the abnormal tau. Proc Natl Acad Sci, 94 (1997): 298-303.

Alvarez G, Muñoz-Montaño JR, Satrústegui J, Avila J, Bogonez E, Díaz-Nido J. Lithium protects cultured neurons against beta-amyloid-induced neurodegeneration. FEBS Lett, 453 (1999): 260-264.

Alzheimer A. Ueber eigenartige Krankheitsfaelle des spaeteren Alters. Zeitschrift fuer die gesamte Neurologie und Psychiatrie, 4 (1911): 356-386.

Amadoro G, Corsetti V, Ciotti MT, Florenzano F, Capsoni S, Amato G, Calissano P. Endogenous AB causes cell death via early tau hyperphosphorylation. Neurobiol Aging, 32 (2011): 969990.

Andorfer C, Acker CM, Kress Y, Hof PR, Duff K, Davies P. Cell-cycle reentry and cell death in transgenic mice expressing nonmutant human tau isoforms. J Neurosci, 25 (2005): 54465454.

Anlar B, Sullivan KA, Feldman EL. Insulin-like growth factor-I and central nervous system development. Horm Metab Res, 31 (1999): 120-125

Apostolova LG, Dinov ID, Dutton RA, Hayashi KM, Toga AW, Cummings JL. 3D comparison of hippocampal atrophy in amnestic mild cognitive impairment and Alzheimer's disease. Brain, 129 (2006a): 2867-2873.

Apostolova LG, Dutton RA, Dinov ID, Hayashi KM, Toga AW, Cummings JL. Conversion of mild cognitive impairment to Alzheimer disease predicted by hippocampal atrophy maps. Arch Neurol, 63 (2006b): 693-699. 
Apostolova LG, Thompson PM. Mapping progressive brain structural changes in early Alzheimer's disease and mild cognitive impairment. Neuropsychologia, 46 (2008): 1597- 1612

Arif M, Chikuma T, Ahmed MM, Nakazato M, Smith MA, Kato T. Effects of memantine on soluble Alphabeta(25-35)-induced changes in peptidergic and glial cells in Alzheimer's disease model rat brain regions. Neuroscience, 164 (2009): 1199-1209.

Arrasate M, Mitra S, Schweitzer ES, Segal MR, Finkbeiner S. Inclusion body formation reduces levels of mutant huntingtin and the risk of neuronal death. Nature, 431 (2004): 805-810.

Avila J. Tau phosphorylation and aggregation in Alzheimer's disease pathology. FEBS Lett, 580 (2006): 2922-2927

Baki L, Shioi J, Wen P, Shao Z, Schwarzman A, Gama-Sosa M, Neve R, Robakis NK. PS1 activates PI3K thus inhibiting GSK-3 activity and tau overphosphorylation: effects of FAD mutations. EMBO J, 23 (2004): 2586-2596.

Barber R, Gholkar A, Scheltens P, Ballard C, McKeith IG, Morris CM, O’Brien JT. Apolipoprotein E epsilon4 allele, temporal lobe atrophy, and white matter lesions in late-life dementias. Arch Neurol, 56 (1999): 961-965.

Barber R, McKeith IG, Ballard C, Gholkar A, O'Brien JT. A comparison of medial and lateral temporal lobe atrophy in dementia with Lewy bodies and Alzheimer's disease: magnetic resonance imaging volumetric study. Dement Geriatr Cogn Disord, 12 (2001): 198-205.

Barclay LL, Linden C, Murtagh R. Medial temporal atrophy as a magnetic resonance imaging marker for Alzheimer's disease. J Neuroimaging, 2 (1992): 131-135.

Baron JC, Chetelat G, Desgranges B, Perchey G, Landeau B, de la Sayette V. In vivo mapping of gray matter loss with voxel-based morphometry in mild Alzheimer's disease. Neuroimage, 14 (2001): 298-309.

Bartke A. Impact of reduced insulin-like growth factor-1/insulin signalling on aging in mammals: novel findings. Aging Cell, 7 (2008a): 285-290.

Bartke A. Insulin and aging. Cell Cycle, 7 (2008b): 3338-3343.

Baudier J, Lee SH, Cole RD. Separation of the different microtubule-associated tau protein species from bovine brain and their mode II phosphorylation by $\mathrm{Ca2}+/$ phospholipiddependent protein kinase C. J Biol Chem, 262 (1987): 17584-17590.

Belinson $\mathrm{H}$, Michaelson DM. ApoE4-dependent Abeta-mediated neurodegeneration is associated with inflammatory activation in the hippocampus but not the septum. J Neural Transm, 116 (2009): 1427-1434.

Bell-McGinty S, Lopez OL, Meltzer CC. Differential cortical atrophy in subgroups of mild cognitive impairment. Arch Neurol, 62 (2005): 1393-1397.

Biernat J, Mandelkow EM, Schröter C, Lichtenberg-Kraag B, Steiner B, Berling B, Meyer H, Mercken M, Vandermeeren A, Goedert M, Mandelkow E. The switch of tau protein to an Alzheimer-like state includes the phosphorylation of two serine-proline motifs upstream of the microtubule binding region. EMBO Journal, 11 (1992): 1593-1597.

Biessels GJ, Kappelle LJ. Increased risk of Alzheimer's disease in type II diabetes: insulin resistance of the brain or insulin-induced amyloid pathology? Biochem Soc Trans, 33 (2005): 1041-1044

Bigler ED, Tate DF, Miller MJ, Rice SA, Hessel CD, Earl HD, Tschanz JT, Plassman B, WelshBohmer KA. Dementia, asymmetry of temporal lobe structures, and apolipoprotein E genotype: relationships to cerebral atrophy and neuropsychological impairment. J Int Neuropsychol Soc, 8 (2002): 925-933.

Bird TD, Nochlin D, Poorkaj P, Cherrier M, Kaye J, Payami H, Peskind E, Lampe TH, Nemens E, Boyer PJ, Schellenberg GD. A clinical pathological comparison of three families with frontotemporal dementia and identical mutations in the tau gene (P301L). Brain, 122 (1999): 741-756. 
Black SE, Moffat SD, Yu DC, Parker J, Stanchev P, Bronskill M. Callosal atrophy correlates with temporal lobe volume and mental status in Alzheimer's disease. Can J Neurol Sci, 27 (2000): 204-209.

Blaschke W. Vorlesungen uber Integralgeometrie. Chelsea Publishing Company. New York (1949).

Blass JP, Gibson GE, Hoyer S. The role of the metabolic lesion in Alzheimer's disease. J Alzheimers Dis, 4 (2002): 225-232.

Bobinski M, de Leon MJ, Convit A. MRI of entorhinal cortex in mild Alzheimer's disease. Lancet, 353 (1999): 38-40.

Bobinski M, Wegiel J, Tarnawski M, de Leon MJ, Dziewiatkowski J, Wisniewski HM. Computerassisted 3D-reconstruction of the hippocampal formation in AD. J Neuropath Exp Neurol, 52 (1993): 263.

Bobinski M, de Leon MJ, Wegiel J, Desanti S, Convit A, Saint Louis LA, Rusinek H, Wisniewski HM. The histological validation of post mortem magnetic resonance imaging-determined hippocampal volume in Alzheimer's disease. Neuroscience, 95 (2000):721-725.

Boccardi M, Laakso MP, Bresciani L, Galluzzi S, Geroldi C, Beltramello A, Soininen H, Frisoni GB. The MRI pattern of frontal and temporal brain atrophy in fronto-temporal dementia. Neurobiol Aging, 24 (2003): 95-103.

Bondareff W, Mountjoy CQ, Roth M, Hauser DL. Neurofibrillary degeneration and neuronal loss in Alzheimer's disease. Neurobiol Aging, 10 (1989): 709-715.

Bonnesen T. and Fenchel W. Theorie der Konvexen Körper. Ergebenisse der mathematic und ihrer grenzgebiete, 3 (1934): 1.

Bottino CM, Castro CC, Gomes RL, Buchpiguel CA, Marchetti RL, Neto MR. Volumetric MRI measurements can differentiate Alzheimer's disease, mild cognitive impairment, and normal aging. Int Psychogeriatr, 14 (2002): 59-72.

Bouwman FH, Schoonenboom SNM, van der Flier WM, van Elk EJ, Kok A, Barkhof F. CSF biomarkers and medial temporal lobe atrophy predict dementia in mild cognitive impairment. Neurobiol Aging, 28 (2007): 1070-1074.

Bozzali M, Filippi M, Magnani G, Cercignani M, Franceschi M, Schiatti E. The contribution of voxel-based morphometry in staging patients with mild cognitive impairment. Neurology, 67 (2006): 453-460.

Braak H, Alafuzoff I, Arzberger T, Kretzschmar H, Del Tredici K. Stagign of Alzheimer diseaseassociated neurofibrillary pathology using paraffin sections and immunocytochemistry. Acta Neuropathol, 112 (2006): 389-404.

Braak H, Braak E. Neuropathological stageing of Alzheimer-related changes. Acta Neuropathol, 82 (1991): 239-259.

Bracco L, Piccini C, Manfredi G, Fonda C, Falcini M, Amaducci L. Magnetic resonance measures in Alzheimer disease: their utility in early diagnosis and evaluating disease progression. Alzheimer Dis Assoc Disord, 13 (1999): 157-164.

Brands AM, Biessels GJ, de Haan EH, Kappelle LJ, Kessels RP. The effects of type 1 diabetes on cognitive performance: a meta-analysis. Diabetes Care, 28 (2005): 726-735

Brandt R, Hundelt $M$, Shahani N. Tau alteration and neuronal degeneration in tauopathies: mechanisms and models. Biochim Biophys, Acta 1739 (2005): 331-354.

Bresciani L, Rossi R, Testa C, Geroldi C, Galluzzi S, Laakso MP, Beltramello A, Soininen H, Frisoni GB. Visual assessment of medial temporal atrophy on MR films in Alzheimer's disease: comparison with volumetry. Aging Clin Exp Res, 17 (2005): 8-13.

Brunet A, Bonni A, Zigmond MJ, Lin MZ, Juo P, Hu LS, Anderson MJ, Arden KC, Blenis J, Greenberg ME. Akt promotes cell survival by phosphorylating and inhibiting a Forkhead transcription factor. Cell, 96 (1999): 857-868 
Buffa R, Solcia E, Fiocca R, Crivelli O, Pera A. Complement mediated binding of immunoglobulins to some endocrine cells of the pancreas and gut. J Histochem Cytochem, 27 (1979): $1279-1280$

Burack MA, Halpain S. Site-specific regulation of Alzheimer-like tau phosphorylation in living neurons. Neuroscience, 72 (1996): 167-184.

Busatto GF, Garrido GE, Almeida OP, Castro CC, Camargo CH, Cid CG. A voxel-based morphometry study of temporal lobe gray matter reductions in Alzheimer's disease. Neurobiol Aging, 24 (2003): 221-231.

Busciglio J, Lorenzo A, Yeh J, Yankner BA. Betaamyloid fibrils induce tau phosphorylation and loss of microtubule binding. Neuron, 14 (1995): 879-888.

Cabrero FJ. Imagen radiológica: Principios físicos e instrumentación. Masson. Barcelona. ISBN: 9788445814505. (2004).

Caceres A, Kosik KS. Inhibition of neurite polarity by tau antisense oligonucleotides in primary cerebellar neurons. Nature, 343 (1990): 461-463.

Callen DJ, Black SE, Gao F, Caldwell CB, Szalai JP. Beyond the hippocampus: MRI volumetry confirms widespread limbic atrophy in AD. Neurology, 57 (2001): 1669-1674

Carretero J, Rubio M, Navarro N, Prieto P, Vázquez RJ, Sánchez F, Vázquez R. In Vitro modifications in the proliferation rate of prolactin cells are accompanied by nuclear morphometric variations. Histol Histopathol, 10 (1995a): 135-139.

Carretero J, Rubio M, Sánchez F, Cabo JJ, Riesco JM, Angoso M, Vázquez R. Immunocytochemical and morphometric study of the PRL-cell following chronic administration of TRH and methymazole. An Anat, 38 (1992a): 183-189.

Carretero J, Rubio M, Sánchez F, Vázquez RJ, Santos M, Blanco J, Vázquez R. In vitro morphometric and proliferative variatins in VIP-immunoreactive pituitary cells induced by estradiol. Neuroendocrinology, 62 (1995b): 277-282.

Carretero J, Rubio M, Vázquez-Perfecto RJ, Sánchez F, Torres JL, Pérez RM, Vázquez R. Decreases in the size and proliferation rate of VIP-immunoreative cells induced in Vitro by testosterone are associated with decreases in VIP release. Neuroendocrinology, 65 (1997):173-178.

Carretero J, Sánchez F, Montero M, Blanco E, Riesco JM, Carbajo E, Vázquez R. Morphological and functional study of the $\mathrm{GH}$ immunoreactive adenohypophyseal cells in ovariectomized rats. Histochemical Journal, 22 (1990): 679-687.

Carretero J, Sánchez F, Rubio M, Lorenzo MJ, Francos M, Cacicedo L, Sánchez-Franco F, Vázquez R. Immunocytochemical evidence of hypothalamic regulation of adenohypophyseal VIP in the male-rat. Neuropeptides, 23 (1992b): 239-243

Carretero J, Sánchez F, Torres JL, Blanco E, Riesco JM, Vázquez R. Study of h-TSH immunoreactive adenohypophyseal cells following treatment with methymazole. Histol Histopathol, 4 (1989): 71-76.

Carretero J, Sánchez F, Vázquez R, Cacicedo L, Sánchez-Franco F, Fernández G, Montero M. In vivo and in Vitro evidence of growth hormone-releasing factor-like produced locally in the adenohypophyseal cells of the rat. Neuropeptides, 19 (1991): 223-229.

Carretero J, Vázquez G, Blanco E, Rubio M, Santos M, Martín-Clavijo A, Torres JL, Vázquez R. Immunohistochemical evidence of the presence of aromatase P450 in the rat hypophysis. Cell Tissue Res, 295 (1999a): 419-423.

Carretero J, Vázquez G, Martín-Clavijo A, Rubio M, Hernández E, Moro JA, Gato A, Barbosa E, Vázquez R. In vivo studies on cytodifferentiation of pituitary aromatase-immunoreactive cells. Eur J Anat, 3 (1999b): 79-85.

Carro E, Trejo JL, Gomez-Isla T, LeRoith D, Torres-Aleman I. Serum insulin-like growth factor I regulates brain amyloid-B levels. Nat Med, 8 (2002): 1390-1397 
Carvalho CR, Brenelli SL, Silva AC, Nunes AL, Velloso LA, Saad MJ. Effect of aging on insulin receptor, insulin receptor substrate-1, and phosphatidylinositol 3-kinase in liver and muscle of rats. Endocrinology, 137 (1996): 151-159.

Cerpa W, Hancke JL, Morazzoni P, Bombardelli E, Riva A, Marin PP, Inestrosa NC. The hyperforin derivative IDN5706 occludes spatial memory impairments and neuropathological changes in a double transgenic Alzheimer's mouse model. Curr Alzheimer Res, 7 (2010): 126-133.

Cheng CM, Tseng V, Wang J, Wang D, Matyakhina L, Bondy CA. Tau is hyperphosphorylated in the insulin-like growth factor-I null brain. Endocrinology, 146 (2005): 5086-5091

Cheng $\mathrm{Z}$, Tseng $\mathrm{Y}$, White MF. Insulin signaling meets mitochondria in metabolism. Trends Endocrinol Metab, 21 (2010): 589-598.

Chetelat G, Landeau B, Eustache F, Mezenge F, Viader F, de la Sayette V. Using voxel-based morphometry to map the structural changes associated with rapid conversion in $\mathrm{MCl}$ : a longitudinal MRI study. Neuroimage, 27 (2005): 934-946.

Choudhury Al, Heffron H, Smith MA, Al-Qassab H, Xu AW, Selman C, Simmgen M, Clements M, Claret M, MacColl G, Bedford DC, Hisadome K, Diakonov I, Moosajee V, Bell JD, Speakman JR, Batterham RL, Barsh GS, Ashford ML, Whiters DJ. The role of insulin receptor substrate 2 in hypothalamic and cell function. J Clin Invest, 115 (2005): 940-950.

Chow SK, Yu D, Macdonald CL, Buibas M, Silva GA. Amyloid B-peptide directly induces spontaneous calcium transients, delayed intercellular calcium waves and gliosis in rat cortical astrocytes. ASN Neuro, 2 (2010):e00026.

Chung CW, Song YH, Kim IK, Yoon WJ, Ryu BR, Jo DG, Woo HN, Kwon YK, Kim HH, Gwag BJ, Mook-Jung IH, Jung YK. Proapoptotic effects of tau cleavage product generated by caspase-3. Neurobiol Dis, 8 (2001): 162-172

Cleveland DW, Hwo SY, Kirschner MW. Purification of tau, a microtubule-associated protein that induces assembly of microtubules from purified tubulin. J Mol Biol, 116 (1977): 207-225.

Clodfelder-Miller BJ, Zmijewska AA, Johnson GV, Jope RS. Tau is hyperphosphorylated at multiple sites in mouse brain in vivo after streptozotocin-induced insulin deficiency. Diabetes, 55 (2006): 3320-3325

Colliot O, Chetelat G, Chupin M, Desgranges B, Magnin B, Benali H. Discrimination between Alzheimer disease, mild cognitive impairment, and normal aging by using automated segmentation of the hippocampus. Radiology, 248 (2008): 194-201.

Convit A, de Asis J, de Leon MJ, Tarshish C, De Santi S, Rusinek H. Atrophy of the medial occipitotemporal, inferior, and middle temporal gyri in non-demented elderly predict decline to Alzheimer's disease. Neurobiol Aging, 21 (2000): 19-26.

Convit A, de Leon MJ, Golomb J. Hippocampal atrophy in early Alzheimer's disease: anatomic specificity and validation. Psychiatr Q, 64 (1993): 371-387.

Correas I, Díaz-Nido J, Avila J. Microtubuleassociated protein tau is phosphorylated by protein kinase $C$ on its tubulin binding domain. J Biol Chem, 267 (1992): 15721-15728.

Costantini C, Scrable H, Puglielli L. An aging pathway controls the TrkA to P75NTR receptor switch and amyloid -peptide generation. EMBO J, 25 (2006): 1997-2006.

Cox DJ, Kovatchev BP, Gonder-Frederick LA, Summers KH, McCall A, Grimm KJ, Clarke WL. Relationships between hyperglycemia and cognitive performance among adults with type 1 and type 2 diabetes. Diabetes Care, 28 (2005): 71-77

Cras P, Smith MA, Richey PL, Siedlak SL, Mulvihill P, Perry G. Extracellular neurofibrillary tangles reflect neuronal loss and provide further evidence of extensive protein cross-linking in Alzheimer disease. Acta Neuropathol, 89 (1995): 291-295.

Crofton MW. Geometrical theorems related to mean values. Proc Lond Math Soc 8 (1877): 304.

Crowther RA, Olesen OF, Jakes R, Goedert $M$. The microtubule binding repeats of tau protein assemble into filaments like those found in Alzheimer's disease. FEBS Lett, 309 (1992): 199-202. 
Datta SR, Dudek H, Tao X, Masters S, Fu H, Gotoh Y, Greenberg ME. Akt phosphorylation of BAD couples survival signals to the cell-intrinsic death machinery. Cell, 91 (1997): 231-241

Dawson HN, Ferreira A, Eyster MV, Ghoshal N, Binder LI, Vitek MP. Inhibition of neuronal maturation in primary hippocampal neurons from tau deficient mice. J Cell Sci, 114 (2001): 1179-1187.

De Carli C, Frisoni GB, Clark CM. Alzheimer's Disease Cooperative Study Group. Qualitative estimates of medial temporal atrophy as a predictor of progression from mild cognitive impairment to dementia. Arch Neurol, 64 (2007): 108-115.

De la Monte SM, Wands JR. Review of insulin and insulin-like growth factor expression, signaling, and malfunction in the central nervous system: relevance to Alzheimer's disease. J Alzheimers Dis, 7 (2005): 45-61

De Leon MJ, Convit A, Wolf OT. Prediction of cognitive decline in normal elderly subjects with 2[18F]fluoro-2-deoxy- D-glucose/positron-emission tomography (FDG/PET). Proc Natl Acad Sci USA, 98 (2001): 10966-10971

De Leon MJ, DeSanti S, Zinkowski R, Mehta PD, Pratico D, Segal S, Clark C, Kerkman D, DeBernardis J, Li J, Lair L, Reisberg B, Tsui W, Rusinek H. MRI and CSF studies in the early diagnosis of Alzheimer's disease. J Intern Med, 256 (2004): 205-223

De Leon MJ, George AE, Golomb J. Frequency of hippocampal formation atrophy in normal aging and Alzheimer's disease. Neurobiol Aging, 18 (1997): 1-11

De Leon MJ, George AE, Stylopoulos LA, Smith G, Miller DC. Early marker for Alzheimer's disease: the atrophic hippocampus. Lancet, 2 (1989): 672-673.

De Leon MJ, Golomb J, George AE. The radiologic prediction of Alzheimer's disease: the atrophic hippocampal formation. Am J Neuroradiol, 14 (1993): 897-906.

De Leon MJ, Mosconi L, Blennow K, DeSanti S, Zinkowski R, Mehta PD. Imaging and CSF studies in the preclinical diagnosis of Alzheimer's disease. Anne NY Acad Sci, 1097 (2007): 114-145.

De Santi S, de Leon MJ, Rusinek H, Convit A, Tarshish CY, Roche A, Tsui WH, Kandil E, Boppana M, Daisley K, Wang GJ, Schlyer D, Fowler J. Hippocampal formation glucose metabolism and volume losses in $\mathrm{MCl}$ and AD. Neurobiol Aging, 22 (2001): 529-539

De Toledo-Morrell L, Dickerson B, Sullivan MP, Spanovic C, Wilson R, Bennett DA. Hemispheric differences in hippocampal volume predict verbal and spatial memory performance in patients with Alzheimer's disease. Hippocampus, 10 (2000): 136-142.

De Toledo-Morrell L, Stoub TR, Bulgakova M, Wilson RS, Bennett DA, Leurgans S. MRI-derived entorhinal volume is a good predictor of conversion from $\mathrm{MCl}$ to AD. Neurobiol Aging, 25 (2004): 1197-1203.

Delacourte A, David JP, Sergeant N, Buee L, Wattez A, Vermersch P, Ghozali F, Fallet-Bianco C, Pasquier F, Lebert F, Petit H, Di Menza C. The biochemical pathway of neurofibrillary degeneration in aging and Alzheimer's disease. Neurology, 52 (1999): 1158-1165.

Delobel P, Lavenir I, Fraser G, Ingram E, Holzer M, Ghetti B, Spillantini MG, Crowther RA, Goedert M. Analysis of tau phosphorylation and truncation in a mouse model of human tauopathy. Am J Pathol, 172 (2008): 123-131

Delthiel R. Probabilities geometriques (Gauthier-Villars Eds). Ecole Polytechnique. París (1926).

Den Heijer T, Vermeer SE, van Dijk EJ, Prins ND, Koudstaal PJ, Hofman A, Breteler MM. Type 2 diabetes and atrophy of medial temporal lobe structures on brain MRI. Diabetologia, 46 (2003):1604-1610.

Denihan A, Wilson G, Cunningham C, Coakley D, Lawlor BA. CT measurement of medial temporal lobe atrophy in Alzheimer's disease, vascular dementia, depression and paraphrenia. Int J Geriatr Psychiatry, 15 (2000): 306-312.

Dentremont KD, Ye P, D'Ercole AJ, O'Kusky JR. Increased insulin-like growth factor-I (IGF-I) expression during early postnatal development differentially increases neuron number and growth in medullary nuclei of the mouse. Brain Res Dev Brain Res, 114 (1999): 135-141. 
Dermaut B, Kumar-Singh S, Engelborghs S, Theuns J, Rademakers R, Saerens J, Pickut BA, Peeters K, van den Broeck M, Vennekens K, Claes S, Cruts M, Cras P, Martin JJ, Van Broeckhoven C, De Deyn PP. A novel presenilin 1 mutation associated with Pick's disease but not betaamyloid plaques. Ann Neurol, 55 (2004): 617-626.

Desikan RS, Cabral HJ, Hess CP, Dillon WP, Glastonbury CM, Weiner MW, Schmansky NJ, Greve DN, Salat DH, Buckner RL, Fischl B. Alzheimer's Disease Neuroimaging Initiative. Automated MRI measures identify individuals with mild cognitive impairment and Alzheimers disease. Brain, 132 (2009): 2048-2057

Desikan RS, Cabral HJ, Settecase F, Hess CP, Dillon WP, Glastonbury CM, Weiner MW, Schmansky NJ, Salat DH, Fischl B, Alzheimer's Disease Neuroimaging Initiative. Automated MRI measures predict progression to Alzheimer's disease. Neurobiol Aging, 31 (2010): 13641374

Devanand DP, Liu X, Tabert MH, Pradhaban G, Cuasay K, Bell K. Combining early markers strongly predicts conversion from mild cognitive impairment to Alzheimer's disease. Biol Psychiatry, 64 (2008): 871-879.

Devanand DP, Pradhaban G, Liu X, Khandji A, De Santi S, Segal S. Hippocampal and entorhinal atrophy in mild cognitive impairment: prediction of Alzheimer disease. Neurology, 68 (2007): 828-836.

DiCicco-Bloom E, Black IB. Insulin growth factors regulate the mitotic cycle in cultured rat sympathetic neuroblasts. Proc Natl Acad Sci, 85 (1988): 4066-4070

Dickerson BC, Goncharova I, Sullivan MP, Forchetti C, Wilson RS, Bennett DA. MRI-derived entorhinal and hippocampal atrophy in incipient and very mild Alzheimer's disease. Neurobiol Aging, 22 (2001): 747-754.

Drechsel DN, Hyman AA, Cobb MH, Kirschner MW. Modulation of the dynamic instability of tubulin assembly by the microtubule-associated protein tau. Mol Biol Cell, 3 (1992): 11411154

Drewes G, Lichtenberg KB, Doring F, Mandelkow EM, Biernat J, Goris J, Doree M, Mandelkow E. Mitogen activated protein (MAP) kinase transforms tau protein into an Alzheimer-like state. EMBO J, 11 (1992): 2131-2138.

Drubin DG, Kirschner MW. Tau protein function in living cells. J Cell Biol, 103 (1986): 2739-2746.

Du AT, Schuff N, Amend D, Laakso MP, Hsu YY, Jagust WJ, Yaffe K, Kramer JH, Reed B, Norman $D$, Chui HC, Weiner MW. Magnetic resonance imaging of the entorhinal cortex and hippocampus in mild cognitive impairment and Alzheimer's disease. J Neurol Neurosurg Psychiatry, 71 (2001): 441-447

Du AT, Schuff N, Kramer JH, Rosen HJ, Gorno-Tempini ML, Rankin K. Different regional patterns of cortical thinning in Alzheimer's disease and frontotemporal dementia. Brain, 130 (2007): 1159-1166.

Dubois B, Feldman HH, Jacova C, Dekosky ST, Barberger-Gateau P, Cummings J, Delacourte A, Galasko D, Gauthier S, Jicha G, Meguro K, O'brien J, Pasquier F, Robert P, Rossor M, Salloway S, Stern Y, Visser PJ, Scheltens P. Research criteria for the diagnosis of Alzheimer's disease: revising the NINCDS-ADRDA criteria. Lancet Neurol, 6 (2007): 734-746.

Dudek H, Datta SR, Franke TF, Birnbaum MJ, Yao R, Cooper GM, Segal RA, Kaplan DR, Greenberg ME. Regulation of neuronal survival by the serine-threonine protein kinase Akt. Science, 275 (1997): 661-665.

Duff K, Planel E. Untangling memory deficits. Nat Med, 11 (2005): 826-827.

Ebmeier KP, Prentice N, Ryman A, Halloran E, Rimmington JE, Best JK, Goodwin GM. Temporal lobe abnormalities in dementia and depression: a study using high resolution single photon emission tomography and magnetic resonance imaging. J Neurol Neurosurg Psychiatry, 63 (1997): 597-604.

Ebneth A, Godemann R, Stamer K, Illenberger S, Trinczek B, Mandelkow EM, Mandelkow E. Overexpression of tau protein inhibits kinesin-dependent trafficking of vesicles, mitochondria, 
and endoplasmic reticulum: implications for Alzheimer's disease. J Cell Biol, 143 (1998): 777-794.

Eckerstrom C, Olsson E, Borga M, Ekholm S, Ribbelin S, Rolstad S. Small baseline volume of left hippocampus is associated with subsequent conversion of $\mathrm{MCl}$ into dementia: the Goteborg MCl study. J Neurol Sci, 272 (2008): 48-59.

Edwards JL, Vincent AM, Cheng HT, Feldman EL. Diabetic neuropathy: mechanisms to management. Pharmacol Ther, 120 (2008): 1-34

Elias H, Henning A, Schwartz DE. Stereology: applications to biomedical research. Physiol Rev, 51 (1971): 158-200.

Elias $\mathrm{H}$, Hide DM. An elementary introduction to stereology (quantitative microscopy). Am J Anat, 159 (1980): 411-446.

Erten-Lyons D, Howieson D, Moore MM. Brain volume loss in $\mathrm{MCl}$ predicts dementia. Neurology, 66 (2006): 233-235.

Farlow M, Lane R, Kudaravalli S, He Y. Differential qualitative responses to rivastigmine in APOE epsilon 4 carriers and noncarriers. Pharmacogenomics J, 4 (2004): 332-335.

Fernyhough P, Mill JF, Roberts JL, Ishii DN. Stabilization of tubulin mRNAs by insulin and insulinlike growth factor I during neurite formation. Brain Res Mol Brain Res, 6 (1989): 109-120

Fleisher AS, Sun S, Taylor C, Ward CP, Gamst AC, Petersen RC. Volumetric MRI vs clinical predictors of Alzheimer disease in mild cognitive impairment. Neurology, 70 (2008): 191-199.

Forette F, Seux ML, Staessen JA. Prevention of dementia in randomised double-blind placebocontrolled Systolic Hypertension in Europe (Syst-Eur) trial. Lancet, 352 (1998): 13471351.

Forssmann WG, Pickel V, Reinecke M, Hock D, Metz J. Immunohistochemistry and immunocytochemistry of nervous tissue. En: Techniques in neuroanatomical research (Heym C, Forsmann WG, eds.). Springer-Verlag. Berlín (1981): 171-205

Foundas AL, Leonard CM, Mahoney SM, Agee OF, Heilman KM. Atrophy of the hippocampus, parietal cortex, and insula in Alzheimer's disease: a volumetric magnetic resonance imaging study. Neuropsychiatry Neuropsychol Behav Neurol, 10 (1997): 81-89.

Fox NC, Warrington EK, Rossor MN. Serial magnetic resonance imaging of cerebral atrophy in preclinical Alzheimer's disease. Lancet, 353 (1999): 2125.

Franklin KB, Paxinos G. The mouse brain in stereotaxic coordinates. Academic Press. San Diego (1997)

Freude S, Hettich MM, Schumann C, Stöhr O, Koch L, Köhler C, Udelhoven M, Leeser U, Müller M, Kubota N, Kadowaki T, Krone W, Schröder H, Brüning JC, Schubert M. Neuronal IGF-1 resistance reduces Abeta accumulation and protects against premature death in a model of Alzheimer's disease. FASEB J, 23 (2009a): 3315-3324.

Freude S, Leeser U, Müller M, Hettich MM, Udelhoven M, Schilbach K, Tobe K, Kadowaki T, Köhler C, Schröder H, Krone W, Brüning JC, Schubert M. IRS-2 branch of IGF-1 receptor signaling is essential for appropiate timing of myelination. J Neurochem, 107 (2008): 907-917.

Freude S, Plum L, Schnitker J, Leeser U, Udelhoven M, Krone W, Bruning JC, Schubert M. Peripheral hyperinsulinemia promotes tau phosphorylation in vivo. Diabetes, 54 (2005): 33433348

Freude S, Schilbach $\mathrm{K}$, Schubert M. The role of IGF-1 receptor and insulin receptor signaling for the pathogenesis of Alzheimer's disease: from model organisms to human disease. Curr Alzheimer Res, 6 (2009b): 213-223.

Frisoni GB, Beltramello A, Weiss C, Geroldi C, Bianchetti A, Trabucchi M. Linear measures of atrophy in mild Alzheimer disease. Am J Neuroradiol, 17 (1996): 913-923. 
Frisoni GB, Geroldi C, Beltramello A, Bianchetti A, Binetti G, Bordiga G, DeCarli Ch, Laakso MP, Soininen $\mathrm{H}$, Testa $\mathrm{C}$, Zanetti $\mathrm{O}$, Trabucchi M. Radial width of the temporal horn: a sensitive measure in Alzheimer disease. Am J Neuroradiol, 23 (2002): 35-47.

Frisoni GB. Structural imaging in the clinical diagnosis of Alzheimer's disease: problems and tolos. J Neurol Neurosurg Psychiatry, 70 (2001): 711-718.

Froelich-Fabre s, Bhat RV. Mechanisms of tauopathies. Drug Discovery Today: Disease Mechanims, 1 (2004): 394-398.

Frolich L, Blum-Degen D, Riederer P, Hoyer S. A disturbance in the neuronal insulin receptor signal transduction in sporadic Alzheimer's disease. Ann NY Acad Sci, 893 (1999): 290-293.

Fukutani Y, Kobayashi K, Nakamura I, Watanabe K, Isaki K, Cairns NJ. Neurons, intracellular and extracelular neurofibrillary tangles in subdivisions of the hippocampal cortex in normal ageing and Alzheimer's disease. Neurosci Lett, 200 (1995): 57-60.

Gamblin TC, Chen F, Zambrano A, Abraha A, Lagalwar S, Guillozet AL, Lu M, Fu Y, Garcia-Sierra F, LaPointe N, Miller R, Berry RW, Binder LI, Cryns VL. Caspase cleavage of tau: linking amyloid and neurofibrillary tangles in Alzheimer's disease. Proc Natl Acad Sci, 100 (2003): 10032-10037

Gamblin TC. Potential structure/function relationships of predicted secondary structural elements of tau. Biochim Biophys, Acta 1739 (2005): 140-149.

García A, Cereghini S, Sontag E. Protein phosphatase 2A and phosphatidylinositol 3-kinase regulate the activity of Sp1-responsive promoters. J Biol Chem, 275 (2000): 9385-9389

García T, Jay D. Fosforilación de tau y enfermedad de Alzheimer. Gac Med Mex, 140 (2002): 329333.

Garrido GEJ, Furuie SS, Buchpiguel CA, Bottino CMC, Almeida OP, Cid CG, Camargo CHP, Castro CC, Glabus MF, Busatto GF. Relation between medial temporal atrophy and funtional brain activity during memory processing in Alzheimer's disease: a combined MRI and SPECT study. J Neurol Neurosurg Psychiatry, 73 (2002): 508-516.

Gasparini L, Netzer WJ, Greengard P, Xu H. Does insulin dysfunction play a role in Alzheimer's disease? Trends Pharmacol Sci, 23 (2002): 288-293.

Gault VA, Hölscher C. GLP-1 agonists facilitate hippocampal LTP and reverse the impairment of LTP induced by beta-amyloid. Eur J Pharmacol, 587 (2008): 112-117.

George AE, de Leon MJ, Stylopoulos LA. CT diagnostic features of Alzheimer disease: importance of the choroidal/ hippocampal fissure complex. Am J Neuroradiol, 11 (1990): 101-107.

Geroldi C, Laakso MP, DeCarli C, Beltramello A, Bianchetti A, Soininen H, Trabucchi M, Frisoni GB. Apolipoprotein E genotype and hippocampal asymmetry in Alzheimer's disease: a volumetric MRI study. J Neurol Neurosurg Psychiatry, 68 (2000): 93-96.

Gil J. Estudio inmunocitoquímico de las estirpes productoras de neuropéptidos: péptido intestinal vasoactivo (VIP), hormona liberadora de GH (GRF) y somatostatina (SRIF), en la hipófisis de la rata. Tesis doctoral en Medicina y Cirugía. Universidad de Salamanca. (1992)

Goedert M, Hasegawa M, Jakes R, Lawler S, Cuenda A, Cohen P. Phosphorylation of microtubuleassociated protein tau by stress-activated protein kinases. FEBS Lett, 409 (1997): 57-62.

Goedert M, Jakes R, Spillantini MG, Hasegawa M, Smith MJ, Crowther RA. Assembly of microtubuleassociated protein tau into Alzheimer-like filaments induced by sulphated glycosaminoglycans. Nature, 383 (1996): 550-553.

Goedert M, Spillantini MG, Potier MC, Ulrich J, Crowther RA. Cloning and sequencing of the CDNA encoding an isoform of microtubule-associated protein tau containing four tandem repeats: differential expression of tau protein mRNAs in human brain. EMBO J, 8 (1989): 393-399.

Goedert M, Wischik CM, Crowther RA, Walker JE, Klug A. Cloning and sequencing of the CDNA encoding a core protein of the paired helical filament of Alzheimer disease: identification as the microtubule-associated protein tau. Proc Natl Acad Sci, 85 (1988): 4051-4055. 
Goedert M. Filamentous nerve cell inclusions in neurodegenerative diseases: tauopathies and alpha-synucleinopathies. Philos Trans R Soc Lond B Biol Sci, 354 (1999): 1101-1118.

Goedert M. Tau gene mutations and their effects. Mov Disord, 20 (Suppl 12) (2005): S45-S52.

Golick ML, Rice M. Optimum staining of PCNA in paraffin sections is dependent of fixation, drying and intensification. J Histotechnol, 15 (1992): 39-41.

Golomb J, de Leon MJ, Kluger A, George AE, Tarshish C, Ferris SH. Hippocampal atrophy in normal aging: an association with recent memory impairment. Arch Neurol, 50 (1993): 967973.

Gómez-Ramos A, Díaz-Hernández M, Cuadros R, Hernández F, Avila J. Extracellular tau is toxic to neuronal cells. FEBS Lett, 580 (2006): 4842-4850

Gong CX, Liu F, Grundke-lqbal I, Iqbal K. Posttranslational modifications of tau protein in Alzheimer's disease. J. Neural Transm, 112 (2005): 813-838.

Good CD, Scahill RI, Fox NC, Ashburner J, Friston KJ, Chan D. Automatic differentiation of anatomical patterns in the human brain: validation with studies of degenerative dementias. Neuroimage, 17 (2002): 29-46.

Granata R, Settanni F, Gallo D, Trovato L, Biancone L, Cantaluppi V, Nano R, Annunziata M, Campiglia P, Arnoletti E, Ghè C, Volante M, Papotti M, Muccioli G, Ghigo E. Obestatin promotes survival of pancreatic beta-cells and human islets and induces expression of genes involved in the regulation of beta-cell mass and function. Diabetes, 57 (2008): 967 979.

Gross U, Mandelkow EM, Biernat J, Marx A, Thiemann A, Meyer HE, Metzger J, Mandelkow E. Phosphorylation sites in tau protein and paired helical filaments. Mol Biol Cell, 5 (1994): 289a.

Grossman M, McMillan C, Moore P, Ding L, Glosser G, Work M. What's in a name: voxel-based morphometric analyses of MRI and naming difficulty in Alzheimer's disease, frontotemporal dementia and corticobasal degeneration. Brain, 127 (2004): 628-649.

Grundke-Iqbal I, Iqbal K, Quinlan M, Tung YC, Zaidi MS, Wisniewski HM. Microtubule-associated protein tau. A component of Alzheimer paired helical filaments. J Biol Chem, 261 (1986a): 6084-6089.

Grundke-lqbal I, Iqbal K, Tung YC, Quinlan M, Wisniewski HM, Binder LI. Abnormal phosphorylation of the microtubule-associated protein tau (tau) in Alzheimer cytoskeletal pathology. Proc Natl Acad Sci, 83 (1986b): 4913-4917.

Grundman M, Sencakova D, Jack CR Jr. Alzheimer's Disease Cooperative Study. Brain MRI hippocampal volume and prediction of clinical status in a mild cognitive impairment trial. J Mol Neurosci, 19 (2002): 23-27.

Hall PA, Levinson DA, Woods AL, Yu CCW, Kellock DB, Watkins JA, Barnes DM, Gillet CE, Camplejohn R, Dover R, Waseem NH, Lane DP. Proliferating cell nuclear antigen (PCNA) immunolocalization in paraffin sections: $a$ index of cell proliferation with evidence of deregulated expression in some neoplasm. J Pathol, 162 (1990): 285-294.

Hamalainen A, Grau-Olivares M, Tervo S, Niskanen E, Pennanen C, Huuskonen J. Apolipoprotein E epsilon4 allele is associated with increased atrophy in progressive mild cognitive impairment: a voxel-based morphometric study. Neurodegener Dis, 5 (2008): 186-189.

Hamalainen A, Tervo S, Grau-Olivares M, Niskanen E, Pennanen C, Huuskonen J. Voxel-based morphometry to detect brain atrophy in progressive mild cognitive impairment. Neuroimage, 37 (2007): 1122-1131.

Hanger DP, Hughes K, Woodgett JR, Brion JP, Anderton BH. Glycogen synthase kinase-3 induces Alzheimer's disease-like phosphorylation of tau: generation of paired helical filament epitopes and neuronal localisation of the kinase. Neurosci Lett, 147 (1992): 58-62.

Hansson L. Antihypertensive treatment and the prevention of dementia: further insights from the Syst-Eur trial. J Hypertens, 17 (1999): 307-308. 
Harada A, Oguchi K, Okabe S, Kuno J, Terada S, Ohshima T, Sato-Yoshitake R, Takei Y, Noda T, Hirokawa N. Altered microtubule organization in smallcalibre axons of mice lacking tau protein. Nature, 369 (1994): 488-491.

Hardy J, Selkoe DJ. The amyloid hypothesis of Alzheimer's disease: progress and problems on the road to therapeutics. Science, 297 (2002): 353-356.

Harper SJ, LoGrasso P. Signalling for survival and death in neurones: the role of stress-activated kinases, JNK and p38. Cell Signal, 13 (2001): 299-310.

Hasegawa M, Morishima-Kawashima M, Takio K, Suzuki M, Titani K, Ihara Y. Protein sequence and mass spectrometric analyses of tau in the Alzheimer's disease brain. J Biol Chem, 26 (1992): 17047-17054.

He J, Farias S, Martinez O, Reed B, Mungas D, Decarli C. Differences in brain volume, hippocampal volume, cerebrovascular risk factors, and apolipoprotein E4 among mild cognitive impairment subtypes. Arch Neurol, 66 (2009): 1393-1399.

Hebert LE, Scherr PA, Bienias JL, Bennett DA, Evans DA. Alzheimer disease in the US population: prevalence estimates using the 2000 census. Archives of Neurology, 8 (2003): 1119-1122.

Heidenreich KA, Toledo SP. Insulin receptors mediate growth effects in cultured fetal neurons. I. Rapid stimulation of protein synthesis. Endocrinology, 125 (1989): 1451-1457

Heneka MT, Rodríguez JJ, Verkhratsky A. Neuroglia in neurodegeneration. Brain Res Rev, 63 (2010): 189-211.

Hernandez F, Perez M, Lucas JJ, Avila J. Are intracellular paired helical filaments (PHFs) from Alzheimer's disease toxic for a neuron? Brain Aging, 1 (2001): 12-15.

Himmler A, Drechsel D, Kirschner MW, Martin DJ. Tau consists of a set of proteins with repeated $\mathrm{C}$-terminal microtubule-binding domains and variable $\mathrm{N}$-terminal domains. Mol Cell Biol, 9 (1989): 1381-1388.

Himmler A. Structure of the bovine tau gene: alternatively spliced transcripts generate a protein family. Mol Cell Biol, 9 (1989): 1389-1396.

Hirata Y, Matsuda H, Nemoto K, Ohnishi T, Hirao K, Yamashita F. Voxel-based morphometry to discriminate early Alzheimer's disease from controls. Neurosci Lett, 382 (2005): 269-274.

Holodny Al, Waxman R, George AE, Golomb J, Rusinek H, de Leon MJ. MRI differential diagnosis of normal pressure hydrocephalus and Alzheimer disease: significance of the parahippocampal fissures. Am J Neuroradiol, 19 (1998): 813-819.

Hölscher C, Gengler S, Gault VA, Harriott P, Mallot HA. Soluble beta-amyloid[25-35] reversibly impairs hippocampal synaptic plasticity and spatial learning. Eur J Pharmacol, 561 (2007): 85-90.

Hölscher C. Diabetes as a risk factor for Alzheimer's disease: insulin signalling impairment in the brain as an alternative model of Alzheimer's disease. Biochem Soc Trans, 39 (2011): 891897.

Hölscher C. Incretin analogues that have been developed to treat type 2 diabetes hold promise as a novel treatment strategy for Alzheimer's disease. Recent Pat CNS Drug Discov, 5 (2010a): 109-117.

Hölscher C. The role of GLP-1 in neuronal activity and neurodegeneration. Vitam Horm, 84 (2010b): 331-354.

Hong M, Lee VM. Insulin and insulin-like growth factor-1 regulate tau phosphorylation in cultured human neurons. J Biol Chem, 272 (1997): 19547-19553.

Hooper C, Meimaridou E, Tavassoli M, Melino G, Lovestone S, Killick R. p53 is upregulated in Alzheimer's disease and induces tau phosphorylation in HEK293a cells. Neurosci Lett, 418 (2007): 34-37. 
Hoos MD, Ahmed M, Smith SO, Van Nostrand WE. Inhibition of familial cerebral amyloid angiopathy mutant amyloid beta-protein fibril assembly by myelin basic protein. $\mathrm{J}$ Biol Chem, 282, (2007): 9952-9961.

Hoyer $\mathrm{S}$. The aging brain. Changes in the neuronal insulin/insulin receptor signal transduction cascade trigger late-onset sporadic Alzheimer disease (SAD). A mini-review. J Neural Transm, 109 (2002): 991-1002.

Hrnkova M, Zilka N, Minichova Z, Koson P, Novak M. Neurodegeneration caused by expression of human truncated tau leads to progressive neurobehavioural impairment in transgenic rats. Brain Res, 1130 (2007): 206-213

Hunter $\mathrm{K}$, Hölscher C. Drugs developed to treat diabetes, liraglutide and lixisenatide, cross the blood brain barrier and enhance neurogenesis. BMC Neurosci, 13 (2012): 33.

Hutson JC, Childs GV, Gardner PJ. Considerations for establishing the validity of immunocytological studies. J Histochem Cytochem, 27 (1979): 1201-1202.

Hutton M, Lendon CL, Rizzu P, Baker M, Froelich S, Houlden H, Pickering-Brown S, Chakraverty S, Isaacs A, Grover A, Hackett J, Adamson J, Lincoln S, Dickson D, Davies P, Petersen RC, Stevens $M$, de Graaff E, Wauters E, van Baren J, Hillebrand M, Joosse M, Kwon JM, Nowotny P, Che LK, Norton J, Morris JC, Reed LA, Trojanowski J, Basun H, Lannfelt L, Neystat M, Fahn S, Dark F, Tannenberg T, Dodd PR, Hayward N, Kwok JB, Schofield PR, Andreadis A, Snowden J, Craufurd D, Neary D, Owen F, Oostra BA, Hardy J, Goate A, van Swieten J, Mann D, Lynch T, Heutink P. Association of missense and 50-splice-site mutations in tau with the inherited dementia FTDP-17. Nature, 393 (1998): 702-705.

Imahori K, Uchida T. Physiology and pathology of tau protein kinases in relation to Alzheimer's disease. J Biochem, 121 (1997): 179-188.

Iqbal K, Flory $M$, Khatoon S, Soininen $\mathrm{H}$, Pirttila T, Lehtovirta M, Alafuzoff I, Blennow K, Andreasen N, Vanmechelen E, Grundke-lqbal I. Subgroups of Alzheimer's disease based on cerebrospinal fluid molecular markers. Ann Neurol, 58 (2005): 748-757.

Irvine EE, Drinkwater L, Radwanska K, Al-Qassab H, Smith MA, O'Brien M, Kielar C, Choudhury Al, Krauss S, Cooper JD, Withers DJ, Giese KP. Insulin receptor substrate 2 is a negative regulator of memory formation. Learn Mem, 18 (2011): 375-383.

Ishiguro K, Takamatsu M, Tomizawa K, Omori A, Takahashi M, Arioka M, Uchida T, Imahori K. Tau protein kinase I converts normal tau protein into A68-like component of paired helical filaments. J Biol Chem, 267 (1992): 10897-10901.

Jack CR Jr, Dickson DW, Parisi JE. Antemortem MRI findings correlate with hippocampal neuropathology in typical aging and dementia. Neurology, 58 (2002): 750-757.

Jack CR Jr, Lowe VJ, Senjem ML, Weigand SD, Kemp BJ, Shiung MM. 11C PiB and structural MRI provide complementary information in imaging of Alzheimer's disease and amnestic mild cognitive impairment. Brain, 131 (2008): 665-680.

Jack CR Jr, Petersen RC, Xu Y, O'Brien PC, Smith GE, Ivnik RJ, Tangalos EG, Kokmen E. Rate of medial temporal lobe atrophy in typical aging and Alzheimer's disease. Neurology, 51 (1998a): 993-999.

Jack CR Jr, Petersen RC, Xu Y, O'Brien PC, Smith GE, Ivnik RJ. Rates of hippocampal atrophy correlate with change in clinical status in aging and AD. Neurology, 55 (2000): 484-489.

Jack CR Jr, Petersen RC, Xu YC, O'Brien PC, Waring SC, Tangalos EG, Smith GE, Ivnik RJ, Thibodeau SN, Kokmen E. Hippocampal atrophy and apolipoprotein E genotype are independently associated with Alzheimer's disease. Ann Neurol, 43 (1998b): 303-310.

Jack CR Jr, Petersen RC, Xu YC, O'Brien PC, Smith GE, Ivnik RJ. Prediction of AD with MRI-based hippocampal volume in mild cognitive impairment. Neurology, 52 (1999): 1397-1403.

Jack CR Jr, Petersen RC, Xu YC, Waring SC, O'Brien PC, Tangalos EG, Smith GE, Ivnik RJ, Kokmen E. Medial temporal atrophy on MRI in normal aging and very mild Alzheimer's disease. Neurology, 49 (1997): 786-794. 
Jack CR Jr, Shiung MM, Gunter JL, O'Brien PC, Weigand SD, Knopman DS, Boeve BF, Ivnik RJ, Smith GE, Cha RH, Tangalos EG, Petersen RC. Comparison of different MRI brain athrophy rate measures with clinical disease progression in AD. Neurology, 62 (2004): 591-600

Jack CR Jr, Shiung MM, Weigand SD, O'Brien PC, Gunter JL, Boeve BF. Brain atrophy rates predict subsequent clinical conversion in normal elderly and amnestic MCl. Neurology, 65 (2005): 1227-1231.

Jauhiainen AM, Pihlajamäki M, Tervo S, Niskanen E, Tanila H, Hänninen T, Vanninen RL, Soininen $\mathrm{H}$. Discriminating accuracy of medial temporal lobe volumetry and fMRI in mild cognitive impairment. Hippocampus, 19 (2009): 166-175.

Jhala US, Canettieri G, Screaton RA, Kulkarni RN, Krajewski S, Reed J, Walker J, Lin X, White M, Montminy M. CAMP promotes pancreatic cell survival via CREB-mediated induction of IRS2. Genes Dev, 17 (2003): 1575-1580.

Jiang $Y$, Walker R, Steinle JJ. Age-associated increase in cleaved caspase 3 despite phosphorylation of IGF-1 receptor in the rat retina. J Gereontol A Biol Sci Med Sci, 64 (2009) : 11541159.

Jimenez S, Torres M, Vizuete M, Sanchez-Varo T, Sanchez-Mejias E, Trujillo-Estrada L, CarmonaCuenca I, Caballero C, Ruano D, Gutierrez A, Vitorica J. Age-dependent accumulation of soluble amyloid beta (Abeta) oligomers reverses the neuroprotective effect of soluble amyloid precursor protein-alpha (SAPP(alpha)) by modulating phosphatidylinositol 3kinase (PI3K)/Akt-GSK-3beta pathway in Alzheimer mouse model. J Biol Chem, 286 (2011): 18414-18425.

Johnson GV, Jope RS, Binder LI. Proteolysis of tau by calpain. Biochem Biophys Res Commun, 163 (1989): 1505-1511.

Johnson KA, Jones K, Holman BL. Preclinical prediction of Alzheimer's disease using SPECT. Neurology, 50 (1998): 1563-1571

Jolivalt CG, Lee CA, Beiswenger KK, Smith JL, Orlov M, Torrance MA, Masliah E. Defective insulin signaling pathway and increased glycogen synthase kinase-3 activity in the brain of diabetic mice: parallels with Alzheimer's disease and correction by insulin. J Neurosci Res, 86 (2008): 3265-3274

Julin P, Lindqvist J, Svensson L, Slomka P, Wahlund LO. MRI-guided SPECT measurements of medial temporal lobe blood flow in Alzheimer's disease. J Nucl Med, 38 (1997): 914-919.

Juottonen K, Laakso MP, Insausti R. Volumes of the entorhinal and perirhinal cortices in Alzheimer's disease. Neurobiol Aging, 19 (1998): 15-22.

Juottonen K, Laakso MP, Partanen K, Soininen H. Comparative MR analysis of the entorthinal cortex and hippocampus in diagnosing Alzheimer disease. Am J Neuroradiol, 20 (1999):139144.

Kamphuis W, Orre M, Kooijman L, Dahmen M, Hol EM. Differential cell proliferation in the cortex of the APPswePS1dE9 Alzheimer's disease mouse model. Glia, 60 (2012): 615-629.

Karas G, Sluimer J, Goekoop R, van der Flier W, Rombouts SARB, Vrenken H. Amnestic mild cognitive impairment: structural MR imaging findings predictive of conversion to Alzheimer disease. AJNR Am J Neuroradiol, 29 (2008): 944-949.

Karas GB, Burton EJ, Rombouts SA, van Schijndel RA, O'Brien JT, Scheltens P. A comprehensive study of gray matter loss in patients with Alzheimer's disease using optimized voxelbased morphometry. Neuroimage, 18 (2003): 895-907.

Karas GB, Scheltens P, Rombouts SA, Visser PJ, van Schijndel RA, Fox NC. Global and local gray matter loss in mild cognitive impairment and Alzheimer's disease. Neuroimage, 23 (2004): 708-716.

Kaufer DI, Miller BL, Itti L, Fairbanks LA, Li J, Fishman J, Kushi J, Cummings JL. Midline cerebral morphometry distinguishes frontotemporal dementia and Alzheimer's disease. Neurology, 48 (1997): 978-985. 
Kellogg AP, Pop-Busui R. Peripheral nerve dysfunction in experimental diabetes is mediated by cyclooxygenase-2 and oxidative stress. Antioxid Redox Signal, 7 (2005): 1521-1529

Khlistunova I, Biernat J, Wang Y, Pickhardt M, von Bergen M, Gazova Z, Mandelkow E, Mandelkow $E M$. Inducible expression of Tau repeat domain in cell models of tauopathy: aggregation is toxic to cells but can be reversed by inhibitor drugs. J Biol Chem, 281 (2006): 12051214.

Killiany RJ, Gomez-Isla T, Moss M, Kikinis R, Sandor T, Jolesz F, Tanzi R, Jones K, Hyman BT, Albert MS. Use of structural magnetic resonance imaging to predict who will get Alzheimer's disease. Ann Neurol, 47 (2000): 430-439.

Killick R, Scales G, Leroy K, Causevic M, Hooper C, Irvine EE, Choudhury Al, Drinkwater L, Kerr F, Al-Qassab H, Stephenson J, Yilmaz Z, Giese KP, Brion JP, Withers DJ, Lovestone S. Deletion of Irs2 reduces amyloid deposition and rescues behavioural deficits in APP transgenic mice. Biochem Biophys Res Commun, 386 (2009): 257-262.

Kim B, Backus C, Oh S, Hayes JM, Feldman EL. Increased Tau phosphorylation and cleavage in mouse models of Type 1 and Type 2 Diabetes. Endocrinology, 150 (2009): 5294-5301

Kim B, Feldman EL. Insulin resistance in the nervous system. Trends Endocrinol Metab, 23 (2012): 133-141.

Kinkingnehun S, Sarazin M, Lehericy S, Guichart-Gomez E, Hergueta T, Dubois B. VBM anticipates the rate of progression of Alzheimer disease: a 3-year longitudinal study. Neurology, 70 (2008): 2201-2211.

Knops J, Kosik KS, Lee G, Pardee JD, Cohen-Gould L, McConlogue L. Overexpression of tau in a nonneuronal cell induces long cellular processes. J Cell Biol, 114 (1991): 725-733.

Kobayashi K, Nakano H, Hayashi M, Shimazaki M, Fukutani Y, Sasaki K, Sugimori K, Koshino Y. Association of phosphorylation site of tau protein with neuronal apoptosis in Alzheimer's disease. J Neurol Sci, 208 (2003): 17-24.

Kochunov $\mathrm{P}$, Mangin JF, Coyle T, Lancaster J, Thompson P, Rivière D, Cointepas $\mathrm{Y}$, Régis J, Schlosser A, Royall DR, Zilles K, Mazziotta J, Toga A, Fox PT. Age-related morphology trends of cortical sulci. Hum Brain Mapp, 26 (2005): 210-220

Köhler S, Black SE, Sinden M, Szekely C, Kidron D, Parker JL, Foster JK, Moscovitch M, Winocour G, Szalai JP, Bronskill MJ. Memory impairments associated with hippocampal versus parahippocampal-gyrus atrophy: an MR volumetry study in Alzheimer's disease. Neuropsychologia, 36 (1998): 901-914

Köpke E, Tung YC, Shaikh S, Alonso AC, Iqbal K, Grundke-lqbal I. Microtubule-associated protein tau. Abnormal phosphorylation of a non-paired helical filament pool in Alzheimer disease. J Biol Chem, 268 (1993): 24374-24384.

Korf ESC, Wahlund LO, Visser PJ, Scheltens P. Medial temporal lobe atrophy on MRI predicts dementia in patients with mild cognitive impairment. Neurology, 63 (2004): 94-100.

Kosik KS, Greenberg SM. Tau protein and Alzheimer's disease. En Alzheimer Disease. (Terry R, Katzman R, Bick K, eds.). Raven Press. Nueva York (1994): 335-344.

Ksiezak-Reding H, Liu WK, Yen SH. Phosphate analysis and dephosphorylation of modified tau associated with paired helical filaments. Brain Res, 597 (1992): 209-219.

Kubota N, Terauchi Y, Tobe K, Yano W, Suzuki R, Ueki D, Takamoto I, Satoh T, Maki T, Kubota T, Moroi M, Okada-Iwabu M, Ezaki O, Nagai R, Ueta Y, Kadowaki T, Noda T. Insulin receptor substrate 2 plays a crucial role in $\beta$ cells and the hypothalamus. J Clin Invest, 114 (2004): 917-927.

Kushner JA, Ye J, Schubert M, Burks DJ, Dow MA, Flint CL, Dutta S, Wright CV, Montminy MR, White MF. Pdx1 restores beta cell function in Irs2 knockout mice. J Clin Invest, 109 (2002): 1193-1201.

Laakso MP, Lehtovirta M, Partanen K, Riekkinen PJ, Soininen H. Hippocampus in Alzheimer's disease: a 3-year follow-up MRI study. Biol Psychiatry, 47 (2000): 557-561. 
Laakso MP, Tiihonen J, Syvälahti E, Vilkman H, Laakso A, Alakare B, Räkköläinen V, Salokangas RK, Koivisto E, Hietala J. A morphometric MRI study of the hippocampus in first-episode, neuroleptic-naïve schizophrenia. Schizophr Res, 50 (2001): 3-7.

Landerbg G, Ross G. Antibodies to proliferating cell nuclear antigen as S-phase probes in flow cytometric cell cycle analysis. Cancer Res, 51(1991): 4570-4574.

Lazarov 0, Peterson LD, Peterson DA, Sisodia SS. Expression of a familial Alzheimer's diseaselinked presenilin- 1 variant enhances perforant pathway lesion-induced neuronal loss in the entorhinal cortex. J Neurosci, 26 (2006): 429-434.

Lee HG, Perry G, Moreira PI, Garrett MR, Liu Q, Zhu X, Takeda A, Nunomura A, Smith MA. Tau phosphorylation in Alzheimer's disease: pathogen or protector? Trends Mol Med, 11 (2005): 164-169.

Lee VM, Goedert M, Trojanowski JQ. Neurodegenerative tauopathies. Annu Rev Neurosci, 24 (2001): 1121-1159.

Leibson CL, Rocca WA, Hanson VA, Cha R, Kokmen E, O'Brien PC, Palumbo PJ. Risk of dementia among persons with diabetes mellitus: a population-based cohort study. Am J Epidemiol, 145 (1997): 301-308

Lesort M, Johnson GV. Insulin-like growth factor-1 and insulin mediate transient site-selective increases in tau phosphorylation in primary cortical neurons. Neuroscience, 99 (2000): 305316

Li ZG, Zhang W, Sima AA. Alzheimer-like changes in rat models of spontaneous diabetes. Diabetes, 56 (2007): 1817-1824

Lim F, Hernandez F, Lucas JJ, Gomez-Ramos P, Moran MA, Avila J. FTDP-17 mutations in tau transgenic mice provoke lysosomal abnormalities and Tau filaments in forebrain. Mol Cell Neurosci, 18 (2001): 702-714.

Lin AL, Laird AR, Fox PT, Gao JH. Multimodal MRI neuroimaging biomarkers for cognitive normal adults, amnestic mild cognitive impairment, and Alzheimer's disease. Neurol Res Int, 2012 (2012): 907409

Little DVA. Third note on recent research in geometrical probability. Advanc Appl Prob, 6 (1974): 103.

Loud AV, Barany WC, Pack BA. Quantitative evaluation of cytoplasmic structure in electron micrographs. Lab Invest, 14 (1965): 258-270.

Lucas JJ, Hernandez F, Gomez-Ramos P, Moran MA, Hen R, Avila J. Decreased nuclear betacatenin, tau hyperphosphorylation and neurodegeneration in GSK-3beta conditional transgenic mice. EMBO J, 20 (2001): 27-39.

Luo J, Balkin N, Stewart J, Sarwark J, Charrow J, Nye J. Neural tube defects and the 13q deletion syndrome: evidence for a critical region in 13q33-34. Am J Med Genet, 91 (2000): 227-230

Lupien SJ, Evans A, Lord C, Miles J, Pruessner M, Pike B, Pruessner JC. Hippocampal volume is as variable in young as in older adults: implications for the notion of hippocampal atrophy in humans. Neuroimage, 34 (2007): 479-485.

Ma XH, Zhong P, Gu Z, Feng J, Yan Z. Muscarinic potentiation of GABA(A) receptor currents is gated by insulin signaling in the prefrontal cortex. J Neurosci, 23 (2003): 1159-1168.

Maccioni RB, Muñoz JP, Barbeito L. The molecular bases of Alzheimer's disease and other neurodegenerative disorders. Arch Med Res, 32 (2001): 367-381.

Mandelkow E-M, Schweers O, Drewes G, Biernat J, Gustke N, Trinczek B, Mandelkow E. Structure, Microtubule Interactions, and Phosphorylation of Tau Protein. Ann New York Acad Sci, 777 (1996): 96-106.

Mandrekar-Colucci S, Landreth GE. Microglia and inflammation in Alzheimer's disease. CNS Neurol Disord Drug Targets, 9 (2010): 156-167. 
Martin SB, Smith CD, Collins HR, Schmitt FA, Gold BT. Evidence that volume of anterior medial temporal lobe is reduced in seniors destined for mild cognitive impairment. Neurobiol Aging, 31 (2010): 1099-1106.

Mayhew TM, Cruz Orive LM. Stereological correction procedures for estimating true volume proportions from biased samples. J Microscopy, 99 (1973): 287-299.

McClean PL, Gault VA, Harriott P, Hölscher C. Glucagon-like peptide-1 analogues enhance synaptic plasticity in the brain: a link between diabetes and Alzheimer's disease. Eur J Pharmacol, 630 (2010): 158-162.

MCManus MJ, Murphy MP, Franklin JL. The mitochondria-targeted antioxidant MitoQ prevents loss of spatial memory retention and early neuropathology in a transgenic mouse model of Alzheimer's disease. J Neurosci, 31 (2011): 15703-15715.

Miettinen PS, Pihlajamäki M, Jauhiainen AM, Niskanen E, Hänninen T, Vanninen R, Soininen H. Structure and function of medial temporal and posteromedial cortices in early Alzheimer's disease. Eur J Neurosci, 34 (2011): 320-330.

Miles RE. Multi-dimensional perspectives on stereology. J Microscopy, 95 (1972): 181-195.

Milionis HJ, Florentin M, Giannopoulos S. Metabolic syndrome and Alzheimer's disease: a link to a vascular hypothesis? CNS Spectr, 13 (2008): 606-613

Mill JF, Chao MV, Ishii DN. Insulin, insulin-like growth factor II, and nerve growth factor effects on tubulin mRNA levels and neurite formation. Proc Natl Acad Sci, 82 (1985): 7126-7130

Mizuno K, Wakai M, Takeda A, Sobue G. Medial temporal atrophy and memory impairment in early stage of Alzheimer's disease: an MRI volumetric and memory assessment study. J Neurol Sci, 173 (2000): 18-24.

Mocanu MM, Nissen A, Eckermann K, Khlistunova I, Biernat J, Drexler D, Petrova O, Schönig K, Bujard H, Mandelkow E, Zhou L, Rune G, Mandelkow EM. The potential for beta-structure in the repeat domain of tau protein determines aggregation, synaptic decay, neuronal loss, and coassembly with endogenous Tau in inducible mouse models of tauopathy. J Neurosci, 28 (2008): 737-748.

Modrego PJ. Predictors of conversion to dementia of probable Alzheimer type in patients with mild cognitive impairment. Current Alzheimer Res, 3 (2006): 161-170.

Moloney AM, Griffin RJ, Timmons S, O'Connor R, Ravid R, O'Neill C. Defects in IGF-1 receptor, insulin receptor and IRS-1/2 in Alzheimer's disease indicate possible resistance to IGF-1 and insulin signaling. Neurobiol Aging, 31 (2010): 224-243.

Mondragón-Rodríguez S, Basurto-Islas G, Santa-Maria I, Mena R, Binder LI, Avila J, Smith MA, Perry G, García-Sierra F. Cleavage and conformational changes of tau protein follow phosphorylation during Alzheimer's disease. Int J Exp Pathol, 89 (2008): 81-90

Montejo de Garcini E, Serrano L, Avila J. Selfassembly of microtubule associated protein tau into filaments resembling those found in Alzheimer disease. Biochem Biophys Res Commun, 141 (1986): 790-796.

Montero M, Sánchez F, Juanes JA, Blanco E, González R, Vázquez R, Carretero J. Morphometric study of the ACTH-immunoreactive adenohypophysary cells. An Anat, 36 (1990): 47-54.

Mori E, Lee K, Yasuda M, Hashimoto M, Kazui H, Hirono N, Matsui M. Accelerated hippocampal atrophy in Alzheimer's disease with apolipoprotein E epsilon4 allele. Ann Neurol, 51 (2002): 209-214.

Mori T, Koyama N, Arendash GW, Horikoshi-Sakuraba Y, Tan J, Town T. Overexpression of human S100B exacerbates cerebral amyloidosis and gliosis in the Tg2576 mouse model of Alzheimer's disease. Glia, 58 (2010): 300-314.

Morishima-Kawashima M, Hasegawa M, Takio K, Suzuki M, Yoshida H, Titani K, Ihara Y. Prolinedirected and non-proline-directed phosphorylation of PHF-tau. J Biol Chem, 270 (1995): 823-829. 
Morris JK, Zhang H, Gupte AA, Bomhoff GL, Stanford JA, Geiger PC. Measures of striatal insulin resistance in a 6-hydroxydopamine model of Parkinson's disease. Brain Res, 1240 (2008): 185-195.

Morys J, Bobek-Billewicz B, Dziewiatkowski J, Bidzan L, Ussorowska D, Narklewicz O. Changes in the volume of temporal lobe structures related to Alzheimer's type dementia. Folia Neuropathol, 40 (2002): 47-56.

Mountjoy CQ, Tomlingon BE, Gibson PH. Amyloid and senile plaques and cerebral blood vessels. A semi-quantitative investigation of a possible relationship. J Neurol Sci, 57 (1982): 89-103.

Mueller SG, Weiner MW, Thal LJ, Petersen RC, Jack CR, Jagust W, Trojanowski JQ, Toga AW, Beckett L. Ways toward anearly diagnosis in Alzheimer's disease: the Alzheimer's disease neuroimaging initiative (ADNI). Alzheimers Dement, 1 (2005): 55-66

Muntané G, Dalfó E, Martínez A, Ferrer I. Phosphorylation of tau and alfa-synuclein in synapticenriched fractions of the frontal cortex in Alzheimer's disease, and in Parkinson's disease and related alfa-synucleinopathies. Neurosciencie, 152 (2008): 913-923.

Nakane PK, Moriuchi T, Koji T, Taniguchi Y, Izumi S, Hui L. Proliferating cell nuclear antigen (PCNA/Cyclin): review and some new findings. Acta Histochem Cytochem, 22 (1989): 105116.

Narkiewicz O, de Leon MJ, Convit A. Dilatation of the lateral part of the transverse fissure of the brain in Alzheimer's disease. Acta Neurobiol Exp (Warsz), 53 (1993): 457-465.

Noble W, Planel E, Zehr C, Olm V, Meyerson J, Suleman F, Gaynor K, Wang L, LaFrancois J, Feinstein B, Burns M, Krishnamurthy P, Wen Y, Bhat R, Lewis J, Dickson D, Duff K. Inhibition of glycogen synthase kinase-3 by lithium correlates with reduced tauopathy and degeneration in vivo. Proc Natl Acad Sci, 102 (2005): 6990-6995.

Noppe M, Crols R, Andries D, Lowenthal A. Determination in human cerebrospinal fluid of glial fibrillary acidic protein, S-100 and myelin basic protein as indices of non-specific or specific central nervous tissue pathology. Cin Chim Acta, 155 (1986): 143-150.

Nordahl CW, Ranganath C, Yonelinas AP, DeCarli C, Reed BR, Jagust WJ. Different mechanisms of episodic memory failure in mild cognitive impairment. Neuropsychologia, 43 (2005): 1688-1697.

Olabarria M, Noristani HN, Verkhratsky A, Rodríguez JJ. Concomitant astroglial atrophy and astrogliosis in a triple transgenic animal model of Alzheimer's disease. Glia, 58 (2010): 831-838.

Ott A, Stolk RP, van Harskamp F, Pols HA, Hofman A, Breteler MM. Diabetes mellitus and the risk of dementia: The Rotterdam Study. Neurology, 53 (1999): 1937-1942

Pantel J, Schroder J, Jauss M, Essig M, Minakaran R, Schonknecht P, Schneider G, Schad LR, Knopp MV. Topography of callosal atrophy reflects distribution of regional cerebral volume reduction in Alzheimer's disease. Psychiatry Res, 90 (1999): 181-192.

Pantel J, Schroder J, Schmitt R, Schad LR, Knopp MV, Geissler M, Uhde WH, Bluml S, Friedlinger $M$, Klemenz $M$, Essig $M$, Sauer H. Quantitative magnetic resonance tomography and the severity of deficits in dementia of the Alzheimer type. Nervenarzt, 67 (1996): 46-52.

Pardini AW, Nguyen HT, Figlewicz DP, Baskin DG, Williams DL, Kim F, Schwartz MW. Distribution of insulin receptor substrate-2 in brain areas involved in energy homeostasis. Brain Res, 1112 (2006): 169-178.

Park S, Dong X, Fisher TL, Dunn S, Omer AK, Weir G, White MF. Exendin-4 uses Irs2 signaling to mediate pancreatic beta cell growth and function. J Biol Chem, 281 (2006): 1159-1168.

Pennanen C, Testa C, Laakso MP, Hallikainen M, Helkala EL, Hanninen T, Kivipelto M, Könönen M, Nissinen A, Tervo S, Vanhanen M, Vanninen R, Frisoni GB, Soininen H. A voxel based morphometry study on mild cognitive impairment. J Neurol Neurosurg Psychiatry, 76 (2005): 11-14. 
Perez JL, Carrero I, Gonzalo P, Arevalo-Serrano J, Sanz-Anquela JM, Ortega J, Rodriguez M, Gonzalo-Ruiz A. Soluble oligomeric forms of beta-amyloid (Abeta) peptide stimulate Abeta production via astrogliosis in the rat brain. Exp Neurol, 223 (2010): 410-421.

Perez M, Cuadros R, Smith MA, Perry G, Avila J. Phosphorylated, but not native, tau protein assembles following reaction with the lipid peroxidation 4-hydroxy-2-nonenal. FEBS Lett, 486 (2000): 270-274.

Perez M, Valpuesta JM, Medina M, Montejo de Garcini E, Avila J. Polymerization of tau into filaments in the presence of heparin: the minimal sequence required for tau-tau interaction. J Neurochem, 67 (1996): 1183-1190.

Petrusz $\mathrm{P}$, Sar M, Ordronneau $\mathrm{P}$, Dimeo $\mathrm{P}$. Specificity in immunocytochemical staining. J Histochem Cytochem, 24 (1976): 1110-1115.

Pihlaja R, Koistinaho J, Kauppinen R, Sandholm J, Tanila H, Koistinaho M. Multiple cellular and molecular mechanisms are involved in human $A B$ clearance by transplanted adult astrocytes. Glia, 59 (2011): 1643-1657.

Pihlajamäki $M$, Jauhiainen $A M$, Soininen $H$. Structural and functional MRI in mild cognitive impairment. Curr Alzheimer Res, 6 (2009): 179-85.

Pixley SK, Danogoria NS, Odoms KK, Hastings L. Effects of insulin-like growth factor 1 on olfactory neurogensis in vivo and in vitro. Ann NY Acad Sci, 855 (2000): 244-247

Planel E, Tatebayashi Y, Miyasaka T, Liu L, Wang L, Herman M, Yu WH, Luchsinger JA, Wadzinski $B$, Duff KE, Takashima A. Insulin dysfunction induces in vivo tau hyperphosphorylation through distinct mechanisms. J Neurosci, 27 (2007): 13635-13648

Plattner F, Angelo M, Giese KP. The roles of ciclyn-dependent kinase 5 and glycogen synthase kinase 3 in tau hyperphosphorylation. J Biol Chem, 281 (2006): 25457-25465.

Poorkaj P, Bird TD, Wijsman E, Nemens E, Garruto RM, Anderson L, Andreadis A, Wiederholt WC, Raskind M, Schellenberg GD. Tau is a candidate gene for chromosome 17 frontotemporal dementia. Ann Neurol, 43 (1998): 815-825.

Porzig R, Singer D, Hoffmann R. Epitope mapping of mAbs AT8 and Tau5 directed against hyperphosphorylated regions of the human tau protein. Biochem Biophys Res Commun, 358 (2007): 644-649.

Price DL, Sisodia SS, Borchelt DR. Alzheimer disease - when and why? Nat Genet, 19 (1998): 314316.

Puig B, Ferrer I, Luduena RF, Avila J. Betalltubulin and phospho-tau aggregates in Alzheimer's disease and Pick's disease. J Alzheimers Dis, 7 (2005): 213-220.

Rankin CA, Gamblin TC. Assessing the toxicity of tau aggregation. J Alzheimers Dis, 14 (2008): 411-416.

Recio-Pinto E, Lang FF, Ishii DN. Insulin and insulin-like growth factor II permit nerve growth factor binding and the neurite formation response in cultured human neuroblastoma cells. Proc Natl Acad Sci, 81 (1984): 2562-2566

Ridha BH, Anderson VM, Barnes J, Boyes RG, Price SL, Rossor MN. Volumetric MRI and cognitive measures in Alzheimer disease: comparison of markers of progression. J Neurol, 255 (2008): 567-574.

Risacher SL, Saykin AJ, West JD, Shen L, Firpi HA, McDonald BC; Alzheimer's Disease Neuroimaging Initiative (ADNI). Baseline MRI predictors of conversion from $\mathrm{MCl}$ to probable $A D$ in the ADNI cohort. Curr Alzheimer Res, 6 (2009): 347-361

Rissman RA, Poon WW, Blurton-Jones M, Oddo S, Torp R, Vitek MP, LaFerla FM, Rohn TT, Cotman CW. Caspase-cleavage of tau is an early event in Alzheimer disease tangle pathology. J Clin Invest, 114 (2004): 121-130

Robinson JL, Geser F, Corrada MM, Berlau DJ, Arnold SE, Lee VM, Kawas CH, Trojanowski JQ. Neocortical and hippocampal amyloid- $B$ and Tau measures associate with dementia in the oldest-old. Brain, 134 (2011): 3705-3712 
Rodríguez RM, Aldrey JM, Pumar JM, Lema M, Noya M. The evaluation of the temporal lobe size by magnetic resonance in Alzheimer's disease. Rev Neurol, 23 (1995): 59-61.

Roher AE, Weiss N, Kokjohn TA, Kuo YM, Kalback W, Anthony J, Watson D, Luehrs DC, Sue L, Walker D, Emmerling M, Goux W, Beach T. Increased A beta peptides and reduced cholesterol and myelin proteins characterize white matter degeneration in Alzheimer's disease. Biochemistry, 41 (2002): 11080-11090.

Rohr HP, Bartsch G, Oberholzer M, Reith A, Holliger O. Stereology. En: Electron Microscopy in Human Medicine (Johanessen JA, ed.) Vol 1. Instrumentation and techniques. Mc GrawHill Int. Londres, (1978): 285-310.

Rubio M, Carretero J, Sánchez F, Riesco JM, Vázquez RJ, Vázquez R. Estradiol influences the LH response to met-enkephalin. Acta Anat, 145 (1992): 382-386

Rubio M, Sánchez F, Carretero J, Riesco JM, Cabo L, Vázquez R. Immunohistochemical morphometric study of the LH-adenohypophyseal cells following chronic treatment with metenkephalin. Histol Histopathol, 9 (1994): 221-226.

Russell JW, Windebank AJ, Schenone A, Feldman EL. Insulin-like growth factor-I prevents apopstis in neurons after nerve growth factor withdrawal. J Neurobiol, 36 (1998): 455467

Sadagurski M, Cheng Z, Rozzo A, Palazzolo I, Kelley GR, Dong X, Krainc D, White MF. IRS2 increases mitochondrial dysfunction and oxidative stress in a mouse model of Huntington disease. J Clin Invest, 121 (2011): 4070-4081.

Sánchez F, Carretero J, Rubio M, Riesco JM, Vázquez R. Morphometric analysis of the hypoactivity of FSH-immunoreactive cells in estrogen-primed male rats. Acta Histochem, 94 (1993): 125-130.

Santacruz K, Lewis J, Spires T, Paulson J, Kotilinek L, Ingelsson M, Guimaraes A, DeTure M, Ramsden M, McGowan M, Forster C, Yue M, Orne J, Janus C, Mariash A, Kuskowski M, Hyman B, Hutton $M$, Ashe $\mathrm{KH}$. Tau suppression in a neurodegenerative mouse model improves memory function. Science, 309 (2005): 476-481.

Santa-Maria I, Hernandez F, Martin CP, Avila J, Moreno FJ. Quinones facilitate the self-assembly of the phosphorylated tubulin binding region of tau into fibrillar polymers. Biochemistry, 43 (2004): 2888-2897.

Santa-María I, Pérez M, Hernández F, Muñoz V, Moreno FJ, Avila J. In vitro tau fibrillization: mapping protein regions. Biochim Biophys Acta, 1762 (2006): 683-692.

Sasaki A, Kawarabayashi T, Murakami T, Matsubara E, Ikeda M, Hagiwara H, Westaway D, GeorgeHyslop PS, Shoji M, Nakazato Y. Microglial activation in brain lesions with tau deposits: Comparison of human tauopathies and tau transgenic mice TgTau P301L. Brain Res, 1214 (2008): 159-168.

Saykin AJ, Wishart HA, Rabin LA, Santulli RB, Flashman LA, West JD. Older adults with cognitive complaints show brain atrophy similar to that of amnestic MCl. Neurology, 67 (2006): 834-842.

Schechter R, Beju D, Miller KE. The effect of insulin deficiency on tau and neurofilament in the insulin knockout mouse. Biochem Biophys Res Commun, 334 (2005): 979-986

Scheltens P, Korf ES. Contribution of neuroimaging in the diagnosis of Alzheimer's disease and other dementias. Curr Opin Neurol, 13 (2000): 391-396

Schneider JA, Arvanitakis Z, Bang W, Bennett DA. Mixed brain pathologies account for most dementia cases in community-dwelling older persons. Neurology, 69 (2007): 2197-2204.

Schonknecht P, Pantel J, Schroder J. Quantitative magnetic resonance tomography in diagnosis of Alzheimer dementia. Z Gerontol Geriatr, 34 (2001): 101-107.

Schroder J, Pantel J, Ida N, Essig M, Hartmann T, Knopp MV, Schad LR, Sandbrink R, Sauer H, Masters CL, Beyreuther K. Cerebral changes and cerebrospinal fluid beta-amyloid in Alz- 
heimer's disease: a study with quantitative magnetic resonance imaging. Mol Psychiatry, 2 (1997): 505-507.

Schubert M, Brazil DP, Burks DJ, Kushner JA, Ye J, Flint CL, Farhang-Fallah J, Dikkes P, Warot $\mathrm{XM}$, Rio C, Corfas G, White MF. Insulin receptor substrate-2 deficiency impairs brain growth and promotes tau phosphorylation. J Neurosci, 23 (2003): 7084-7092.

Scott CW, Spreen RC, Herman JL, Chow FP, Davison MD, Young J, Caputo CB. Phosphorylation of recombinant tau by CAMP-dependent protein kinase. Identification of phosphorylation sites and effect on microtubule assembly. J Biol Chem, 268 (1993): 1166-1173.

Selnes OA, Grega MA, Bailey MM. Cognition 6 years after surgical or medical therapy for coronary artery disease. Ann Neurol, 63 (2008): 581-590.

Serrano-Pozo A, Frosch MP, Masliah E, Hyman BT. Neuropathological alterations in Alzheimer disease. Cold Spring Harb Perspect Med, 1 (2011a): a006189.

Serrano-Pozo A, Mielke ML, Gómez-Isla T, Betensky RA, Growdon JH, Frosch MP, Hyman BT. Reactive glia not only associates with plaques but also parallels tangles in Alzheimer's disease. Am J Pathol, 179 (2011b): 1373-1384.

Seshadri S, Beiser A, Kelly-Hayes $M$. The lifetime risk of stroke: estimates from the Framingham Study. Stroke, 37 (2006): 345-350

Shimura H, Schwartz D, Gygi SP, Kosik KS. HIP-Hsc70 complex ubiquitinates phosphorylated tau and enhances cell survival. J Biol Chem, 279 (2004): 4869-4876.

Sima AA, Zhang W, Xu G, Sugimoto K, Guberski D, Yorek MA. A comparison of diabetic polyneuropathy in type II diabetic BBZDR/Wor rats and in type I diabetic BB/Wor rats. Diabetologia, 43 (2000): 786-793

Singh VK, Fudenberg HH. Detection of brain autoantibodies in the serum of patients with Alzheimer's disease but not Down's syndrome. Immunol Lett, 12 (1986): 277-280.

Singh VK, Yang YY, Singh EA. Immunoblot detection of antibodies to myelin basic protein in Alzheimer's disease patients. Neurosci Lett, 147 (1992): 25-28.

Singh VK. Studies of neuroimmune markers in Alzheimer's disease. Mol Neurobiol, 9 (1994): 73 81.

Singhrao SK, Neal JW, Piddlesden SJ, Newman GR. New immunocytochemical evidence for a neuronal/oligodendroglial origin for corpora amylacea. Neuropathol Appl Neurobiol, 20 (1994): 66-73.

Smith CD, Malcein M, Meurer K, Schmitt FA, Markesbery WR, Pettigrew LC. MRI temporal lobe volume measures and neuropsychologic function in Alzheimer's disease. J Neuroimaging, 9 (1999): 2-9.

Sofroniew MV, Vinters HV. Astrocytes: biology and pathology. Acta Neuropathol, 119 (2010): 735.

Spillantini MG, Goedert M. Tau protein pathology in neurodegenerative diseases. Trends Neurosci, 21 (1998a): 428-433

Spillantini MG, Murrell JR, Goedert M, Farlow MR, Klug A, Ghetti B. Mutation in the tau gene in familial multiple system tauopathy with presenile dementia. Proc Natl Acad Sci, 95 (1998b): 7737-7741.

Stamer K, Vogel R, Thies E, Mandelkow E, Mandelkow EM. Tau blocks traffic of organelles, neurofilaments, and APP vesicles in neurons and enhances oxidative stress. J Cell Biol, 156 (2002): 1051-1063.

Stein TD, Anders NJ, DeCarli C, Chan SL, Mattson MP, Johnson JA. Neutralization of transthyretin reverses the neuroprotective effects of secreted amyloid precursor protein (APP) in APPSW mice resulting in tau phosphorylation and loss of hippocampal neurons: support for the amyloid hypothesis. J Neurosci, 24 (2004): 7707-7717. 
Stephenson J, Fuller JH, Group EICS. Microvascular and acute complications in IDDM patients: the EURODIAB IDDM Complications Study. Diabetologia, 37 (1994): 278-285

Sternberger L. Immunocytochemistry. Wiley J, Sons, eds. New York (1979).

Stöhr O, Schilbach K, Moll L, Hettich MM, Freude S, Wunderlich FT, Ernst M, Zemva J, Brüning JC, Krone W, Udelhoven M, Schubert $M$. Insulin receptor signaling mediates APP processing and $\beta$-amyloid accumulation without altering in a transgenic mouse model of Alzheimer's disease. Age, (2011) DOI 10.1007/s11357-011-9333-2.

Stoub TR, Bulgakova M, Leurgans S, Bennett DA, Fleischman D, Turner DA. MRI predictors of risk of incident Alzheimer disease: a longitudinal study. Neurology, 64 (2005): 1520-1524.

Strachan MW, Deary IJ, Ewing FM, Frier BM. Is type II diabetes associated with an increased risk of cognitive dysfunction? A critical review of published studies. Diabetes Care, 20 (1997): 438-445

Stricker NH, Chang YL, Fennema-Notestine C, Delano-Wood L, Salmon DP, Bondi MW, Dale AM; Alzheimer's Disease Neuroimaging Initiative. Distinct profiles of brain and cognitive changes in the very old with Alzheimer disease. Neurology, 77 (2011): 713-21

Sullivan KA, Hayes JM, Wiggin TD, Backus C, Su Oh S, Lentz SI, Brosius 3rd F, Feldman EL. Mouse models of diabetic neuropathy. Neurobiol Dis, 28 (2007): 276-285

Takashima A, Noguchi K, Sato K, Hoshino T, Imahori K. Tau protein kinase I is essential for amyloid betaprotein- induced neurotoxicity. Proc Natl Acad Sci, 90 (1993): 7789-7793.

Tam J, Rosenberg L, Maysinger D. INGAP peptide improves nerve function and enhances regeneration in streptozotocin-induced diabetic C57BL/6 mice. FASEB J, 18 (2004): 1767-1769

Tanna NK, Kohn MI, Horwich DN, Jolles PR, Zimmerman RA, Alves WM. Analysis of brain and cerebrospinal fluid volumes with MR imaging: impact on PET data correction for atrophy. Part II. Aging and Alzheimer dementia. Radiology, 178 (1991): 123-130.

Tapiola T, Pennanen C, Tapiola M, Tervo S, Kivipelto M, Hanninen T. MRI of hippocampus and entorhinal cortex in mild cognitive impairment: a follow-up study. Neurobiol Aging, 29 (2008): 31-38.

Thangavel R, Sahu SK, Van Hoesen GW, Zaheer A. Modular and laminar pathology of Brodmann's area 37 in Alzheimer's disease. Neuroscience, 152 (2008): 50-55.

Thangavel R, Van Hoesen GW, Zaheer A. The abnormally phosphorylated tau lesion of early Alzheimer's disease. Neurochem Res, 34 (2009): 118-123.

Thirone AC, Huang C, Klip A. Tissue-specific roles of IRS proteins in insulin signaling and glucose transport. Trends Endocrinol Metab, 17 (2006): 72-78.

Thompson PM, Hayashi KM, De Zubicaray GI, Janke AL, Rose SE, Semple J, Hong MS, Herman DH, Gravano D, Doddrell DM, Toga AW. Mapping hippocampal and ventricular change in Alzheimer disease. Neuroimage, 22 (2004): 1754-1766

Thompson PM, Hayashi KM, Dutton RA, Chiang MC, Leow AD, Sowell ER, De Zubicaray G, Becker JT, Lopez OL, Aizenstein HJ, Toga AW. Tracking Alzheimer's disease. Ann N Y Acad Sci, 1097 (2007): 183-214.

Thomson JL. M.R.I. in Alzheimer's disease. West Engl Med J, 105 (1990): 74-76.

Toledo-Morrell L, Goncharova I, Dickerson B, Wilson RS, Bennett DA. From healthy aging to early Alzheimer's disease: in vivo detection of entorhinal cortex atrophy. Ann NY Acad Sci, 911 (2000): 240-253.

Trinczek B, Ebneth A, Mandelkow E. Tau regulates the attachment / detachment but not the speed of motors in microtubule-dependent transport of single vesicles and organelles. J Cell Sci, 112 (1999): 2355-2367.

Trivedi MA, Wichmann AK, Torgerson BM, Ward MA, Schmitz TW, Ries ML. Structural MRI discriminates individuals with mild cognitive impairment from age-matched controls: a com- 
bined neuropsychological and voxel based morphometry study. Alzheimers Dement, 2 (2006): 296-302.

Underwood EE. Quantitative stereology. Addisson Wesley. Massachusetts (1970).

Van de Nes JAP, Nafe R, Schlote W. Non-tau based neuronal degeneration in Alzheimer's disease - an immunocytochemical and quantitative study in the supragranular layers of the middle temporal neocotex. Brain Res, 1213 (2008): 152-165.

Varma AR, Adams W, Lloyd JJ, Carson KJ, Snowden JS, Testa HJ, Jackson A, Neary D. Diagnostic patterns of regional atrophy on MRI and regional cerebral blood flow change on SPECT in young onset patients with Alzheimer's disease, frontotemporal dementia and vascular dementia. Acta Neurol Scand, 105 (2002a): 261-269.

Varma AR, Laitt R, Lloyd JJ, Carson KJ, Snowden JS, Neary D, Jackson A. Diagnostic value of high signal abnormalities on T2 weighted MRI in the differentiation of Alzheimer's, frontotemporal and vascular dementias. Acta Neurol Scand, 105 (2002b): 355-364.

Visser PJ, Scheltens P, Verhey FR, Schmand B, Launer LJ, Jolles J, Jonker C. Medial temporal lobe atrophy and memory dysfunction as predictors for dementia in subjects with mild cognitive impairment. J Neurol, 246 (1999): 477-485.

Visser PJ, Verhey FR, Hofman PA, Scheltens P, Jolles J. Medial temporal lobe atrophy predicts Alzheimer's disease in patients with minor cognitive impairment. J Neurol Neurosurg Psychiatry, 72 (2002): 491-497.

Von Bergen M, Friedhoff P, Biernat J, Heberle J, Mandelkow EM, Mandelkow E. Assembly of tau protein into Alzheimer paired helical filaments depends on a local sequence motif ((306)VQIVYK(311)) forming beta structure. Proc Natl Acad Sci, 97 (2000): 5129-5134.

Von Bernhardi R, Eugenín J. Microglial reactivity to beta-amyloid is modulated by astrocytes and proinflammatory factors. Brain Res, 1025 (2004): 186-193.

Wahlund LO, Julin P, Johansson SE, Scheltens P. Visual rating and volumetry of the medial temporal lobe on magnetic resonance imaging in dementia: a comparative study. J Neurol Neurosurg Psychiatry, 69 (2000): 630-635.

Wahlund LO. Magnetic resonance imaging and computed tomography in Alzheimer's disease. Acta Neurol Scand Suppl, 168 (1996): 50-53

Wang DS, Bennett DA, Mufson E J, Mattila P, Cochran E, Dickson DW. Contribution of changes in ubiquitin and myelin basic protein to age-related cognitive decline. Neurosci Res, 48 (2004): 93-100.

Wang PN, Lirng JF, Lin KN, Chang FC, Liu HC. Prediction of Alzheimer's disease in mild cognitive impairment: a prospective study in Taiwan. Neurobiol Aging, 27 (2006): 1797-1806.

Wang YP, Biernat J, Pickhardt M, Mandelkow E, Mandelkow EM. Stepwise proteolysis liberates tau fragments that nucleate the Alzheimer-like aggregation of full-length tau in a neuronal cell model. Proc Natl Acad Sci, 104 (2007): 10252-10257

Watanabe A, Hasegawa M, Suzuki M, Takio K, Morishima-Kawashima M, Titani K, Arai T, Kosik KS, Ihara Y. In vivo phosphorylation sites in fetal and adult rat tau. J Biol Chem, 268 (1993): 25712-25717.

Watson GS, Craft S. Modulation of memory by insulin and glucose: neuropsychological observations in Alzheimer's disease. Eur J Pharmacol, 490 (2004): 97-113

Weibel ER, Bolander RP. Stereological techniques for electron microscopy. En: Principle and techniques of electron microscopy (Hyatt MA. ed.) Van Nostran-Reinhold. New York, (1973): 239-296.

Weibel ER, Kistler GS, Scherle WF. Practical stereological methods for morphometric cytology. J Cell Biol, 30 (1966): 23-38.

Weibel ER. Stereological principles for morphometric in electron microscopic cytology. Int Rev Cytol, 26 (1969): 235-302. 
Weihl CC, Ghadge GD, Kennedy SG, Hay N, Miller RJ, Roos RP. Mutant presenilin-1 induces apoptosis and downregulates Akt/PKB. J Neurosci, 19 (1999): 5360-5369.

Weingarten MD, Lockwood AH, Hwo SY, Kirschner MW. A protein factor essential for microtubule assembly. Proc Natl Acad Sci, 72 (1975): 1858-1862.

White MF. IRS proteins and the common path to diabetes. Am J Physiol Endocrinol Metab, 283 (2002): E413-422.

Whitwell JL, Petersen RC, Negash S. Patterns of atrophy differ among specific subtypes of mild cognitive impairment. Arch Neurol, 64 (2007a): 1130-1138.

Whitwell JL, Przybelski SA, Weigand SD, Knopman DS, Boeve BF, Petersen RC. 3D maps from multiple MRI illustrate changing atrophy patterns as subjects progress from mild cognitive impairment to Alzheimer's disease. Brain, 130 (2007b): 1777-1786.

Whitwell JL, Shiung MM, Przybelski SA, Weigand SD, Knopman DS, Boeve BF. MRI patterns of atrophy associated with progression to $A D$ in amnestic mild cognitive impairment. Neurology, 70 (2008): 512-520.

Wille H, Drewes G, Biernat J, Mandelkow EM, Mandelkow E. Alzheimer-like paired helical filaments and antiparallel dimers formed from microtubule-associated protein tau in vitro. $J$ Cell Biol, 118 (1992): 573-584.

Wilson DM, Binder LI. Free fatty acids stimulate the polymerization of tau and amyloid beta peptides. In vitro evidence for a common effector of pathogenesis in Alzheimer's disease. Am J Pathol, 150 (1997): 2181-2195.

Wischik CM, Novak M, Thogersen HC, Edwards PC, Runswick MJ, Jakes R, Walker JE, Milstein C, Roth $M$, Klug A. Isolation of a fragment of tau derived from the core of the paired helical filament of Alzheimer disease. Proc Natl Acad Sci, 85 (1988): 4506-4510.

Withers DJ, Gutierrez JS, Towery H, Burks DJ, Ren JM, Previs S, Zhang Y, Bernal D, Pons S, Shulman GI, Bonner-Weir $S$, White MF. Disruption of IRS-2 causes type 2 diabetes in mice. Nature, 391 (1998): 900-904.

Wittmann CW, Wszolek MF, Shulman JM, Salvaterra PM, Lewis J, Hutton M, Feany MB. Tauopathy in Drosophila: neurodegeneration without neurofibrillary tangles. Science, 293 (2001): 711-714.

Wolf H, Jelic V, Gertz HJ, Nordberg A, Julin P, Wahlund LO. A critical discussion of the role of neuroimaging in mild cognitive impairment. Acta Neurol Scand Suppl, 179 (2003): 52-76

Wong CW, Quaranta V, Glenner GG. Neuritic plaques and cerebro vascular amyloid in Alzheimer disease are antigenically related. Proc Natl Acad Sci USA, 82 (1985): 8729-8732.

Woods KA, Camacho-Hubner C, Savage MO, Clark AJL. Intrauterine growth retardation and postnatal growth failure associated with deletion of the insulin-like growth factor I gene. $\mathrm{N}$ Engl J Med, 335 (1996): 1363-1367

Xie Z, Smith CJ, Van Eldik LJ. Activated glia induce neuron death via MAP kinase signaling pathways involving JNK and p38. Glia, 45 (2004): 170-179.

Xu Y, Jack CR Jr, O'Brien PC, Kokmen E, Smith GE, Ivnik RJ, Boeve BF, Tangalos RG, Petersen RC. Usefulness of MRI measures of entorhinal cortex versus hippocampus in AD. Neurology, 54 (2000): 1760-1767

Yamada M, Ohnishi H, Sano S, Nakatani A, Ikeuchi T, Hatanaka H. Insulin receptor substrate IRS-1 and IRS-2 are tyrosine-phosphorylated an associated with phosphatidylinositol 3-kinase in response to brain-derived neurotrophic factor in cultured cerebral cortical neurons. J Biol Chem, 272 (1997): 30334-30339.

Yang W, Lui RL, Gao JH, Chan TF, Yau ST, Sperling RA, Huang X. Independent component analysis-based classification of Alzheimer's disease MRI data. J Alzheimers Dis, 24 (2011): 775783. 
Ye P, Xing Y, Dai Z, D'Ercole AJ. In vivo actions of insulin-growth factor-I (IGF-I) on cerebellum development in transgenic mice: evidence that IGF-1 increases proliferation of granule cell progenitors. Brain Res Dev Brain Res, 95 (1996): 44-54

Yi X, Schubert M, Peachey NS, Suzuma K, Burks DJ, Kushner JA, Suzuma I, Cahill C, Flint CL, Dow MA, Leshan RL, King GL, White MF. Insulin receptor substrate 2 is essential for maturation and survival of photoreceptor cells. J Neurosci, 25 (2005): 1240-1248.

Yin $\mathrm{H}$, Kuret $\mathrm{J}$. C-terminal truncation modulates both nucleation and extension phases of tau fibrillization. FEBS Lett, 580 (2006): 211-215

Yoshida $\mathrm{H}$, Ihara $\mathrm{Y}$. Tau in paired helical filaments is functionally distinct from fetal tau: assembly incompetence of paired helical filament-tau. J Neurochem, 61 (1993): 1183-1186.

Yoshida S, Maeda M, Kaku S, Ikeya H, Yamada K, Nakaike S. Lithium inhibits stress-induced changes in tau phosphorylation in the mouse hippocampus. J Neural Transm, 113 (2006): 1803-1814.

Zackenfels K, Oppenheim RW, Rohrer H. Evidence for an important role of IGF-I and IGF-II for the early development of chick sympathetic neurons. Neuron, 14 (1995): 731-741

Zhang D, Hu X, Qian L, O'Callaghan JP, Hong JS. Astrogliosis in CNS pathologies: is there a role for microglia? Mol Neurobiol, 41 (2010): 232-241.

Zhu X, Perry G, Smith MA. Insulin signaling, diabetes mellitus and risk of Alzheimer disease. J Alzheimers Dis, 7 (2005): 81-84

Zilka N, Filipcik P, Koson P, Fialova L, Skrabana R, Zilkova M, Rolkova G, Kontsekova E, Novak M. Truncated tau from sporadic Alzheimer's disease suffices to drive neurofibrillary degeneration in vivo. FEBS Lett, 580 (2006): 3582-3588. 